Filogenia, biogeografía y evolución del comportamiento en los Doraditos (Pseudocolopteryx: Tyrannidae: Aves)

\author{
Emilio Ariel Jordan
}

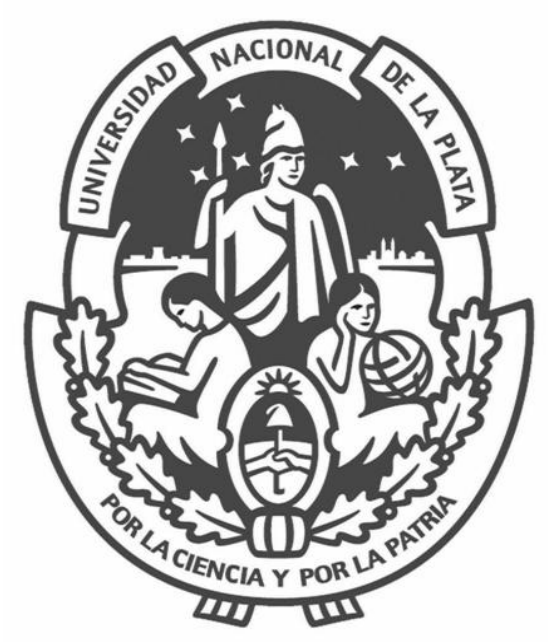

Tesis doctoral en Ciencias Naturales

Director: Dr. Juan Ignacio Areta

Co-director: Dr. Diego Montalti

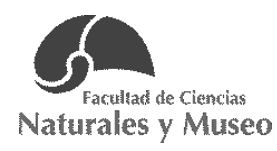

Facultad de Ciencias Naturales y Museo

Universidad Nacional de La Plata

$-2018-$ 
A Meme mi amorcita, la luna de sus ojos y el gaviotín de su panza 


\section{Agradecimientos}

La prehistoria de esta tesis se remonta a los tiempos platenses del Grupo FALCO: a las charlas, discusiones, peleas, proyectos, ideas y bebidas blancas compartidas con Kini Roesler (el primer "grande" que conocí), Luis Pagano, Palito Jensen, Nacho Areta, Juan Mazar, Ale Bodrati, Mark Pearman, Pablo Grilli, Tyto Seipke y Mati Juhant. En esos tiempos y con estas personas la ornitología se hizo carne en mí. Gracias a ellos aprendí "de pájaros" como nunca antes y como nunca después.

Esta tesis se gestó como una idea insipiente entre tantas otras, producto de apasionantes charlas pajareras con Nacho Areta. Compañero de ideas y prisiones, a él le debo la oportunidad de materializar esas ideas en un trabajo concreto. Su apoyo como director y amigo fue decisivo. Las discusiones compartidas, sus apretadas de clavijas, las palabras de aliento hicieron posible esta tesis.

Fueron muchas personas las que me acompañaron durante el trabajo de campo: Nacho Areta, el sigiloso Juan Pombo, mi amigo Emi Depino, mi viejo Eddie Jordan, y Marcos "el Pampa" Cenizo un tipazo como pocos.

Los guardaparques de Punta Lara, especialmente Juan Pablo Carricant, me brindaron todo su apoyo. Pablo Mitchelutti, guarda de Anzenuza, me ofreció desinteresadamente sus conocimientos del Doradito Pardo y sus anillos metálicos, fundamentales para realizar este trabajo. Conocer a Álvaro Calderón fue una grata sorpresa y se convirtió en un fugaz pero eficiente instructor en el manejo de redes.

Para el desarrollo del Capítulo 1 fue fundamental la asociación con el Dr. José "Pepe" Tello, experto en los misterios moleculares de los tiránidos.

Kini Roesler no solo es un amigo profundo, sino que fue también el primer gran conocedor de Doraditos. Kini compartió ideas generosamente y fue el primero en leer el Capítulo 3 de biogeografía. Sus comentarios no solo mejoraron el capítulo sino que me alentaron en una etapa difícil.

Pude desarrollar este plan de tesis gracias una beca doctoral del CONICET, producto de un Estado nacional pensado para el desarrollo autónomo de las ciencias en Argentina. Detrás de esta idea reside el hecho concreto de que el aporte de todo un pueblo trabajador es el único garante de un Estado presente.

Un párrafo aparte es para Meme Ripa. Ella fue mi primera y más firme ayudante de campo, única capaz de seguirme hasta las abrasadoras tierras sojeras durante el verano, para filmar y grabar a los Doraditos Oliváceos, y en la infructuosa búsqueda de Doraditos Copetones en los esteros del lberá. Ella leyó los primeros manuscritos y me ayudó a desentrañar el misterioso "cálculo de promedios anidados". Sostén emocional imprescindible, a ella le debo gran parte de esta tesis, y de mi vida. 


\section{ÍNDICE}

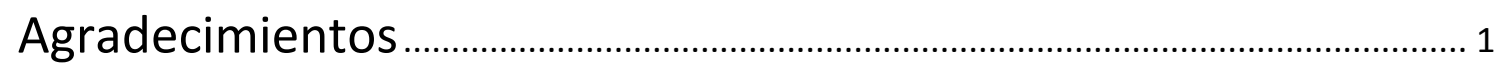

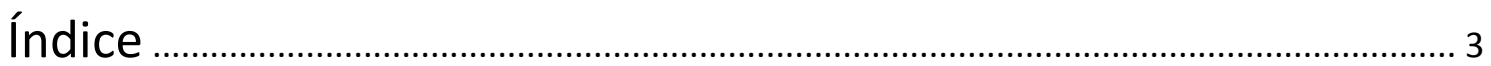

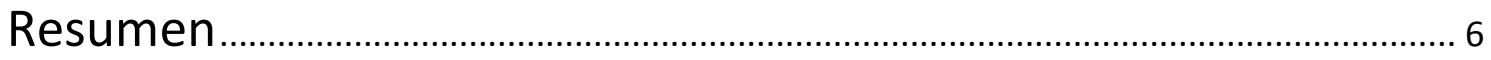

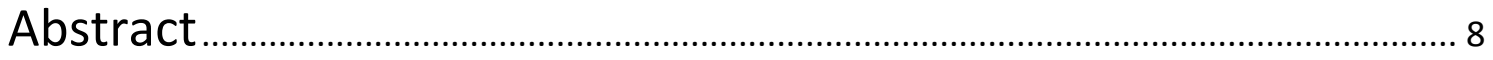

Introducción general........................................................................................... 10

Capítulo 1. Filogenia y evolución del plumaje en los Doraditos (Pseudocolopteryx spp.)

Introducción

\section{Materiales y Métodos}

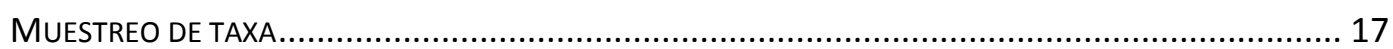

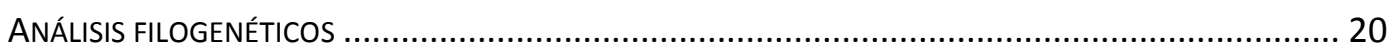

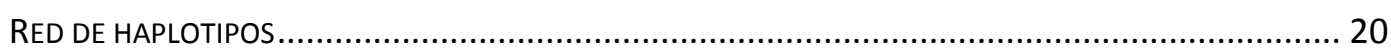

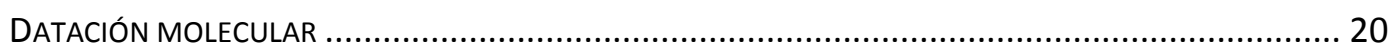

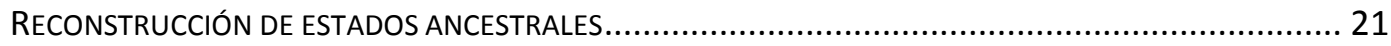

\section{Resultados}

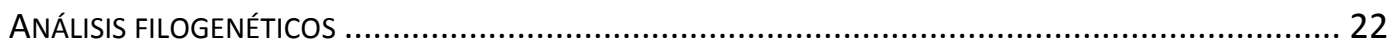

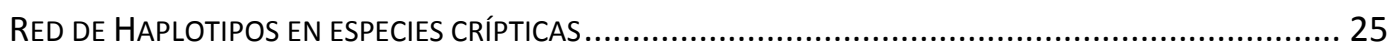

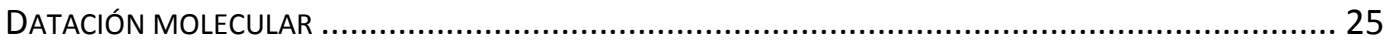

DESCRIPCIÓN DE LOS CARACTERES ANALIZADOS …................................................................. 26

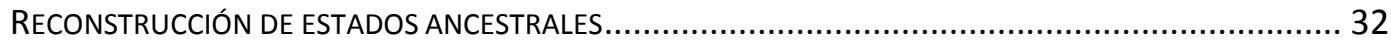

\section{Discusión}

EVOLUCIÓN DEL PLUMAJE Y MORFOLOGÍA ALAR ........................................................... 36

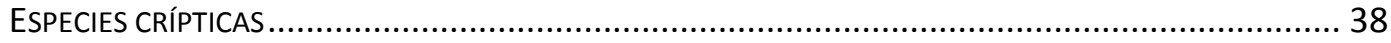


Capítulo 2. Evolución modular de voces, sonidos mecánicos y despliegues en los Doraditos (Pseudocolopteryx spp.)

Introducción 40

\section{Materiales y métodos}

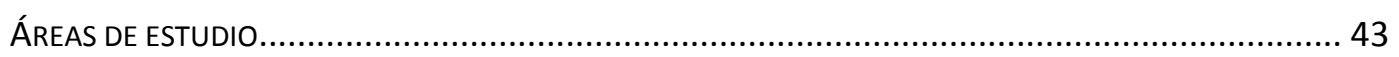

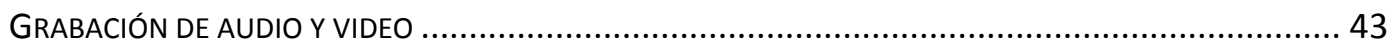

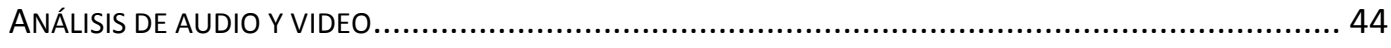

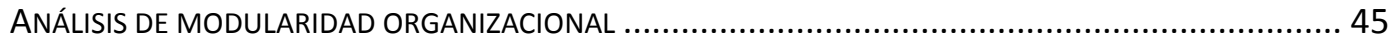

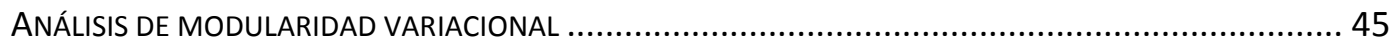

\section{Resultados}

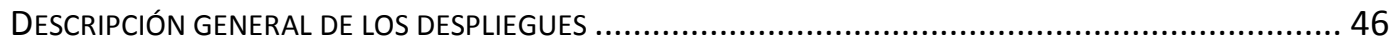

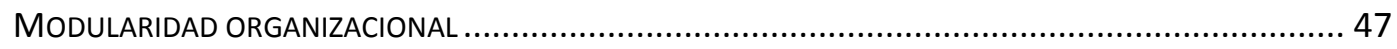

Módulos de Momento ...................................................................................... 49

Módulos de Acción ......................................................................................... 50

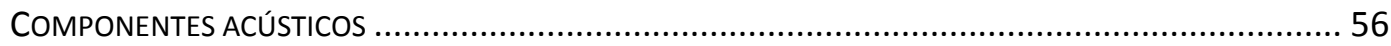

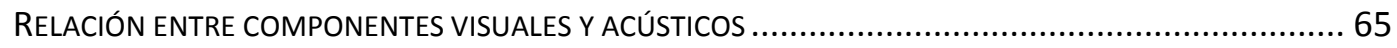

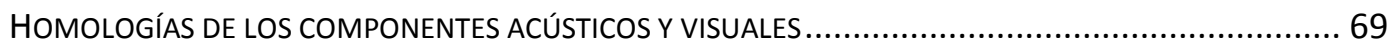

\section{Discusión}

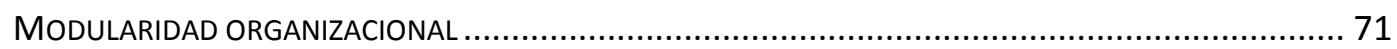

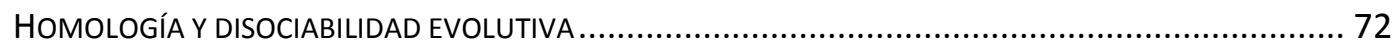

MODULARIDAD EN LOS DESPLIEGUES DE OTROS TIRÁNIDOS ......................................................... 75 


\section{Capítulo 3. Biogeografía y migración de los Doraditos (Pseudocolopteryx spp.)}

Introducción

ESTADO DE CONOCIMIENTO DE LA DISTRIBUCIÓN Y DE LOS MOVIMIENTOS

ESTACIONALES DE LOS DORADITOS (PSEUDOCOLOPTERYX SPP.)

\section{Materiales y métodos}

DATOS DE PRESENCIA .

Modelos de Nicho ECológICO (MNE) Y DE DistRIBUCIÓN PotenCIAL (MDP) ............................. 83

GRADO DE SUPERPOSICIÓN EN EL ESPACIO DE NICHO BIOCLIMÁTICO............................................... 85

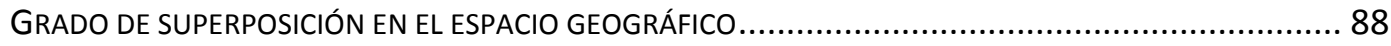

DISTANCIA GENÉTICA Y SUPERPOSICIÓN EN EL ESPACIO GEOGRÁFICO Y DE NICHO.............................. 88

\section{Resultados}

MODELOS DE NICHO ECOLÓGICO Y DE DISTRIBUCIÓN POTENCIAL................................................. 90

SUPERPOSICIÓN EN EL ESPACIO DE NICHO BIOCLIMÁTICO Y EN EL ESPACIO GEOGRÁFICO ..................... 100

DISTANCIA GENÉTICA Y SUPERPOSICIÓN EN EL ESPACIO GEOGRÁFICO Y DE NICHO............................. 102

\section{Discusión}

DISTRIBUCIÓN Y MIGRACIÓN. 105

ECOLOGÍA, BIOGEOGRAFÍA Y ESPECIACIÓN 108

ESPECIACIÓN CRÍPTICA Y ANCESTRALIDAD

Discusión general 113

Bibliografía 116 


\section{Resumen}

El género Pseudocolopteryx (Doraditos) tiene una distribución exclusiva en Sudamérica y está compuesto por cinco especies de pequeños tiránidos de áreas abiertas: $P$. sclateri, $P$. acutipennis, $P$. dinelliana, $P$. citreola y $P$. flaviventris, todas las cuales muestran movimientos estacionales en algún grado. En este trabajo se construyó la primera hipótesis filogenética de Doraditos basada en secuencias de ADN, que fue luego utilizada para estudiar: 1) la evolución de los caracteres de estructura y color de plumaje, 2) los despliegues nupciales y 3) la biogeografía.

Las relaciones filogenéticas se basaron en análisis Bayesianos y de máxima verosimilitud de genes mitocondriales (ND2 y COI) y nucleares (MYO y ODC). La filogenia resultante pudo recuperar la monofilia de Pseudocolopteryx, resolviendo las relaciones entre las especies de doraditos ( $P$. sclateri ( $P$. acutipennis ( $P$. dinelliana ( $P$. citreola- $P$. flaviventris))). Estos análisis filogenéticos no pudieron sin embargo recuperar la monofilia de las especies crípticas $P$. flaviventris y $P$. citreola. En general, estos genes mostraron divergencias muy bajas e inconsistentes entre P. flaviventris y P. citreola. Dos haplotipos débilmente diferenciados de ND2 fueron exclusivos de $P$. flaviventris y tres fueron exclusivos de $P$. citreola, pero las diferencias interespecíficas oscilaron entre uno y dos pasos mutacionales. La datación molecular estimó una divergencia muy reciente entre $P$. citreola y $P$. flaviventris de aproximadamente 60000 años.

Todas las especies mostraron dimorfismo sexual en el color del pico: machos con picos completamente negros y hembras con el interior del pico y base de la mandíbula rosácea y el resto negro. Pseudocolopteryx sclateri, $P$. dinelliana y $P$. acutipennis exhiben dimorfismo sexual sólo visible con ejemplares en mano, donde las plumas primarias $p 6$ y $p 7$ de los machos son atenuadas y/o modificadas estructuralmente. El grado de dicromatismo sexual basado en los caracteres de coloración del plumaje fue ALTO para $P$. sclateri, MODERADO para $P$. acutipennis, $P$. citreola y $P$. flaviventris, y BAJO para $P$. dinelliana. La reconstrucción de estados ancestrales indicó que el dicromatismo sexual es ancestral en Pseudocolopteryx, y el monocromatismo, aunque parcial, aparece como un carácter derivado solo en $P$. dinelliana. Los cambios en el fenotipo de color en los machos, y no en el de las hembras, fueron los que contribuyeron a la pérdida de dimorfismo sexual, con $P$. dinelliana adquiriendo caracteres de plumaje que son femeninos en las demás especies. Las primarias modificadas también aparecen como un carácter ancestral en Pseudocolopteryx, y se pierden sólo en $P$. citreola y $P$. flaviventris junto con despliegues aéreos y la producción de sonidos mecánicos. La extrema similitud de los plumajes de $P$. citreola y $P$. flaviventris se debe a su ancestralidad común y no a un caso de convergencia ni retención de plesiomorfías previas. Sus vocalizaciones y su capacidad de reconocimiento recíproco han divergido marcadamente en un período de tiempo muy breve, mientras que el plumaje se ha mantenido en una estasis total.

A partir del estudio de grabaciones de audio y video se identificaron y describieron en detalle las unidades comportamentales (visuales y acústicas) que conforman el fenotipo de los despliegues de Pseudocolopteryx. El fenotipo comportamental fue analizado bajo el concepto de modularidad. La modularidad es la propiedad que permite a los caracteres organizarse y evolucionar como unidades y subunidades coherentes (los módulos). Así, los módulos pueden ser organizacionales cuando existen como tales en un mismo organismo, y poseen: 1) organización jerárquica, 2) existencia discreta y 3) forma estereotipada; y pueden ser variacionales cuando son heredables y susceptibles de evolucionar, y poseerán 1) homología y 2) disociabilidad evolutiva.

Los despliegues nupciales en Pseudocolopteryx se organizaron en tres módulos de jerarquía mayor (Módulos de Momento): Presentación, Remate y Despliegue Aéreo de dos perchas. Estos módulos contienen a su vez módulos de jerarquía menor (Módulos de Acción): Cabeceos, Giros y Arqueos, y Cierre. Estas unidades comportamentales modulares visuales se 
acoplaron de manera plenamente modular con las componentes acústicas. La Presentación se relacionó con el componente acústico Introducción y el Remate con la Floritura, mientras que el Despliegue Aéreo de dos perchas incluyó todos o alguno de los módulos de acción de la Floritura. Los módulos de acción están acoplados plenamente a componentes acústicos: Cabeceos y notas iniciales, Giros y Arqueos con notas intermedias y Cierre con notas finales. Las unidades del fenotipo comportamental de los despliegues nupciales en Pseudocolopteryx se acoplaron de manera plenamente modular, y presentaron las características de modularidad organizacional y variacional. El modulo de acción Presentación está constituido fundamentalmente por la duplicación de los módulos de acción Cabeceos, y puede presentar algunos Giros y Arqueos. El Remate está caracterizado por la presencia del Cierre, pero tiene también Cabeceos y Giros y Arqueos. El Despliegue Aéreo de dos perchas está constituido por los mismos módulos de acción que el Remate. El módulo de momento Despliegue Aéreo de dos perchas habría aparecido en la evolución temprana de Pseudocolopteryx como una duplicación con modificación del módulo de momento Remate.

El reemplazo de sonidos vocales por sonidos putativamente mecánicos (o viceversa) aparece dos veces en Pseudocolopteryx: las notas iniciales son chasquidos del pico en $P$. sclateri pero vocalizaciones en las demás especies, y en $P$. acutipennis las notas finales, que son siringeales en las demás especies, aparecen como sonidos putativamente mecánicos producidos por sus plumas primarias modificadas.

La Presentación y el Remate en Pseudocolopteryx presentan diferencias estructurales indicarían que son módulos portadores de información diferente: durante el Remate el macho transmitiría información sobre su identidad específica, relevante para el emparejamiento, mientras que la Presentación funcionaría simplemente como un llamado de atención previo al Remate. Así, el Remate habría evolucionado bajo fuertes presiones selectivas que lo habrían moldeado mas rígidamente que a la Presentación.

Mediante el desarrollo de modelos de nicho ecológico y de distribución potencial se analizaron las distribuciones y movimientos estacionales de los Doraditos. Pseudocolopteryx sclateri es una especie nómade, que podría criar cuando y donde ciertas condiciones estén dadas haciendo que su geonemia sea muy dinámica. Las poblaciones del sur de $P$. acutipennis son migradoras, mientras que las norteñas serían residentes anuales. Pseudocolopteryx dinelliana tiene una distribución chaqueña con acotados movimientos estacionales. $P$. citreola nidifica fundamentalmente el Matorral chileno y el Monte de Argentina y migraría al Chaco en invierno. $P$. flaviventris cría en los pastizales pampeanos y durante al inverno migraría hacia el sur de Brasil y el Chaco húmedo de Argentina. Las comparaciones pareadas de superposición en el espacio geográfico y de nicho demuestran que ninguna de las especies tiene nichos ecológicos equivalentes entre sí. Al ponderar las comparaciones de superposición geográfica y de nicho en cada nodo del árbol filogenético se observó que la especiación en Pseudocolopteryx se dio bajo un patrón general de alopatría y divergencia de nicho ecológico. Las distribuciones y nichos ecológicos actuales de $P$. sclateri y $P$. acutipennis se vieron modificados fuertemente por cambios post especiacionales, debido a su posición basal en la filogenia y a sus tiempos de divergencia mas antiguos. En cambio, $P$. dinelliana, $P$. citreola y $P$. flaviventris sufrieron procesos de especiación mas recientes donde las presiones mediadas por el hábitat habrían tenido un papel importante. Dado el reciente evento de especiación ente $P$. citreola y $P$. flaviventris, se plantea la posibilidad de que una de las dos especies sea el ancestro de la otra. Los datos de distribución y migración son consistentes con dos escenarios posibles de especiación (Especiación peripátrica y Especiación por "dosificación de migrantes") que indican que $P$. citreola es el ancestro de $P$. flaviventris y no al revés. 


\section{Abstract}

The genus Pseudocolopteryx (Doraditos) comprises five species of South American open-area flycatchers: P. sclateri, P. acutipennis, P. dinelliana, P. citreola and P. flaviventris, all of which have some kind of seasonal movement. In the present study we built the first phylogenetic hypothesis for Doraditos based on DNA sequence data and used it to study: 1) the evolution of plumage structure and color patterns, 2) nuptial displays, and 3) biogeography.

The phylogenetic relationships were estimated with Bayesian and Maximum Likelihood analyses of mitochondrial (ND2 y COI) and nuclear (MYO y ODC) gene sequences. The resulting phylogeny recovered the monophyly of Pseudocolopteryx, resolving the relationships among species: $(P$. sclateri ( $P$. acutipennis $(P$. dinelliana $(P$. citreola- $P$. flaviventris $))$ ). These phylogenetic analyses did not recover the monophyly of the cryptic species $P$. citreola and $P$. flaviventris. Overall, these genes showed very low and inconsistent divergences between $P$. flaviventris and $P$. citreola. Two weakly differentiated haplotypes ofND2 were exclusive to $P$. flaviventris and three were exclusive to $P$. citreola, but interspecific differences ranged between one and two mutational steps. A molecular clock estimated a very recent divergence between $P$. citreola and $P$. flaviventris: approximately 60000 years before present.

All the species showed sexual dimorphism in bill color: males had wholly black bills, and females had black bills with orange gape and mandible base. Pseudocolopteryx sclateri, $P$. dinelliana and $P$. acutipennis exhibit a sexual dimorphism only visible with specimens in hand: male's p6 and p7 primaries were attenuated and/or structurally modified. The degree of sexual dichromatism based on plumage features was high in $P$. sclateri, moderate in $P$. acutipennis, $P$. citreola, and $P$. flaviventris, and low in $P$. dinelliana. Ancestral state reconstruction showed that sexual dichromatism is ancestral in Pseudocolopteryx, and that partial monochromatism appears as a derived character only in $P$. dinelliana. Changes in color phenotype of males, but not those of females, contributed to the reduction of dimorphism, with $P$. dinelliana acquiring plumage characters that are feminine among the others species. Modified primaries also appeared as an ancestral character in Pseudocolopteryx, and were lost in $P$. citreola and $P$. flaviventris along with both aerial displays and mechanical sounds. The extreme similarity of the plumage of $P$. citreola and $P$. flaviventris is explained by their common ancestry, and not by convergence or retention of plesiomorphies. Their vocalizations and their capability of reciprocal recognition have diverged markedly in a very short period of time, while the plumage has remained in a total stasis.

Through the study of audio and video recordings, the behavioral units that conform the phenotype of Pseudocolopteryx displays were identified and described in detail. The behavioral phenotype was analyzed under the concept of modularity. Modularity is the property that allows characters to organize and evolve as coherent units and subunits (modules). Modules can be organizational and/or variational. Modules can be considered organizational when existing as such in the same organism, and posses: 1) hierarchical organization, 2) discrete existence and 3) stereotyped form. Variational modules are heritable and susceptible to evolve, and exhibit: 1 ) homology and 2) evolutionary dissociability.

Nuptial displays of Pseudocolopteryx were organized into three modules of higher hierarchy (Momentum Modules): Presentation, Crowning, and Two-perch Aerial Display. These modules contained modules of lower hierarchy (Action Modules): Noddings, Twists and Bowings, and Closing. These visual modular behavioral units were coupled in a fully modular way with the acoustic components. Presentation was related to the acoustic component Introduction, and Crowningwas related to Flourish, while Two-perch Aerial Display included all or some of the action modules of the Flourish. The action modules are fully coupled to acoustic components: Noddings to initial notes, Twists and Bowings to middle notes, and Closing to final notes. The units of the behavioral phenotype of the nuptial displays in Pseudocolopteryx were coupled in a fully modular way, and presented the characteristics of organizational and 
variational modularity. The action module Presentation is mainly constituted by the duplication of the action modules Noddings, and may present some Twists and Bowings. Crowning is characterized by the presence of Closing, but also has Noddings and Twists and Bowings. Two-perch Aerial Display is constituted by the same action modules that Crowning. The Two-perch Aerial Display momentum module would have appeared in the early evolution of Pseudocolopteryx as a duplication with modification of the Crowning momentum module.

The replacement of vocal sounds by mechanical sounds (or vice versa) appears twice in Pseudocolopteryx: the initial notes are bill snaps in $P$. sclateri but vocalizations in the other species, and the final notes of $P$. acutipennis are mechanical sounds produced by their modified primary feathers, while they are syringeal in the other species. Presentation and Crowning in Pseudocolopteryx present structural differences that would indicate that they are modules carrying different information: during Crowning the male would transmit information about his specific identity relevant for mating, whereas Presentation would work simply to draw attention to the upcoming Crowning. Thus, the highly rigid and diagnostic Crowning would have evolved under strong selective pressures while the Presentation was more variable and similar among species would have been under less severe selection pressures.

The distribution and seasonal movements of Doraditos were analyzed through the development of both ecological niche and potential distribution models. Pseudocolopteryx sclateri is a nomadic species, which could breed when and where certain conditions are met, resulting in a very dynamic geographic range. The southern populations of $P$. acutipennis are migratory, while the northern populations would be annual residents. Pseudocolopteryx dinelliana has a chacoan distribution with limited seasonal movements. Pseudocolopteryx citreola breeds essentially in Chilean Matorral and Monte Desert of Argentina, and migrates north to the Chaco region during winter. Pseudocolopteryx flaviventris breeds in the Pampas grasslands and migrates in winter to southern Brazil and the humid Chaco of Argentina. Analysis of both niche and geographic overlap show that none of the species has equivalent ecological niches to each other. When species-pair comparisons of geographic and niche overlap where compared taking into account their position in each node of the phylogenetic tree, it was observed that the speciation in Pseudocolopteryx occurred under a general pattern of allopatry and divergence of ecological niche. Current distributions and ecological niches of both $P$. sclateri and $P$. acutipennis were strongly modified by post-speciational changes, due to their basal position in phylogeny and their deeper divergence times. In contrast, $P$. dinelliana, $P$. citreola and $P$. flaviventris underwent more recent speciation events where pressures mediated by habitat would have played an important role. Given the recent speciation event between $P$. citreola and $P$. flaviventris, it is possible that one of the two species is the ancestor of the other one. Migration and distributional data are consistent with two possible speciation scenarios (Peripatric speciation and Migration-dosing speciation) showing that $P$. citreola would be the ancestor of $P$. flaviventris, and not viceversa. 


\section{Introducción general}

El género Pseudocolopteryx está compuesto por cinco especies de pequeños tiránidos de la subfamilia Elaeniinae (Tello et al. 2009) que se distribuyen desde el norte de Sudamérica hasta el norte de la Patagonia: P. sclateri, P. acutipennis, P. dinelliana, P. citreola y P. flaviventris (Ridgely \& Tudor 1989, Fitzpatrick 2004, Ábalos \& Areta 2009).

Los doraditos presentan varias características que los posicionan como un buen objeto de estudio para abordar preguntas evolutivas y biogeográficas. El primer aspecto a tomar en cuenta es que las relaciones filogenéticas a nivel de especie en Pseudocolopteryx no han sido estudiadas hasta el momento. En base a caracteres anatómicos (Lanyon 1988), comportamentales (Birdsley 2002) y de apariencia externa, voces y despliegues sexuales (Parker \&Willis 1997, Roesler 2009, Abalos \& Areta 2009) se ubicó a Pseudocolopteryx como cercanamente emparentado con Polystictus. Sin embargo, estudios recientes basados en datos moleculares ubican a Pseudocolopteryx como grupo hermano de Serpophaga (Tello et al. 2009).

Por otro lado, los doraditos presentan varias particularidades en lo que respecta al plumaje. Las diferencias observables a campo en el patrón de coloración de las especies son sutiles: ventralmente son amarillos en diferentes tonalidades, el dorso es pardo con variantes olivas, y presentan contrastes más notables en la corona (Narosky \& Yzurieta 1987, Ridgely \& Tudor 1989, Fitzpatrick 2004). Es especialmente interesante que dos especies, $P$. citreola y $P$. flaviventris, son especies crípticas (i.e. son virtualmente indistinguibles por anatomía externa en la naturaleza y en especímenes de museo) y fueron hasta hace poco tiempo consideradas como parte de una única especie bajo el nombre de P. flaviventris. Ábalos \& Areta (2009) demostraron que las poblaciones de $P$. citreola (del sur y del oeste) se diferencian en sus voces y despliegues visuales, y utilizan hábitats diferentes. En un contexto evolutivo, el plumaje críptico de estas dos especies podría ser producto de una convergencia evolutiva, deberse a la retención de plesiomorfías en los caracteres de coloración, o ser el producto de una divergencia reciente de especies hermanas.

Por otro lado, parece que todas las especies de Pseudocolopteryx presentan algún grado de dimorfismo sexual. Este dimorfismo puede evidenciarse como diferencies entre sexos en el color del plumaje (dicromatismo) y/o en la estructura de las plumas de las alas. La especie que presenta dicromatismo sexual más marcado es $P$. sclateri (Bostwick \& Zyskowski 2001), aunque también $P$. flaviventris presenta un dicromatismo sexual más sutil (Cardoni et al. 2016). Además, es posible que exista algún tipo de tenue diferencia sexual en la coloración de las restantes especies de Pseudocolopteryx (obs. pers.). Por otro lado Pseudocolopteryx 
sclateri, $P$. dinelliana y $P$. acutipennis exhiben también dimorfismo sexual sólo visible con ejemplares en mano, donde las plumas primarias p6 y p7 de los machos están modificadas (Wetmore 1926, Hellmayr 1927, Bostwick \& Zyskowski 2001, Navas 2002). Esclarecer el grado de dicromatismo sexual en un contexto filogenético permitiría poner a prueba diferentes hipótesis respecto de su evolución (e.g. transiciones del dimorfismo a monomorfismo, convergencia del fenotipo femenino en un fenotipo masculino) e indagar acerca del rol de la selección sexual sobre estos caracteres.

Otro aspecto interesante es la relación entre despliegues visuales, sonidos mecánicos y vocalizaciones. Tres especies ( $P$. sclateri, $P$. dinelliana y $P$. acutipennis) presentan despliegues en vuelo que están acompañados por sonidos que parecen ser mecánicos, producidos por las modificaciones en las plumas primarias. Aunque estas modificaciones generalmente están asociadas a sonidos mecánicos en otras especies de aves, es escasa la documentación crítica para este tipo de sonidos en Pseudocolopteryx (Wetmore 1926, Bostwick \& Zyskowski 2001, Roesler 2009). Además se han descripto diferencias en el patrón de movimientos de la cabeza durante las vocalizaciones de las dos especies crípticas $P$. citreola y $P$. flaviventris (Ábalos y Areta 2009) y en P. sclateri, que suma chasquidos hechos con el pico a los movimientos de cabeza y voces (Bostwick \& Zyskowski 2001). Las voces de Pseudocolopteryx son heterogéneas y constituyen la mejor manera de identificarlos a campo. En líneas generales el canto está compuesto de una serie de notas que van cambiando (generalmente ascendiendo) en volumen y frecuencia, para terminar en una segunda serie de notas más aceleradas formando un patrón complejo (Bostwick \& Zyskowski 2001, Abalos \& Areta 2009). A partir de esta evidencia preliminar, resulta pertinente explorar la posibilidad de que los despliegues de Pseudocolopteryx presenten las características de modularidad (Schlosser \& Wagner 2004, Scholes 2006, 2008b, 2008b) y analizarlos bajo este paradigma.

En cuanto a la distribución de los doraditos, $P$. sclateri se distribuye en las cuencas de los ríos Paraná y Uruguay, y costa sureste de Brasil. Además, cuenta con registros aislados en Bolivia, Guyana, Guyana Francesa, Venezuela y Trinidad (Ridgely \& Tudor1989, Hilty 1999, Bostwick 2004, Claessens \& Comité d'Homologation de Guyane 2015, Herzog et al. 2016). Pseudocolopteryx acutipennis se distribuye por la zona andina desde Colombia al sur hasta Argentina, en las Serranías Centrales de Argentina, tierras bajas de Paraguay y en la región Pampeana (Fjeldsa \& Krabbe 1990, Bostwick 2004, Schulenberg et al. 2007, Ridgely \& Tudor 1989, Navas 2002, Roesler 2009, Hayes 1995, Smith et al. 2014). Pseudocolopteryx dinelliana se distribuye desde el noreste de Córdoba en Argentina hacia el norte hasta Paraguay. Las distribuciones de $P$. citreola y $P$. flaviventris guardan un alto grado de incertidumbre, ya que la imposibilidad de determinar con seguridad cuáles registros corresponden a una u otra especie 
(dado su carácter de especies crípticas) dificultan la tarea. En términos generales se puede afirmar que en época estival $P$. citreola habita el sur oeste de Argentina y centro de Chile, mientras que $P$. flaviventris lo hace en las Pampas de Argentina (Ábalos \& Areta 2009). El estatus migratorio de las especies de doraditos permanece sin resolverse. Pseudocolopteryx flaviventris es considerado residente en la mayor parte de su distribución (Narosky \& Di Giácomo 1993, Belton 1994, Azpiroz 2001) o migrante austral o parcial en algunas regiones (Short 1975, Ridgely \& Tudor 1989, Fjeldså \& Krabbe 1990, Hayes et al. 1994, Di Giacomo 2005, Repenning \& Fontana 2009, Pagano et al. 2013). Pseudocolopteryx dinelliana cría en el centronorte de Argentina y se mueve en el invierno al sur de Bolivia y Chaco paraguayo (Ridgely \& Tudor 1989, Hayes et al. 1994, Fitzpatrick 2004). Durante el invierno las poblaciones de $P$. acutipennis de Argentina y Bolivia migrarían parcial o totalmente al norte a través de los Andes y las colindantes tierras bajas amazónicas de Perú, Ecuador y Colombia, y hasta el Chaco paraguayo (Olrog 1979, Parker 1982, Ridgely \& Tudor 1989, Fjeldså \& Krabbe 1990, Navas 2002, Fitzpatrick 2004). Para algunos autores $P$. sclateri es considerado migratorio (Olrog 1979, Canevari et al. 1991), y en el sur de Brasil se ha demostrado su presencia sólo en otoño e invierno (Almeida Accordi \& Hartz 2006). Otros autores, sin embargo creen que es residente (Ridgely \& Tudor 1989, Fitzpatrick 2004, Pagano et al. 2013). Pseudocolopteryx citreola es claramente migratorio en Mendoza (Ábalos \& Areta 2009) y Chile (Reed 1877, Housse 1947, Johnson 1967), pero no se conoce su zona de invernada con certeza, aunque se ha indicado Bolivia como sitio de visita invernal (Ábalos \& Areta 2009). La preferencia de hábitat de los doraditos está muy poco explorada: existe información para $P$. acutipennis, que habitaría áreas arbustivas y matorrales cerca del agua (Nores e Yzurieta 1980, Fjeldså y Krabbe 1990, Fitzpatrick 2004, Ortiz et al. 2006) y cultivos y pastizales (Contino 1982, Roesler 2009). Además, para $P$. citreola se indica que utiliza ambientes con chilcales (Baccharis salicifolia) y tamariscales (Tamarix gallica) (Housse 1947, Ábalos \& Areta 2009). Pseudocolopteryx sclateri parece ser el más fuertemente asociado a ambientes palustres (Narosky \& Di Giacomo 1993, Ortiz et al. 2006, obs. pers.). Estos datos dispersos en la literatura sugieren que las especies de Pseudocolopteryx podrían diferir en sus requerimientos ecológicos. En definitiva resulta necesario esclarecer la distribución geográfica y los posibles patrones migratorios en Pseudocolopteryx, junto con las variables ecológicas para analizarlos en un contexto biogeográfico. 
Esta tesis esta ordenada en tres capítulos principales en donde se abordan estos tópicos evolutivos y biogeográficos, con los siguientes objetivos:

Capítulo 1. Generar una hipótesis filogenética de las especies de Pseudocolopteryx basada en secuencias de ADN para mapear la evolución de caracteres de estructura y color de plumaje mediante la reconstrucción de estados ancestrales.

Capítulo 2. Describir detalladamente los despliegues multimodales de las cinco especies de Pseudocolopteryx, relacionando señales acústicas y visuales, para luego poner a prueba la hipótesis de que los caracteres etológicos en los despliegues de Pseudocolopteryx están acoplados de manera plenamente modular.

Capítulo 3. Elucidar la distribución geográfica y los posibles movimientos estacionales de las cinco especies de Pseudocolopteryx e integrar las hipótesis filogenéticas con datos ecológicos y de distribución geográfica para explorar los factores que influyeron en la distribución actual de los doraditos y que pudieron haber influenciado en su especiación. 


\section{-Capítulo 1-}

\section{Filogenia y evolución del plumaje en los Doraditos}

\section{(Pseudocolopteryx spp.)}

\section{Introducción}

Los caracteres de plumaje son parte importante del sistema de reconocimiento de parejas en las aves, y por lo tanto se los considera como caracteres sexualmente seleccionados. El dicromatismo sexual, definido como diferencias en la coloración de machos y hembras de la misma especie, se piensa que ha evolucionado repetidamente en las aves en respuesta a presiones de selección que difieren entre los sexos (Badyaev \& Hill 2003). A su vez, ciertos caracteres de plumaje, pueden cumplir funciones como señales intra-sexuales o inter-sexuales durante el emparejamiento (Berglund et al. 1996). La teoría de la selección sexual sugiere que la evolución del plumaje puede ser muy rápida y propensa a altos niveles de homoplasia (Omland \& Lanyon 2000, Badyaev \& Hill 2003, Shultz \& Burns 2017). Consecuentemente, los caracteres de plumaje no son buenos indicadores de afinidades filogenéticas y han llevado frecuentemente al agrupamiento de especies lejanamente relacionadas que se parecen superficialmente en plumajes y a la separación de especies estrechamente emparentadas pero con plumajes divergentes (Rheindt et al. 2008, Shultz \& Burns 2017). Para determinar la forma en que los caracteres de plumaje han evolucionado se necesita que dichos caracteres sean mapeados sobre filogenias bien resueltas.

Como se ha mencionado, el género Pseudocolopteryx está compuesto por cinco especies poco estudiadas de tiránidos que habitan áreas abiertas de Sudamérica: $P$. sclateri, $P$. dinelliana, P. acutipennis, P. flaviventris y P. citreola (Ridgely \& Tudor 1989, Fitzpatrick 2004, Ábalos \& Areta 2009). Diferentes propuestas de relaciones filogenéticas en los Tiránidos ubican al género Pseudocolopteryx dentro del grupo Elaenia o subfamilia Elaeniinae (Lanyon 1988, Fitzpatrick 2004, Tello et al. 2009). En base a caracteres anatómicos (Lanyon 1988), comportamentales (Birdsley 2002), de apariencia externa, voces y despliegues sexuales (Parker \& Willis 1997, Roesler 2009, Ábalos \& Areta 2009) se considera a Pseudocolopteryx como cercano a Polystictus. Sin embargo, estudios más recientes basados en datos moleculares ubican a Pseudocolopteryx como grupo hermano de Serpophaga (Tello et al. 2009). Hasta el momento no han sido estudiadas las relaciones filogenéticas de Pseudocolopteryx a nivel de especie. 
Las diferencias observables a campo en el patrón de coloración de las especies de este género son generalmente sutiles: ventralmente son amarillos en diferentes tonalidades, el dorso es pardo u oliva, y presentan los contrastes más notables en la corona (Narosky \& Yzurieta 1987, Ridgely \& Tudor 1989, Fitzpatrick 2004). Aunque el dimorfismo ha sido escasamente caracterizado en el grupo, todas las especies poseen algún grado de diferencia en la coloración de machos y hembras (obs. pers.). La especie en la que se reporta el dicromatismo sexual más marcado es $P$. sclateri: los machos tienen un antifaz de plumas negras que se extienden desde la base del pico, a través del lorum hasta la parte posterior del parche auricular y alrededor del ojo. El copete es casi todo negro, aunque las plumas mas sagitales tienen el borde amarillento, lo que le da al copete un sutil estriado central. El pico es completamente negro. Las hembras poseen la cara mucho más pálida y presentan una ancha ceja color crema. Las plumas del copete son pardas oscuras con bordes amarillentos, y la base de la mandíbula es rosácea (Bostwick \& Zyskowski 2001). También P. flaviventris presenta dicromatismo sexual, aunque más sutil: en los machos, las plumas de la cara son grises y negras formando una máscara oscura (menos conspicua y menos desarrollada que en $P$. sclateri), mientras que en las hembras las plumas de la cara son pardo grisáceas y no forman una máscara oscura. El pico en machos es negro tanto por fuera como por dentro, mientras que en las hembras el interior es naranja y se extiende externamente como una línea rosácea bordeando las mandíbula y maxila, formando un sutil "labio" (Cardoni et al. 2016). Se desconoce la función de los caracteres de coloración durante el proceso de emparejamiento en los Doraditos.

Además del dicromatismo sexual, existe un dimorfismo sexual en la estructura de las rémiges primarias en algunas especies y distintas modificaciones en la estructura alar de los machos en diferentes especies. Los machos de $P$. sclateri, $P$. dinelliana y $P$. acutipennis exhiben las plumas primarias p6 y p7 con algún tipo de modificación estructural (e.g. atenuaciones, miniaturizaciones, escotaduras) (Wetmore 1926, Hellmayr 1927, Bostwick \& Zyskowski 2001, Navas 2002). Adicionalmente, $P$. sclateri presenta modificaciones microestructurales en las plumas p6 a p9: las barbas proximales del vexilo anterior están elongadas y presentan menos cantidad de bárbulas (Bostwick \& Zyskowski 2001). Los despliegues en vuelo de $P$. sclateri y $P$. acutipennis parecen estar acompañados de sonidos mecánicos producidos por estas modificaciones en las plumas primarias, aunque es escasa la documentación crítica para este tipo de sonidos en Pseudocolopteryx (Wetmore 1926, Bostwick \& Zyskowski 2001, Roesler 2009).

Las especies crípticas son dos o más especies distintas cuya similitud morfológica es tan estrecha que su identificación resulta difícil o imposible sin herramientas auxiliares. 
Frecuentemente, por lo tanto, las especies crípticas son reconocidas tardíamente en las clasificaciones y suelen ser consideradas como representantes de una u otra especie hasta que su taxonomía es esclarecida. Los casos de especies crípticas están ampliamente distribuidos entre los principales taxa de metazoos y regiones biogeográficas (Pfenninger \& Schwenk 2007). Dentro de la familia Tyrannidae existen muchos géneros que presentan especies crípticas que se diferencian mayormente por sus vocalizaciones: Serpophaga (Straneck 1993; 2007), Suiriri (Zimmer et al. 2001), Empidonax (Johnson \& Cicero 2002), Elaenia (Rheindt et al. 2009), o Zimmerius (Rheindt et al. 2013), entre otros. Pseudocolopteryx flaviventris y P. citreola son especies crípticas, ya que son virtualmente indistinguibles por anatomía externa, tanto en la naturaleza como en especímenes de museo, pero reconocibles por sus vocalizaciones y comportamiento (Ábalos \& Areta 2009). Hasta hace poco, ambas eran consideradas como una misma especie bajo el nombre de P. flaviventris. Ábalos \& Areta (2009) demostraron que las poblaciones de $P$. citreola (del sur y del oeste) se diferencian en sus voces y despliegues visuales, y utilizan hábitats diferentes. En los experimentos de playback recíprocos, estos autores demostraron que tanto $P$. flaviventris como $P$. citreola ignoran las voces de la otra especie, mientras que responden fuertemente a sus propias vocalizaciones. A partir de allí las poblaciones del sur y oeste recibieron el estatus de especie plena como $P$. cf. citreola. El fenotipo indistinguible de las especies crípticas $P$. flaviventris y $P$. citreola podría ser producto de una convergencia evolutiva, deberse al conservadurismo en caracteres ancestrales de coloración o ser el producto de una divergencia reciente de especies hermanas donde las vocalizaciones habrían cambiado a una tasa evolutiva mayor que los plumajes.

Los objetivos de este capítulo son 1) generar una hipótesis filogenética de las especies de doraditos basada en secuencias de ADN, 2) calcular los tiempos de divergencia de los eventos de especiación mediante un reloj molecular y 3) mapear la evolución de caracteres de estructura y color de plumaje mediante la reconstrucción de estados ancestrales. A partir de esta base, discutimos la evolución del dicromatismo sexual y morfología alar en los doraditos y ponemos a prueba si las especies crípticas están más cercanamente emparentadas entre sí o si hay homoplasias en la evolución de los plumajes de Pseudocolopteryx. 


\section{Materiales y métodos}

\section{MUeStREO De TAXA}

Se obtuvieron muestras de tejido de las cinco especies de Pseudocolopteryx de 36 individuos. Las muestras utilizadas para estos análisis se obtuvieron de individuos vivos capturados y liberados durante el trabajo de campo $(n=23)$, de pequeñas porciones de tejido (c. $0.05 \mathrm{~g}$ de peso en seco) de especímenes de museo $(n=5)$ y de secuencias de genes disponibles en GenBank $(n=8)$ (Tabla 1). Mediante tres mecanismos se aseguró la correcta identificación de los individuos de los que se les extrajo sangre. 1) En la mayoría de las localidades donde se realizó el trabajo de campo se registró a una sola especie de Pseudocolopteryx: en las localidades de Córdoba sólo se registró a $P$. dinelliana, en Santa Fe sólo a $P$. acutipennis y en Río Negro solo a P. citreola. Sólo en las localidades de Buenos Aires y Formosa ocurrieron en sintopía P. flaviventris y P. sclateri. 2) Las capturas fueron focales: luego de encontrar un territorio e identificar a la especie, los individuos fueron atraídos hacia las redes de niebla mediante el uso de playback. 3) Todos los individuos a los que se les extrajo sangre fueron identificados por el canto. Además, cuando fue posible, sus voces fueron grabadas antes de su captura y luego de ser anillados y liberados. La única manera conocida de identificar con certeza a los individuos de $P$. flaviventris y $P$. citreola es a través de sus voces. Por eso, la correcta identificación de estas especies estuvo asegurada porque: a) estas especies no ocurren en simpatría durante la época reproductiva (ver Capítulo 3), y como era de esperar, solo se registró a una de ellas en cada localidad; y b) todos los individuos de los que se obtuvieron muestras fueron identificados por sus voces, luego capturados mediante playback y anillados, reasegurando su identificación nuevamente por el canto luego de ser liberados.

Como grupo externo (outgroup) se incluyeron cuatro especies pertenecientes a los dos géneros que han sido considerados como grupo hermano de Pseudocolopteryx en trabajos de historia natural y en filogenias con muestreos densos de taxa (Parker \& Willis 1997, Roesler 2009, Ábalos \& Areta 2009, Tello et al. 2009): Polystictus p. pectoralis, Serpophaga griseicapilla, S. subcristata y S. nigricans (Tabla 1). En el presente trabajo se eligió analizar a tres especies de Serpophaga ya que S. griseicapilla y S. subcristata son especies crípticas que presentan morfología externa y preferencias de hábitat muy diferentes a S. nigricans (Straneck 1993, 2007; Fitzpatrick 2004). Esta última por su lado, comparte caracteres de plumaje y hábitos acuáticos con S. cinerea, especie utilizada para sus análisis por Tello et al. (2009). La muestra de S. griseicapilla provino de un individuo grabado, capturado y posteriormente liberado, asegurando así su identidad específica. 
El ADN de las muestras se extrajo usando el kit de extracción DNeasy, siguiendo las recomendaciones del fabricante (Qiagen, MD). El pellet final fue resuspendido en $200 \mu \mathrm{l}$ de solución de hidratación de ADN Qiagen. Se utilizaron primers de PCR para dos genes mitocondriales codificadores de proteínas: NADH deshidrogenasa 2(ND2) y citocromo oxidasa I (COI), y dos intrones nucleares: intron 2 del gen de Myoglobina (MB) e intrones 6 y 7 de ornitina decarboxilasa (ODC). Las amplificaciones de PCR se realizaron en un volumen final de $15 \mu \mathrm{L}$ usando $7.5 \mu \mathrm{L}$ de Classic++ ${ }^{\mathrm{TM}}$ Hot Start Taq DNA Polymerase Master Mix (TONBO biosciences, USA), 0.75 $\mu \mathrm{L} 10 \mu \mathrm{M}$ de cada primer, y $1 \mu \mathrm{L}$ de 10-25 ng de ADN modelo. Las amplificaciones de todas las regiones de ADNmt incluyeron una desnaturailzación inicial de 2 min a $94{ }^{\circ} \mathrm{C}$, seguida de 35 ciclos de: $94{ }^{\circ} \mathrm{C}$ durante $30 \mathrm{~s}, 50 / 54 / 65{ }^{\circ} \mathrm{C}$ durante 45 s y $72{ }^{\circ} \mathrm{C}$ durante $2 \mathrm{~min}$, y una extensión final a $72{ }^{\circ} \mathrm{C}$ durante $10 \mathrm{~min}$. El proceso general del PCR de intrones nucleares incluyó un ciclo inicial de 2 min de desnaturalización a $95{ }^{\circ} \mathrm{C}$, seguido de 35 ciclos de desnaturalización a: $95{ }^{\circ} \mathrm{C}$ durante $20 \mathrm{~s}, 60-53{ }^{\circ} \mathrm{C}$ durante $15 \mathrm{~s}$, y $72{ }^{\circ} \mathrm{C}$ durante $60 \mathrm{~s}$, y una extensión final de 5 min a $72{ }^{\circ} \mathrm{C}$. Para ciertos taxones y pares de primers fue necesario variar la temperatura de recocido y el número de ciclos para optimizar la amplificación PCR. Los productos del PCR fueron purificados con el kit ExoSAP-it (Affymetrix, Santa Clara, California, USA) siguiendo las instrucciones del fabricante. Los productos ya purificados del PCR fueron entregados con los primers apropiados a EonBio para su secuenciación (http://www.EtonBio.com). El ensamblado y edición de secuencias fue realizado mediante Geneious (www.geneious.com). Las secuencias completas fueron depositadas en GenBank. Todos los análisis moleculares se realizaron en el Laboratorio de Sistemática Molecular de la Universidad de Long Island bajo la supervisión del Dr. José G. Tello. 
Tabla 1. Muestras de tejido (con su vocuher asociado) y genes utilizados para construir las hipótesis filogenéticas de los Doraditos Pseudoclopteryx spp

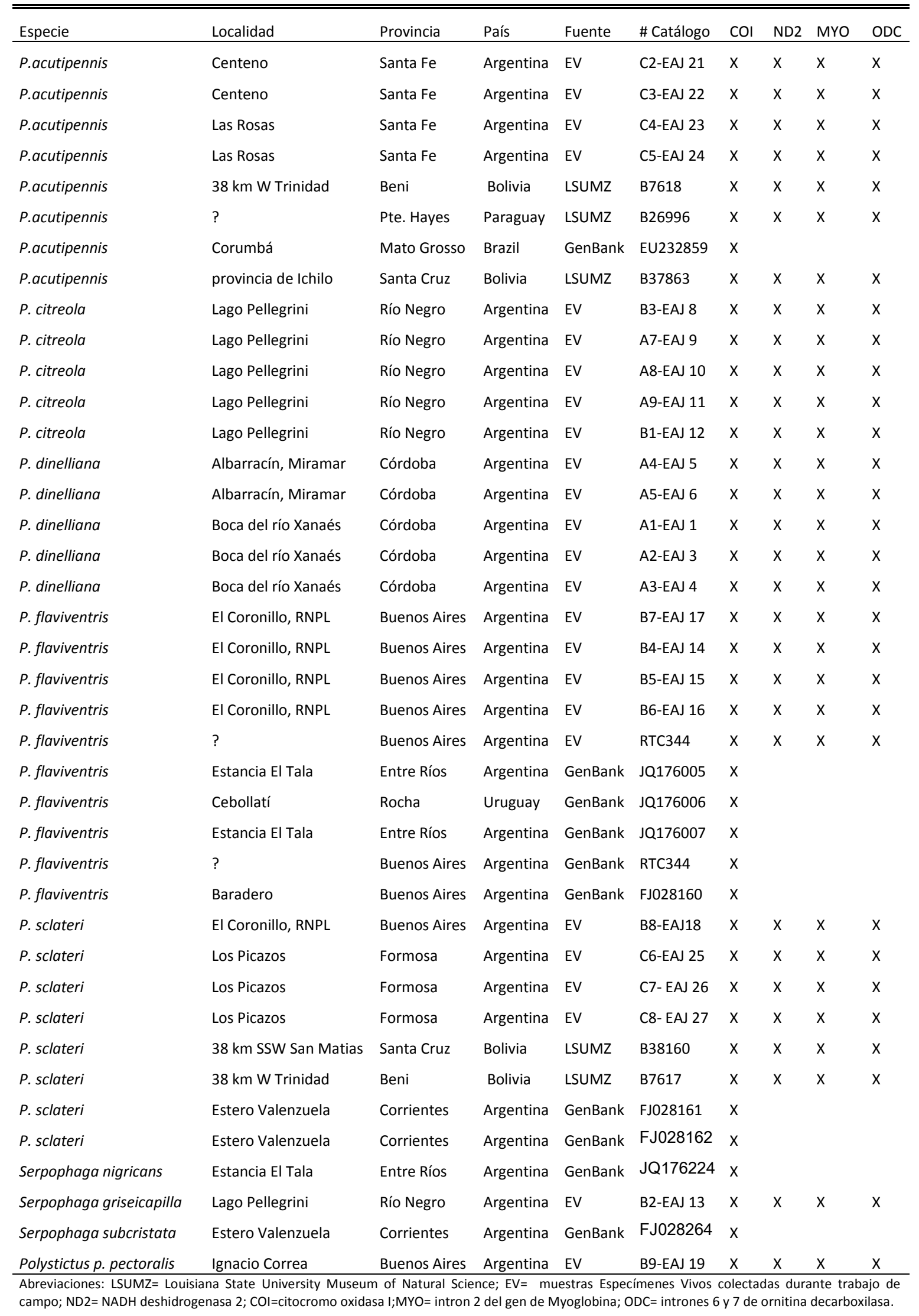




\section{ANÁLISIS FILOGENÉTICOS}

Las relaciones filogenéticas se llevaron a cabo utilizando inferencias Bayesianas (BI, por sus siglas en inglés) y análisis de máxima verosimilitud ( $\mathrm{ML}$, por sus siglas en inglés). Antes de los análisis, se utilizó el jModelTest (Posada 2008) para elegir el modelo más apropiado de evolución del ADN según lo determinado por los criterios de información bayesianos (Posada \& Buckley 2004). Para los análisis de BI se usó MrBayes 3.2 (Ronquist et al., 2012; Huelsenbeck \& Ronquist, 2001). Se realizaron dos corridas independientes de 10 millones de generaciones usando el parámetro de temperatura por defecto y valores predeterminados como valores iniciales para los parámetros del modelo. Los árboles fueron muestreados cada 100 generaciones. Las probabilidades posteriores bayesianas se obtuvieron del consenso (regla de la mayoría del $50 \%$ ) de todos los árboles retenidos después de un $10 \%$ de corrida. Los valores de probabilidad posterior se consideraron estadísticamente significativos cuando $\mathrm{P}$ fue igual o mayor que 0,95. Los análisis de ML se realizaron utilizando el algoritmo de aproximación rápida en RaXML v. 8.2.7 con 1.000 repeticiones de bootstrap (Stamatakis, 2006). Los valores porcentuales de Bootstrap se consideraron robustos cuando fueron iguales o mayores que el 70\%. Adicionalmente, también inferimos genealogías genéticas intraespecíficas utilizando parsimonia estadística usando el programa PopART versión 1.7 (http://popart.otago.ac.nz).

\section{RED DE HAPLOTIPOS}

Para intentar esclarecer las relaciones a más baja escala entre $P$. flaviventris y $P$. citreola, se obtuvieron redes de haplotipos para los cuatro genes secuenciados mediante el programa Network 4.6.1.2. Los mejores modelos de ajuste de evolución molecular seleccionados de acuerdo con el criterio BIC fueron TPM1uf + I para los genes nucleares y HKY para los mitocondriales.

\section{DATACIÓN MOLECULAR}

Se hizo un test de proporción de verosimilitud de la hipótesis de reloj molecular en Mega v7 (Kumar et al. 2016) para examinar si los linajes dentro de Pseudocolopteryx están evolucionando en forma de reloj, y luego los resultados se utilizaron para estimar los tiempos de divergencia para esos linajes. Las estimaciones del tiempo de divergencia se calcularon utilizando BEAST 1.7.5 (Drummond et al. 2012). La calibración de los árboles se realizó utilizando la tasa de sustitución mitocondrial de 2,1\% de divergencia de secuencias por millón de años (Weir \& Schluter 2008, Weir et al. 2009). Se realizaron dos corridas independientes de 10 millones de generaciones, muestreando un árbol por cada 1000. Las probabilidades posteriores de nodos se calcularon a través de los árboles muestreados después de un $10 \%$ de 
corrida. Se examinaron las probabilidades marginales de todas las muestras en Tracer 1.6 (Rambaut et al., 2014) para verificar un tamaño de muestra efectivo superior a 200 para todos los parámetros.

\section{RECONSTRUCCIÓN DE ESTADOS ANCESTRALES}

Para reconstruir las historias evolutivas del plumaje, se usó la reconstrucción de estados ancestrales con el método de máxima verosimilitud sobre el árbol Bayesiano de consenso. Los caracteres analizados incluyeron el patrón de coloración y formas de las plumas rémiges primarias. Se definieron los caracteres que, según la bibliografía (e.g. Fitzpatrick 2004, Bostwick \& Zyskowski 2001, Cardoni et al. 2016) y la experiencia previa, presentan las diferencias más notables entre especies (copete, color de la corona, color del dorso, color de las alas) o entre sexos de una misma especie (cejas, antifaz, color del pico, modificación de plumas primarias). Además, el carácter dicromatismo sexual se definió usando un sistema de gradación combinando los estados de carácter cejas, antifaz y color del pico. Se definió el carácter grado de ornamentación combinando los caracteres copete, color de la corona, color del dorso y color de las alas. En este capítulo la palabra ornamentación hace referencia a un conjunto de caracteres que podría funcionar tanto como ornamento o como armamento (Berglund et al. 1996), ya que no se sabe si tales caracteres tienen una función de comunicación intra- o inter-sexual (ver discusión).

La determinación de las diferencias de colores se basó en el examen visual de individuos en el campo y de ejemplares de museos. En este sentido se ha demostrado que la visión humana puede ser utilizada para caracterizar las diferencias de color que sean de interés, ya que puede detectar la mayoría de la variación cromática en el rango visible que también es detectada mediante métodos más objetivos (i.e. espectrofotómetros) (Armenta et al. 2008, Bergeron \& Fuller 2018). La denominación de los colores sigue la tabla de colores de Canevari et al. (1991). La determinación de los estados de carácter de las plumas primarias se basó en el estudio de los ejemplares capturados para la extracción de sangre y en bibliografía (Wetmore 1926, Bostwick \& Zyskowski 2001, Navas 2002) ya que todavía no existen ejemplares de museo con las alas extendidas.

Se reconstruyeron los estados ancestrales de estos caracteres discretos usando el módulo de mapeo de caracteres ("Trace Character History") de Mesquite versión 3.0 (Maddison \& Maddison 2009) con el método de máxima verosimilitud ("Likelihood Ancestral States"). La reconstrucción de máxima verosimilitud encuentra, para cada nodo, la asignación de un estado que maximiza la probabilidad de llegar a los estados observados en los taxones terminales, dado un modelo de evolución. Se utilizó el modelo de evolución de tasa única de 
cambio ("Mk1 model"), donde cualquier cambio particular (e.g. del estado 0 al 1 , o del 3 al 2) es igualmente probable, ya que Pagel (1999) demostró que los modelos de tasa múltiple más complejos no tienen un ajuste significativamente mejor.

\section{Resultados}

\section{ANÁLISIS FILOGENÉTICOS}

Los análisis Bayesianos y de máxima verosimilitud (Fig. 1) recuperaron la monofilia de Pseudocolopteryx mostrando un soporte muy robusto (1.00 de probabilidad posterior y $100 \%$ de las réplicas de bootstrap de $\mathrm{ML}$ ). Sin embargo, su posición respecto de los grupos externos seleccionados (Polystictus p. pectoralis y Serpophaga griseicapilla) quedó irresuelta. Haciendo un análisis de máxima verosimilitud sólo con secuencias de genes mitocondriales COI (694 bps.) y agregando más taxa terminales, esta politomía se resolvió (Fig. 2), e indica a Serpophaga nigricans como la especie hermana de Pseudocolopteryx (83\% de las réplicas bootstrap de $\mathrm{ML})$.

Dentro de Pseudocolopteryx, $P$. sclateri es la especie hermana de todas las demás, y $P$. acutipennis es hermana de un clado (de aquí en más, clado terminal) compuesto por $P$. dinelliana y $P$. flaviventris $+P$. citreola (Figs. 1 y 2). Los análisis muestran soportes robustos en todos los clados del árbol, separando claramente cuatro de las cinco especies de doraditos reconocidas. Sin embargo, ni los análisis Bayesianos de consenso construidos a partir de genes nucleares y mitocondriales, ni los análisis utilizando sólo secuencias de genes mitocondriales COI fueron capaces de separar a las especies crípticas $P$. flaviventris y $P$. citreola (Figs. 1-2). 


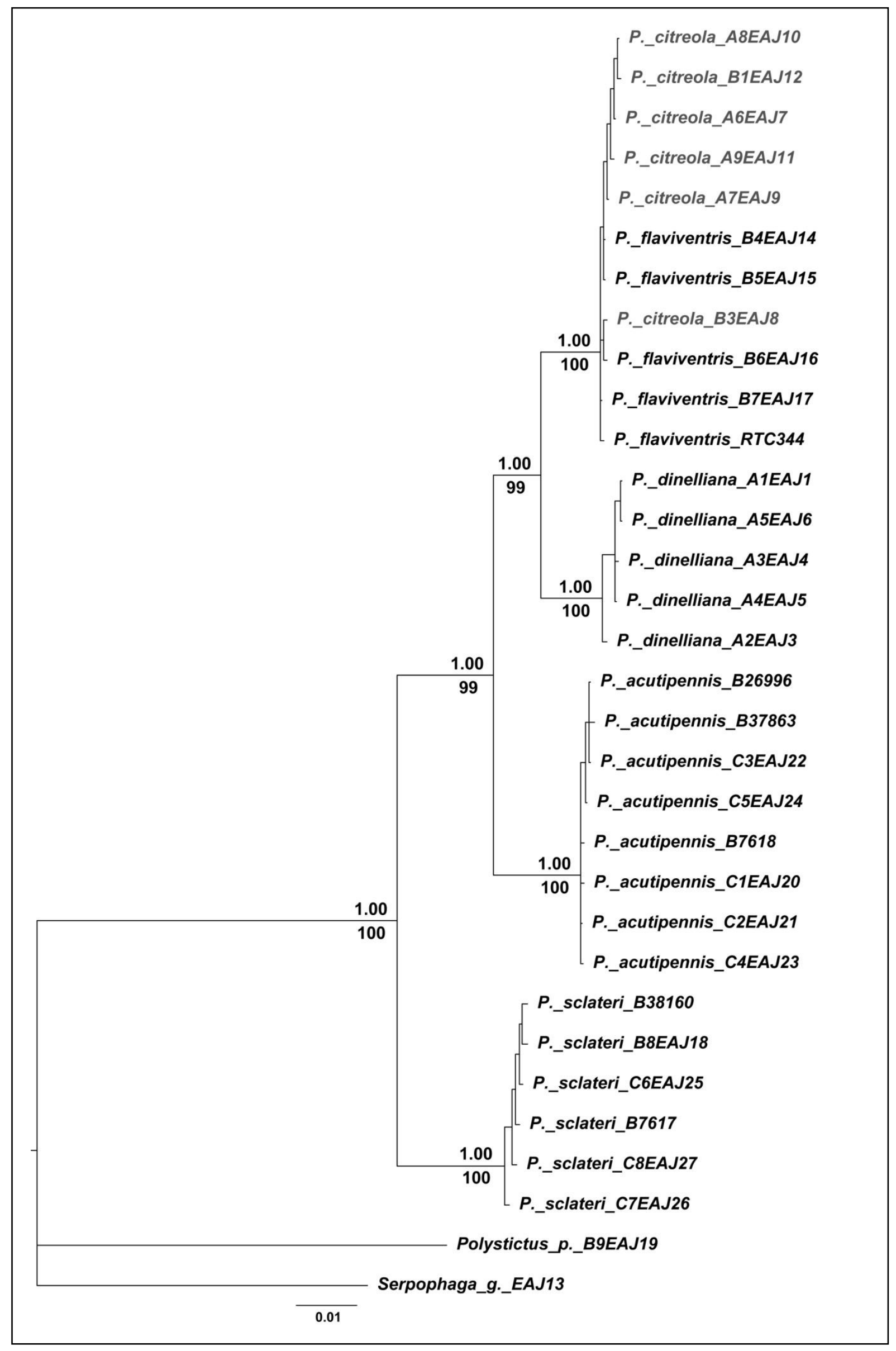

Figura 1. Árbol Bayesiano de consenso de Pseudocolopteryx inferido a partir de genes mitocondriales y nucleares (ND2, COI, MYO, ODC). Los valores en los nodos son las probabilidades posteriores Bayesianas (sobre las ramas) y los porcentajes de los bootstrap de máxima verosimilitud (bajo las ramas) que dan soporte a cada nodo. 


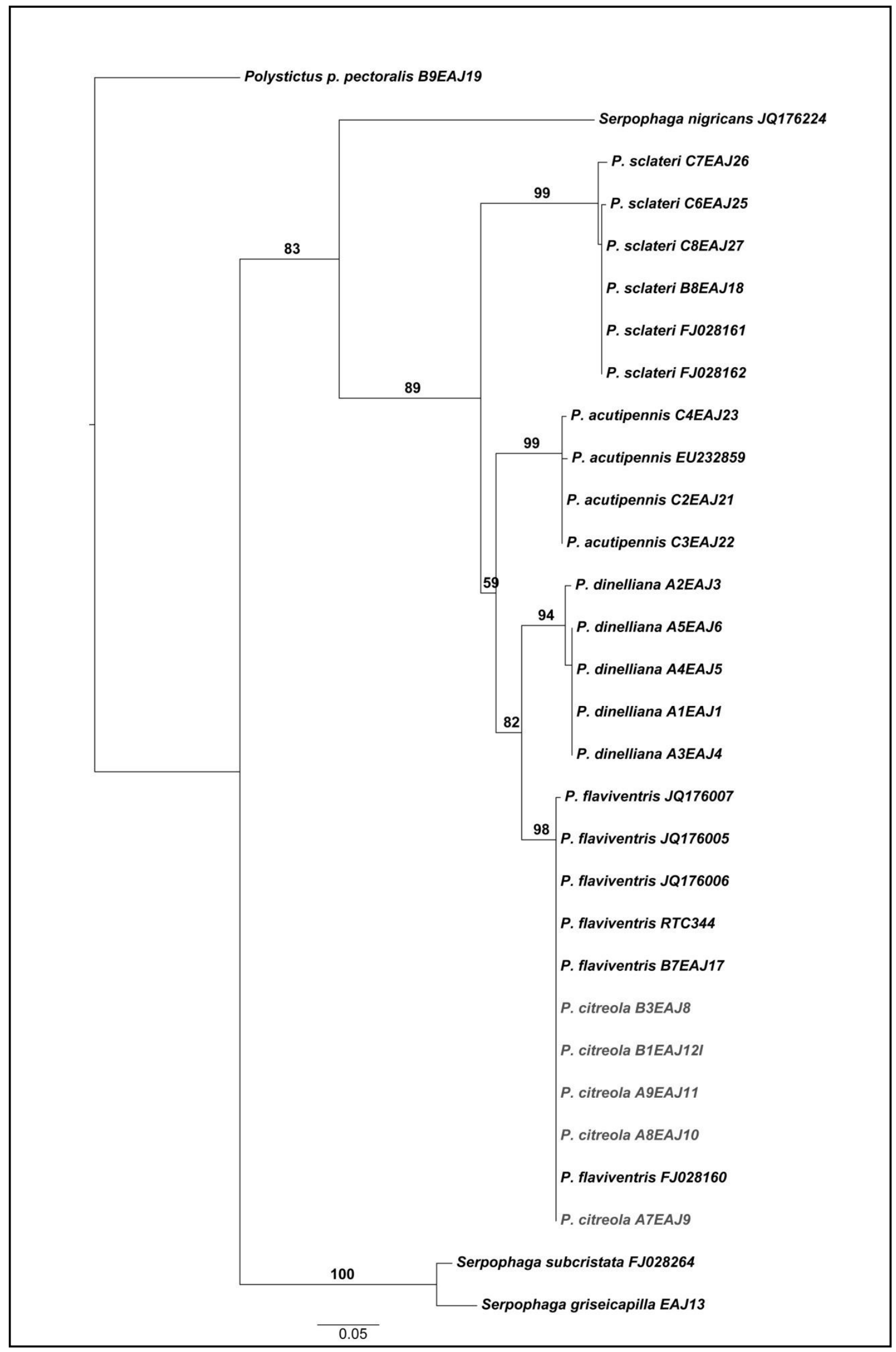

FIGURA 2. Árbol de máxima verosimilitud de Pseudocolopteryx inferido a partir solo de genes mitocondriales COI (694 bps.). Los valores que dan soporte a los nodos corresponden al porcentaje de los bootstrap de máxima verosimilitud. 


\section{RED DE HAPLOTIPOS EN ESPECIES CRÍPTICAS}

La red de haplotipos de $P$. flaviventris y $P$. citreola indica que no existe una clara asociación entre grupos de haplotipos y especies particulares (Fig. 3). El gen nuclear MYO muestra dos haplotipos compartidos por ambas especies, mientras que el gen ODC (también nuclear) muestra un haplotipo ancestral compartido más un haplotipo único para cada especie, los cuales no están agrupados (Fig. 3). Ambos genes nucleares tienen un solo paso mutacional entre cada haplotipo y esta misma distancia separa al haplotipo más cercano al grupo externo. Sólo el gen ND2 muestra una débil asociación específica de haplotipos, pero con muy poca distancia mutacional entre ellos; tres haplotipos fueron exclusivos de $P$. citreola y dos fueron exclusivos de $P$. flaviventris con distancias intraespecíficas de 1 a 2 mutaciones y distancias interespecíficas de 1 a 3 mutaciones. El gen mitocondrial COI presenta un solo haplotipo, muy distante del grupo externo pero compartido entre ambas especies.

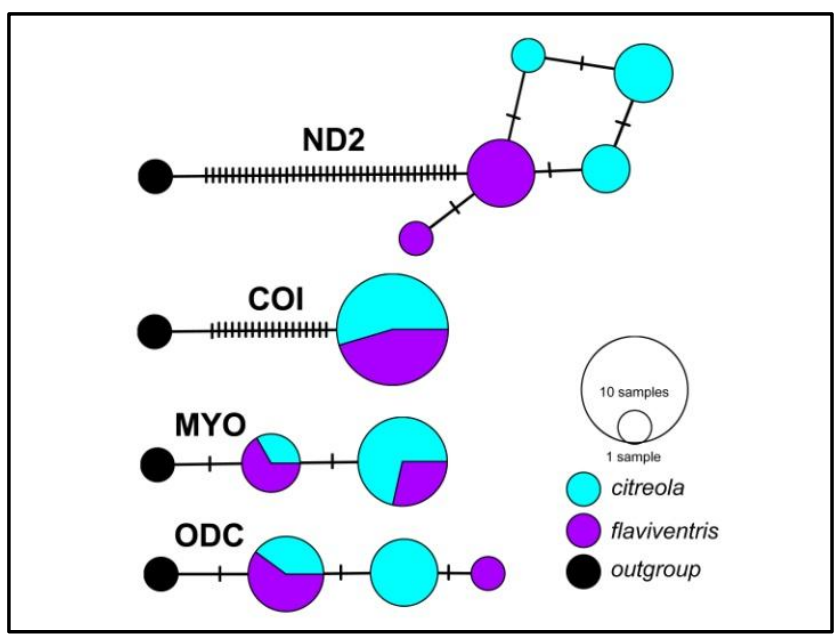

FIGURA 3. Red de haplotipos con datos de secuencias nucleares (ODC y MYO) y mitocondriales (COI y ND2) pare el clado $P$. flaviventris-P.citreola. Los círculos indican diferentes haplotipos con sus proporciones encontradas en ambos linajes. El tamaño de los círculos es proporcional a su frecuencia. Individuos muestreados:

P. flaviventris $\mathrm{n}=5$,

P. citreola $\mathrm{n}=6$.

\section{DATACIÓN MOLECULAR}

Las estimaciones de tiempo de divergencia indican una antigüedad del género de 10 millones de años, y que el proceso de cladogénesis dentro Pseudocolopteryx comenzó entre 3 y 5 millones de años atrás, con una divergencia muy reciente entre $P$. flaviventris y $P$. citreola de aproximadamente sólo 60 mil años (Fig. 4). 


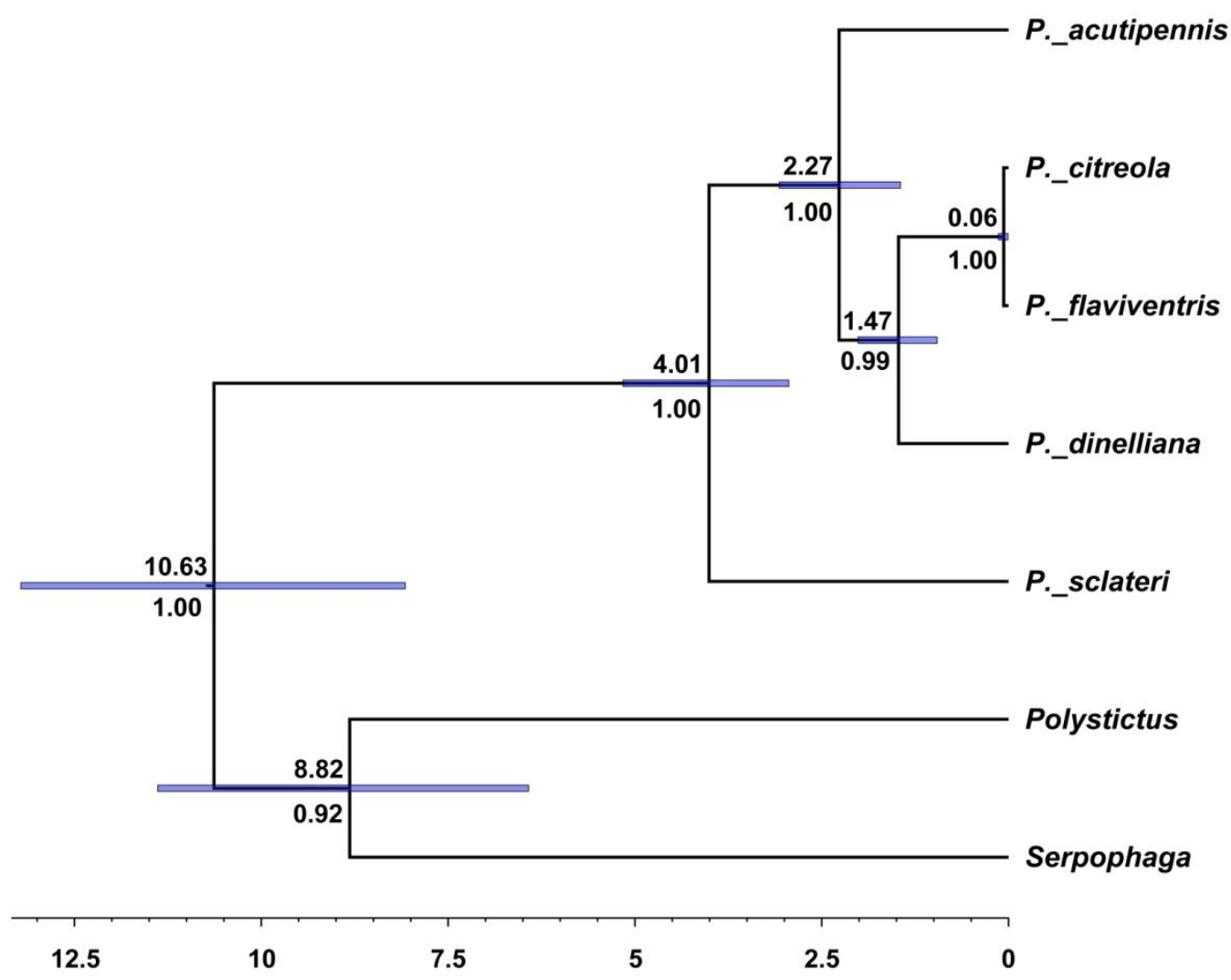

Figura 4. Cronograma de Pseudocolopteryx indicando estimaciones de tiempo de divergencia basadas en el análisis combinado de $A D N$ mitocondrial e intrones nucleares. Los números por encima de las ramas son las estimaciones medias de tiempo de divergencia del nodo. Los números debajo de las ramas son el soporte de probabilidad posterior del nodo. Las barras azules en los nodos corresponden a los intervalos de confianza del $95 \%$ de las estimaciones de tiempo. Los números de escala corresponden a millones de años antes del presente.

\section{DESCRIPCIÓN DE LOS CARACTERES ANALIZADOS}

Se establecieron 10 caracteres de plumaje para ser analizados. Los caracteres están numerados y seguidos de una descripción. Los estados de carácter aparecen en la descripción escritos en cursiva y entre comillas.

1- Copete. Es definido como un conjunto de plumas de la corona que sobresale de la cabeza y forma una estructura prominente. Está "presente" tanto en machos como en hembras de $P$. sclateri y $P$. acutipennis. En $P$. sclateri, el copete es más amplio y mucho más conspicuo que en $P$. acutipennis. En las restantes especies de doraditos el copete está "ausente" tanto en machos como en hembras (Fig. 5).

2- Color de la corona. La corona comienza justo por encima del pico en la frente y se extiende hacia atrás en la parte superior y centro de la cabeza, aproximadamente hasta el punto en donde la cabeza comienza a descender para formar la nuca. El color de la corona, que tiene forma de copete en $P$. sclateri y $P$. acutipennis, fue caracterizada como "negra" para la primera y "oliva" para la segunda especie. La corona en $P$. dinelliana es color pardo castaño, mientras que en $P$. flaviventris y $P$. 
citreola la corona es color castaño rojizo. Dada la sutil diferencia, a las tres especies se le asignó el estado "castaño" para este carácter (Figs. 5 y 6 ).

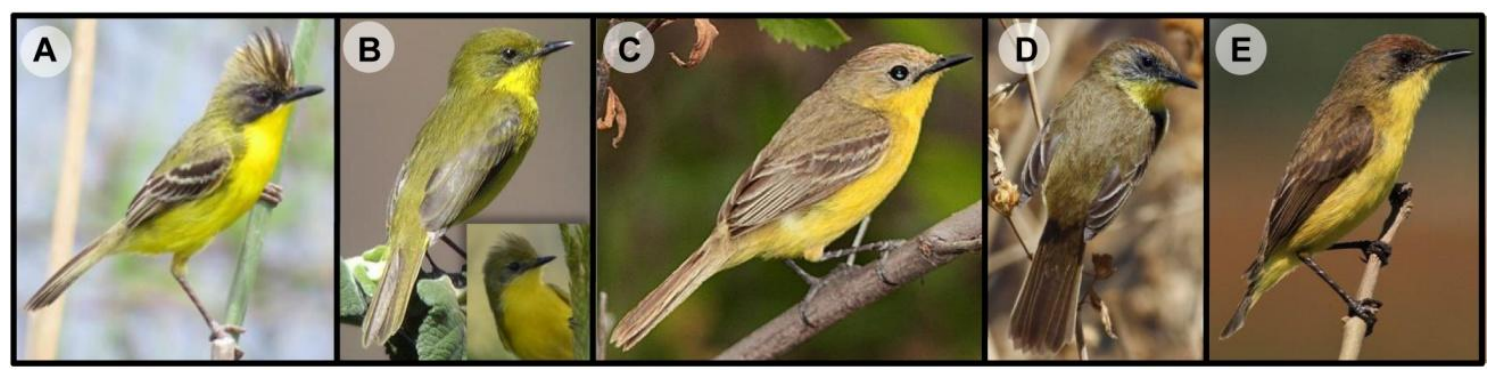

FIGURA 5. Machos adultos de Pseudocolopteryx en donde se aprecian los caracteres 1-4, 6, 7 y 10. A) P. sclateri. 20 de octubre de 2013Río Grande do Sul, Brasil. Foto: S. Klein. B) P. acutipennis (inset mostrando el copete erecto). Diciembre de 2015. Santa Fe, Argentina. Fotos: S. Lamothe. C) P. dinelliana. 19 de noviembre de 2012. Córdoba, Argentina. Foto: P. Eguia, D) P. citreola. San Juan, Argentina. 16 de octubre de 2011. Foto: F. Lucero. E) $P$. flaviventris. Buenos Aires, Argentina. 20 de noviembre de 2016. Foto H. Tolosa.

3- Cejas. Las hembras de todas las especies de doraditos tienen cejas. En las hembras de P. sclateri las cejas son "amplias" y muy notorias de color crema. En las demás especies las cejas de las hembras son más "angostas" y sutiles, de diferentes tonos claros. Los machos adultos no presentan cejas ("ausente") salvo en el caso de $P$. dinelliana, donde los machos muestran una ceja "angosta" parecida a la de las hembras (Fig. 6).

4- Antifaz. Es la zona de la cara que comienza en la zona del lorum y continúa por debajo y encima del ojo, pudiendo llegar hasta la parte posterior del parche auricular. La intensidad del color del antifaz muestra una leve variación entre individuos machos de una misma especie, y parece posible que esta variación sea del tipo etaria (i. e. jóvenes con antifaz menos intenso). A pesar de esto, el patrón general interespecífico muestra claramente que en $P$. sclateri las plumas del antifaz son de color negro intenso, y se extienden a hasta la parte posterior del parche auricular ("intenso y desarrollado"), mientras que en $P$. acutipennis, $P$. flaviventris y $P$. citreola estas plumas son de color pardo negruzco más apagado, que llegan solo hasta la parte posterior del ojo ("poco intenso y poco desarrollado"). Los individuos estudiados de $P$. dinelliana muestran consistentemente la ausencia del antifaz en machos ("ausente"). Las hembras de todas las especies carecen de antifaz (Fig. 6).

5- Color del pico. Se encontró que el dimorfismo en el color del pico que se reporta para P. flaviventris (Cardoni et al. 2016) y P. sclateri (Bostwick \& Zyskowski 2001) es consistente también en $P$. dinelliana, $P$. flaviventris y $P$. citreola. Esto es, pico completamente "negro" en machos, y picos negros con interior y base de la mandíbula anaranjadas en hembras ("naranja") (Fig. 6). 
6- Color del dorso. Pseudocolopteryx sclateri tiene las plumas de la nuca, espalda, escapulares, rabadilla y cobertoras supra caudales color oliva, con un sutil estriado oscuro en la espalda. Mientras que en $P$. acutipennis el dorso es color oliva uniforme. Para ambas especies el estado de carácter fue designado como "oliva". El dorso en $P$. dinelliana es de color pardo claro con un sutil tinte oliva, solo visible con buena luz, mientras que $P$. flaviventris y $P$. citreola tienen el dorso pardo sin tinte oliva. A las tres especies se les asignó "pardo" al estado de este carácter (Fig. 5).

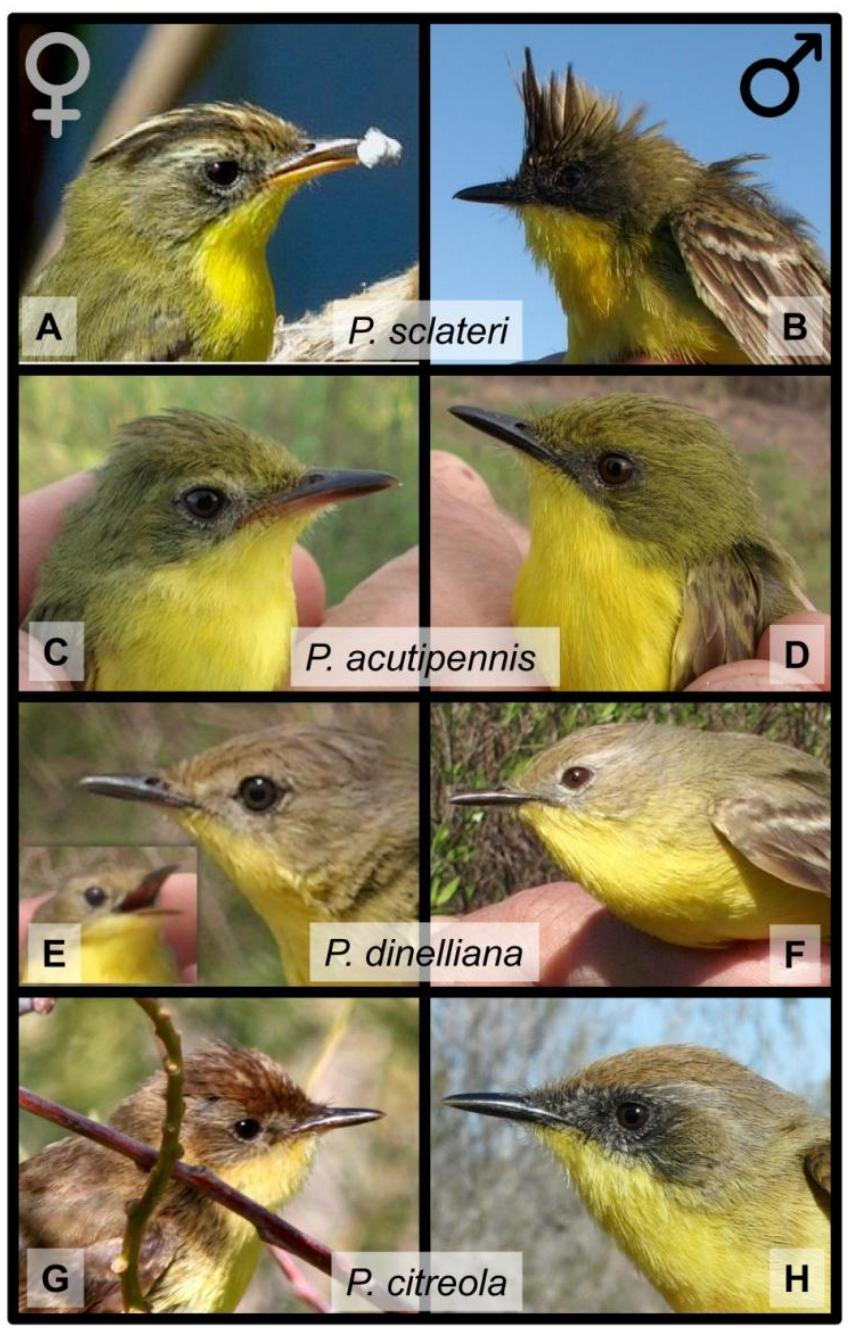

Figura 6. Detalle de los caracteres 1 a 5 de Pseudocolopteryx. A) $P$. sclateri. Hembra sobre el nido. Espírito Santo, Brasil. 27/8/2014. B) P. sclateri. Macho B8-EAJ18. RNPL, Buenos Aires. Argentina. 16/12/2015. C) P. acutipennis. Hembra C4-EAJ23. Las Rosas, Santa Fe, Argentina. 29/01/2016. D) P. acutipennis. Macho C3EAJ22. Las Rosas, Santa Fe, Argentina. 28/01/2016. E) $P$. dinelliana. Hembra A2-EAJ3. Boca del río Xanaés, Córdoba, Argentina. 06/10/2015. El inset es del mismo individuo mostrando el interior del pico naranja. F) $P$. dinelliana. Macho A4-EAJ5. Albarracín, Córdoba, Argentina. 08/10/2015. G) $P$. citreola. Hembra cerca de su nido. Lago Pellegrini, Río Negro, Argentina. 24/10/2015. H) P. citreola. Macho A9-EAJ11. Lago Pellegrini, Río Negro, Argentina. 22/10/2015. Todas las fotos de EAJ, salvo A) de M. Candeias y G) de J.I. Areta.

7- Color de alas. Este carácter se refiere al color de las plumas cobertoras alares y plumas rémiges. Si bien el color de las plumas se ven modificados por desgaste, claramente se puede identificar un patrón general entre los individuos adultos de Pseudocolopteryx en el que $P$. sclateri presenta estas plumas de color "negro", mientras que en las demás especies las plumas de las alas son de color "pardo negruzco" (Fig. 5). 
8- Modificación de primarias. Este carácter se codificó como "presente" en aquellas especies con plumas primarias que presentaran algún tipo de modificación macroestructural ya sean escotaduras, miniaturizaciones o atenuaciones. Los machos de $P$. sclateri y de $P$. dinelliana presentan las plumas p6 y p7 mucho más angostas, de aproximadamente dos tercios del largo de las plumas primarias adyacentes (miniaturizadas), y aguzadas en su tercio terminal (atenuadas), mientras que las plumas p3 a p5 son normales (Fig. 7 A y B). Por otro lado, los machos de $P$. acutipennis presentan un tipo diferente de modificaciones en p6 y p7 (Fig. 7 C): ambas plumas tienen un largo normal, pero el vexilo externo de p7 se reduce abruptamente en su tercio más distal haciendo que el borde exterior de la pluma llegue hasta el raquis en su parte más apical. Así forma la escotadura exterior de p6. El vexilo interno forma un borde notablemente redondeado en el ápice de la pluma y se ensancha suavemente hacia su parte basal, formando una escotadura interior. En p6 el vexilo externo también se reduce, haciendo que el borde externo de la pluma se aproxime al raquis, llegando su máxima aproximación en la zona subapical de la pluma para luego separarse nuevamente hacia la parte más distal. Esto forma la escotadura exterior de p7. La parte más apical del vexilo externo más la del vexilo interno le dan una forma redondeada al ápice de la pluma. Las plumas p3 a p5 tienen una longitud similar a las plumas normales adyacentes, pero están atenuadas en su tercio terminal. Los machos de $P$. flaviventris y $P$. citreola no presentan modificaciones de plumas rémiges, por lo tanto el carácter Modificación de primarias se estableció como "ausente" (Fig. 7 D). Las hembras de todas las especies carecen de modificaciones en las plumas primarias. 

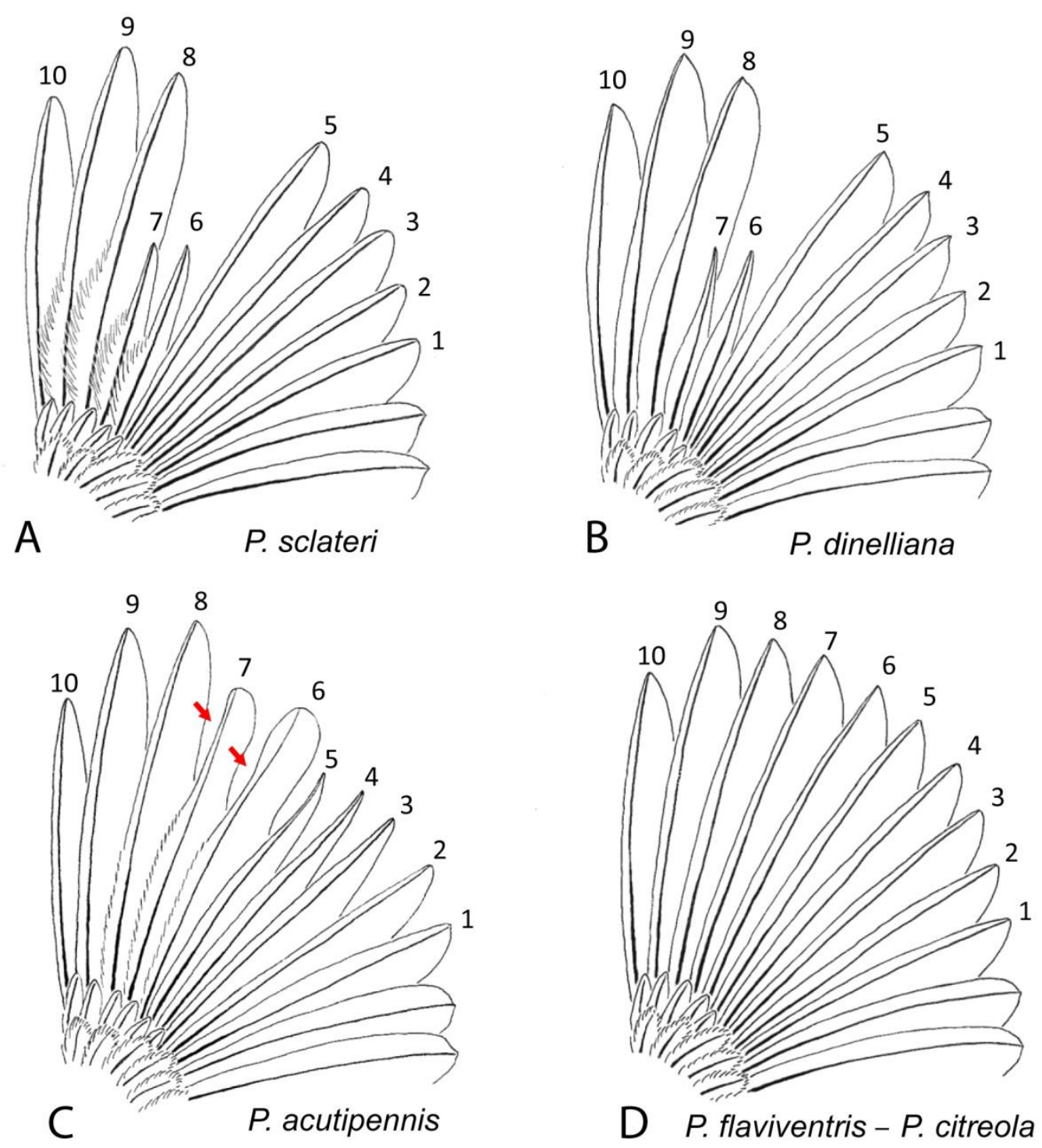

FiguRA 7.Vista dorsal de alas derechas de machos de Pseudocolopteryx. En P. sclateri (A) y P. dinelliana (B) las plumas primarias p6y $\mathrm{p} 7$ están miniaturizadas y atenuadas. En $P$. acutipennis $(\mathrm{C})$ las plumas primarias $\mathrm{p} 6$ y $\mathrm{p} 7$ presentan escotaduras, y las plumas p3 a p5 están atenuadas. Las flechas indican las escotaduras (ver texto para una mejor descripción). Tanto $P$. flaviventris como $P$. citreola $(D)$ presentan plumas rémiges sin modificaciones. Ilustración: Luis G. Pagano.

9- Dicromatismo sexual. A partir de los estados de los caracteres 3 (cejas), 4 (antifaz) y 5 (color del pico) se evidencian patrones de dicromatismo sexual en todos los doraditos (Tabla 2). El color del pico es invariable entre todas las especies: machos con el pico completamente negro y hembras con el pico negro y naranja, mientras que los estados de cejas y antifaz varían entre las especies. Así, se pueden establecer tres grados decrecientes de dicromatismo: 1) "alto", machos con antifaz intenso y desarrollado, y hembras con cejas amplias; 2) "moderado", machos con antifaz poco intenso y poco 
desarrollado, y hembras con cejas angostas; y 3) "bajo", machos con antifaz ausente y en donde tanto machos como hembras presentan cejas angostas (Figs. 5 y 6 ).

TABLA 2. Caracteres asociados al dicromatismo sexual en Pseudocolopteryx utilizados para establecer un grado de dicromatismo sexual.

\begin{tabular}{|c|c|c|c|c|c|c|c|}
\hline & \multicolumn{2}{|l|}{ Antifaz } & \multicolumn{2}{|c|}{ Cejas } & \multicolumn{2}{|c|}{ Color del pico } & \multirow[t]{2}{*}{$\begin{array}{c}\text { Dicromatismo } \\
\text { sexual }\end{array}$} \\
\hline & machos & hembras & machos & hembras & machos & hembras & \\
\hline P. sclateri & $\begin{array}{l}\text { intenso y } \\
\text { desarrollado }\end{array}$ & ausente & ausente & amplia & negro & $\begin{array}{l}\text { negro y } \\
\text { naranja }\end{array}$ & ALTO \\
\hline P. acutipennis & $\begin{array}{l}\text { menos intenso y } \\
\text { poco desarrollado }\end{array}$ & ausente & ausente & angosta & negro & $\begin{array}{l}\text { negro y } \\
\text { naranja }\end{array}$ & MODERADO \\
\hline P. dinelliana & ausente & ausente & angosta & angosta & negro & $\begin{array}{l}\text { negro y } \\
\text { naranja }\end{array}$ & BAJO \\
\hline P. flaviventris & $\begin{array}{l}\text { menos intenso y } \\
\text { desarrollado }\end{array}$ & ausente & ausente & angosta & negro & $\begin{array}{l}\text { negro y } \\
\text { naranja }\end{array}$ & MODERADO \\
\hline P. citreola & $\begin{array}{l}\text { menos intenso y } \\
\text { desarrollado }\end{array}$ & ausente & ausente & angosta & negro & $\begin{array}{l}\text { negro y } \\
\text { naranja }\end{array}$ & MODERADO \\
\hline
\end{tabular}

10- Grado de ornamentación. Éste se estableció por la presencia y extensión del copete, y por el contraste de colores entre el dorso y la corona, y entre el dorso y las alas (Tabla 3). Así, se establecieron tres grados decrecientesde ornamentación: 1) "alto", copete amplio, antifaz intenso y desarrollado, y tanto el color del copete como de las alas contrastan fuertemente con el dorso; 2) "moderado", copete de extensión moderada, antifaz poco intenso y poco desarrollado y ningún contraste de color entre el copete y el dorso; o corona que no forma un copete pero el color es contrastante con el dorso, y alas poco contrastante con el dorso; y 3) "bajo", copete ausente, antifaz ausente, y el color de la corona y de las alas moderadamente contrastante con el dorso (Figs. 5 y 6 ).

TABLA 3. Caracteres asociados al grado de ornamentación en Pseudocolopteryx

\begin{tabular}{|c|c|c|c|c|c|c|c|c|c|}
\hline & \multicolumn{2}{|c|}{ Copete } & \multicolumn{2}{|l|}{ Antifaz } & \multicolumn{2}{|c|}{ Corona vs. dorso } & \multicolumn{2}{|c|}{ Alas vs. dorso } & \multirow[t]{2}{*}{$\begin{array}{c}\text { Grado de } \\
\text { ornamentación }\end{array}$} \\
\hline & machos & hembras & machos & hembras & machos & hembras & machos & hembras & \\
\hline P. sclateri & amplio & amplio & $\begin{array}{l}\text { intenso y } \\
\text { desarrollado }\end{array}$ & ausente & $\begin{array}{l}\text { muy } \\
\text { contrastada }\end{array}$ & $\begin{array}{l}\text { muy } \\
\text { contrastada }\end{array}$ & $\begin{array}{l}\text { muy } \\
\text { contrastada }\end{array}$ & $\begin{array}{l}\text { muy } \\
\text { contrastada }\end{array}$ & ALTO \\
\hline P. acutipennis & moderado & moderado & $\begin{array}{l}\text { poco intenso y poco } \\
\text { desarrollado }\end{array}$ & ausente & sin contraste & sin contraste & $\begin{array}{l}\text { poco } \\
\text { contrastada }\end{array}$ & $\begin{array}{l}\text { poco } \\
\text { contrastada }\end{array}$ & MODERADO \\
\hline P. dinelliana & ausente & ausente & ausente & ausente & $\begin{array}{l}\text { muy poco } \\
\text { contrastada }\end{array}$ & $\begin{array}{l}\text { muy poco } \\
\text { contrastada }\end{array}$ & $\begin{array}{l}\text { poco } \\
\text { contrastada }\end{array}$ & $\begin{array}{l}\text { poco } \\
\text { contrastada }\end{array}$ & BAJO \\
\hline$P$. flaviventris & ausente & ausente & $\begin{array}{l}\text { poco intenso y poco } \\
\text { desarrollado }\end{array}$ & ausente & $\begin{array}{l}\text { poco } \\
\text { contrastada }\end{array}$ & $\begin{array}{l}\text { poco } \\
\text { contrastada }\end{array}$ & $\begin{array}{l}\text { poco } \\
\text { contrastada }\end{array}$ & $\begin{array}{l}\text { poco } \\
\text { contrastada }\end{array}$ & MODERADO \\
\hline P. citreola & ausente & ausente & $\begin{array}{l}\text { poco intenso y poco } \\
\text { desarrollado }\end{array}$ & ausente & $\begin{array}{l}\text { poco } \\
\text { contrastada }\end{array}$ & $\begin{array}{l}\text { poco } \\
\text { contrastada }\end{array}$ & $\begin{array}{l}\text { poco } \\
\text { contrastada }\end{array}$ & $\begin{array}{l}\text { poco } \\
\text { contrastada }\end{array}$ & MODERADO \\
\hline
\end{tabular}




\section{RECONSTRUCCIÓN DE ESTADOS ANCESTRALES}

Las reconstrucciones de estados ancestrales por máxima verosimilitud muestran con buen soporte a un ancestro de Pseudocolopteryx con copete $(p=0.67)$ negro $(p=0.55)$, dorso oliva $(p=$ 0.82), y alas negras ( $p=0.78$ ) (Fig. 8). Además se evidencia que el dimorfismo sexual aparece como estado ancestral: machos con antifaz $(p=0.72)$, sin cejas $(p=0.99)$ y con primarias modificadas $(p=0.67)$ (Fig. 9 y 10). Por otro lado, la pérdida del copete $(p=0.75)$ más la aparición de coronas castañas $(p=0.83)$, y dorsos $(p=0.82)$ y alas pardas $(p=0.97)$ se originan en el ancestro común más reciente (ACMR) entre $P$. dinelliana, $P$. flaviventris y $P$. citreola (clado terminal) (Fig. 8).

A

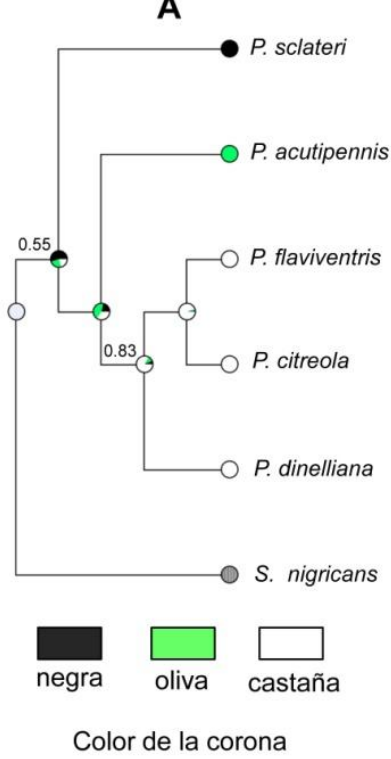

B

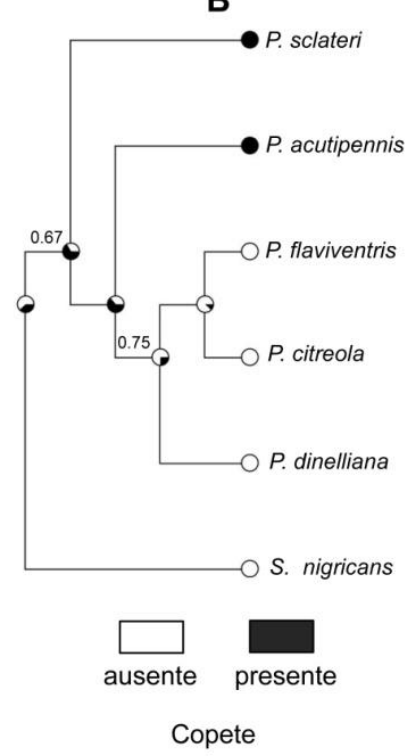

C

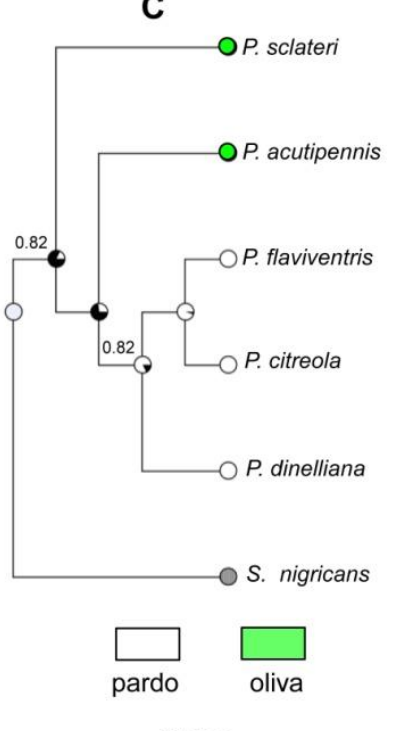

Dorso

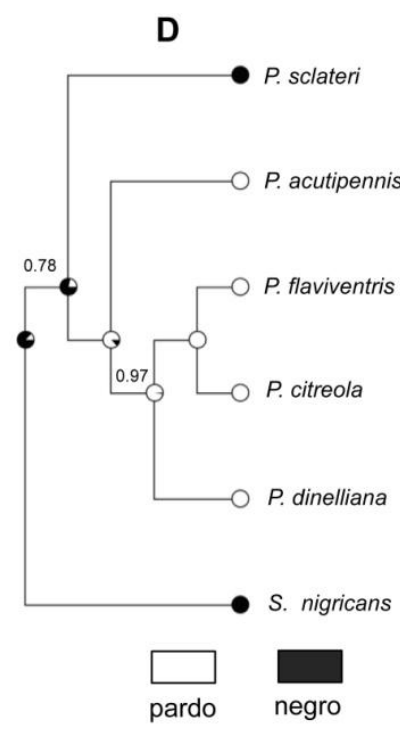

Color de la alas

FIGURA 8. Reconstrucciones de estados ancestrales por máxima verosimilitud de la evolución de caracteres no asociados al dimorfismo sexual en Pseudocolopteryx. Los valores de cada diagrama de torta son las probabilidades de cada estado de carácter para cada nodo ancestral. Las ramas no muestran proporcionalidad de distancia genética. Caracteres: A) Color de la corona, B) Copete, C) Color del Dorso, D) Color de las alas. 


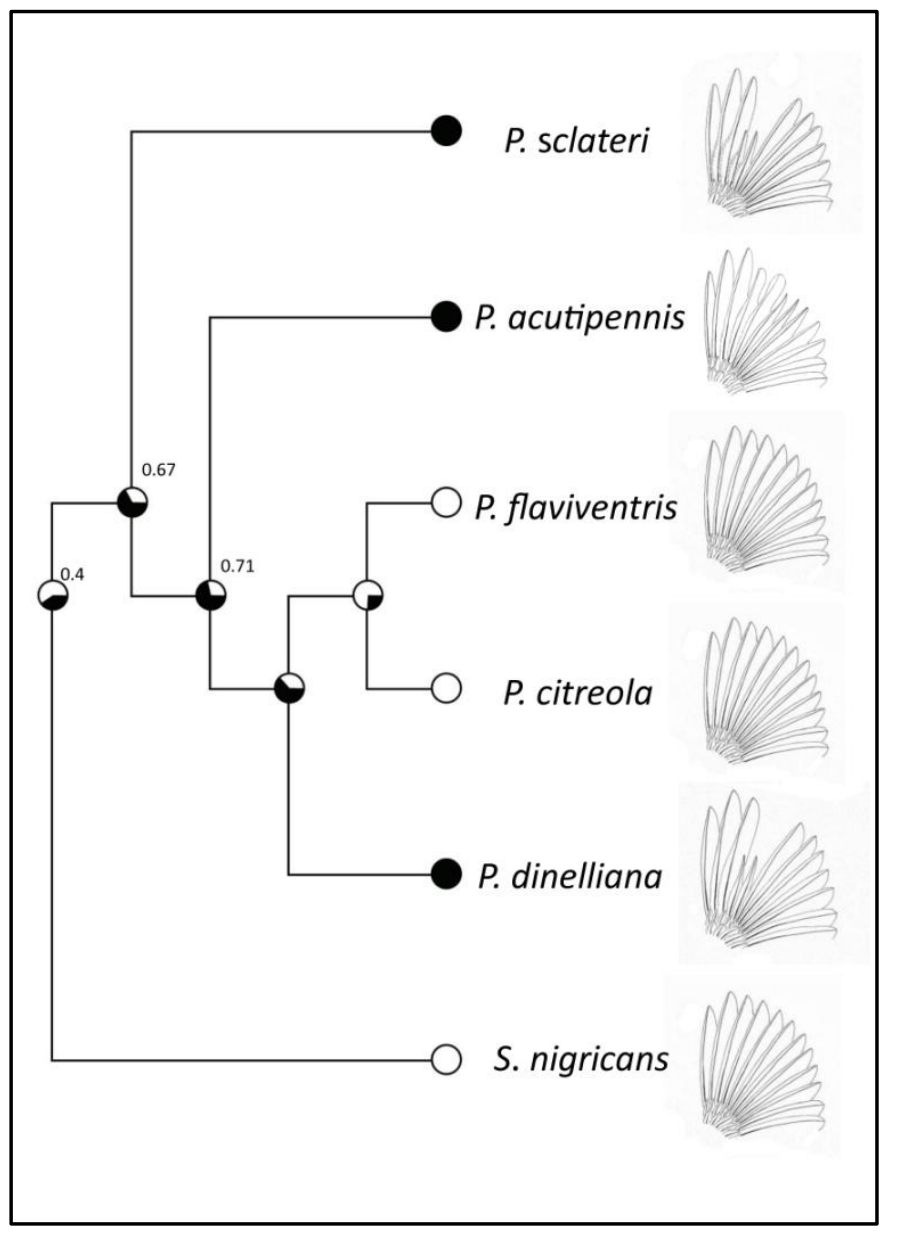

FIGURA 9. Reconstrucción de estados ancestrales por máxima verosimilitud de la evolución de las modificaciones en plumas primarias en machos de Pseudocolopteryx. Los valores asociados a cada diagrama de torta son las probabilidades de cada estado de carácter para cada nodo ancestral. Las ramas no muestran proporcionalidad de distancia genética

Las plumas primarias modificadas aparecen (sólo en machos) como carácter ancestral de todos los Pseudocolopteryx $(\mathrm{p}=0.67)$ y se pierde en el ACMR entre $P$. flaviventris y $P$. citreola $(p=0.26$; Fig. 9)

Entre los caracteres asociados al dicromatismo sexual, la ceja está presente en las hembras de todas las especies y aparece como una amplia ceja en el ancestro común de los Pseudocolopteryx, pasando a ser una ceja mucho más sutil y angosta en el ACMR de $P$. acutipennis y el clado terminal (Fig. 10A). En los machos, la ceja es un carácter que aparece como una novedad para P. dinelliana (Fig. 10A). El carácter antifaz aparece en el ancestro común de todos los doraditos como un carácter exclusivo de los machos ( $p=0.72)$, con mayor probabilidad como un antifaz de color intenso y desarrollado $(p=0.45)$, que se hace menos intenso y con poco desarrollo en el ACMR entre $P$. acutipennis y el clado terminal $(p=0.44)$, hasta estar completamente ausente en los machos de $P$. dinelliana (Fig. 10B). Al contrario que los otros caracteres asociados al dicromatismo sexual, el color del pico no exhibió cambios evolutivos y el mismo grado de dimorfismo fue hallado en todas las especies (Fig. 10C). Al analizar en conjunto los caracteres asociados al dicromatismo sexual, se estableció un grado de dicromatismo sexual (Tabla 2). La reconstrucción ancestral del grado de dicromatismo 
sexual apoya débilmente a un ancestro de Pseudocolopteryx con un alto dicromatismo sexual $(p=0.45)$, que pasa a ser moderado en el $A C M R$ entre $P$. acutipennis y el clado terminal ( $p=0.49)$, y bajo en $P$. dinelliana (Fig. 11).

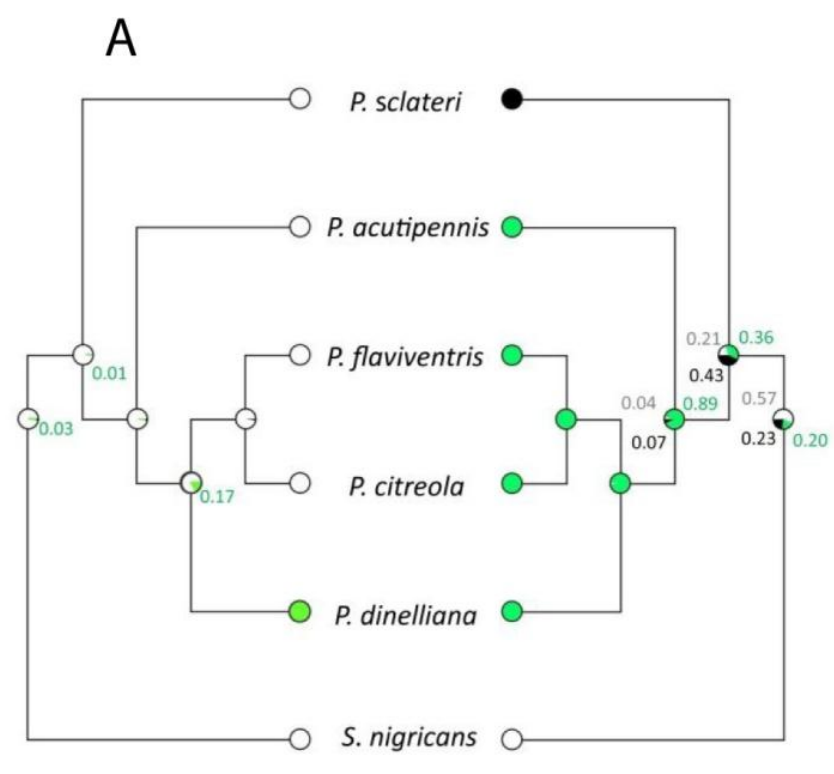

FIGURA 10. Reconstrucciones de estados ancestrales por máxima verosimilitud de la evolución de caracteres asociados al dicromatismo sexual en Pseudocolopteryx. Los valores de cada diagrama de torta son las probabilidades de cada estado de carácter para cada nodo ancestral. Las ramas no muestran proporcionalidad de distancia genética. A) Ceja (carácter 3). B) Antifaz (carácter 4).C) Color del pico (carácter 5).

Machos Hembras

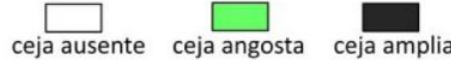

B

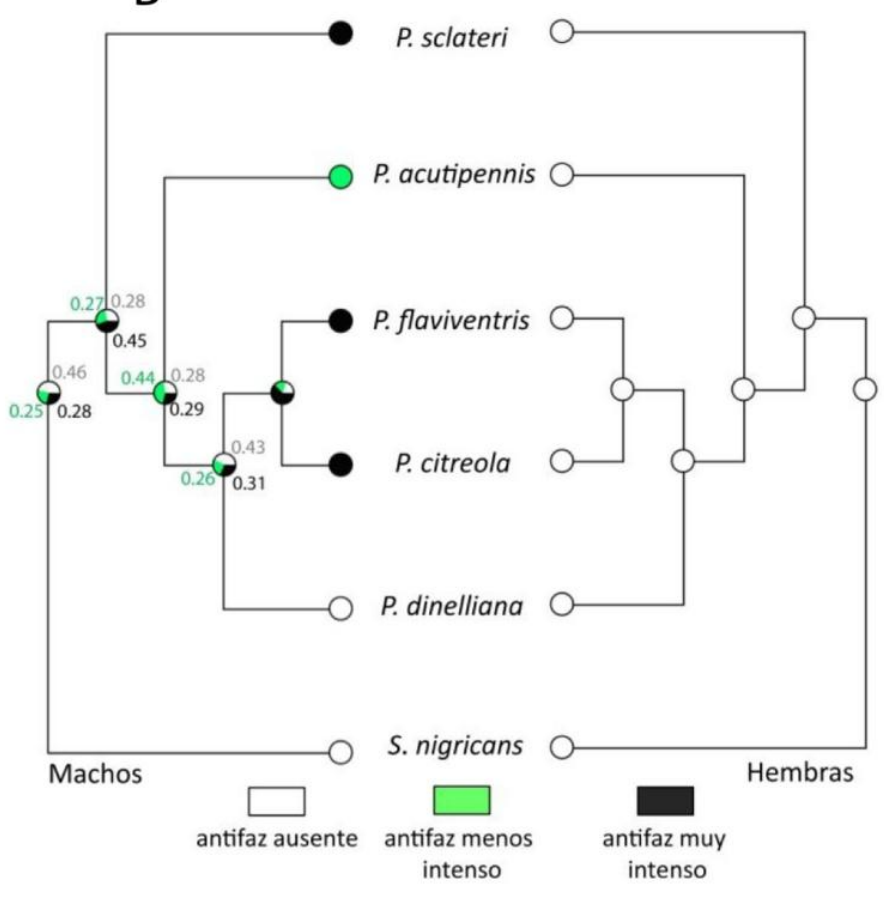

C

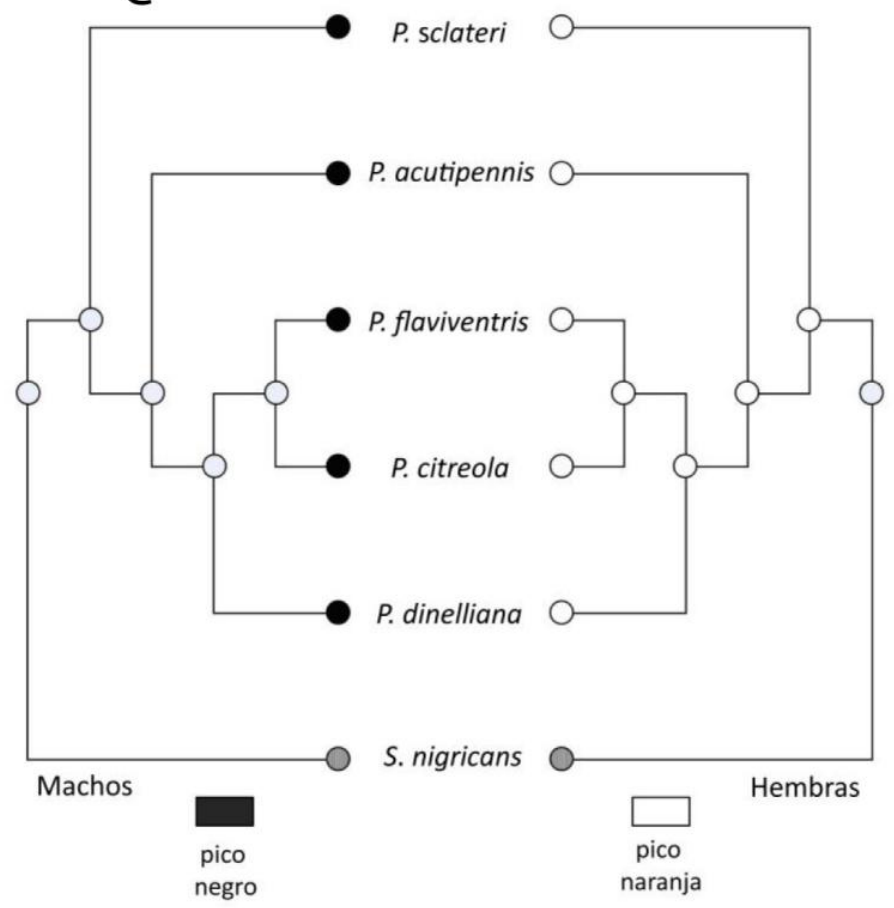




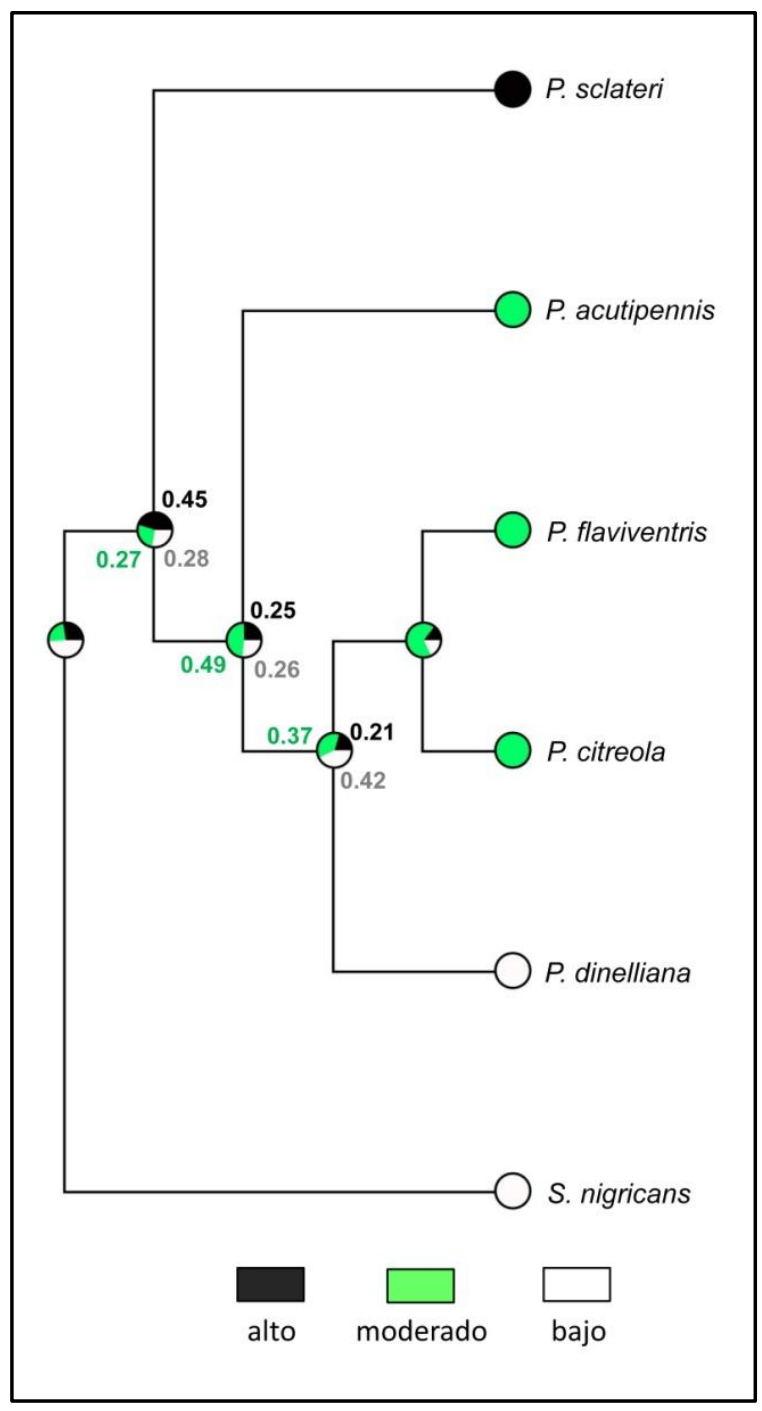

FIGURA 11. Reconstrucción de estados ancestrales por máxima verosimilitud de la evolución del grado de dicromatismo sexual en Pseudocolopteryx. Los valores asociados a cada diagrama de torta son las probabilidades de cada estado de carácter para cada nodo ancestral. Las ramas no muestran proporcionalidad de distancia genética.

A partir de los caracteres copete, color de la corona, antifaz, color de las alas y dorso se estableció un grado de ornamentación (Tabla 3). Así, P. sclateri muestra un alto grado de ornamentación, con un antifaz oscuro y extenso, un negro copete amplio que contrasta con el dorso oliva, y alas negras igualmente contrastadas con el dorso. La ornamentación de $P$. acutipennis es moderada ya que tiene un antifaz poco desarrollado, el copete menos amplio del mismo color oliva que el dorso, y las alas son pardas contrastando poco con el dorso. Las especies crípticas $P$. flaviventris y $P$. citreola también tienen un grado de ornamentación moderado ya que no tienen copete y su corona castaña contrasta sutilmente con el dorso pardo, al igual que las alas. Por último, $P$. dinelliana no tiene copete, la diferencia de color entre corona y dorso es más tenue, y las alas contrastan sutilmente con el dorso pardo. La reconstrucción de estados ancestrales del grado de ornamentación (Fig. 12) apoya débilmente a un ancestro de Pseudocolopteryx altamente ornamentado $(p=0.45)$, y un ACMR entre $P$. 
acutipennis y el clado terminal con una ornamentación moderada $(p=0.48)$, hasta llegar a un bajo grado de ornamentación en $P$. dinelliana.

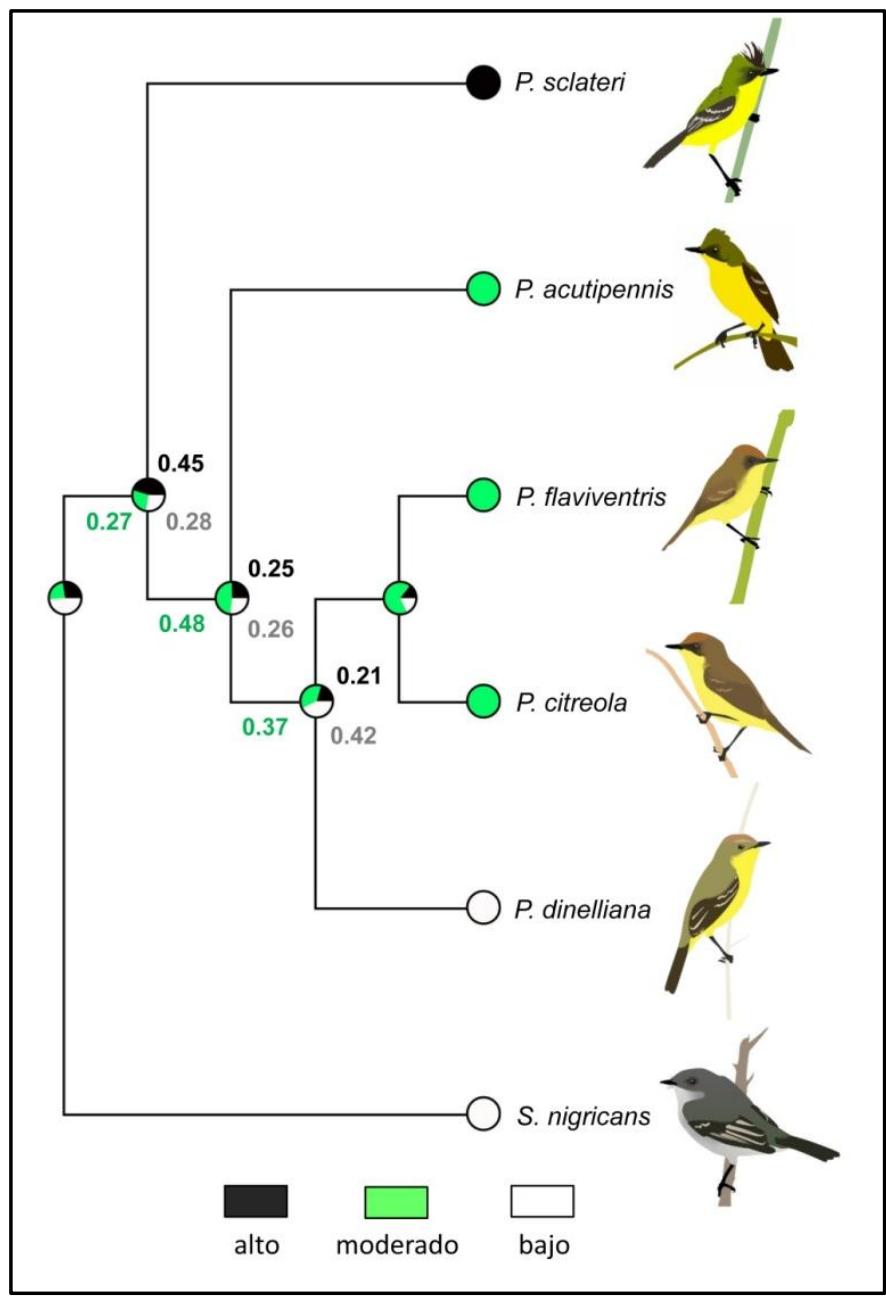

FigURA 12. Reconstrucción de estados ancestrales por máxima verosimilitud de la evolución del grado de ornamentación en Pseudocolopteryx. Los valores asociados a cada diagrama de torta son las probabilidades de cada estado de carácter para cada nodo ancestral. Las ramas no muestran proporcionalidad de distancia genética.

\section{Discusión}

Los resultados aquí presentados muestran que $P$. sclateri es la especie hermana de todas las demás, y $P$. acutipennis es hermana del clado terminal compuesto por $P$. dinelliana y $P$. flaviventris + P. citreola (Figs. 1 y 2). Las especies de Pseudocolopteryx mostraron diferentes grados de dicromatismo sexual y ornamentación, caracteres que parecen haber evolucionado en conjunto. Los análisis moleculares muestran una bajísima divergencia genética entre la especies crípticas $P$. citreola y $P$. flaviventris (Figs.1, 2 y 3) y que esta divergencia habría sido muy reciente (Fig. 4). 


\section{EVOLUCIÓN DEL PLUMAJE Y MORFOLOGÍA ALAR}

El dicromatismo sexual evolucionó numerosas veces de manera independiente entre los paseriformes, y las transiciones del dimorfismo al monomorfismo son más probables que las transiciones en el sentido opuesto (Price \& Birch 1996, Omland 1997, Kimball et al. 2001, Shultz \& Burns 2017). Este es el patrón observado en Pseudocolopteryx, donde el dicromatismo sexual es ancestral y el monocromatismo aparece como un carácter derivado solo en $P$. dinelliana. A partir de un ancestro sexualmente dicromático, dos rutas evolutivas pueden arribar a especies sin dicromatismo sexual: un fenotipo femenino puede converger en un fenotipo masculino, o un fenotipo masculino puede converger en un fenotipo femenino (Wiens 2001, Badyaev \& Hill 2003, Hosner \& Moyle 2012). En su revisión, Badyaev y Hill (2003) observan que la tendencia general entre las aves en el pasaje de dimorfismo a monomorfismo involucra cambios en las hembras adquiriendo un fenotipo masculino. Contrariamente, nuestros resultados indican que los machos de $P$. dinelliana presentan un fenotipo que es femenino en las demás especies de doraditos: ausencia de antifaz y presencia de ceja. En este caso, habrían sido los cambios en el fenotipo de los machos los que contribuyeron a la marcada reducción del dimorfismo sexual, tal como se ha observado recientemente en la familia Thraupidae (Shultz \& Burns 2017).

Los caracteres asociados a la ornamentación en Pseudocolopteryx podrían funcionar tanto como armamento ( $y$ funcionar como una señal intra-sexual, por ejemplo para defender un territorio) o como ornamento (y ser una señal inter-sexual para atraer a una pareja) (Berglund et al. 1996,). Más allá de la denominación elegida en este capítulo, la función específica de la ornamentación en Pseudocolopteryx permanece desconocida. Resulta interesante que el antifaz (solo presente en machos) es el único carácter asociado tanto a la ornamentación como al dimorfismo sexual, mientras que la presencia de copete y el contraste entre las alas y la corona con el dorso son caracteres sexualmente monomórficos (i.e. los estados de carácter no varían con el sexo) (ver tabla 3). Así, por ejemplo, tanto machos como hembras de $P$. sclateri presentan un alto grado de ornamentación. El modelo de "armamentoornamento" propone que los caracteres utilizados principalmente en contiendas entre machos (armamento) son cooptados por las hembras como indicadores de la calidad de los machos y pasan a tener una función de ornamento (Borgia \& Coleman 2000). En los casos de ornamentación sexualmente monomórfica (tal como ocurriría en algunos caracteres de Pseudocolopteryx), el modelo de "armamento-ornamento" podría hacerse extensivo mas allá de los machos, para explicar la evolución de las ornamentaciones también en hembras (Griggio et al. 2010). Así por ejemplo, lo que aquí llamamos ornamentación podría funcionar tanto en machos como en hembras de $P$. sclateri como una señal intra-sexual para defender recursos 
ecológicos probablemente efímeros, dado el posible carácter nómade de esta especie (ver capítulo 3), a la vez que funcionaría como señal inter-sexual para atraer posibles parejas. Esta función dual de la ornamentación (como armamento y ornamento a la vez, tanto en machos como en hembras) ha sido demostrada en dos especies de Hypocnemis (familia Thamnophilidae) y en Philesturnus carunculatus (familia Callaeidae) (Tobias et al. 2011, LloydJones \& Briskie 2015). Futuros trabajos son necesarios para poner a prueba estas hipótesis.

La disminución en el grado de ornamentación y en el dicromatismo sexual asociada a cambios en el plumaje masculino, podría ser indicativo de que la selección sexual opera en $P$. dinelliana sobre otros caracteres sexuales diferentes al plumaje. Por ejemplo, las vocalizaciones exhiben un grado de complejidad mucho mayor en $P$. dinelliana que en cualquier otra especie de doradito, a lo que se suman los despliegues visuales con sonidos mecánicos tenues (Capítulo 2). Por el contrario, P. sclateri es la especie más dimórfica y ornamentada y posee las vocalizaciones menos conspicuas dentro del género.

Las plumas modificadas aparecen como un carácter ancestral en Pseudocolopteryx, y están presentes en $P$. sclateri, $P$. acutipennis y $P$. dinelliana. Estas tres especies son capaces ejecutar despliegues en vuelo en los que producen sonidos que muy probablemente son de origen mecánico (Capítulo 2). Mientras tanto, las dos especies crípticas $P$. citreola y $P$. flaviventris perdieron las modificaciones en las plumas, a la vez que no realizan despliegues en vuelo ni sonidos mecánicos. Así, queda evidenciada la existencia de una relación directa entre modificaciones en las plumas primarias, despliegues aéreos y sonidos mecánicos en Pseudocolopteryx. Futuros trabajos son necesarios para elucidar detalladamente los mecanismos mediante los cuales se producen tales sonidos mecánicos.

\section{ESPECIES CRÍPTICAS}

Las especies crípticas hermanas o "sibling species" son especies prácticamente indistinguibles por anatomía externa (especies crípticas) y que son a su vez los parientes más cercanos entre sí (especies hermanas) (Bickford et al. 2007). Los resultados aquí presentados demuestran que $P$. flaviventris y $P$. citreola son "sibling species", ya que son indistinguibles por plumaje y son especies hermanas.

En las aves parece haber tres características que son comunes entre las especies crípticas hermanas (Johnson \& Cicero 2002). 1) pueden distinguirse por la voz, la que podría inferirse desempeñaría un rol crucial como parte de los sistemas específicos de reconocimiento en ausencia de señales de plumaje especie-específicas. 2) Las especies hermanas típicamente se encuentran en hábitats propios, y muestran una elección de sitios de nidificación en entornos ecológicos específicos. 3) Sus distribuciones de reproducción a 
menudo ocupan regiones ecogeográficas alopátricas. El par $P$. flaviventris y $P$. citreola cumple con estas tres características. 1) Ábalos y Areta (2009) mostraron las diferencias en sus vocalizaciones y realizaron experimentos de playback con los que demostraron que estas vocalizaciones son parte importante de sus sistemas específicos de reconocimiento. 2) Ambas especies ocupan hábitats propios (Ábalos \& Areta 2009). 3) Finalmente, entre los doraditos, estas dos especies son las que menos superponen sus espacios geográfico y de nicho ecológico, y cada una tiene una distribución de cría restringida a ecoregiones particulares: $P$. citreola nidifica fundamentalmente en el Matorral chileno y el Monte de Argentina, mientras que $P$. flaviventris cría en el pastizal Pampeano (Capítulo 3).

Las vocalizaciones de $P$. flaviventris y $P$. citreola y su capacidad de reconocimiento recíproco han divergido marcadamente en un período de tiempo muy breve (cercano a los 60000 años), mientras que el plumaje aparentemente ha mantenido una estasis total. La similitud en plumajes entre estas especies se debe por lo tanto a su ancestralidad común y no a un caso de convergencia ni retención de plesiomorfías previas. Las mosquetas del género Zimmerius muestran algunos casos de especies con plumajes muy similares e incluso especies que podrían ser catalogadas como crípticas (Fitzpatrick 2004). Rheindt et al. (2008) muestran que en este género la taxonomía basada en caracteres morfológicos resulta en casos de polifilia a nivel de especies, mientras que los caracteres vocales están en concordancia con una taxonomía basada en datos moleculares. El caso de $P$. citreola y $P$. flaviventris es incluso más extremo que el de Zimmerius, ya que la bajísima divergencia genética y la prácticamente nula diferencia en el plumaje evidencia que fuertes presiones selectivas operaron fundamentalmente sobre caracteres acústicos y de comportamiento, dando lugar a un proceso de especiación muy veloz (ver Capítulo 2).

Los casos donde especies con morfología externa idéntica o extremadamente similares difieren en caracteres acústicos son muy comunes entre los tiránidos (e. g. Serpophaga [Straneck 1993; 2007], Suiriri [Zimmer et al. 2001], Empidonax [Johnson \& Cicero 2002], Elaenia [Rheindt et al. 2009]). Es probable la existencia de un patrón conservativo en la evolución del plumaje en muchos géneros de tiránidos (Rheindt et al. 2008), que pone de manifiesto la importancia de las vocalizaciones en sus sistemas de reconocimiento específico. Esto, sumado al hecho de que los cantos de los tiránidos son esencialmente innatos (Kroodsma 1984, Kroodsma \& Konishi 1991), deja en evidencia que las vocalizaciones deberían ser parte importante en los estudios sistemáticos y de delimitación de especies en los Tyrannidae. 


\title{
-Capítulo 2-
}

\section{Evolución modular de voces, sonidos mecánicos}

\author{
y despliegues visuales en los Doraditos
}

\author{
(Pseudocolopteryx spp)
}

\section{Introducción}

Los despliegues son posturas, movimientos y vocalizaciones conspicuas y estereotipadas que son usadas durante interacciones sociales (Bradbury \& Vehrencamp 2011). Los despliegues están compuestos por caracteres especiales desarrollados para cumplir una función comunicativa, y por lo tanto estos caracteres especiales llevan el nombre de "señales". Estas señales cumplen diferentes funciones dependiendo de la respuesta que el emisor desencadena en el receptor (i.e. a quién va dirigida la señal) (Candolin 2003). Así, los despliegues pueden ser clasificados de acuerdo a la relación entre emisor y receptor, y a su aparente función: cortejo, agresión, suplica, saludos, y más.

Las señales emitidas durante los despliegues pueden estar compuestas de uno o varios componentes que son evaluados por el receptor al mismo tiempo. Si los componentes de estas señales operan en varias modalidades sensoriales a la vez (e.g. acústicas y visuales), se las llama "señales multimodales" (Partan \& Marler 2005). Las funciones y el significado adaptativo de las señales multimodales no están comprendidos del todo. A grandes rasgos se afirma que por un lado, cada componente de las señales multimodales podría ser informativo en una forma diferente (hipótesis de múltiples mensajes) o por el contrario, cada componente podría portar la misma información y el conjunto funcionaría como un soporte ante posibles errores intrínsecos de cada componente (hipótesis de la señales redundante) (Johnstone 1996; Candolin 2003; Hebets \& Papaj 2005).

Muchas especies de aves desarrollan elaborados despliegues multimodales en los que integran componentes acústicos y visuales (Cooper \& Goller 2004, Dalziell et al. 2013, Ota et al. 2015). Los componentes acústicos de los despliegues pueden provenir de dos fuentes diferentes: aquellos sonidos producidos con la siringe (de aquí en más voces) y los que son producidos por alguna estructura corporal diferente a la siringe (de aquí en más sonidos 
mecánicos) (Prum 1998). Los sonidos mecánicos pueden ser producidos por una gran variedad de estructuras como el pico, cola, alas, o plumas y a través de una gran variedad de mecanismos como percusión, estridulación o aleteo resonante (Botswick \& Prum 2003, 2005, Clark \& Feo 2008).

Entre los despliegues multimodales que utilizan alguna combinación de voces, sonidos mecánicos y señales visuales se pueden nombrar los "bailes" y maniobras acrobáticas de los bailarines (familia Pipridae; e.g. Prum 1990), movimiento de alas y balanceos corporales en tordos (familia Icteridae; e.g. Cooper \& Goller 2004), balanceos y zapateos en azulitos (familia Estrildidae; e.g. Ota et al 2015), despliegues aéreos en picaflores (familia Trochilidae; e.g. Clark et al 2013) o los muy complejos y elaborados cortejos de las aves del paraíso (familia Paradisaeidae; e.g. Scholes 2006, 2008a, 2008b). Dentro de la familia Tyrannidae se han reportado o descripto despliegues visuales en Xolmis, Agriornis, Neoxolmis, Muscisaxicola (Wetmore 1926, Smith 1971), Lessonia (Areta \& Miller 2014), Knipolegus e Hymenops (Straneck \& Carrizo 1983), Gubernetes, Pyrocephalus, Polystictus, y Pseudocolopteryx (Fitzpatrick 2004) entre otros.

Las cinco especies de doraditos presentan despliegues multimodales que son desarrollados exclusivamente por los machos y que parecen cumplir funciones de cortejo o defensa territorial (Fitzpatrick 2004). En este sentido, no se sabe cómo estos despliegues responden al paradigma del armamento-ornamento (Berglund et al. 1996), si cumpliendo una función de comunicación intra-sexual (armamento) o inter-sexual (ornamento). Los machos de tres especies ( $P$. sclateri, $P$. acutipennis y $P$. dinelliana) realizan despliegues que incluyen, además de las vocalizaciones, característicos movimientos de cabeza, vuelos y sonidos putativamente mecánicos; mientras que dos especies ( $P$. citreola y $P$. flaviventris) sólo presentan vocalizaciones y movimientos de cabeza (Hudson 1920, Wetmore 1926, Bostwick \& Zyskowski 2001, Ábalos \& Areta 2009).

Los conceptos de modularidad organizacional y modularidad variacional han sido ampliamente utilizados en el campo de la morfología y en menor medida en estudios de la evolución de despliegues en aves (Scholes 2008a, 2008b). En un contexto morfológico, los módulos son las unidades de la organización fenotípica que muchas veces se repiten o son recurrentes dentro de un mismo fenotipo (Schlosser \& Wagner 2004; West-Eberhard 2003). A la vez, los módulos son las unidades que presentan variación, esto es son los caracteres homólogos de la biología comparativa (Eble 2005). De esta manera, los módulos pueden ser a) organizacionales (cuando existen como tales en un mismo organismo) y poseen: 1) organización jerárquica, 2) recurrencia del mismo set de elementos en espacio y tiempo, 3) existencia discreta espacial o temporal de otras unidades similares y, 4) forma estereotipada 
(West Eberhard 2003); o b) variacionales (cuando son heredables y susceptibles de evolucionar y por lo tanto entendibles en comparaciones entre organismos) y en este caso exhiben 1) homología y 2) disociabilidad (Eble 2005, Scholes 2008b, West-Eberhard 2003). Los módulos pueden ser organizacionales y variacionales al mismo tiempo, pero esto no es obligatoriamente así (Eble 2005). La modularidad permite que cambios en algunos módulos de desarrollo no alteren sustancialmente otros, y que los módulos se reorganicen estructuralmente de maneras novedosas, multiplicando así las posibilidades de cambios evolutivos (Wagner \& Altenberg 1996).

Siendo que el comportamiento, al igual que otros caracteres fenotípicos, evoluciona a partir de estados y mecanismos inherentes pre-existentes en linajes emparentados (Tinbergen 1963, Searcy \& Nowicki 2005) es factible la aplicación fructífera de los conceptos de homología (Wenzel 1992) y modularidad (Scholes 2006, 2008a, 2008b) en estudios etológicos. Bajo esta concepción, las unidades naturales de la organización comportamental son las llamadas unidades modulares que, al igual que en el fenotipo morfológico, son los caracteres homólogos de la biología comparativa (Scholes 2008b). En este capítulo se analizan los despliegues de los machos de Pseudocolopteryx en un marco evolutivo, buscando y analizando los posibles caracteres homólogos que lo componen.

Los objetivos de este capítulo son: 1) describir detalladamente los despliegues multimodales de las cinco especies de Pseudocolopteryx, relacionando señales acústicas y visuales; y 2) poner a prueba la hipótesis de que los caracteres etológicos en los despliegues de Pseudocolopteryx están acoplados de manera plenamente modular. Bajo esta hipótesis se postulan dos predicciones:

a. Los despliegues dentro de cada especie poseerán modularidad organizacional: los módulos poseerán organización jerárquica, existencia discreta espacial o temporal y forma estereotipada (sensu West Eberhard 2003)

b. Los despliegues entre especies mostrarán modularidad variacional (i.e., los módulos son heredables y susceptibles de evolucionar; Scholes 2008a) y por lo tanto las especies presentarán módulos homólogos. 


\section{Materiales y métodos}

ÁREAS DE ESTUDIO

Para todas las especies se filmaron y grabaron sonidos de sus despliegues en diferentes localidades de Argentina: Establecimiento Los Picazos, Formosa $\left(-26.35^{\circ} \mathrm{S},-58.22^{\circ} \mathrm{O}\right)$ durante el mes de Agosto de 2016 (P. sclateri); Reserva Natural Punta Lara, Buenos Aires (RNPL; -58.01 $S,-34.80^{\circ}$ O) en Noviembre de 2014 ( $P$. flaviventris) y Diciembre de 2015 (P. flaviventris y $P$. sclateri); Centeno, Santa Fe $\left(-32.34^{\circ} \mathrm{S},-61.50^{\circ}\right.$ O) en Febrero de 2015 y enero de 2016 ( $P$. acutipennis); Miramar, Córdoba $\left(-39.92^{\circ} \mathrm{S},-62.68^{\circ}\right.$ O) en Septiembre y Octubre de 2014 y Octubre de 2015 ( $P$. dinelliana); y Lago Pellegrini, Rio Negro $\left(-38.70^{\circ} \mathrm{S},-68.05^{\circ} \mathrm{O}\right)$ en Octubre de 2015 (P. citreola).

\section{GRABACIÓN DE AUDIO Y VIDEO}

Se buscaron territorios de despliegues de machos adultos y se ubicaron allí los sitios de observación. Desde estos lugares, la grabación de video tuvo lugar desde la salida del sol hasta las cuatro horas posteriores y de nuevo desde las tres horas previas a la puesta del sol en adelante. Las grabaciones de video se realizaron con una videograbadora digital JVC GCPX100B Procision Full HD utilizando formatos de grabación no entrelazados, lo que permite hacer un análisis cuadro por cuadro de las filmaciones. Éstas se efectuaron a dos tasas de muestreo diferentes: baja velocidad (60 cuadros por segundo a una resolución de 1920×1080 pixeles) y alta velocidad (240 cps a 640×360 pixeles). Como las filmaciones de alta velocidad no graban sonido, y las filmaciones de baja velocidad graban sonido de calidad pobre, en cada filmación se obtuvieron grabaciones de sonido de alta fidelidad con una parábola Telinga equipada con micrófonos Telinga Stereo (Pro6) o Sennheiser ME-62y una grabadora Marantz PMD-661 grabando en formato PCM 24bit/48kHz. Al final de cada filmación se efectuó un clap frente a cámara: un golpe de un pequeño panel de madera pivotante (claqueta) para registrar visualmente un evento sonoro conocido que luego sirviera para alinear sonido y audio. La distancia entre el micrófono y el pájaro filmado nunca superó los 10 metros, por lo tanto el error en la sincronización de audio y video fue de 0,029 segundos como máximo. En total se obtuvieron 495 minutos de video crudo de 39 individuos y 699 cortes de audio de 156 individuos (ver Tabla 1 para los detalles por especie).

En cuanto a la identificación de individuos, la mayoría de los ejemplares filmados fueron previamente capturados para la extracción de sangre y se anillaron antes de su liberación (21 individuos anillados de 25 capturados). Además, el trabajo de campo se realizó en plena época reproductiva, cuando los doraditos tienen un comportamiento fuertemente 
territorial y las parejas defienden una zona de exclusividad. Así, los machos de Pseudocolopteryx utilizan recurrentemente una o dos perchas preferidas para cantar, lo cual permite identificar a los individuos no anillados con un buen grado de confianza.

Tabla 1. Filmaciones y grabaciones de audio de los despliegues de Pseudocolopteryx

\begin{tabular}{lcccc}
\hline \hline & minutos de filmación & individuos filmados & cortes audio & individuos grabados \\
\hline P. citreola & 154 & 5 & 101 & 10 \\
P. dinelliana & 147 & 16 & 225 & 69 \\
P. flaviventris & 46 & 9 & 166 & 35 \\
P. acutipennis & 116 & 6 & 142 & 35 \\
P. sclateri & 32 & 3 & 65 & 7 \\
\hline
\end{tabular}

\section{ANÁLISIS DE AUDIO Y VIDEO}

El análisis de los principales componentes etológicos de los despliegues visuales comenzó con un proceso de tres etapas. Primero, las filmaciones crudas se revisaron cuidadosamente para poder identificar los eventos de despliegue. Una vez identificados, cada ejemplo de los despliegues fue sincronizado manualmente con el archivo de audio y subdividido en cortes individuales para poder ser analizados independientemente. Finalmente, los cortes individuales que representan los eventos de despliegue se revisaron cuidadosamente a velocidades de reproducción normales y de fotograma a fotograma para identificar y describir los componentes del fenotipo conductual.

A partir de las grabaciones de audio se construyeron espectrogramas con Raven 1.5, utilizando los siguientes parámetros fijos en todos los ejemplos: Tipo de Ventana (Window type): Hann, Time Overlap: 50, DFT size: 1024 samples, Grid spacing: $46.9 \mathrm{~Hz}$. El parámetro Tamaño de Ventana (Window Size) fue determinado para cada espectrograma particular (y reportado con la abreviatura WS en cada leyenda), de tal forma que permitiera validar las comparaciones entre especies y dentro de una misma especie. Las medidas acústicas y sus características cualitativas más adecuados fueron evaluados oportunamente para identificar similitudes y diferencias, dependiendo de las señales obtenidas y de la cantidad de variación encontrada. Para las descripciones se definió a una nota como el elemento acústico mínimo que se visualiza en los espectrogramas de manera continua en una vocalización. Las frases son un conjunto de notas emitidas en una sucesión tal que forman un patrón identificable, y que están separadas de otras frases por un corto silencio. La intensidad es una medida relativa de la energía de las notas (en decibeles) dentro de una misma vocalización. Se visualiza en los 
espectrogramas como los diferentes tonos de gris: tonos más oscuros representan mayor intensidad (i.e. mayor valor relativo en decibeles) y tonos más claros, menor intensidad.

\section{ANÁLISIS DE MODULARIDAD ORGANIZACIONAL}

Para examinar la estructura relacional de los componentes conductuales que comprenden el fenotipo de despliegues de Pseudocolopteryx se construyó una ontología simple por especie y se visualizó con una serie de diagramas esquemáticos. Las ontologías son conceptualizaciones formales en las que las entidades se describen tanto por sus significados como por sus relaciones entre sí (Bard \& Rhee 2004). El propósito de estos esquemas es representar los componentes descritos en el estudio con sus interrelaciones en diferentes niveles de integración. Este formato cumple el importante papel de organizar una estructura de conocimiento compleja de manera que se pueda comprender, modificar y actualizar más eficientemente que las descripciones tradicionales de texto (Scholes 2008b).

Aquí consideramos dos jerarquías modulares en los despliegues de los doraditos. Los módulos de mayor jerarquía fueron llamados Módulos de Momento y los módulos incluidos dentro de éstos recibieron el nombre de Módulos de Acción. Los módulos pueden ser homólogos (cuando ocurren en distintas especies; e.g., florituras) u ortólogos (cuando representan duplicaciones modulares de igual jerarquía dentro de una misma especie, constituyendo partes de un mismo nivel horizontal coexistente en las ontologías, e.g., presentaciones estáticas y dinámicas).

Bostwick \& Zyskowski (2001) y Ábalos \& Areta (2009) dividen el canto de los doraditos en dos partes: "notas introductorias", una primera serie de notas que van cambiando (generalmente ascendiendo) en volumen y frecuencia, y el "canto" que es una segunda serie de notas más aceleradas formando un patrón complejo. En este trabajo entendemos que ambas partes son módulos de momento del canto (ver más adelante), y por lo tanto elegimos nuevas denominaciones para evitar la ambigüedad: llamamos "introducción" a lo que estos autores llaman "notas introductorias" y "floritura" a lo que llaman "canto".

\section{ANÁLISIS DE MODULARIDAD VARIACIONAL}

Dos aspectos de la modularidad variacional fueron estudiados: homología y disociabilidad (West-Eberhard 2003). Para identificar las homologías entre los caracteres visuales y entre los caracteres acústicos, aplicamos en primera instancia los criterios de "cualidad especial" y "posición" de Remane (Wenzel 1992). De acuerdo con estos criterios, dos caracteres visuales o acústicos fueron postulados como homólogos si compartieron: una forma distintiva (cualidad especial) y/o una posición relativa en una secuencia (posición). La forma en los caracteres 
visuales se refiere a movimientos característicos e identificables, y en los caracteres acústicos la forma representa la apariencia gráfica en los espectrogramas. Luego de que los homólogos fueran postulados bajo estos criterios, los mismos se reformularon utilizando el criterio de "congruencia con otros datos" (Wenzel 1992). En este caso, la congruencia en el acople temporal entre caracteres visuales y acústicos (i.e. si cada carácter visual se corresponde con la emisión de un elemento acústico) fue considerado fundamental en el arbitro de las homologías. Este procedimiento de dos pasos (postulación de homologías mediante los criterios de Remane, y reformulación bajo el criterio de congruencia) fue repetido en un proceso iterativo hasta establecer la relación más parsimoniosa entre caracteres visuales y acústicos dentro del fenotipo de despliegue en las cinco especies de doraditos.

La disociabilidad evolutiva es la capacidad de un módulo de cierta jerarquía de ser separado de otros módulos de igual jerarquía con los cuales se asociaba y aún así mantener la integridad como una unidad independiente (ver también Scholes 2008b). Aquí analizamos la disociabilidad a través del estudio comparativo de los componentes del fenotipo comportamental de los despliegues de los doraditos a lo largo de su evolución. Un módulo comportamental fue considerado como evolutivamente disociable cuando ocurrió de manera independiente como parte de distintos módulos de mayor jerarquía en diferentes especies (i.e. cuando un módulo de acción ocurrió de manera independiente en distintos módulos de momento de especies diferentes).

\section{Resultados}

\section{DESCRIPCIÓN GENERAL DE LOS DESPLIEGUES}

En líneas generales, los despliegues de los doraditos comienzan con una serie de notas que van ascendiendo en volumen y frecuencia (componente acústico de la señal), mientras el pájaro está posado en la percha y mueve la cabeza (componente visual). Sin solución de continuidad, el despliegue termina en una segunda serie de notas más aceleradas formando un patrón complejo que es acompañado por otros tipos de movimiento de cabeza. A diferencia de las otras cuatro especies, P. acutipennis reemplaza los movimientos de cabeza de esta parte final por un característico vuelo elástico.

Antes de comenzar el despliegue, los machos de doraditos permanecen ocultos en la parte baja de la vegetación dentro de su territorio. El despliegue comienza al posarse en la percha de despliegue. El tipo y ubicación en la percha desde donde desarrollan el despliegue es variable: tanto $P$. sclateri como $P$. acutipennis suelen elegir ramas o varillas que sobresalen de la vegetación circundante y desarrollan su despliegue de manera completamente expuesta 
en el extremo de la rama elegida. Además, utilizan siempre o casi siempre la misma percha para sus despliegues. Ocurre con $P$. dinelliana que despliega la mayoría de las veces en dos (algunas veces en tres) perchas diferentes, aunque en este caso lo hace semi-oculto entre las ramas horizontales $u$ oblicuas más altas de la vegetación, pero nunca en el extremo. Si bien $P$. flaviventris también está completamente expuesto en el extremo de la percha durante sus despliegues, es difícil predecir la percha que va a elegir para cada evento, ya que utiliza dos o más perchas de despliegue, aunque en un radio reducido de no más de 10 metros. Finalmente, $P$. citreola también utiliza varias perchas para los eventos de despliegue y lo hace semi oculto entre el follaje, ubicándose casi en el extremo, pero no en el extremo de las ramas.

Pseudocolopteryx sclateri canta posado en su percha desarrollando los movimientos de cabeza característicos. Muy raramente, y de manera poco predecible, realiza despliegues en vuelo sin movimientos de cabeza previos, que comienza en una percha y termina en otra diferente distante algunos metros (despliegues aéreos de dos perchas). Pseudocolopteryx acutipennis comienza a desarrollar su canto realizando movimientos de cabeza, y termina con un pequeño vuelo acrobático que empieza y finaliza en la misma percha acompañado de un sonido putativamente mecánico producido con las alas. Más raramente realiza despliegues aéreos de dos perchas. Pseudocolopteryx dinelliana canta mientras está posado, realizando llamativos movimientos de cabeza. Muchos, pero no todos los eventos de canto finalizan con un corto despliegue aéreo de dos perchas, en los que realiza una sola vocalización característica. Tanto $P$. flaviventris como $P$. citreola desarrollan característicos movimientos de cabeza mientras cantan perchados y ninguno de los dos tiene despliegues aéreos.

\section{MODULARIDAD ORGANIZACIONAL}

La estructura organizacional de los fenotipos del despliegue de machos de Pseudocolopteryx presentó dos niveles jerárquicos definidos (Fig. 1). En el nivel mas inclusivo se encuentran los Módulos de Momento (rectángulos sin relleno, con ángulos rectos y bordes coloreados en la figura 1): 1- presentación, 2- remate y 3- despliegue en vuelo de dos perchas. En un nivel inferior están los Módulos de Acción (rectángulos con relleno coloreado, con ángulos redondeados y bordes coloreados en figura 1): 1- cabeceos, 2- giros y arqueos, y 3-cierre. Cada color representa un módulo, y los módulos variacionales están dados por los diferentes tonos de un mismo color. 
A

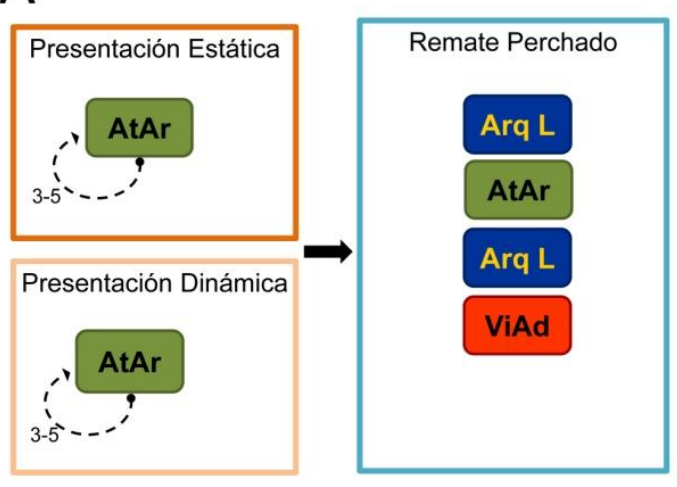

\section{B}

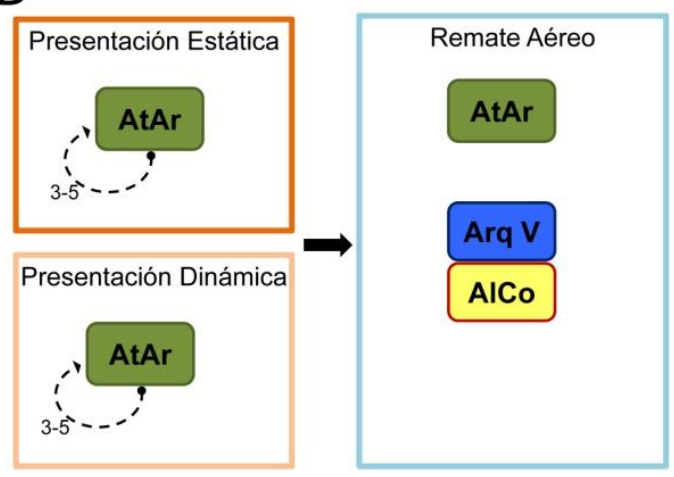

C

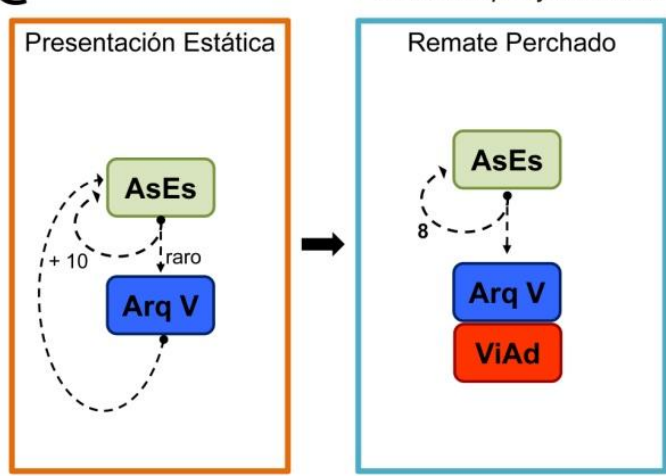

Pseudocolopteryx citreola

D

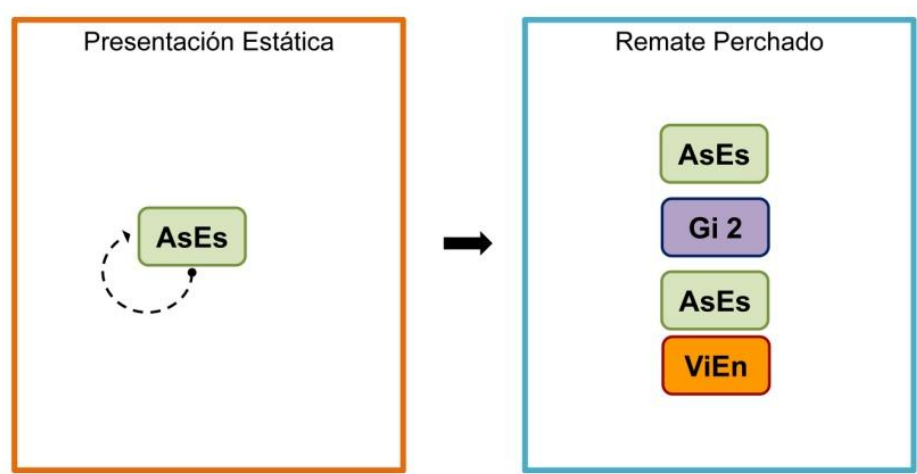

$\mathrm{E}$

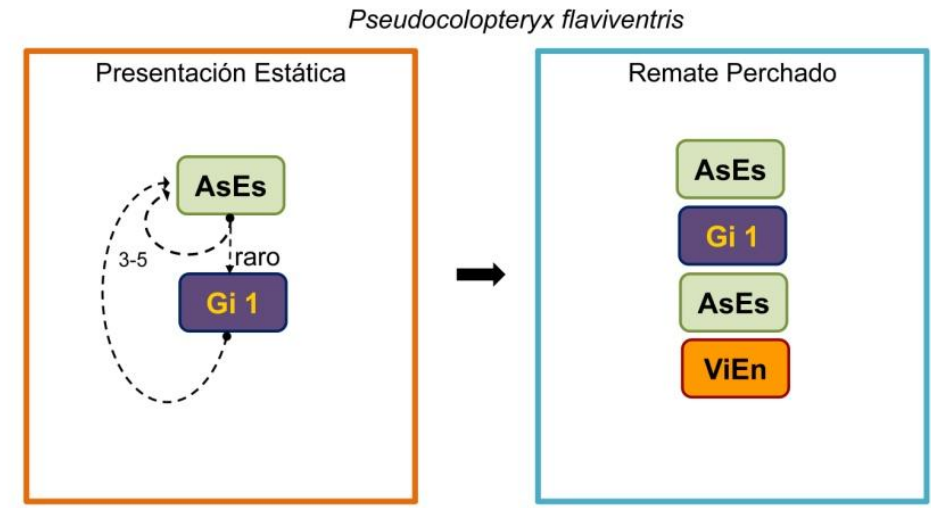

Módulos de Momento

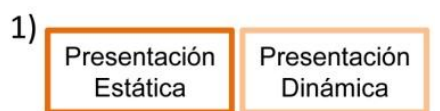

2)

\begin{tabular}{|c|c|}
\hline Remate & Remate \\
Perchado & Aéreo \\
\hline
\end{tabular}

3) Despliegue aéreo de dos perchas

Módulos de Acción
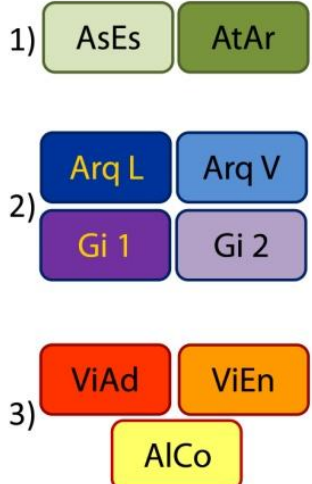

Despliegue aéreo de dos perchas
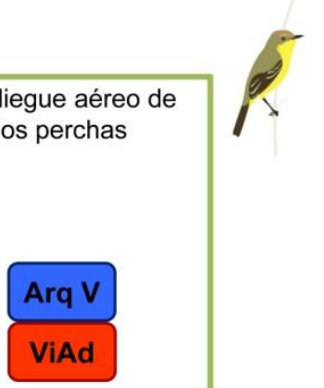

FIGURA 1. Estructura y composición de los fenotipos de despliegue de los machos de Pseudocolopteryx spp. Los recuadros mayores con borde coloreado representan los Módulos de Momento (MM), y dentro de ellos se ubican los Módulos de Acción (MA) representados por los rectángulos redondeados de colores. Las unidades modulares están representadas por un color único y sus versiones variacionales están en diferentes tonos de ese color (ver recuadro). Las flechas indican la secuencia de eventos entre MM. La falta de flechas indica que son eventos no secuenciales. Dentro de los MM, la secuencia de los MA deben ser leídas de arriba hacia abajo. Cuando dos elementos de los MA están en contacto, significa que los movimientos se dan de manera continua, uno detrás del otro. Los MA con bordes punteados, significan que dicho módulo es inferido a partir de su correspondencia con los componentes acústicos del despliegue. Ver texto para la descripción de las abreviaciones de los MA. 
1) Presentación: es la primer parte del despliegue (Fig. 1). El pájaro se posa en la percha y comienza a emitir las primeras notas de la introducción del canto, junto con el módulo de acción característico de su especie (ver más adelante). La presentación en cada especie está compuesta por uno a tres módulos de acción, aunque la cantidad de veces que se repiten (y la duración de la presentación) varían en cada evento de despliegue visual. Al principio de esta etapa los módulos de acción se suceden de manera espaciada. A medida que la introducción avanza, el tiempo entre ellos se acorta y los movimientos de cada módulo se hacen más exagerados. Las versiones variacionales de la introducción son:

Estática: el individuo desarrolla toda la introducción posado en el mismo lugar (Fig. 2).

Dinámica: el pájaro va acercándose al extremo del posadero a medida que la introducción avanza (Fig. 3).

2) Remate: es la parte final del despliegue y comienza inmediatamente después de la introducción. En esta etapa el pájaro emite la floritura del canto (ver más adelante). Está compuesto por muchos módulos de acción, haciéndolo más complejo que la introducción, a la vez que es más corto que ésta. El remate tiene las siguientes versiones variacionales.

Perchado: el pájaro permanece en la percha donde comenzó la presentación.

Aéreo: el remate se desarrolla durante un corto vuelo que empieza y termina en la misma percha.

3) Despliegue Aéreo de dos perchas: según la especie, puede ser ejecutado como la parte final del remate (o mas raramente luego de éste), o como un evento independiente de la presentación y remate. Consiste en un vuelo relativamente corto, con una trayectoria en forma de $\mathrm{V}$ invertida, donde el doradito produce sonidos vocales y putativamente mecánicos junto a un módulo de acción característico en el punto de inflexión de su trayectoria. 


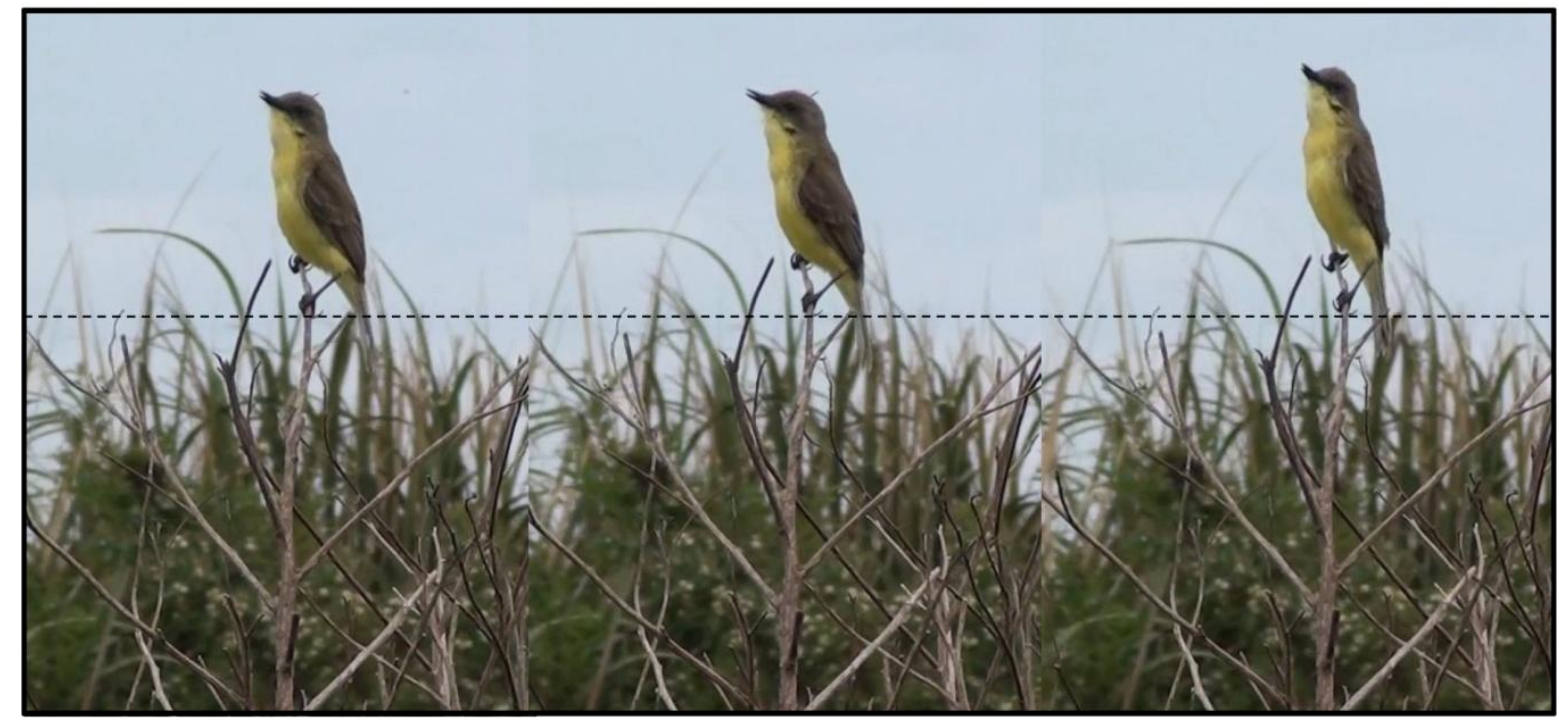

FiguRA 2. Introducción estática de P. flaviventris (video 00255). Reserva Natural Punta Lara, Buenos Aires, Argentina. 10 de noviembre de 2014. La línea punteada indica una misma altura de la percha en los distintos fotogramas.

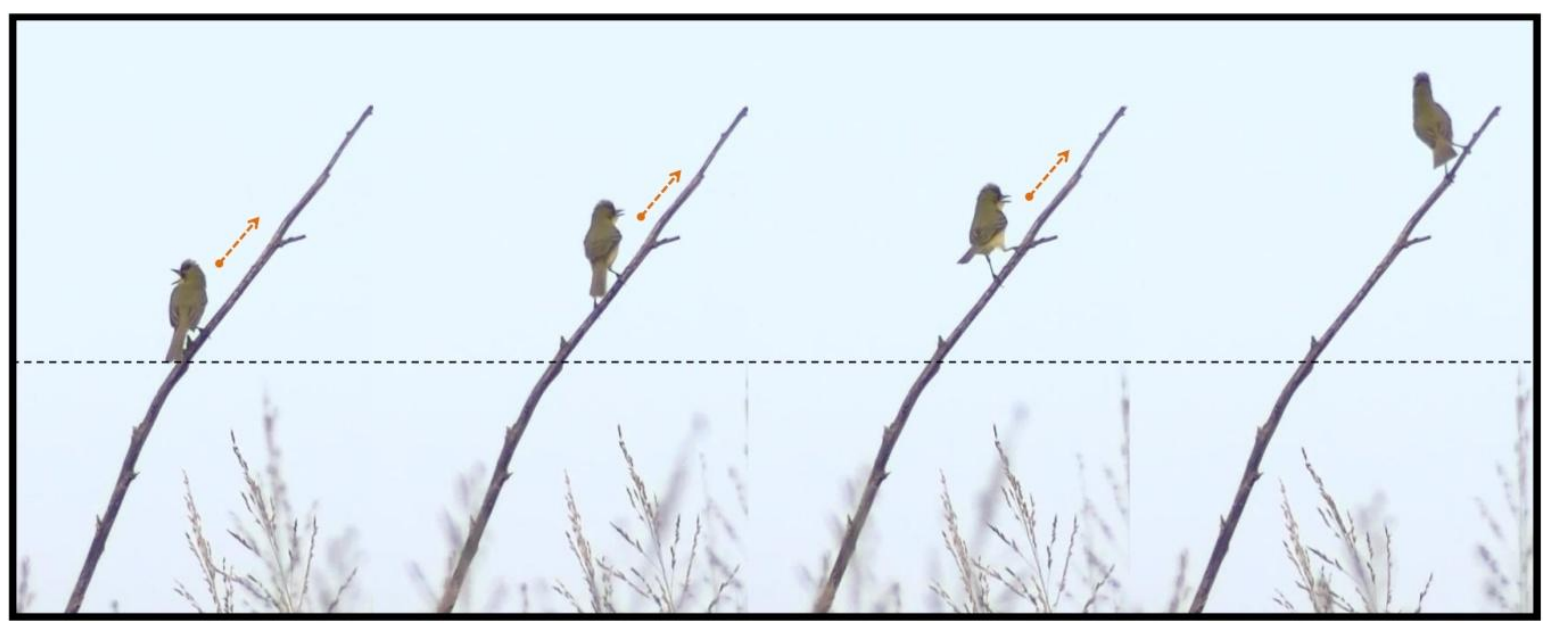

FigURA 3. Introducción dinámica de $P$. acutipennis (video 00010). Zona rural de Centeno, Santa Fe, Argentina. 28 de enero de 2016. La línea punteada indica una misma altura de la percha en los distintos fotogramas.

\section{MÓDULOS DE ACCIÓN}

\section{1) Cabeceos}

Ascenso-Estiramiento (AsEs): la cabeza gira hacia arriba, haciendo que el pico ascienda a la vez que el cuello se estira hacia arriba y levemente hacia delante, mientras la cola se eleva sutilmente (Fig. 4).

Atrás y Arriba (AtAr): la cabeza se dirige hacia atrás y luego hacia arriba rápidamente (Fig. 5). 

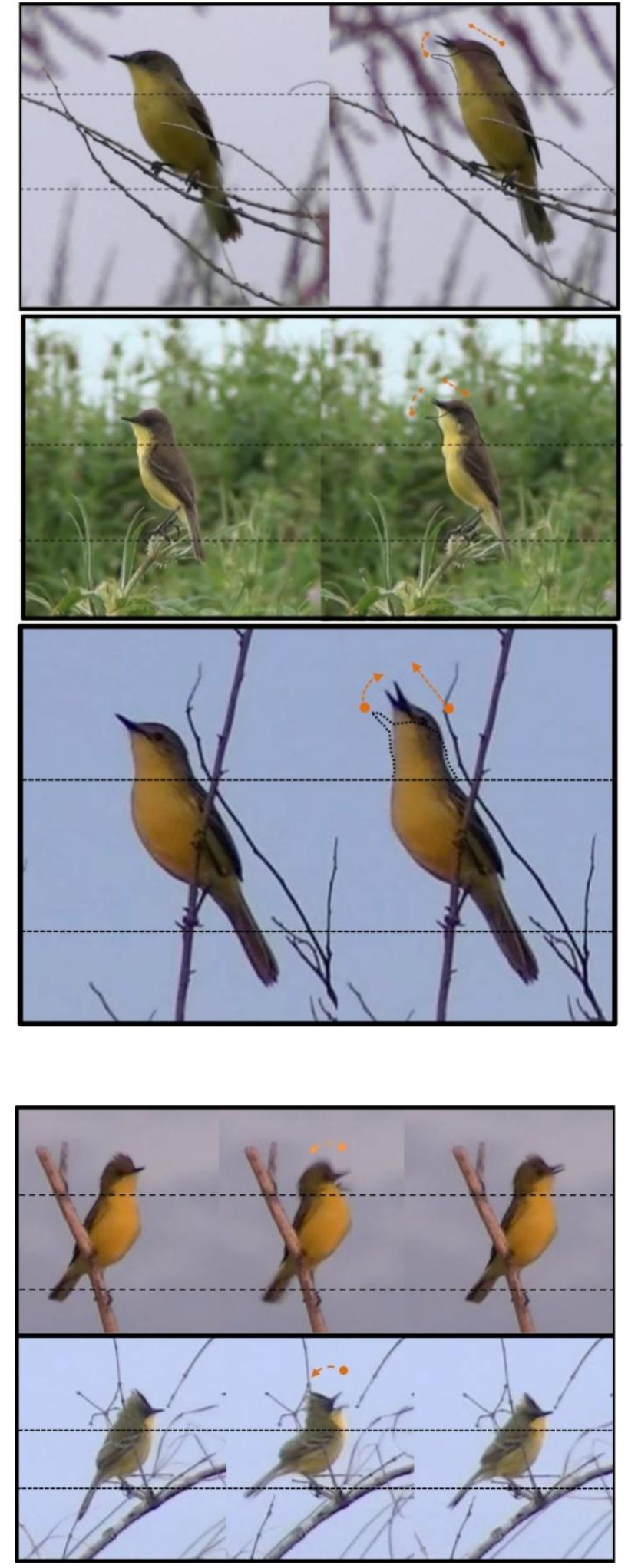

Figura 4. Cabeceo de Ascenso y Estiramiento (AsEs). A) P. citreola (video 00056). Reserva Privada El Escondido, Río Negro, Argentina. 29 de octubre de 2015. B) $P$. flaviventris (video 00263). Reserva Natural Punta Lara, Buenos Aires, Argentina. 10 de noviembre de 2014. C) P. dinelliana (video 00016). Miramar, Córdoba, Argentina. 5 de octubre de 2015. La línea punteada inferior indica una misma altura de la percha en los distintos fotogramas. La línea superior es paralela a la inferior para resaltar el movimiento. La silueta punteada representa la posición estacionaria de la cabeza antes del movimiento.

Figura 5. Cabeceo Atrás y Arriba (AtAr). A) $P$. acutipennis (video 00002). Zona rural de Centeno, Santa Fe, Argentina. 28 de enero de 2016. B) P. sclateri (video 00041). Estancia Los Picazo, Formosa, Argentina. 13 de julio de 2016.La línea punteada inferior indica una misma altura de la percha en los distintos fotogramas. La línea superior es paralela a la inferior para resaltar el movimiento. 
Giro horizontal 1 (Gi 1): la cabeza gira hacia la derecha sobre el eje vertical de manera abrupta. El cuerpo acompaña sutilmente al movimiento de la cabeza (Fig. 6).

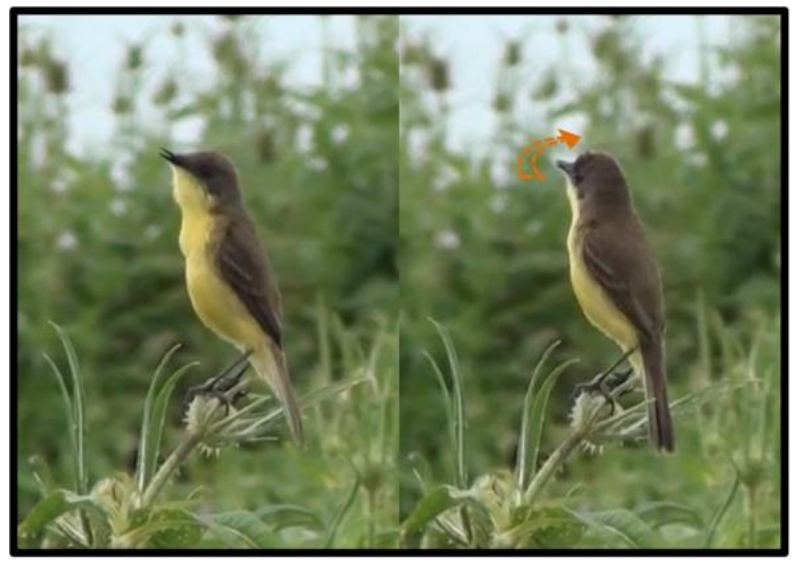

FIGURA 6. Giro horizontal 1 (Gi 1). P. flaviventris (video 00263). Reserva Natural Punta Lara, Buenos Aires, Argentina. 10 de noviembre de 2014.

Giro horizontal 2 (Gi 2): la cabeza gira rápida y sutilmente sobre el eje del cuello primero hacia un lado y luego hacia el otro (izquierda y derecha, o viceversa). El cuerpo no acompaña el movimiento de la cabeza.

Arqueo Lateral (Arq L): la cabeza gira hacia arriba y hacia atrás, mientras sobresale el pecho y la espalda se arquea y se eleva la cola. En el punto de máximo arqueo, la cabeza se inclina sobre el lado derecho (Fig. 7).

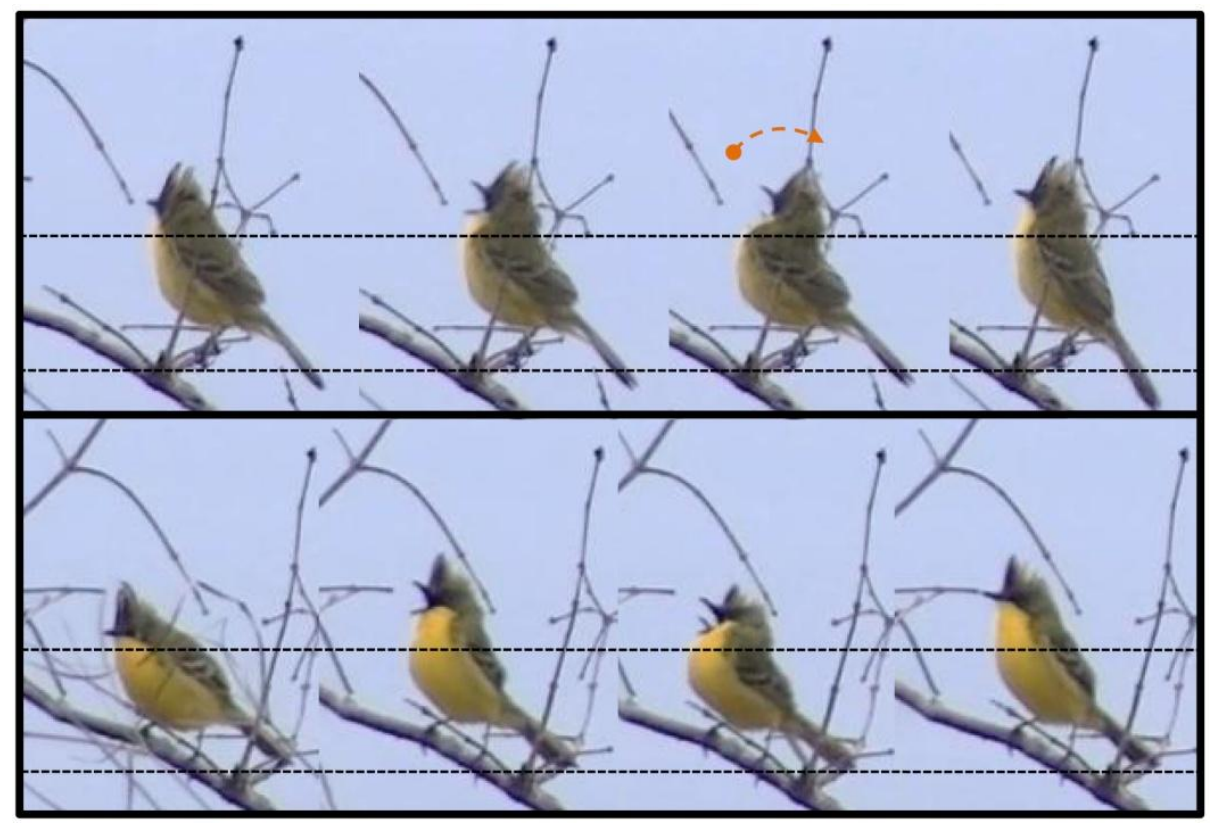

Figura 7. Arqueo Lateral (Arq L). P. sclateri (video 00041). Estancia Los Picazos, Formosa, Argentina. 13 de julio de 2016. 
Arqueo Vertical (Arq V): la cabeza gira hacia arriba y hacia atrás, mientras sobresale el pecho y la espalda se arquea. El arco formado es menos pronunciado que el anterior y el movimiento es completamente vertical (Figs. 8 y 9).

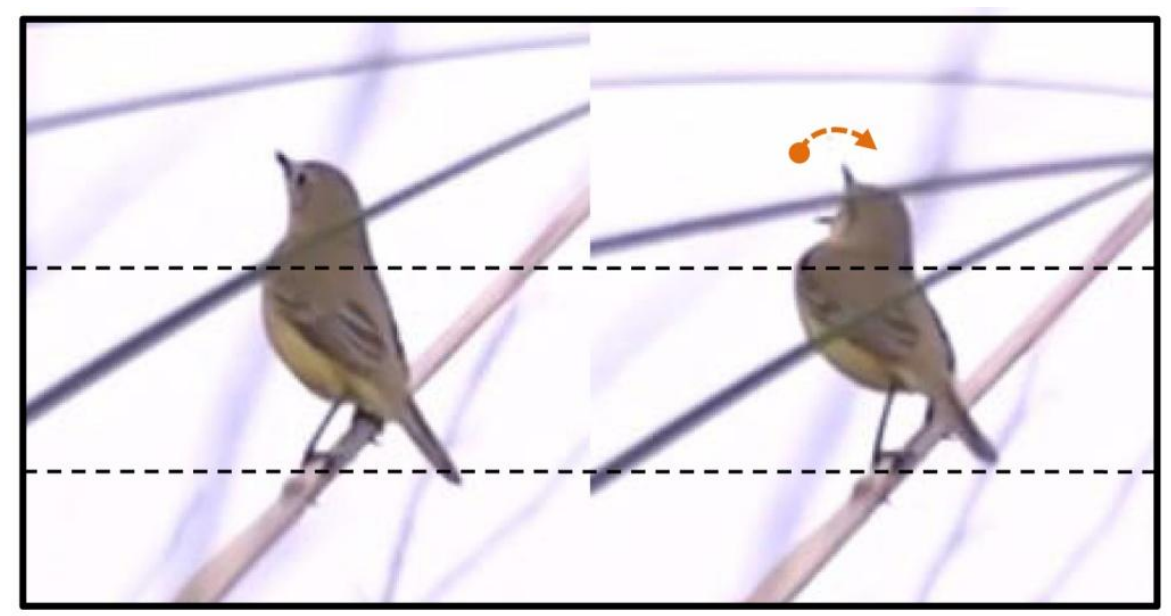

Figura 8. Arqueo Vertical (Arq V) en P. dinelliana (video PIC_247). Miramar, Córdoba, Argentina. 13 de octubre de 2015. La línea punteada inferior indica una misma altura de la percha en los distintos fotogramas. La línea superior es paralela a la inferior para resaltar el movimiento.

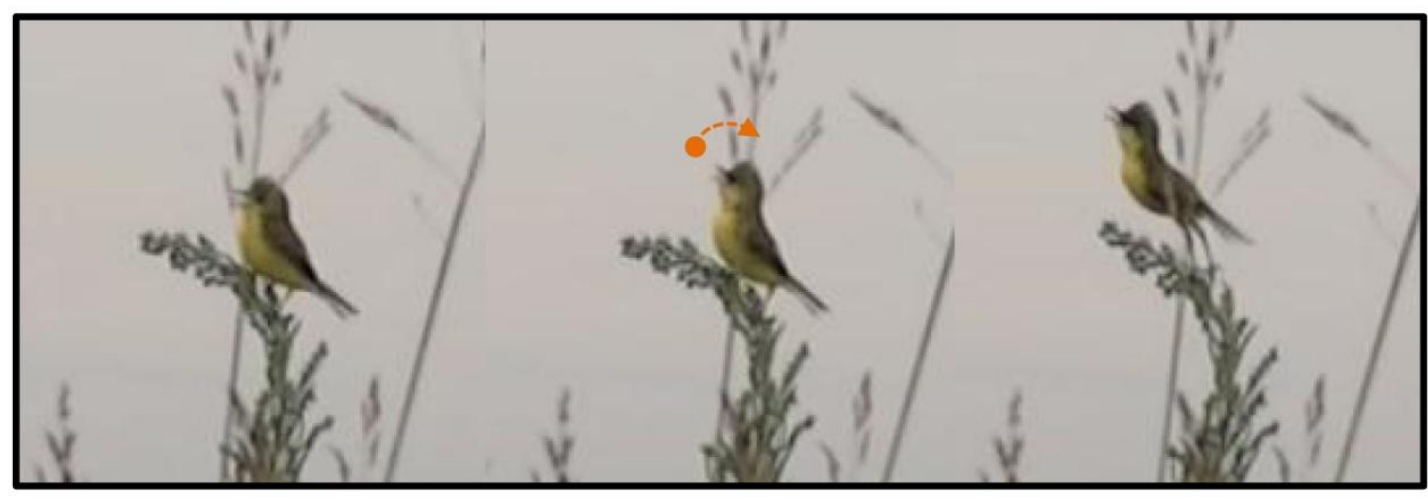

FIGURA 9. Arqueo Vertical (Arq V) en P. acutipennis durante el remate (video PIC_706). Se observa que durante este módulo de acción, el ave comienza a levantar vuelo. Centeno, Santa Fe, Argentina. 30 de enero de 2016. 
Viboreo Adelante (ViAd): el pájaro sacude la cabeza rápidamente hacia atrás y hacia delante un movimiento diagonal y luego desciende (Figs. 10 y 11).

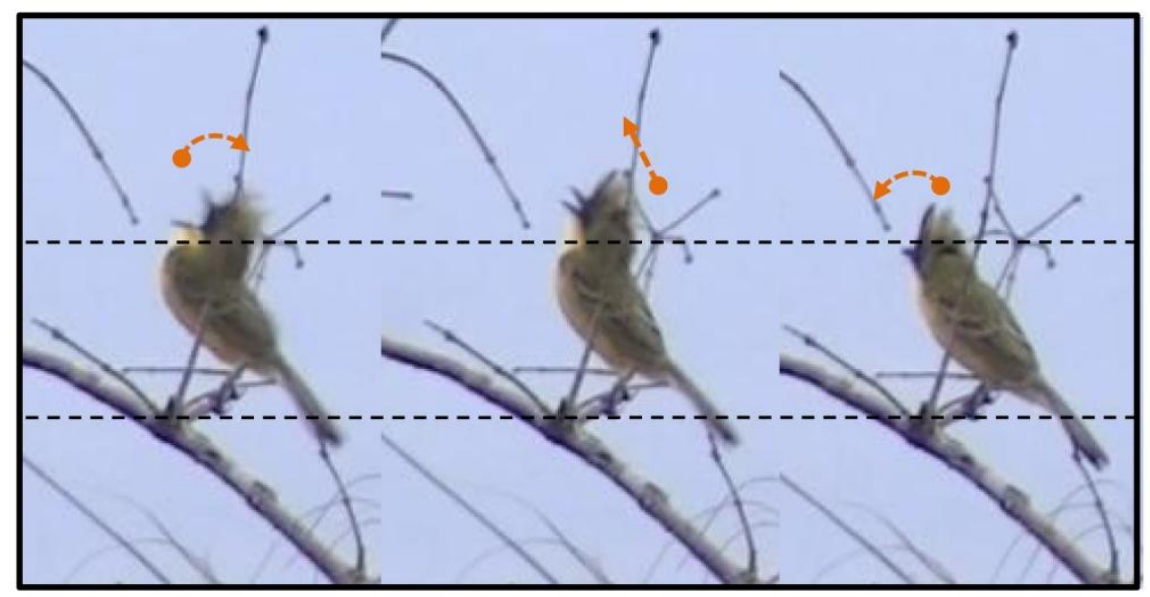

FIGURA 10. Viboreo Adelante (ViAd) en $P$. sclateri realizado durante el remate perchado (video 00041). Estancia Los Picazos, Formosa, Argentina. 13 de julio de 2016. La línea punteada inferior indica una misma altura de la percha en los distintos fotogramas. La línea superior es paralela a la inferior para resaltar el movimiento.

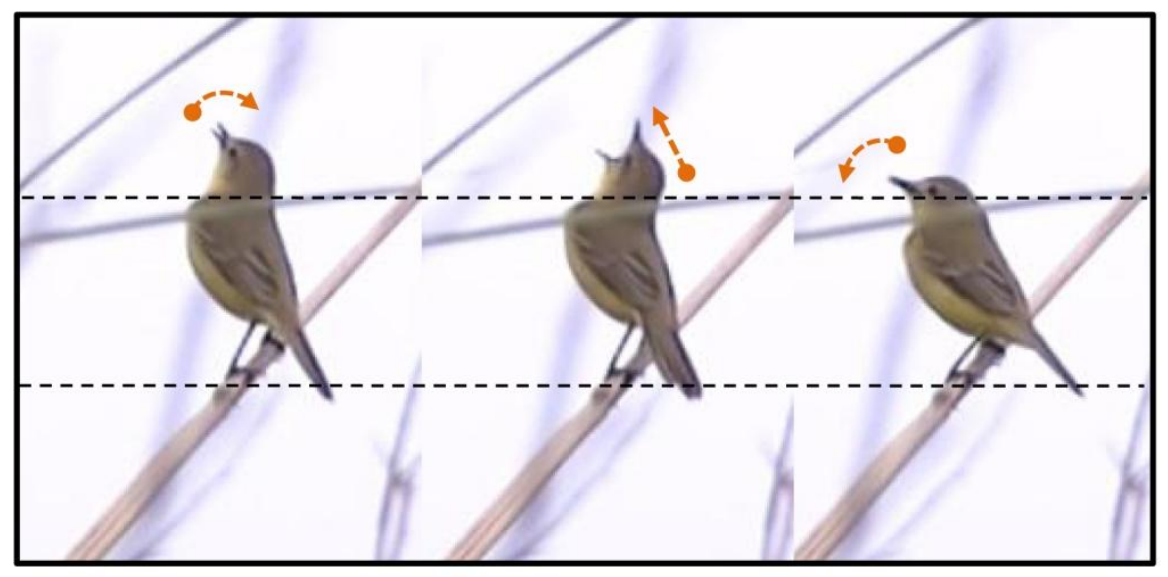

FIGURA 11. Viboreo Adelante (ViAd) en $P$. dinelliana realizado durante el remate perchado (video PIC_246). Miramar, Córdoba, Argentina. 13 de octubre de 2015.La línea punteada inferior indica una misma altura de la percha en los distintos fotogramas. La línea superior es paralela a la inferior para resaltar el movimiento.

Viboreo y encogimiento (ViEn): el pájaro sacude la cabeza rápidamente hacia atrás y hacia delante mientras la misma desciende, encogiendo el cuello hacia los "hombros" (Fig. 12). 


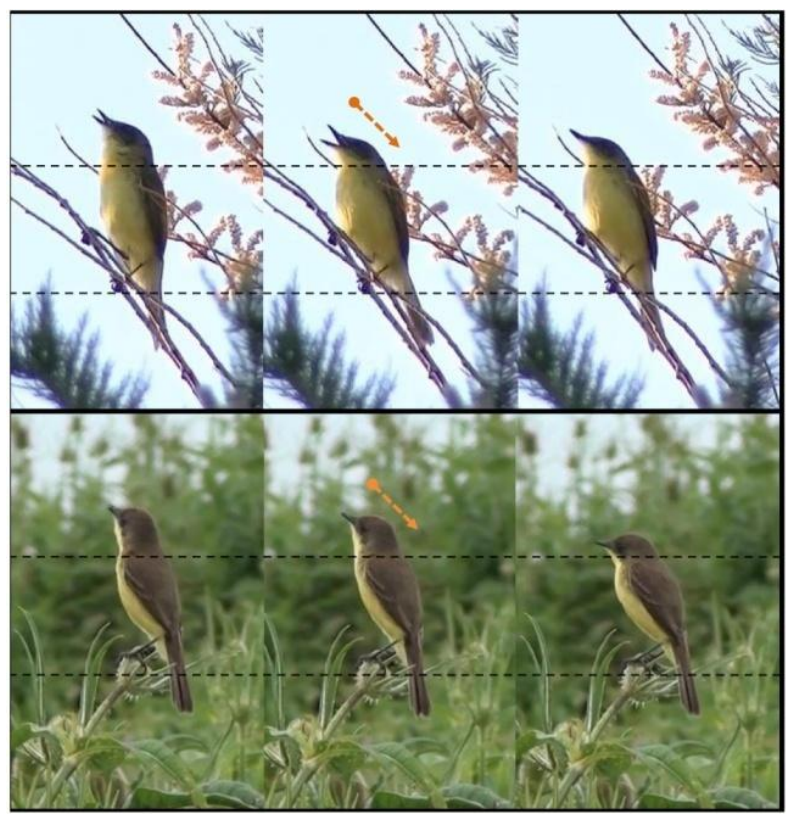

FIGURA 12. Viboreo y encogimiento (ViEn). A) P. citreola (video 00053). Lago Pellegrini, Río Negro, Argentina. 29 de Octubre de 2015. B) P. flaviventris (video 00263) Reserva Natural Punta Lara, Buenos Aires, Argentina. 10 de noviembre de 2014.La línea punteada inferior indica una misma altura de la percha en los distintos fotogramas. La línea superior es paralela a la inferior para resaltar el movimiento.

Aleteo Corto ( $\mathrm{AlCo}$ ): es una serie de tres aleteos extremadamente veloces, en el que las alas no llegan a extenderse del todo (Fig. 13).

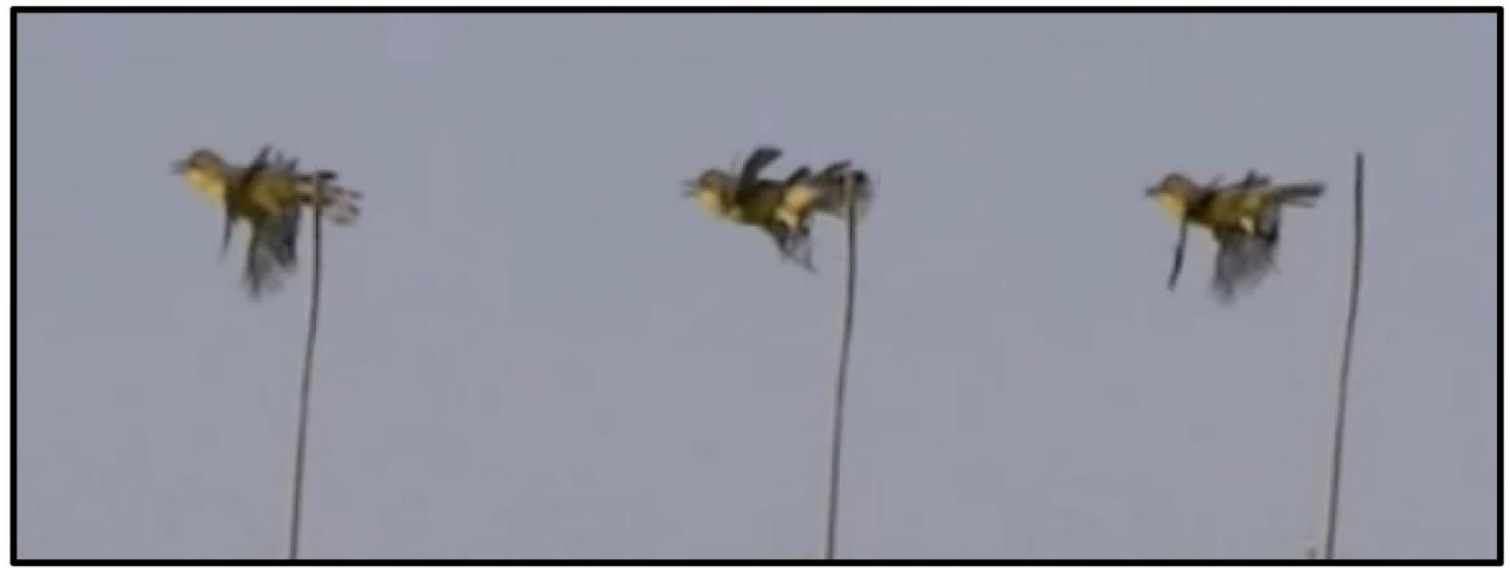

Figura 13. Aleteo Corto (AICo) en P. acutipennis realizado durante el remate en vuelo (video PIC_541). Se observan tres fotogramas correspondientes a cada uno de los tres aleteos cortos. Centeno, Santa Fe, Argentina. 26 de enero de 2016. 
El canto de los doraditos está compuesto por dos partes principales: introducción y floritura (Fig. 14). En general, durante la introducción el ave emite notas introductorias simples con una amplia distribución en frecuencia y corta duración, que se suceden de forma espaciada en un patrón repetitivo donde la variación acústica entre notas es escasa. A medida que el canto avanza, la distancia entre notas introductorias se acorta y la intensidad de éstas aumenta, acelerándose rápidamente hacia el final de esta etapa. La introducción es seguida inmediatamente por la floritura que está compuesta por diferentes tipos de notas sucesivas (de mayor intensidad que las notas introductorias) y que conforman un patrón temporal y estructuralmente más complejo (Fig. 14). Este patrón es evidente en casi todas las especies de doraditos pero se complejiza drásticamente en $P$. dinelliana. 

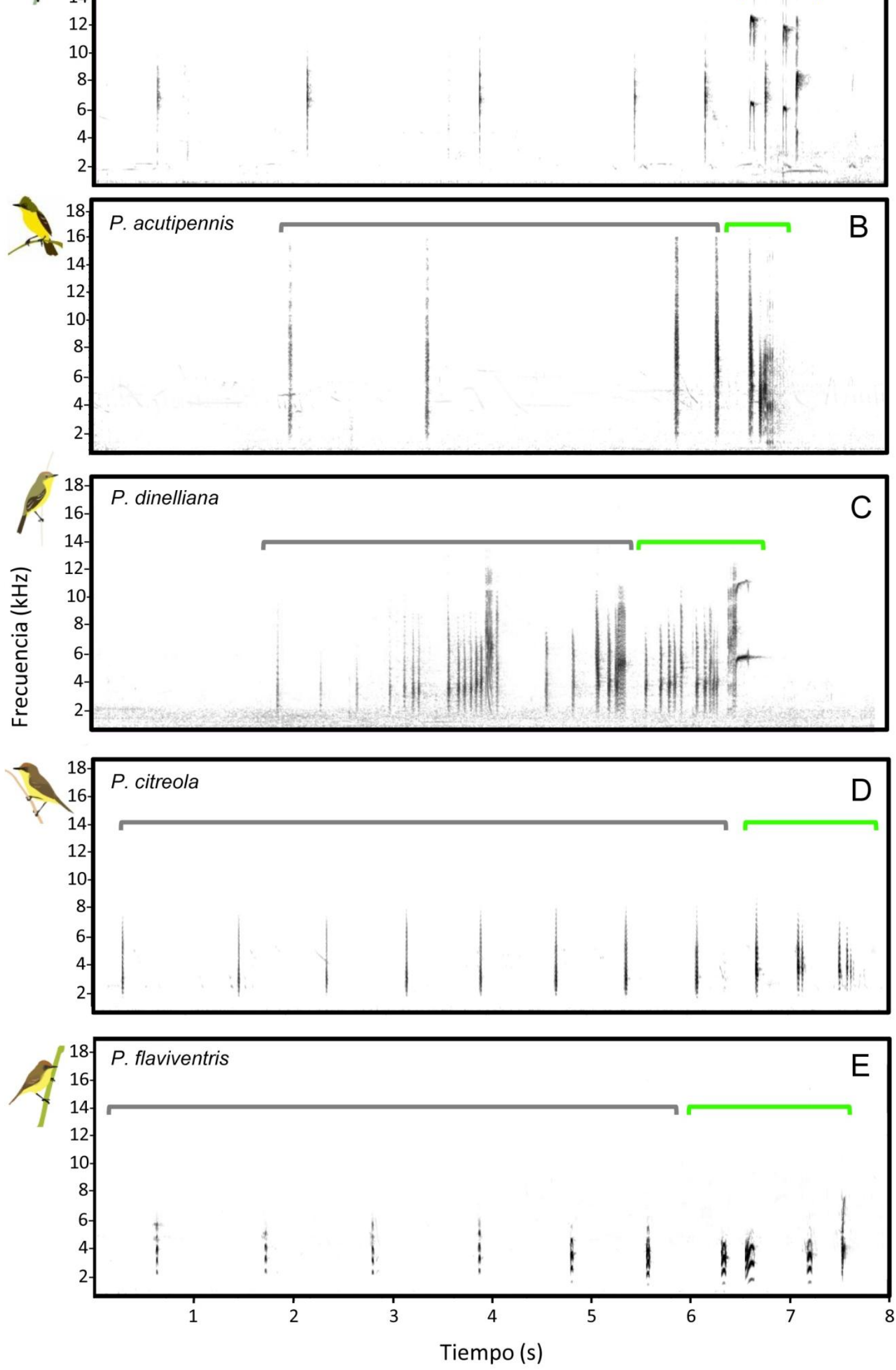

FIGURA 14. Espectrogramas del canto de machos adultos de doraditos Pseudocolopteryx spp. Entre paréntesis los números de catalogo de la Macaulay Library of Natural Sounds. Las llaves grises indican la introducción y las verdes la floritura. A) P. sclateri. Los Picazos, Formosa, Argentina. 13 de Julio 2016 (ML 224892). B) P. acutipennis. Centeno, Santa Fe, Argentina. 30 de Enero 2016 (ML 224890). C) P. dinelliana. Miramar, Córdoba, Argentina (número de catálogo pendiente). D) P. citreola. Lago Pellegrini, Río Negro, Argentina. 27 de Octubre 2015 (ML 224886). E) P. flaviventris. Reserva Natural Punta Lara, Buenos Aires, Argentina. 15 de Diciembre 
La introducción del canto de $P$. sclateri está compuesta por un tipo de nota suave (i.e. de baja intensidad) y seca (sin reverberación y que termina abruptamente) aparentemente producida mediante el golpe entre la mandíbula y la maxila: chasquidos del pico o "bill snaps" según Bostwick y Zyskowski (2001). Estas notas introductorias tienen una amplia distribución en frecuencia $(1,6-9,6 \mathrm{kHz})$ y una muy corta duración (0,016 s). La introducción está compuesta por entre tres y ocho "chasquidos". La floritura tiene cuatro notas, y comienza con una breve $(0,045 \mathrm{~s})$ nota aguda, monotonal en forma de "repisa plana" con una frecuencia fundamental aproximada en $7 \mathrm{kHz}$ y con el primer armónico (en $14 \mathrm{kHz}$ ) concentrando la máxima energía (frecuencia pico). Le sigue un chasquido igual al producido durante la introducción, y la tercer nota es idéntica a la primera. La cuarta y última nota es más corta que la anterior, también presenta armónicos y muestra una forma de "repisa inclinada", donde el segundo armónico (con máxima energía) tiene una distribución de frecuencia en ascenso que comienza en $7 \mathrm{kHz}$ y termina $0,02 \mathrm{~s}$ después en $8 \mathrm{kHz}$ (Fig. 15).

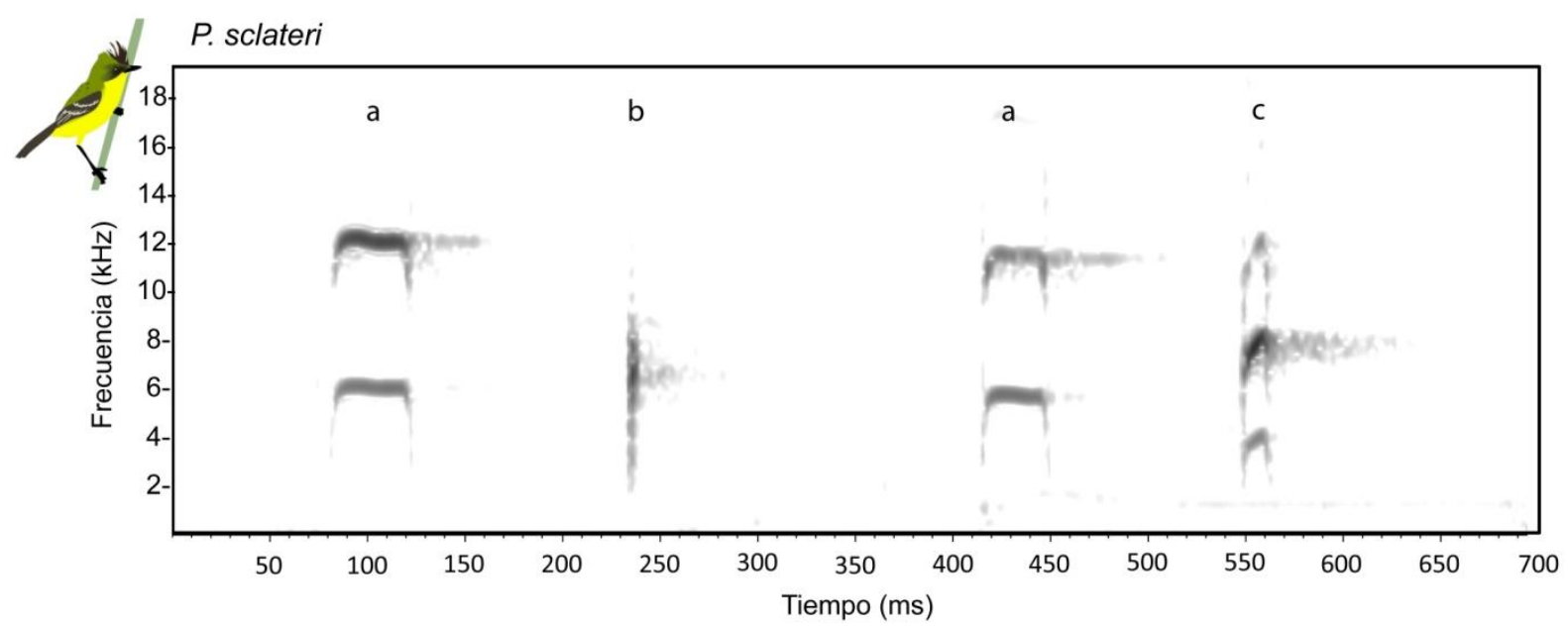

FIGURA 15. Detalle de la floritura de $P$. sclateri donde se observan los tres tipos de notas: a) repisa, b) chasquido, c) repisa inclinada. Los Picazos, Formosa, Argentina. 13 de Julio 2016 (ML 224892). WS: 218.

El canto de $P$. acutipennis comienza con notas introductorias fuertes (i.e. de alta intensidad) y ásperas, de aproximadamente 0,04 s de duración que va desde los 0,95 a los 16 $\mathrm{kHz}$ que fonéticamente puede representarse como "chik". En los espectrogramas se visualiza una primera mitad de cada "chik" en forma de estrías macizas y finalizan como cortas parábolas apiladas (Fig. 16). La introducción está compuesta por entre 3 y 5 notas "chik", a la que le sigue una floritura de 5 notas cortas, una detrás de la otra casi sin espacio de silencio entre ellas. La primera es una nota áspera, más nasal y más grave que las notas introductorias, compuesta por una sucesión elementos de cortísimo desarrollo temporal y un desarrollo en 
frecuencia proporcionalmente amplio. Visualmente parecen un cúmulo de "varillas", y esa es la denominación que le hemos asignado. Le sigue una nota que en forma de ves cortas (V) invertidas apiladas formando un "chevrón", y la floritura termina con tres "notas mecánicas" iguales muy cortas $(0,01 \mathrm{~s})$ con frecuencia pico en $3,5 \mathrm{kHz}$. Fonéticamente todo el canto puede expresarse como "chik, chik, chik, tchi-crruú". Cada aleteo corto (AICo) se corresponde temporalmente con cada una de las notas mecánicas, lo cual apoya fuertemente el origen mecánico de estos sonidos. Sin embargo, para demostrar el origen mecánico de estas notas de manera concluyente, las hipótesis de producción de sonidos mecánicos deben ponerse a prueba mediante el análisis de filmaciones de alta velocidad (a 1000 cps o mas) sincronizadas con grabaciones de audio, y examinando en detalle la estructura de las plumas primarias (Jordan \& Areta in prep.), métodos por excelencia en estos estudios (Bostwick \& Prum 2006, Clark et al 2011). Aunque sigue pendiente la definitiva demostración del origen mecánico de estas notas, y la descripción detallada de los mecanismos que las producen, parece pertinente a los objetivos de este capítulo considerarlas como putativamente mecánicas.

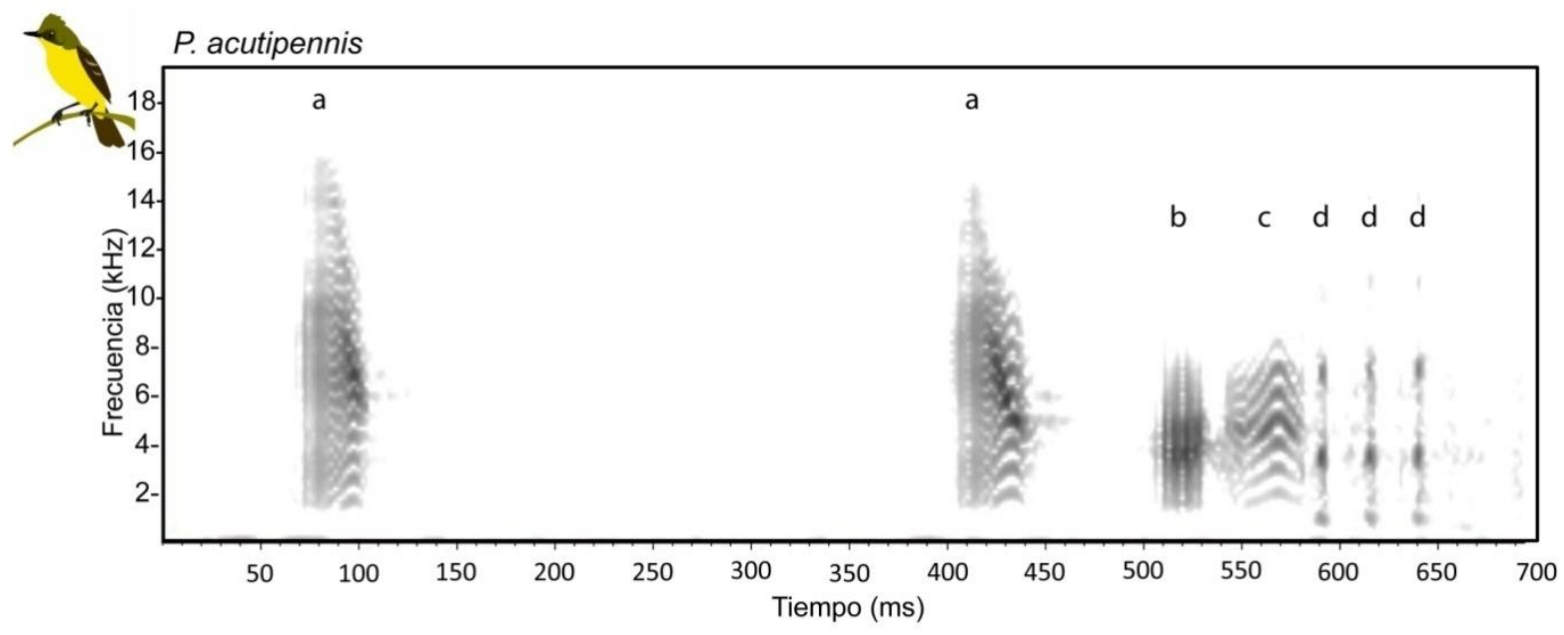

Figura 16. Detalle de las ultimas notas de la introducción seguidas por la floritura de $P$. acutipennis. Se observan los cuatro tipos de notas: a) chik, b) varillas, c) chevrón, d) notas mecánicas. Centeno, Santa Fe, Argentina. 30 de Enero 2016 (ML 224890). WS: 218.

El canto de $P$. citreola es probablemente el más sutil de todos. Se compone de "un número variable de notas introductorias nasales muy suaves y una serie sincopada de notas igualmente nasales, que incrementan su volumen y aceleran hacia el final en un patrón complejo" (Ábalos \& Areta 2009-pp. 220). La última serie mencionada corresponde a lo que aquí llamamos floritura (Fig. 17). Fonéticamente todo el canto puede expresarse como "cué, cué, cué, cué, cré cué-requé". La estructura general de las notas es llamativamente homogénea, con un desarrollo temporal corto $(0,036 \mathrm{~s}$ aproximadamente) y una distribución 
en frecuencia que abarca desde 2 a $7 \mathrm{kHz}$. Las notas difieren sutilmente en su frecuencia pico, el desarrollo de frecuencia y en el volumen de cada nota. La diferencia más notoria radica en el ritmo en que son emitidas: la primera nota de la floritura es un cué individual, seguida por dos notas juntas (cré), luego nuevamente un cué individual y finaliza con tres notas muy pegadas requé. Es resaltable que al contrario de la floritura de las otras especies, las últimas notas en $P$. citreola son emitidas en una intensidad descendiente.

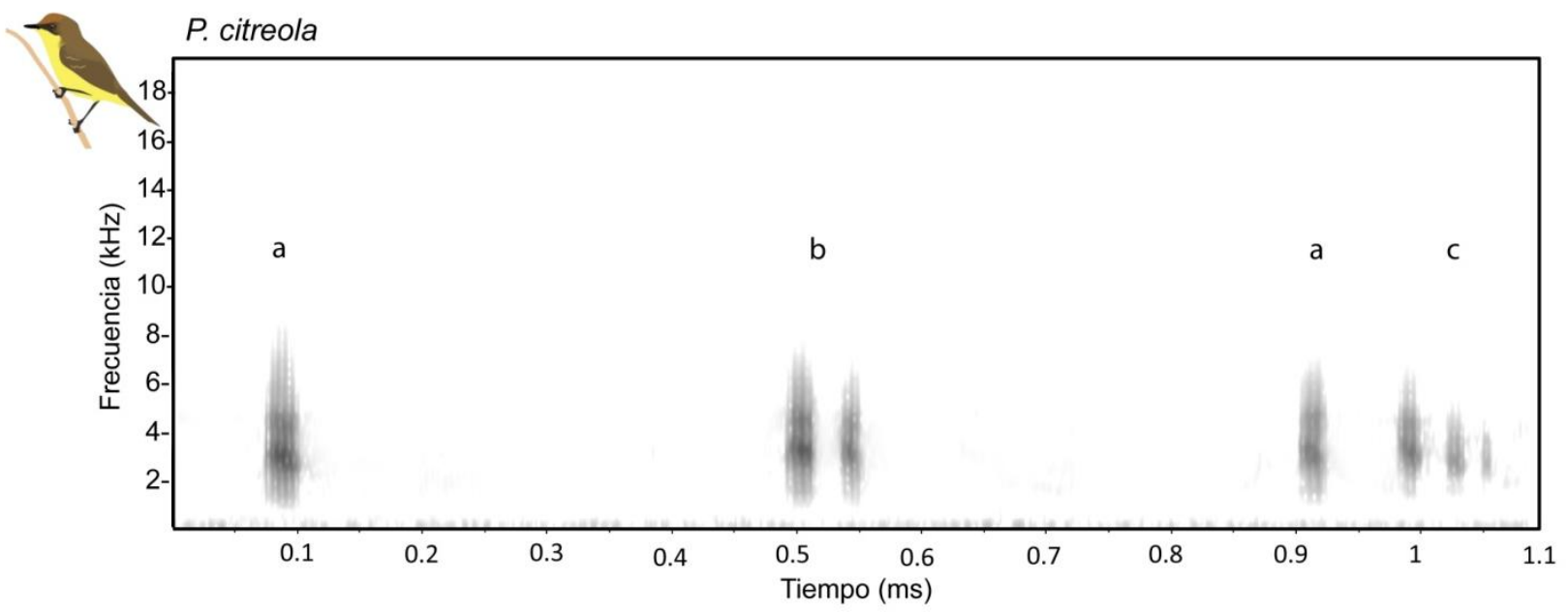

Figura 17. Detalle de la floritura de P. citreola. Se observan los tres tipos de notas: a) cué, b) cré, c) -requé. Lago Pellegrini, Río Negro, Argentina. 27 de octubre de 2015 (ML 224886). WS: 176

La introducción del canto de $P$. flaviventris está compuesta por notas metálicas huecas, cortas y de amplia distribución en frecuencia. Varían en una serie sincopada que cambia de volumen y frecuencia fundamental de manera más o menos alternada (Ábalos \& Areta 2009). La apariencia gráfica general de estas notas en el espectrograma es de una pila de pequeñas "ues invertidas" apiladas. La floritura presenta cuatro notas: la primera y la tercera generalmente corresponden al tipo de "ues invertidas", en cambio la segunda es una nota más larga en duración $(0,08 \mathrm{~s})$ y forma una curva ascendente en frecuencia, pero con un pequeño descenso en el final, dando un aspecto de "ola". La cuarta y última es más aguda que las anteriores y es emitida a mayor intensidad. Su frecuencia fundamental concentra la mayor energía y tiene una forma de anzuelo que se replica en un armónico, dándole la apariencia de "anzuelo doble". 


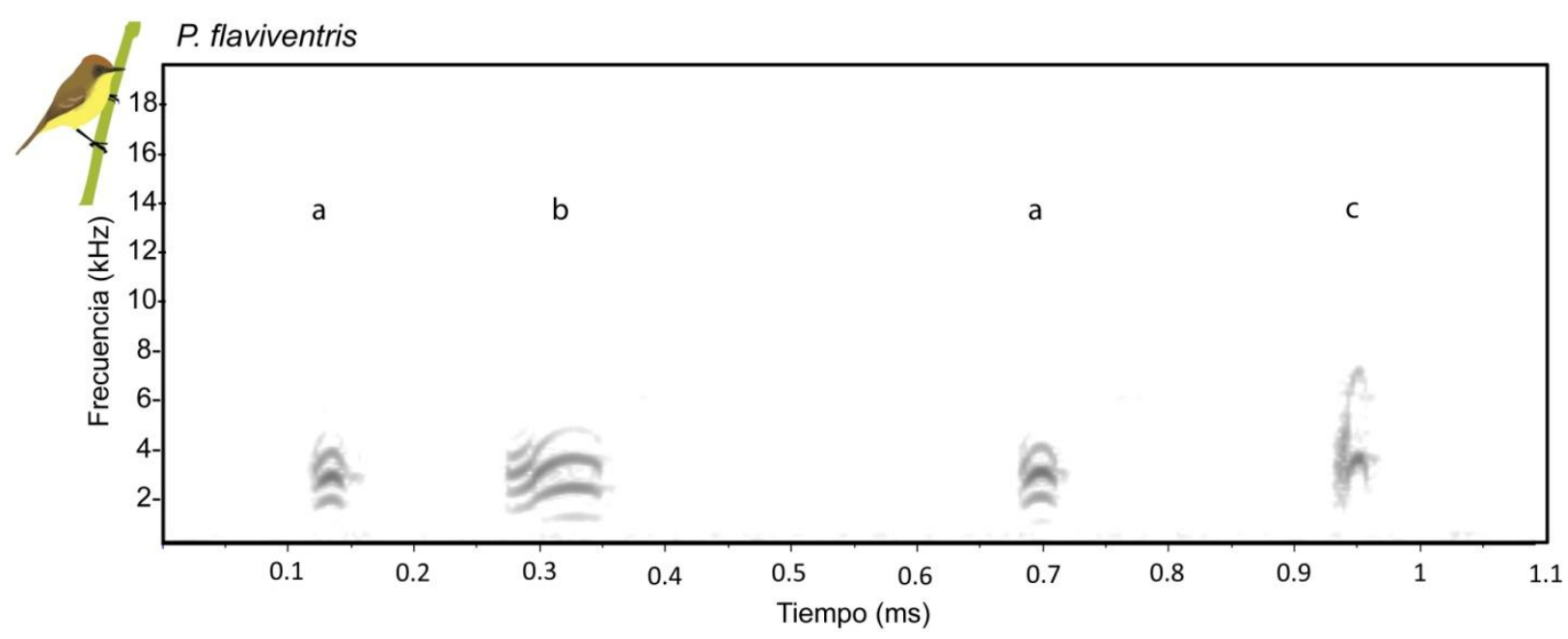

Figura 18. Detalle de la floritura de $P$. flaviventris. Se observan los tres tipos de notas: a) ues invertidas, b) ola, c) anzuelo doble. Reserva Natural Punta Lara, Buenos Aires, Argentina. 15 de Diciembre 2015 (ML 224888). WS: 333

Pseudocolopteryx dinelliana desarrolla por lejos el canto más complejo y diverso entre los doraditos. El límite entre introducción y floritura, evidente en las demás especies, es más difuso en esta especie dada la cantidad, tipos y ubicación de las notas en el canto. Se destacan notas compuestas por subelementos muy cortos y con amplia distribución de frecuencia (pero con la frecuencia pico muy concentrada) que son emitidos uno al lado del otro. Casi sin espacio entre ellos, estos subelementos se acoplan unos con otros en lo que podría denominarse "trenes sonoros", que varían mucho en su desarrollo temporal, y pueden durar entre 0,019 s y 0,375 s. Éstos subelementos pueden ir variando su frecuencia fundamental a medida que avanzan, o mantenerlas constantes dentro de cada tren. De manera poco frecuente aparecen notas menos ásperas con mayor desarrollo temporal que ascienden en frecuencia, para luego volver a caer en forma de "tobogán". Un cuarto tipo de notas son las "ues invertidas dobles", de corta duración y amplio desarrollo en frecuencia que solo aparecen seguidas de la "nota $F$ " ocupando la misma posición que el tobogán. Las notas tobogán y ues invertidas dobles parecen ser un caso de ortología (ver más adelante). La nota más conspicua en el canto de $P$. dinelliana es sin duda la nota "nota $F$ ", compuesta de una primera parte áspera a la que le sigue una parte monotonal muy aguda cuya frecuencia fundamental está en los $5 \mathrm{kHz}$, con al menos un armónico conspicuo (Fig. 19). 


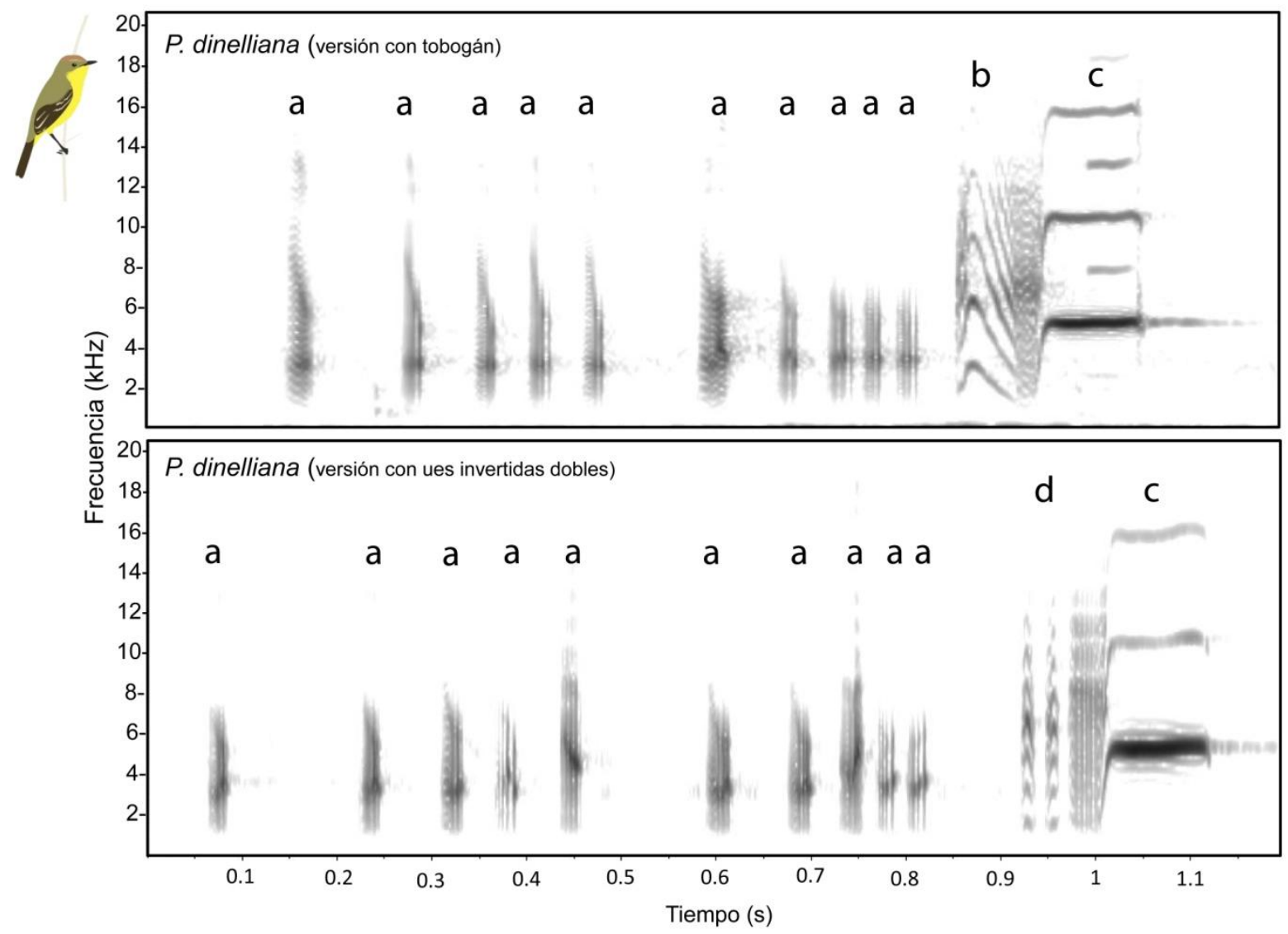

Figura 19. Detalle de la floritura de $P$. dinelliana. Se observan los tres tipos de notas: a) trenes sonoros de diferentes tipos y duraciones, b) tobogán, c) nota F, d) ues invertidas dobles. A) Reserva Natural Formosa, Formosa, Argentina. 22 de noviembre de 2014 (ML 213139). B) Miramar, Córdoba, Argentina. 30 de septiembre de 2014 (número de catálogo pendiente). WS: 512

El complejo canto de $P$. dinelliana tiene la particularidad de estar compuesto de frases. Las frases son un conjunto de notas emitidas en una sucesión tal que forman un patrón definido, y que están separadas de otras frases por un corto silencio. Dentro de las frases de $P$. dinelliana se suceden los trenes sonoros en cantidades y duraciones variables intercalados con los menos frecuentes toboganes (Fig. 20). Las frases típicamente terminan con una nota $F$ más corta que la de la floritura (Fig. 20 A), y menos frecuentemente finalizan con un tobogán (Fig. 20 B); luego de un silencio se da lugar a la siguiente frase. El número de frases es muy variable entre individuos y entre eventos vocales de cada individuo. La última frase del canto termina con la floritura propiamente dicha, en la que aparece la nota $F$ larga precedida por ues dobles o un tobogán (Figs. 19 y 20 C). La floritura está definida por un patrón llamativamente regular: una sucesión rápida de diez trenes seguidos de las ues invertidas dobles o un tobogán, para finalizar en una nota $F$ larga e intensa (Fig. 19). En resumen, $P$. dinelliana repite e intercala elementos tanto en la introducción como en la floritura. Entonces, el tobogán (que precede a la nota $\mathrm{F}$ final en la floritura) puede aparecer intercalado entre los trenes en cualquier parte de 
la introducción. Del mismo modo hay notas $F$ más cortas en el final de algunas frases del canto (Fig. 20).
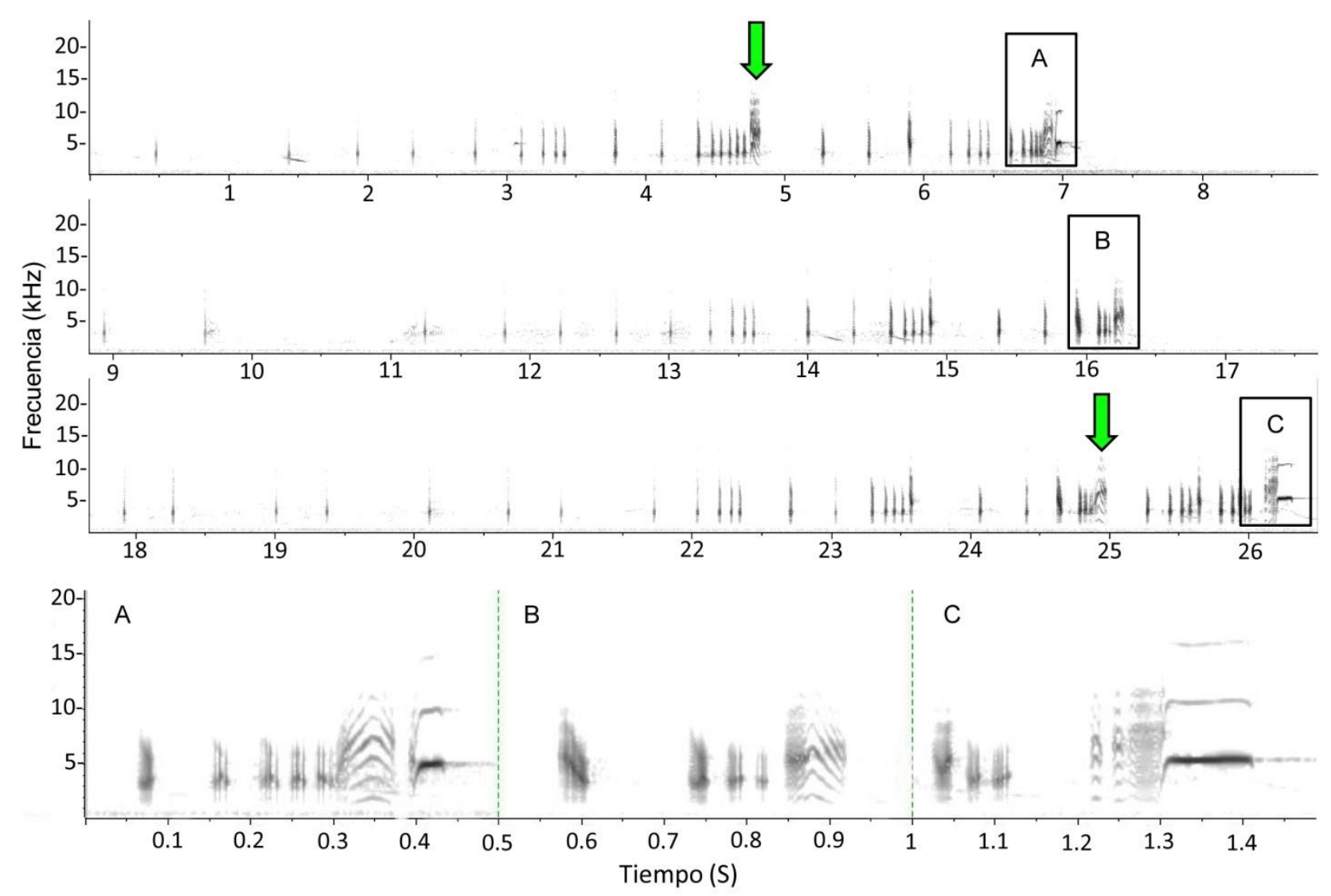

FIGURA 20. Espectrograma del canto de $P$. dinelliana. Se muestra un corte de 26.5 segundos en los que el individuo desarrolla 3 frases. La primera frase finaliza con un tobogán seguido de una nota $F$ corta(A), la segunda frase finaliza con un nota tobogán (B), y la tercera finaliza en una floritura con ues invertidas dobles y una nota $F$ larga (C). Las flechas verdes indican toboganes intercalados entre los trenes. Miramar, Córdoba, Argentina. 30 de septiembre de 2014 (ML 213118). WS: 512

Tres de las especies ( $P$. sclateri, $P$. acutipennis y $P$. dinelliana) realizan despliegues aéreos de dos perchas durante los cuales emiten sonidos vocales y sonidos putativamente mecánicos (Figs. 21, 22 y 23). Durante el vuelo, emiten notas que también son usadas durante la introducción y floritura del canto. Una vez que está en vuelo, $P$. sclateri emite una serie de 5 a 8 chasquidos y finaliza con una repisa plana mas una repisa inclinada, para luego posarse en la segunda percha (Fig. 21). Pseudocolopteryx acutipennis comienza su vuelo diagonal en silencio y emite las tres notas de la floritura en el punto de inflexión justo antes de comenzar a descender (Fig. 22). El despliegue aéreo de dos perchas de $P$. dinelliana, consiste en un corto vuelo diagonal ascendente $\mathrm{y}$ en el punto de altura máximo emite una nota $F$, para luego posarse en otra rama. Este despliegue puede desencadenarse inmediatamente después de que el doradito finalice su canto perchado, o que en vez de finalizar la floritura "normal", 
emita la nota $F$ durante el vuelo de dos perchas (Fig. 23). A la nota $F$ en vuelo le preceden y le suceden dos o tres suaves notas sibilantes imperceptibles por oído humano, pero visibles en los espectrogramas (Fig. 23 B). Es posible que dichas notas sean producidas mecánicamente por las alas.

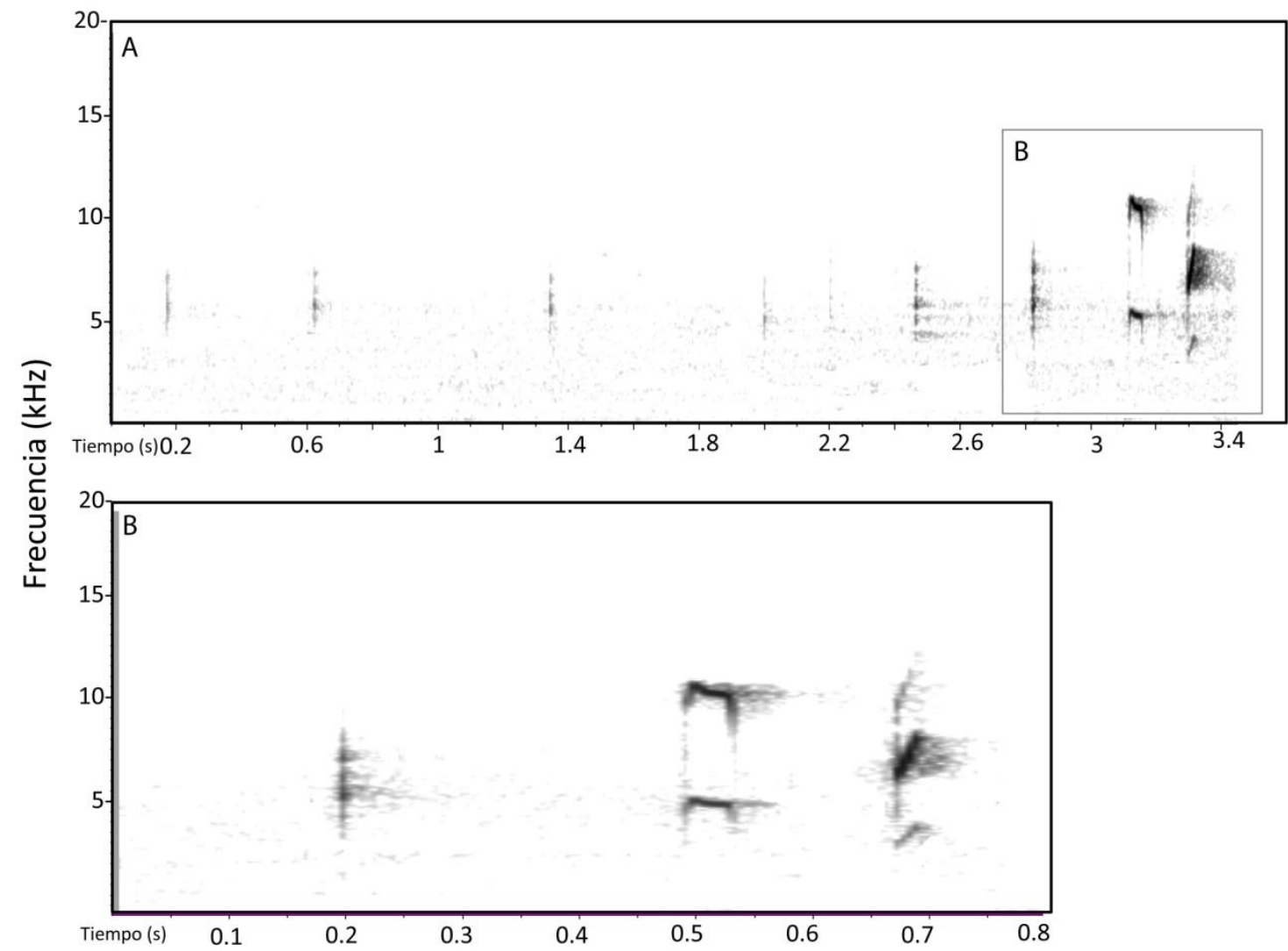

FIGURA 21. Despliegue aéreo de dos perchas de $P$. sclateri. A) Se observan 6 chasquidos seguidos por una repisa plana y una repisa inclinada. WS: 733. B) Detalle de las últimas tres notas. WS: 512

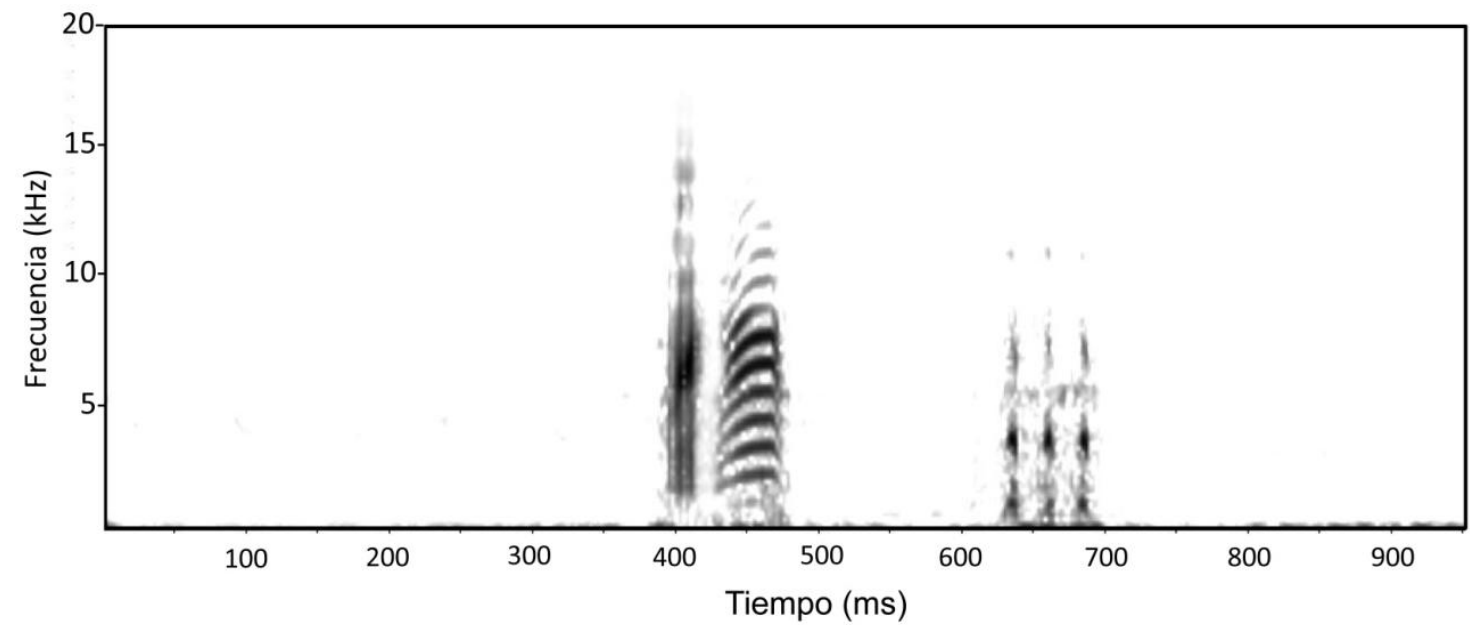

FIGURA 22. Despliegue aéreo de dos perchas de $P$. acutipennis. Se observan las notas tipo varillas, chevrón y tres notas mecánicas. Centeno, Santa Fe, Argentina. 27 de enero de 2014 (ML 224889). WS: 250 


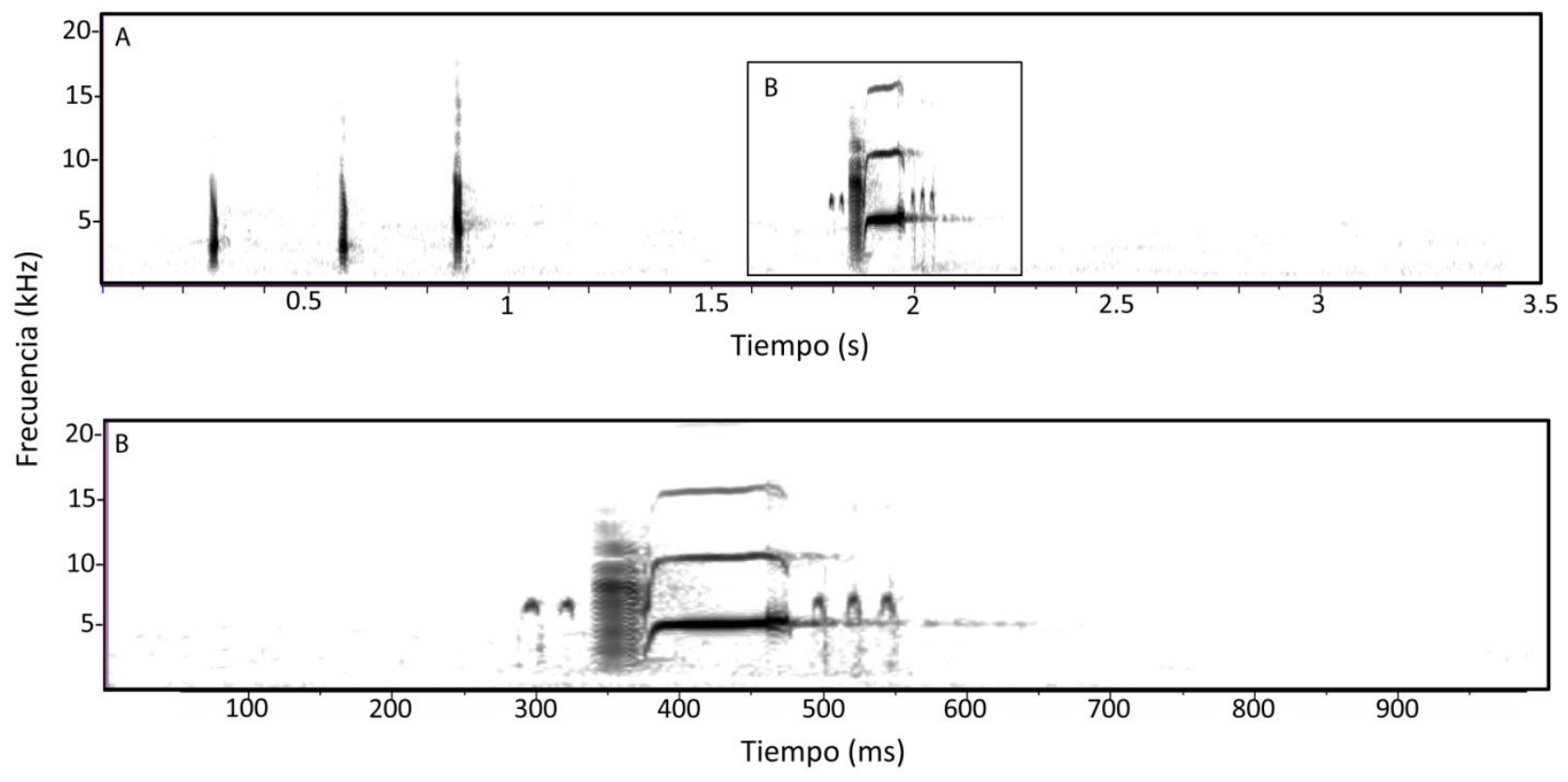

FiguRA 23. Despliegue aéreo de dos perchas de $P$. dinelliana. A) Se observan las últimas tres notas que el ave emite perchada y luego la nota F en vuelo. WS: 512. B) Detalle de la nota F precedida y sucedida por notas posiblemente mecánicas. Miramar, Córdoba, Argentina.30 de noviembre de 2014. WS: 512

\section{RELACIÓN ENTRE COMPONENTES VISUALES Y ACÚSTICOS DE LOS DESPLIEGUES}

Los componentes visuales y acústicos de los despliegues de Pseudocolopteryx están plenamente acoplados entre sí (Fig. 24). En P. sclateri durante el módulo de acción Arqueo Lateral se emite la nota en repisa, en el cabeceo Atrás y Arriba se acopla con un chasquido, y al comienzo del Viboreo Adelante se emite la repisa inclinada (Fig. 24 A). En P. acutipennis la nota introductoria chik se emite en el módulo de acción Atrás y Arriba, el Arqueo Vertical comienza cuando el ave todavía está despegando de la percha y se emiten las varillas junto al chevrón; y las notas mecánicas se producen en vuelo durante el Aleteo Corto (Fig. 24 B). En los rápidos módulos de Ascenso y Estiramiento de $P$. dinelliana se desencadenan los trenes en repeticiones que pueden llegar a varias decenas (Fig. 25), y en el Arqueo Vertical se emiten las ues invertidas dobles (Fig. 24 C y 25) o los toboganes (Fig. 24 D). La nota F está acoplada al Viboreo Adelante. A pesar de la estructura homogénea de las notas de $P$. citreola, los módulos de acción se acoplan consistentemente con éstas en la secuencia de eventos. Entonces, la nota cué se corresponden con los módulos de Ascenso y Estiramiento, las notas cré con los Giros horizontales tipo 2, y la nota triple -requé con el Viboreo y Encogimiento (Fig. 24 E). En P. flaviventris las ues invertidas se emiten durante el Ascenso y Estiramiento, en el Giro tipo 1 se emite la ola y el Viboreo y Encogimiento comienza con el anzuelo doble (Fig. 24 F). 

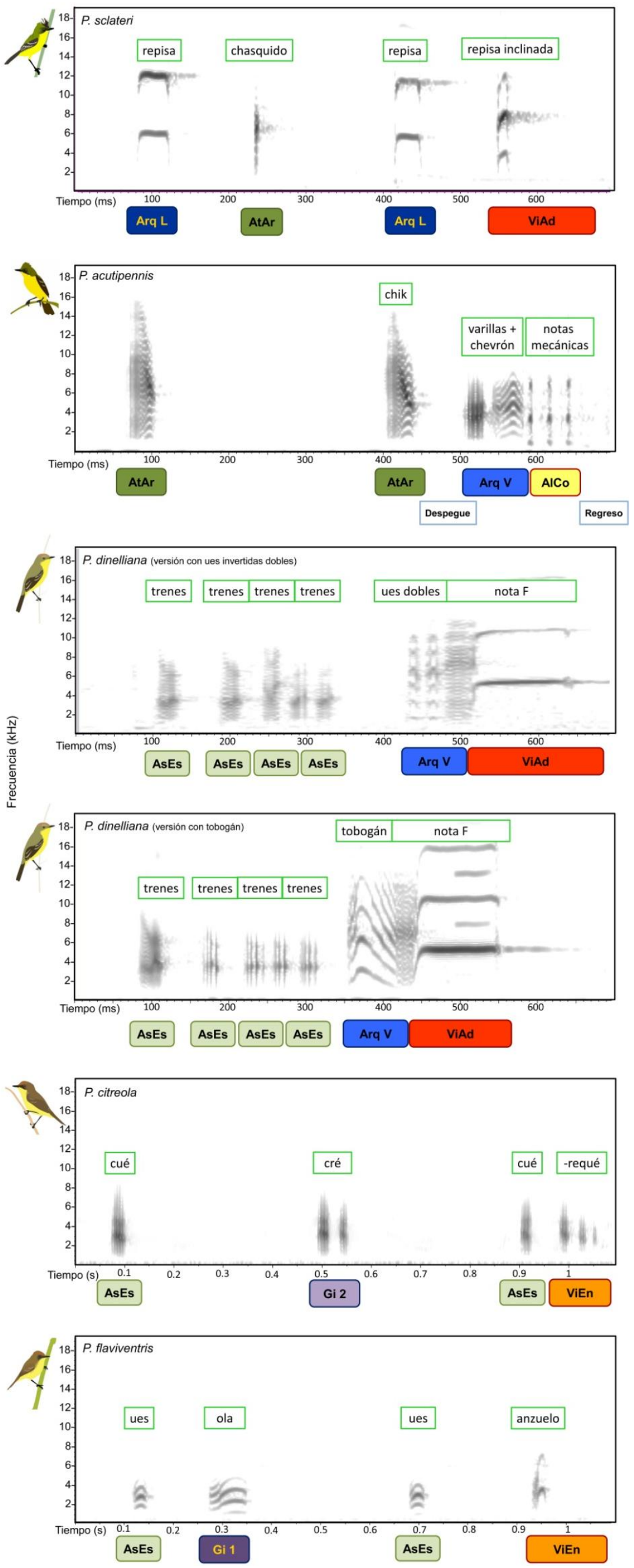

Figura 24. Esquema de la relación entre los componentes visuales y acústicos de la parte final del despliegue en Pseudocolopteryx. Los espectrogramas son los mismos que en las figuras 15 a 19. Dentro de los recuadros verdes están los nombres de las notas. Los rectángulos coloreados corresponden a los Módulos de Acción descriptos en la Fig. 1. 


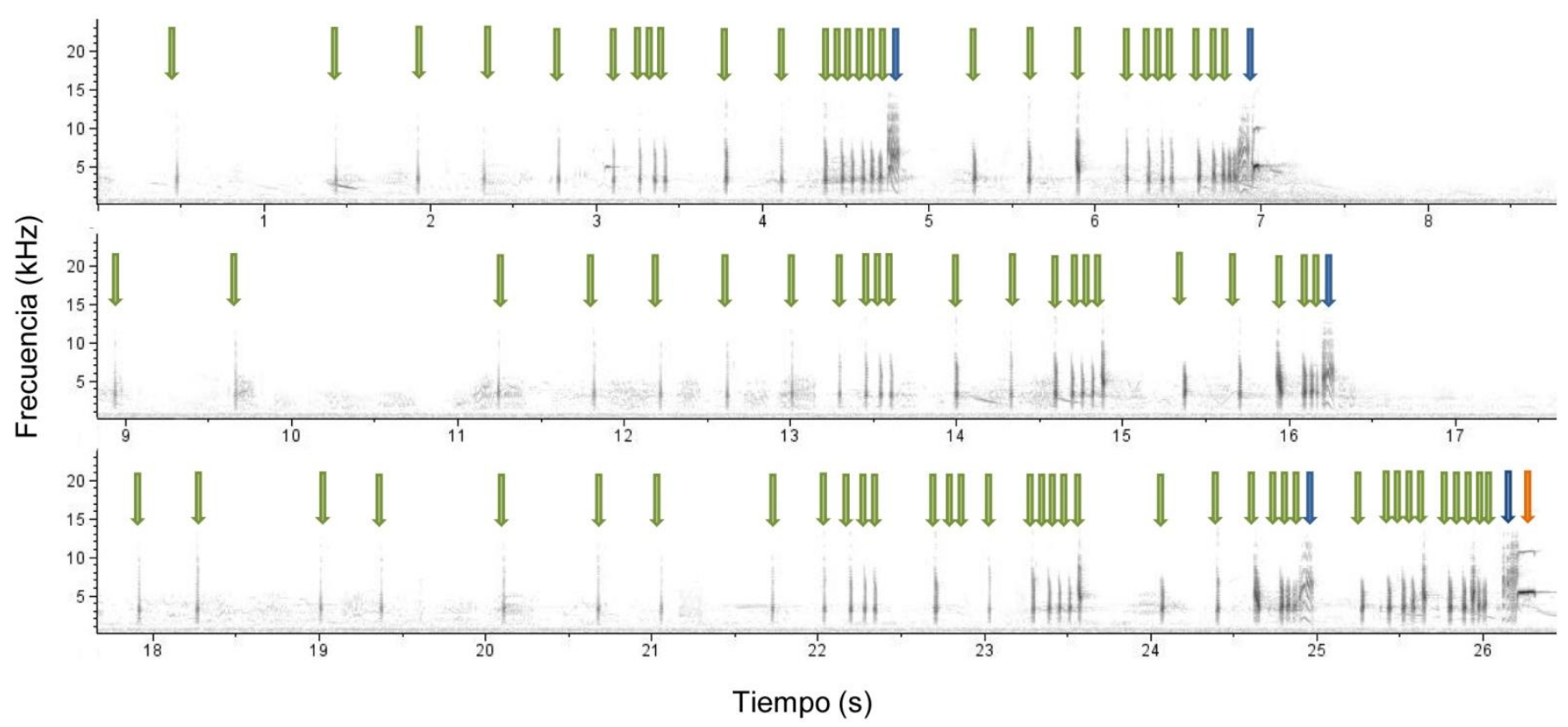

Figura 25. Espectrograma del despliegue de $P$. dinelliana. Las flechas indican la aparición de un elemento del Módulo de Acción: flechas verdes: Ascenso Estiramiento, flechas azules: Arqueo Vertical, y flecha naranja: Viboreo Adelante.

Los despliegues aéreos de dos perchas de $P$. sclateri no pudieron ser filmados y los de $P$. acutipennis se filmaron a velocidad normal de grabación y a una distancia tal que impidió detectar los movimientos corporales en grano fino. Solo los despliegues aéreos de $P$. dinelliana pudieron ser filmados a corta distancia, aunque a velocidad normal de grabación. Por lo tanto, los componentes visuales en los despliegues aéreos de dos perchas fueron inferidos a partir de la notable consistencia en el acople con los componentes acústicos que muestran las demás partes del despliegue. 


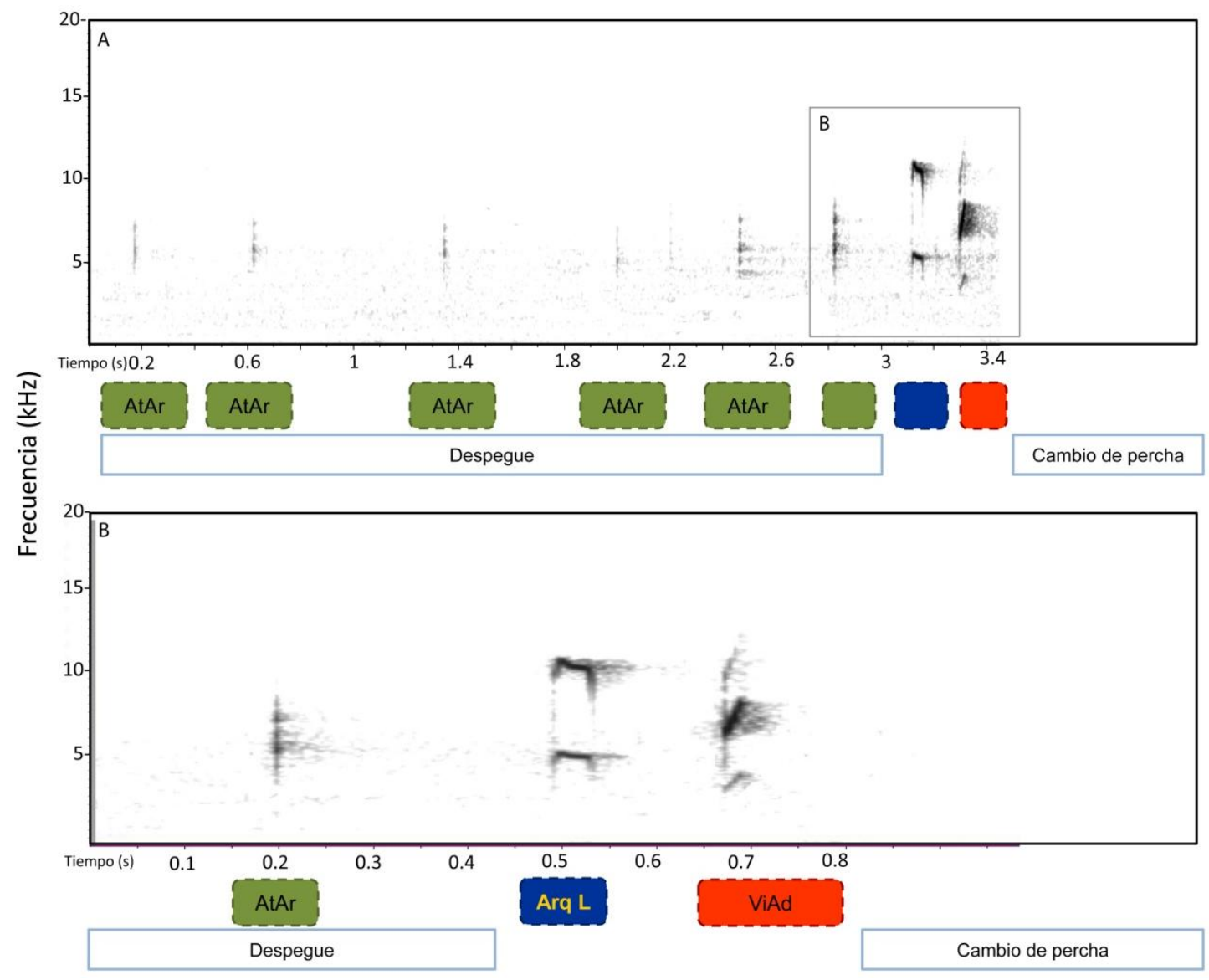

FigURA 26. Esquema del despliegue aéreo de dos perchas de $P$. sclateri. Los módulos de acción se corresponden con los de la figura 1. Las líneas punteadas indican que dichos módulos fueron inferidos.

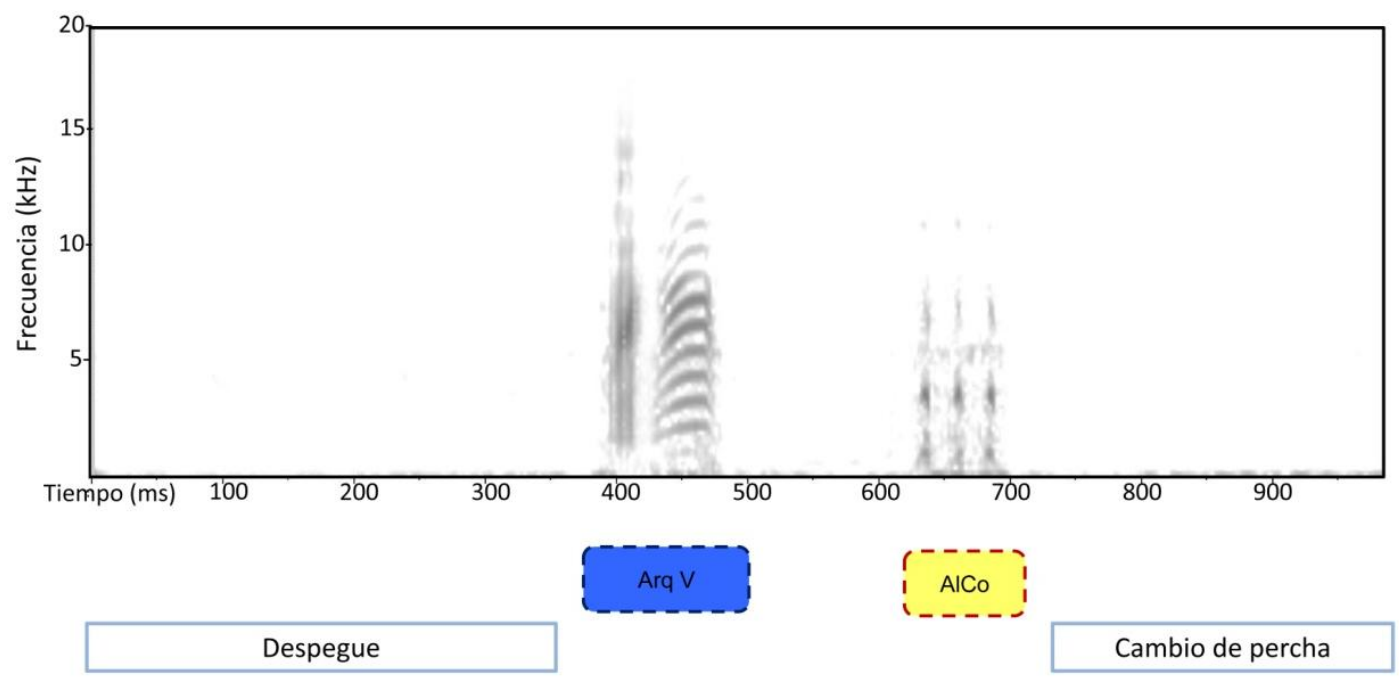

FIGURA 27. Esquema del despliegue aéreo de dos perchas de $P$. acutipennis. Los módulos de acción se corresponden con los de la figura 1. Las líneas punteadas indican que dichos módulos fueron inferidos. 

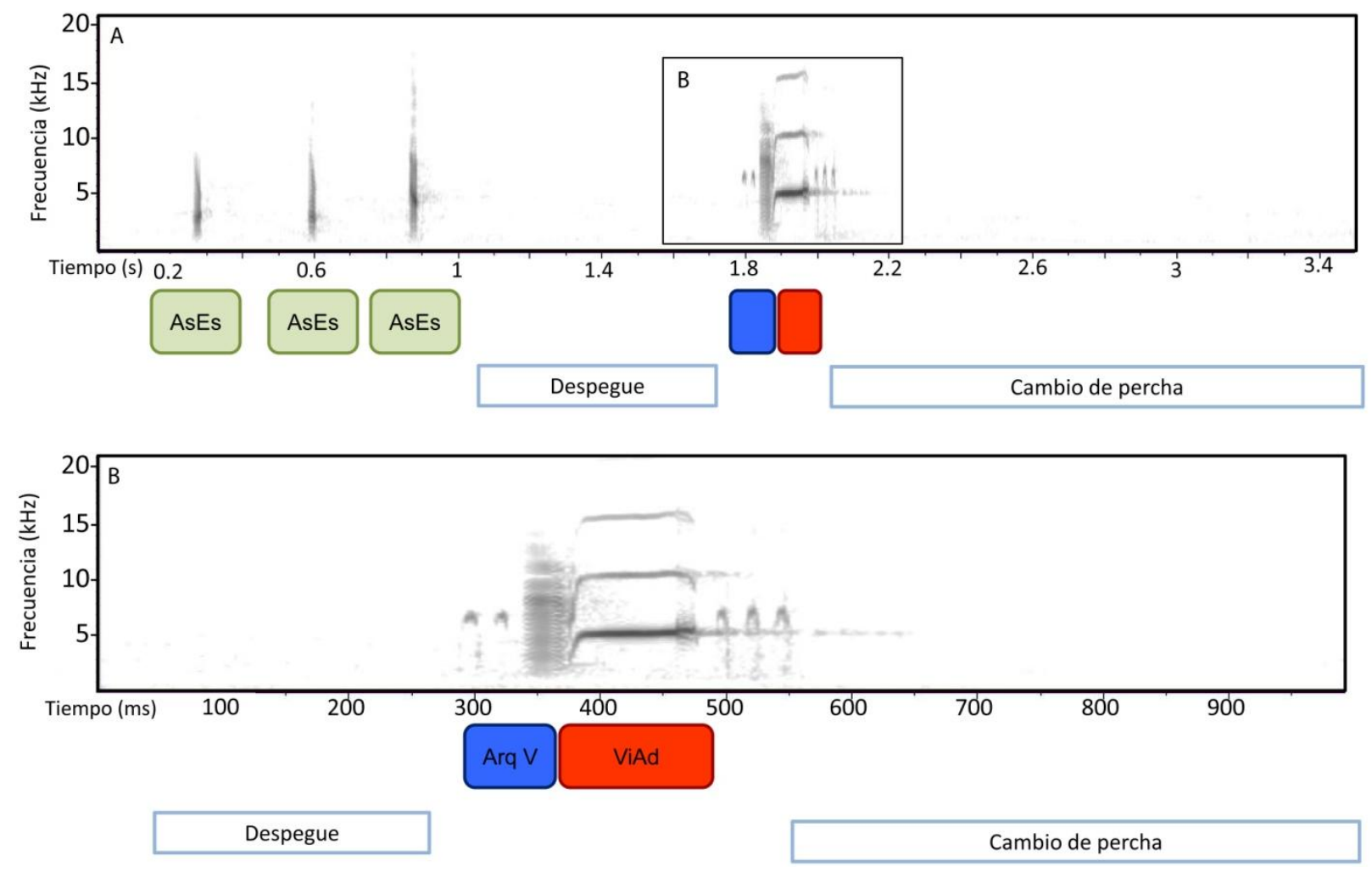

Figura 28. Esquema del despliegue aéreo de dos perchas de $P$. dinelliana. Los módulos de acción se corresponden con los de la figura 1.

\section{HOMOLOGÍAS DE LOS COMPONENTES ACÚSTICOS Y VISUALES}

En un primer conjunto de notas homologas se encuentran los chasquidos producidos con el pico por $P$. sclateri junto a las notas vocales chik, cué, y ues invertidas de las demás especies. Estas notas homologas reciben la denominación grupal de notas iniciales (Fig. 29 A). Estas notas iniciales están acopladas a un módulo de acción Cabeceo. En un segundo grupo de notas intermedias está la nota repisa de $P$. sclateri, que parece ser homóloga a la ola de $P$. flaviventris y al tobogán de $P$. dinelliana, que adquieren en estas dos especies una primera parte ascendente en frecuencia y una segunda parte descendente (Fig. 29 B). En P. dinelliana, el tobogán tiene una variante ortóloga, la nota ues dobles, que puede ser interpretada como una partición del tobogán en dos subcomponentes seguida de modificación. En P. acutipennis la nota intermedia homóloga al tobogán también aparece particionada y modificada como varillas + chevrón, y algo similar ocurre en $P$. citreola con la doble nota cré que aparecería solo particionada. Cada una de estas notas intermedias se corresponde consistentemente con el módulo de acción Giros y arqueos (Fig. 29 B). El tercer grupo de notas homologas son las notas finales, que corresponden a las notas de la floritura y se emite durante el módulo de acción Cierre (Fig. 29 C). La nota final repisa inclinada de $P$. sclateri se corresponde con la nota $F$ de P. dinelliana, y con el anzuelo de $P$. flaviventris, todas con una apariencia similar en el espectrograma. En P. citreola esta nota aparece particionada en la nota triple -requé. EI 
cambio más extremo es el de $P$. acutipennis en donde esta nota que es vocal en las demás especies, está reconfigurada aquí (también en forma triple) como notas mecánicas.
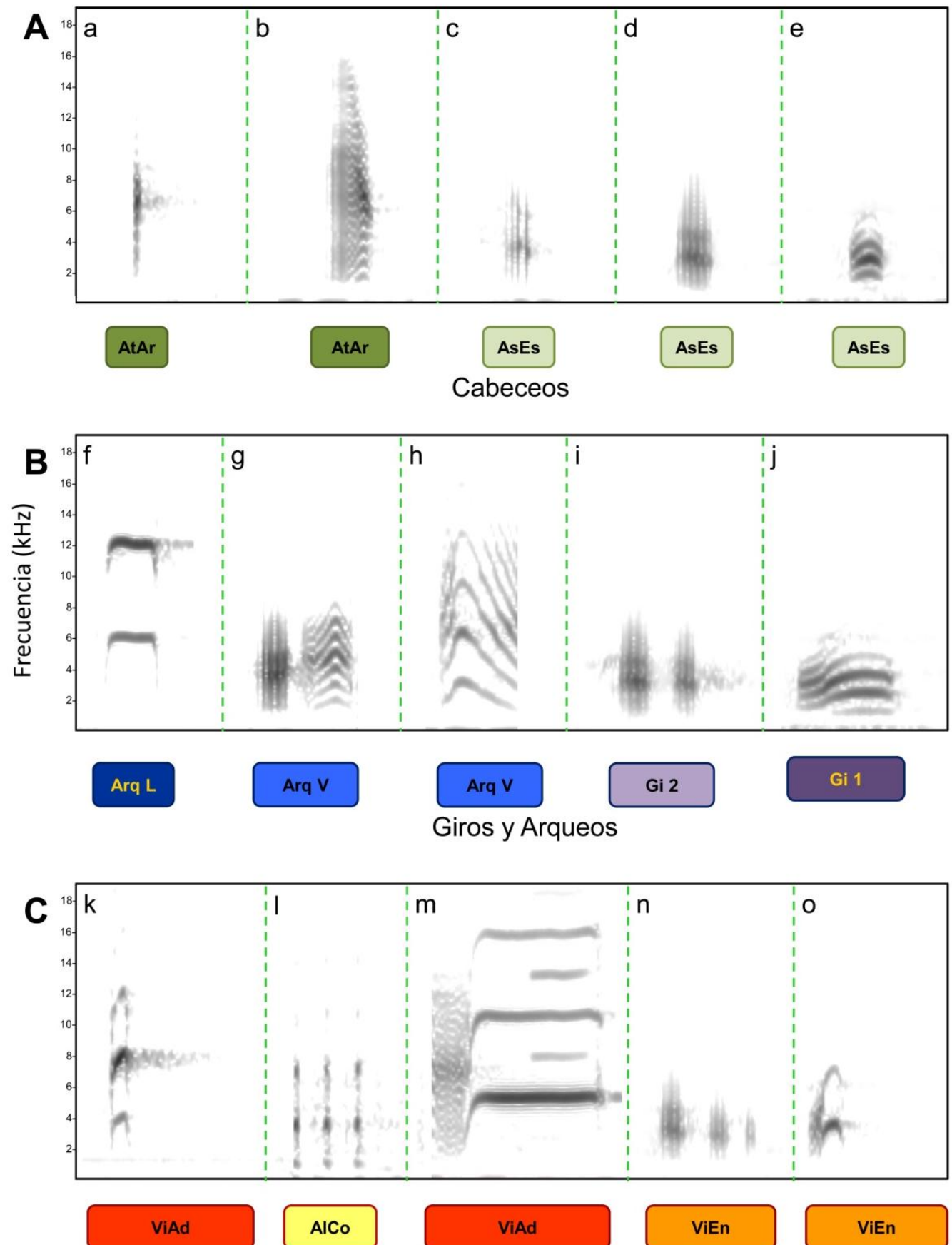

ViEn

ViEn

Cierre

\section{$0,1 \mathrm{~s}$}

FIGURA 29. Espectrogramas de las diferentes notas homólogas en Pseudocolopteryx y su acople con los Módulos de Acción correspondientes. A- notas iniciales: a) chasquido, b) chek, c) trenes, d) cué, e) ues invertidas. B- notas intermedias: f) repisa, g) varilla+chevrón, i) cré, j) ola. C- notas finales: k) repisa inclinada, I) notas mecánicas, m) nota $F, n$ ) -requé, o) anzuelo. Las letras mayúsculas indican paneles de notas homólogas, En cada panel las notas pertenecen a diferentes especies siguiendo siempre el siguiente orden: P. sclateri - P. acutipennis - P. dinelliana P. citreola - P. flaviventris 


\section{DISCUSIÓN}

En este capítulo se identificaron y describieron en detalle las unidades comportamentales visuales y acústicas que conforman el fenotipo de los despliegues de los machos de todas las especies de Pseudocolopteryx. Estas unidades comportamentales multimodales se acoplaron de manera plenamente modular, presentaron las características de modularidad organizacional y variacional (West-Eberhard 2003)

\section{MODULARIDAD ORGANIZACIONAL}

El carácter jerárquico del fenotipo comportamental de los despliegues y la semiindependencia de las unidades modulares de menor jerarquía son importantes ya que implican la potencialidad de ser eliminadas, duplicadas o reubicadas durante el desarrollo ontogenético y la evolución (West Eberhard 2003). En los despliegues de Pseudocolopteryx, el ejemplo más contundente de reubicación y duplicación se visualiza en los módulos de acción Cabeceos. Los Cabeceos (ya sea en su versión de Ascenso-Estiramiento o de Atrás y Arriba) se reubican dentro de la estructura del despliegue de cada especie apareciendo en diferentes Módulos de Momento: son parte constitutiva de la Presentación y del Remate en todas las especies, y en $P$. sclateri aparecen también en el Despliegue Aéreo de dos Perchas (Fig. 1). Otros ejemplos de reubicación dentro de una especie son los Giros y Arqueos, que en sus versiones de Arqueo Vertical en P. dinelliana y de Giro Horizontal 1 en P. flaviventris son parte del Remate, y aparecen de manera espaciada pero consistente durante la Presentación (Fig. 1 y 25). Los Módulos de Acción Cierre también se ven reubicados, apareciendo en el Remate y en Despliegue Aéreo de dos Perchas en P. sclateri, P. acutipennis y P. dinelliana. En conclusión, estos Módulos de Acción (Cabeceos, Giros y Arqueos, y Cierre) se reubican desde un Módulo de Momento a otro dentro de la misma especie, en lo que podría visualizarse como un desplazamiento horizontal en la Figura 1.

Los Cabeceos (ya sea como Atrás-Arriba o como Ascenso Estiramiento) son las unidades constitutivas del módulo de momento Presentación de todas las especies de doraditos. Dentro de este módulo, los cabeceos aparecen en un número muy variable en cada especie (Fig. 1). Por ejemplo, el Ascenso-Estiramiento en la presentación de $P$. dinelliana está duplicado de manera extrema, y un solo evento de presentación puede contener decenas de cabeceos (Fig. 25). Esta capacidad de duplicar los Cabeceos ocurre de manera más moderada en los despliegues de las demás especies, las cuales normalmente no realizan más de 8 cabeceos durante una presentación. En todas las especies, el número de veces que se repiten los cabeceos es muy variable, y puede cambiar no solo en cada individuo sino también en cada evento de despliegue. Esta propiedad repetitiva de la Presentación se ve brutalmente 
exacerbada durante los cantos de amanecer. Antes de salir el sol, durante el alba todas las especies de doraditos realizan cantos de amanecer que consisten en una repetición pausada y rítmica de notas iniciales acompañadas de cabeceos (Jordan \& Areta in prep.). Estos cabeceos (que son algo menos pronunciados que los del despliegue) se repiten de a decenas de manera continua, incluso durante varios minutos. Muy espaciadamente, aparecen los remates intercalados con los cabeceos. Es posible que la repetición de cabeceos en la Presentación sea una expresión reducida de la repetición dramática de cabeceos que ocurre durante el canto de amanecer.

Esta capacidad de repetición y variabilidad parece una característica intrínseca del módulo de momento Presentación que contrasta fuertemente con la rigidez estructural del Remate. En P. dinelliana la presentación puede contener 10 cabeceos o más de 30, pero el remate siempre está constituido por 10 cabeceos, seguidos por el Arqueo Vertical y el Cierre (Fig. 1 C). Esta rigidez también se observa en el Remate de las demás especies en donde sus módulos de acción constituyentes (Cabeceos, Giros y Arqueos, y Cierre) aparecen siempre en un mismo número y posición (Figs. 1 y 24). Esta rigidez en los Remates se ve reflejada en la estructura de los Despliegues Aéreos de dos perchas, donde aparecen todos o algunos de módulos de acción del Remate de manera consistente (Fig.1). Por ejemplo en P. sclateri el Despliegue Aéreo de dos perchas tiene los mismos tres módulos de acción que el Remate, pero los Cabeceos se ven duplicados. En cambio tanto en $P$. acutipennis como en $P$. dinelliana desaparecen los Cabeceos y solo se conservan el Arqueo Vertical y el Cierre. Las similitudes estructurales entre estos dos módulos de momento, plantean la posibilidad de que el módulo de momento Despliegue Aéreo de dos perchas haya aparecido muy tempranamente en la evolución de Pseudocolopteryx como una duplicación con modificación del módulo de momento Remate. Posteriormente, el módulo Despliegue Aéreo de dos perchas se habría perdido en $P$. citreola y $P$. flaviventris.

Tanto los módulos de acción como los módulos de momento presentan la capacidad de ser duplicados y reubicados horizontalmente dentro del fenotipo comportamental de una misma especie, lo que constituye evidencia contundente de la existencia de la modularidad organizacional en los despliegues de Pseudocolopteryx.

\section{HOMOLOGÍA Y DISOCIABILIDAD EVOLUTIVA}

Una de las características de la modularidad variacional es la existencia de módulos homólogos entre especies. Los módulos de mayor jerarquía (Módulos de Momento) de una especie están compuestos por Módulos de Acción. En Pseudocolopteryx cada módulo de acción está plenamente acoplado con un componente acústico particular. Entonces los 
Cabeceos se acoplan con las notas iniciales, los Giros y Arqueos se acoplan con las notas intermedias, y el Cierre con las notas finales (Fig. 29).

Los Módulos de Acción pueden duplicarse, reubicarse o desaparecer en cada especie dentro de los Módulos de Momento sin perder identidad (Fig. 1). Por ejemplo, el módulo de acción Cabeceo aparece solo al principio de la secuencia temporal del Remate de $P$. sclateri, $P$. acutipennis y $P$. dinelliana, sin embargo en $P$. citreola y $P$. flaviventris aparecen duplicados y reubicados temporalmente justo antes del Cierre. Por otro lado, el Cabeceo aparece en el Despliegue Aéreo de dos perchas en $P$. sclateri, pero desaparece de ese mismo módulo de momento en $P$. acutipennis y $P$. dinelliana. El hecho de que el Cabeceo desaparezca en el Despliegue Aéreo de dos perchas no imposibilita su existencia en los demás módulos de momento de esas especies. En un nivel jerárquico mayor, el Despliegue Aéreo de dos perchas que está presente en $P$. sclateri, $P$. acutipennis y $P$. dinelliana desaparece por completo en $P$. citreola y $P$. flaviventris sin afectar la existencia de los demás módulos de momento ni de los módulos de acción en estas especies. En conclusión, los Módulos de Acción se duplican, reubican o desaparecen desde un Módulo de Momento de una especie hacia el mismo Módulo de Momento de otra especie sin perder identidad; y del mismo modo los Módulos de Momento se modifican o desaparecen de una especie a otra. Ambos son casos de disociabilidad evolutiva que se visualizan como desplazamientos y modificaciones verticales de módulos en la Figura 1. Esta capacidad de duplicación, reubicación y desaparición vertical, son evidencias de la existencia de la modularidad variacional en los despliegues de Pseudocolopteryx.

Las homologías dentro del módulo de acción Cierre están dadas por su posición relativa en el despliegue, y por la relación entre sus componentes visuales y acústicos. Las notas finales repisa (de $P$. sclateri) y anzuelo (de $P$. flaviventris) se emiten al comienzo del módulo de acción Cierre (Fig. 29 C). En ambos casos, la actividad motora continúa luego de finalizada la nota final: en el caso de $P$. sclateri el movimiento hacia adelante continúa después de la emisión de la repisa y $P$. flaviventris encoje los hombros ya en silencio. La nota $\mathrm{F}$ de $P$. dinelliana es notoriamente más larga que las demás notas finales y se desarrollan durante todo el transcurso de la actividad motora (en este caso también un movimiento hacia adelante) (Fig. 29C). En $P$. citreola y $P$. acutipennis, las notas finales también se desarrollan durante todo el transcurso de la actividad motora, pero en estos casos el componente acústico está particionado en tres subunidades menores (que en la primer especie son de origen siringeal y en la segunda son sonidos putativamente mecánicos, ver abajo).

El reemplazo de sonidos vocales por sonidos mecánicos (o viceversa), o incluso por comportamientos ritualizados, parece ser recurrente en los tiránidos (Bostwick \& Zyskowski 
2001, Areta \& Miller 2014). Por ejemplo, se ha hipotetizado que el "despliegue de la esfinge" de Muscisaxicola maculirostris, en el cual estira las alas en $V$ en el aire mientras sus patas cuelgan, podría ser homólogo al giro con sonido mecánico de Lessonia y Knipolegus (Areta \& Miller 2014). En este caso, asumiendo la ancestralidad de los sonidos mecánicos, el componente visual del comportamiento se ve transformado desde un aleteo rápido a un movimiento estático prolongado, mientras que el componente acústico desaparece. En Pseudocolopteryx el módulo de acción Cabeceo se asocia con el conjunto de notas iniciales (Fig. 29 A). Mientras que en P. sclateri el Cabeceo resulta en la emisión de chasquidos producto del choque de la mandíbula superior con la inferior, en el resto de los doraditos las notas iniciales son producidas vocalmente por la siringe (Fig. 29 A). En este caso, el exagerado movimiento realizado con el pico en $P$. sclateri deriva en la producción de sonidos mecánicos sin emisión de sonidos vocales, mientras que en las otras especies el cierre del pico no produce ningún sonido evidente y en cambio el componente acústico es completado con la acción de la siringe. Un caso más radical de reemplazo de sonidos vocales por sonidos mecánicos en los doraditos lo constituye el reemplazo de la nota final producida durante los Viboreos por las notas mecánicas producidas durante el Aleteo Corto en P. acutipennis (Fig. 29 C). Este reemplazo es radical ya que implica la actividad motora de muy diferentes estructuras corporales: mientras que en los demás homólogos del módulo Cierre (Viboreo Adelante y Viboreo Encogimiento) el movimiento de la cabeza se asocia con la emisión de las notas finales que son vocales, durante el Aleteo Corto, los tres aleteos veloces y profundos coinciden perfectamente con las tres notas mecánicas y no se emite ninguna vocalización. Resulta muy relevante en este contexto el hecho de que en $P$. citreola la nota final -requé (emitida durante el Cierre) también esté compuesta por tres elementos (Fig. 29 C). Esto permite especular que un tren de tres impulsos nerviosos puede haber sido transferido a las vías motoras alares, desviándolo de las vías siringeales, para lograr el traspaso de una homología comportamental modular a diferentes estructuras anatómicas.

Las diferentes partes de una señal pueden estructurarse de tal forma que contengan diferentes tipos de información (Candolin 2003, Partan \& Marler 2005). La Presentación y el Remate en Pseudocolopteryx presentan diferencias estructurales que parecen indicar que contienen información diferente. La estructura de la Presentación es muy variable dentro de cada especie respecto a la cantidad de duplicaciones de los módulos de acción, sin embargo los componentes visuales y acústicos de estos módulos en la Presentación son muy parecidos entre especies. Esto es, tanto las notas iniciales (Fig. 29 A) como los cabeceos AscensoEstiramiento y Atrás-Adelante (Figs. 4 y 5) son muy similares. En contraposición con la Presentación, el Remate es muy rígido dentro de cada especie (i.e. es un módulo que se 
mantiene muy conservado dentro de la especie), pero sus elementos visuales y acústicos son muy divergentes entre especies (Fig. 29 B y C). Por ejemplo, el Remate en P. sclateri se presenta con marcados movimientos de todo el cuerpo acompañados de notas distintivas pero débiles cuando el doradito está perchado (Fig. 24 A), mientras que en $P$. acutipennis se configura como un vuelo corto con emisión de sonidos putativamente mecánicos producidos por las alas (Fig. 24 B). Sin dudas el Remate es la parte más distintiva del despliegue de cada especie de Pseudocolopteryx, y está constituido por módulos de acción donde los movimientos y los componentes acústicos son más conspicuos que en la Presentación. Este conservadurismo estructural y su conspicuidad podrían deberse a que durante el Remate el macho transmita información sobre su identidad específica, relevante para el emparejamiento. Así, el Remate habría evolucionado bajo fuertes presiones selectivas que lo habrían moldeado mas rígidamente que a la Presentación. En cambio la presentación, como su nombre lo indica, funcionaría simplemente como un llamado de atención previo al desarrollo de la señal que contiene información más importante para el emparejamiento.

\section{MODULARIDAD EN LOS DESPLIEGUES DE OTROS TIRÁNIDOS}

Los despliegues visuales están ampliamente distribuidos entre los tiránidos, y parecen ser especialmente conspicuos en los Fluvicolinae (Smith 1971, Fitzpatrick 2004, Areta \& Miller 2014).

En particular, algunas especies de Muscisaxicola, Neoxolmis, Pyrocephalus, Knipolegus y Lessonia realizan despliegues en vuelo en los que emiten voces y sonidos mecánicos (Wetmore 1926, Vuilleumier 1971, Smith 1971, Straneck \& Carrizo 1983, Areta \& Miller 2014). Estos autores realizan descripciones detalladas de los componentes acústicos y visuales de los despliegues en vuelo, para luego proponer homologías entre especies relacionadas. El hecho de que estos comportamientos complejos puedan ser divididos en subcomponentes discretos menores, para luego ser parte de un estudio comparativo, expone el posible carácter modular de estos despliegues. Por ejemplo, los despliegues en vuelo de Knipolegus striaticeps, $K$. aterrimus, K. hudsoni y Lessonia oreas parecen compartir sonidos vocales y mecánicos homólogos: notas en percha, notas en vuelo, descenso con sonido mecánico, y nota vocal aguda (Areta \& Miller 2014). Del mismo modo, el despliegue en vuelo de M. maculirostris también parece compartir estos tres de estos elementos, las notas en percha están ausentes y el sonido mecánico es aparentemente reemplazado por el despliegue de la esfinge (Areta \& Miller 2014).

Bajo el paradigma de la modularidad podrían plantearse homologías profundas, no solo entre estas especies sino también por ejemplo con $P$. acutipennis. En un planteo 
hipotético, estas especies podrían compartir un fenotipo de despliegue en donde exista una presentación con notas perchadas y un remate con voces en vuelo y sonidos mecánicos, en las que ocurrirían pérdidas, reubicaciones y duplicaciones.

Para poder avanzar en los estudios comparativos en los que se investiguen homologías profundas en clados extensos, se vuelve necesario realizar descripciones detalladas del fenotipo comportamental y analizarlas bajo el paradigma de la evolución modular. De esta forma la estructura compleja del comportamiento puede modificarse, actualizarse y reanalizarse ante la evidencia de nuevos datos. 


\section{-Capítulo 3-}

\section{Biogeografía y migración de los Doraditos}

\section{(Pseudocolopteryx spp.)}

\section{Introducción}

Los factores geográficos y ecológicos parecen estar involucrados en la mayoría de los eventos de especiación de las aves, ya que la separación geográfica promueve la divergencia mediante la limitación del flujo génico, a la vez que la tasa de divergencia se acelera cuando las poblaciones ocupan diferentes ambientes que conducen a diferentes presiones selectivas (Price 2008). De este modo, las investigaciones que integran hipótesis filogenéticas con datos ecológicos y de distribución geográfica son centrales para la interpretación biogeográfica y evolutiva de las especies (Godown \& Peterson 2000, Anderson et al. 2002, Wiens \& Graham 2005).

La determinación de la distribución geográfica de especies involucra como condición necesaria la interpretación de localidades puntuales de ocurrencia en áreas de distribución o geonemias. Existe una gran variedad de métodos para convertir los datos crudos de localidades puntuales en geonemias. Algunos de los métodos más comunes son el de mano alzada (e.g. Morrone et al. 1994), polígonos convexos, propincuidad media y cuadriculación (Mota-Vargas \& Rojas-Soto 2012). En los últimos 20 años la utilización de los modelos de nicho ecológico (MNE) ha crecido exponencialmente. Los MNE correlacionan mediante algún algoritmo localidades de ocurrencia y sus variables ambientales asociadas, para generar un objeto (tabla, fórmula o conjunto) en el espacio ecológico. Este objeto del espacio ecológico luego puede ser proyectado en el espacio geográfico para generar los modelos de distribución potencial (MDP) (Soberón et al. 2017). Si bien existe una intima relación entre nichos y áreas de distribución, los MNE y los MDP son dos procesos de modelación conceptualmente diferentes (Soberón et al. 2017).

En años recientes se han desarrollado diferentes técnicas para cuantificar la superposición del espacio de nicho ecológico entre especies a partir de los MNE, como complemento de los MDP inferidos mediante los primeros (Warren et al. 2008, Broennimann et al. 2012, Gomez et al. 2016). Estas técnicas permiten cuantificar en qué grado se superponen los nichos ecológicos de dos especies, ampliando los límites analíticos impuestos por las clásicas comparaciones en el espacio geográfico. Así, los mapas de distribución 
geográfica y los MNE se pueden integrar para aportar información diferente y complementaria sobre la distribución de una especie dada (Graham et al. 2004).

Las distribuciones geográficas de especies se han usado en combinación con hipótesis filogenéticas para inferir los modos de especiación. A finales del siglo XX se desarrollaron metodologías reconociendo explícitamente que las distribuciones cambian a lo largo del tiempo significativamente más rápido que la cladogénesis. Bajo esta idea, si la especiación alopátrica es la regla, entonces la superposición de distribuciones entre las especies hermanas comenzará en $0 \%$ y la superposición aumentará gradualmente a medida que las distribuciones cambien con el tiempo. En contraste, si la mayoría de la especiación es simpátrica, la superposición debe comenzar cerca del $100 \%$ y tenderá a disminuir con el tiempo. En términos generales estas metodologías (llamadas ARC: age-range correlation) describen cómo los patrones de superposición de distribuciones en un clado cambian a lo largo del tiempo (Barraclough et al. 1998, Barraclough \& Vogler 2000, Berlocher \& Feder 2002, Fitzpatrick \& Turelli 2006). Estos estudios han comparado el espacio geográfico ocupado por las especies en relación con las filogenias, sin considerar el espacio de nicho ecológico (Graham et al. 2004).

La inclusión de la dimensión de nicho ecológico en estos análisis puede permitirnos evaluar cómo operan las presiones ambientales en relación a la especiación. En este sentido, se ha planteado que si especies hermanas alopátricas se segregan también en el espacio ecológico, entonces las presiones mediadas por el hábitat pueden haber tenido un papel importante en la especiación. De manera alternativa, si las especies hermanas alopátricas superponen en algún grado su espacio ecológico, la divergencia ecológica no sería un factor importante (Peterson et al. 1999). Bajo este marco conceptual, Graham et al. (2004) desarrollaron metodologías para examinar simultáneamente las distribuciones geográficas y nichos ecológicos de especies hermanas, como una forma de explorar factores que pueden haber influido en su especiación. Luego Warren et al. (2008) elaboraron un enfoque cuantitativo para analizar la evolución del nicho en un marco filogenético, superando las comparaciones sólo entre especies hermanas. Este enfoque se basa en que muchos aspectos del nicho fundamental pueden conservarse en largas escalas evolutivas. La tendencia de las especies a retener aspectos de su nicho fundamental a través del tiempo se llama conservadurismo de nicho, mientras que la tendencia opuesta es llamada divergencia de nicho. La metodología de Warren et al. (2008) pretende elucidar cuál de estas dos tendencias es la que opera con mayor fuerza en un grupo dado.

Para el caso de especies migratorias, se espera que los aspectos del espacio geográfico y de nicho que influyen en la especiación operen fundamentalmente durante la época reproductiva. Por eso, para evaluar dichas presiones ecológicas y geográficas es necesario 
desarrollar MNE y MDP que tengan en cuenta las distribuciones durante las épocas reproductiva y no reproductiva por separado.

Los objetivos de este capítulo son: 1) analizar la distribución geográfica y los posibles movimientos estacionales de las cinco especies de Pseudocolopteryx mediante el desarrollo de modelos de distribución potencial (MDP) para las épocas reproductiva y no reproductiva, y 2) comparar la superposición de nichos ecológicos durante la época reproductiva para poner a prueba las hipótesis de similitud de nicho, equivalencia de nicho y similitud ambiental a partir del desarrollo de MNE (Warren 2010). Estas hipótesis se discuten en un contexto filogenético para explorar los factores ecológicos y geográficos que influyeron en la distribución actual de los doraditos y que pudieron haber influenciado en su especiación.

\section{ESTADO DE CONOCIMIENTO DE LA DISTRIBUCIÓN Y DE LOS MOVIMIENTOS ESTACIONALES DE LOS DORADITOS}

\section{(PSEUDOCOLOPTERYX SPP.)}

Las especies de Pseudocolopteryx y habitan ambientes abiertos asociados, en diferentes grados, a humedales. Las cinco especies se reproducen principalmente en el cono sur del continente (ver excepciones más adelante), y para todas se ha reportado algún tipo de movimiento estacional (Olrog 1979, Ridgely \& Tudor 1989, Mazar Barnett \& Pearman 2001, Fitzpatrick 2004, Ábalos \& Areta 2009).

El Doradito Copetón (Pseudocolopteryx sclateri) habita humedales con abundante vegetación herbácea y terrenos altos cercanos al agua (Di Giácomo 2005), y en pajonales y esteros (Hilty 2003, Bostwick 2004). Se distribuye en las cuencas de los ríos Paraná y Uruguay en Argentina y Paraguay, el sur y sureste de Brasil, y en los llanos de este en Bolivia. Además, cuenta con registros aislados en el Pantanal Boliviano, extremo norte del Cerrado brasilero, Guyana, Guyana Francesa, Venezuela y Trinidad (Ridgely \& Tudor 1989, Hilty 1999, Bostwick 2004, Claessens 2015, Herzog et al. 2016). Es considerado residente en el este de Formosa (Di Giácomo 2005), noreste de Buenos Aires (Pagano et al 2013), en Paraguay (Hayes 1995) o en toda su distribución (Bostwick 2004), y en Venezuela y la isla de Trinidad se lo registró en todas las temporadas pero en años diferentes y salteados (Hilty 1999, ffrench 2012). Es considerado migratorio por Short (1975) y migrante austral por Chesser (1997). La biología reproductiva de la especie es muy poco conocida (Fitzpatrick 2004), con pocos nidos estudiados. En Argentina (la porción más austral de su distribución) cuenta datos de nidificación desde noviembre a fines de marzo (Holland \& Sclater 1896, Hartert \& Venturi 1909, De la Peña 1987, Di Giacomo 1992, Di Giacomo 2005). Además se ha fotografiado una nidada exitosa en Espírito Santo, costa de Brasil entre los meses de julio y agosto (Días 2014). En la isla de Trinidad fueron colectados dos ejemplares en "condiciones de cría" en Junio de 1928 y Julio de 1931 (Belcher 
\& Smooker 1937) y entre el 24 de Julio y el 18 de Septiembre de 2010 se observaron 3 parejas nidificando (D. Smith y M. Kenefick in litt.). En Venezuela se observaron volantones en octubre, juveniles en enero, febrero y julio, y subadultos en septiembre en años alternos (Hilty 1999, 2003).

El Doradito Oliváceo ( $P$. acutipennis) habita humedales arbustivos, juncales, pastizales húmedos y hábitats agrícolas (Bostwick 2004, Ridgely \& Tudor 1989, Roesler 2009). Se distribuye en la zona andina con registros dispersos desde Colombia hasta el norte de Argentina entre los 850-3500 msnm, y las Serranías Centrales argentinas, llegando a tierras bajas del Chaco húmedo de Paraguay y las Pampas de Argentina (Fjeldsa \& Krabbe 1990, Bostwick 2004, Schulenberg et al. 2007, Ridgely \& Tudor 1989, Navas 2002, Roesler 2009, Hayes et al. 1994, Smith et al. 2014). Las poblaciones de Argentina (límite sur de la distribución) nidifican entre mediados de diciembre y finales de febrero, con pichones dependientes hasta marzo y la especie deja de registrarse en Argentina aproximadamente a partir del mes de abril (Navas 2002, Roesler 2009). En Paraguay hay menciones de nidificación no confirmadas y sin documentación que las respalde (Guyra Paraguay 2005). Los individuos registrados en las tierras bajas de Bolivia y Perú son considerados migrantes post reproductivos (Chesser 1997, Fjeldsa \& Krabbe 1990, Schulenberg et al. 2007, Herzog et al. 2016), mientras que en Ecuador y Colombia es considerado un nidificante muy local y raro sin reconocerse movimientos estacionales (Ridgely \& Greenfield 2001). En los últimos años se ha registrado a la especie en Brasil en el Pantanal, humedales del centro-oeste amazónico y la costa sur. Estos registros fueron interpretados como individuos migrantes australes (latitudinales) o altitudinales (Whittaker 2004, de Vasconcelos et al. 2008, Capllonch et al. 2009, Guilherma 2012, Bornschein et al. 2017).

El Doradito Pardo ( $P$. dinelliana) habita arbustales y vegetación herbácea cercana a cuerpos de agua (Fitzpatrick 2004). Se distribuye desde el noreste de Córdoba en Argentina hacia el norte hasta el sur de Bolivia y Paraguay. Se considera que el área de cría está restringida al centro-norte de Argentina en la región chaqueña (Short 1975, Chesser 1997, BirdLife 2014), llegando a la provincia de Formosa en Argentina, Paraguay y Bolivia en el invierno como un migrante parcial (Hayes et al. 1994, Hayes 1995, Guyrá Paraguay 2004, Di Giácomo 2005, Herzog et al. 2016).

El Doradito Común ( $P$. flaviventris) y el Doradito Limón $(P$. citreola) eran considerados como parte de una misma especie hasta 2009 , cuando fueron separados por sus diferencias en vocalizaciones, comportamiento y uso de hábitat (Ábalos \& Areta 2009). Al ser especies crípticas, sólo son identificables a través del canto. Es por eso que las distribuciones de ambas especies guardan un alto grado de incertidumbre, ya que no hay actualmente forma de 
establecer si los registros bibliográficos anteriores al 2009-2010 o especímenes de museo identificados como $P$. flaviventris pertenecen efectivamente esta especie o si se trata de $P$. citreola. En términos generales se puede afirmar que en época estival $P$. citreola habita el sur oeste de Argentina y centro de Chile, mientras que $P$. flaviventris lo hace en las Pampas de Argentina (Ábalos \& Areta 2009). Así podemos decir que P. flaviventris habita esteros con juncales, pajonales circundantes a humedales, y campos altos con espartillos cercanos al agua (Bostwick 2004, Di Giácomo 2005, Pagano et al. 2013) en el centro este de Argentina, Uruguay y sudeste de Brasil. Considerado parcialmente migratorio por Short (1975), y migrante austral por Chesser (1994). En Paraguay es considerado migrante (Hayes et al. 1994, Hayes 1995, Guyrá Paraguay 2004) y en el este de Formosa migrante austral parcial (López Lanús 1997, Di Giácomo 2005). En el sur de su distribución (provincia de Buenos Aires) es considerado como migrante austral (Pagano et al. 2013, Cardoni et al. 2016) y la costa atlántica del sur de Brasil es el único área confirmada de invernada (Repenning \& Fontana 2009). Nidifica entre Septiembre y Febrero (Pagano et al. 2013, Cardoni et al. 2016, Di Giácomo 2005).

El Doradito Limón ( $P$. citreola) tiene registros estivales desde el noroeste de Chubut, oeste de Rio Negro, Neuquén, oeste de Mendoza, San Juan y La Rioja en Argentina y centro de Chile (Reed 1877, Housse 1947, Johnson 1967, Coconier et al. 2007, Ábalos \& Areta 2009). Es claramente migratorio en Mendoza (Wetmore 1926, Ábalos \& Areta 2009) y Chile (Reed 1877, Housse 1947, Johnson 1967), y aunque no se conoce su zona de invernada con certeza, se ha indicado a Bolivia como probable sitio de visita invernal (Ábalos \& Areta 2009). Además existen tres localidades con registros documentados aislados: en septiembre en el río Caraparí, norte de Salta (Coconier et al. 2007), en septiembre sobre el río Paraná en Santa Fé (Leiva \& Bierig 2014) y otro sobre el río Uruguay en Entre Ríos para el mes de noviembre (López-Lanús et al. 2010).

\section{Materiales y Métodos}

\section{DATOS DE PRESENCIA}

Se compilaron localidades con registros de las cinco especies de Pseudocolopteryx de cuatro fuentes: 1) Base de datos de Internet (eBird y Macaulay Library of Natural Sounds, Cornell Lab of Ornithology, Ithaca, New York, USA; Xeno-canto, www.xeno-canto.org; y Ecoregistros, www.ecoregistros.org), 2) publicaciones en revistas indexadas y literatura gris, 3) datos de etiquetas de especímenes de museo examinados u obtenidos de bases de datos en línea, y 4) muestreos propios. En los casos en que el registro original no contaba con coordenadas geográficas, las mismas se obtuvieron de la serie "Ornithological Gazetteer" (Stephen \& 
Traylor 1983; Paynter 1992, 1995; Paynter \& Traylor 1991) o de Google Earth 7.1. Se recopilaron un total de 3843 registros crudos para todas las estaciones del año. Con el propósito de analizar las aéreas reproductivas y no reproductivas por separado, los registros fueron agrupados en dos sets de datos según categorías estacionales determinadas a priori en función de datos de la literatura y de nuestro conocimiento de las especies. La mayoría de los registros de nidificación de $P$. sclateri (en el bloque sur de su distribución), $P$. dinelliana, $P$. citreola y $P$. flaviventris se encuentran entre los meses de noviembre y enero; en cambio las fechas de nidificación son más tardías en $P$. acutipennis: cría principalmente entre diciembre y marzo (ver Introducción). Así, para P. sclateri, P. dinelliana, P. flaviventris y P. citreola en la categoría "época reproductiva" se incluyeron los meses de noviembre, diciembre, enero y febrero, y en la categoría "época no-reproductiva" se agruparon los registros de mayo, junio, julio y agosto. Cada categoría quedó separada de la otra por dos meses "intermedios" (marzoabril y septiembre-octubre). Para $P$. acutipennis las categorías fueron distintas: "época reproductiva" (diciembre, enero, febrero y marzo), "época no-reproductiva" (junio, julio, agosto y septiembre) y meses "intermedios" (abril-mayo y octubre-noviembre). Los registros de los meses "intermedios" no fueron parte del análisis para ninguna de las especies ya que representarían meses de migración y/o cierto grado de superposición entre las épocas reproductiva y no reproductiva

Para evitar un posible sesgo geográfico de muestreo en los resultados de los modelos, se quitaron del análisis los registros que estaban más densamente concentrados, de modo tal que ninguna localidad estuviera a menos de $3 \mathrm{~km}$ de distancia de cualquier otra. Si bien este método puede subestimar la contribución de áreas idóneas donde la alta densidad es el verdadero reflejo de una elección de nicho, ha sido demostrado que es el mejor método de corrección de sesgo geográfico (Fourcade et al 2014). Los registros que en un principio resultaron dudosos (i. e. registros que dada la localidad y la fecha, pueden llevar a una identificación incorrecta), fueron considerados válidos cuando estaban acompañados de documentación o cuando el autor del registro aportó descripciones tales que permitieron una identificación inequívoca.

Validar los registros de las especies crípticas $P$. flaviventris y $P$. citreola acarrea varios inconvenientes, ya que la única manera de identificarlos con certeza es a partir de sus voces. Dado que el taxon citreola fue revalidado como especie plena en 2009 (Ábalos \& Areta 2009), hay escasos especímenes de museo etiquetados como $P$. citreola, y los especímenes etiquetados como $P$. flaviventris contienen típicamente a ambos taxones. Algo similar ocurre con los registros obtenidos de bases de datos de internet que no están acompañados de grabaciones sonoras o descripciones del canto: la asignación a cualquiera de las dos especies 
puede ser puesta en duda. Para poder utilizar estos datos, asignamos cada registro a una especie en función de su distribución y estacionalidad en zonas donde hemos comprobado la presencia exclusiva de $P$. citreola o de $P$. flaviventris. Esto es, los registros de la época reproductiva sin documentación del oeste y sur (provincias argentinas de San Juan, Salta, Mendoza, Río Negro, Neuquén y Chubut, y todo Chile) fueron asignados a P. citreola, ya que en esa zona existen registros documentados sólo para esa especie. Del mismo modo, los registros de época reproductiva sin documentación del centro-este (provincias argentinas de Buenos Aires, Entre Ríos, Corrientes, Chaco, más Brasil y Uruguay) fueron asignados a $P$. flaviventris. Hay zonas donde existen registros documentados de las dos especies (e.g. sureste de Córdoba), y por lo tanto no se puede aplicar el criterio anterior. En estas zonas los registros que no estaban acompañados de documentación, no se tuvieron en cuenta para los análisis.

Este criterio de asignación no es válido en época no-reproductiva, ya que la distribuciones de $P$. flaviventris y $P$. citreola permanecen desconocidas en esta época del año. De hecho, no existe ningún registro documentado publicado de $P$. citreola en invierno, y para $P$. flaviventris sólo encontramos 5 registros invernales documentados. Entonces, para la época no-reproductiva agrupamos por un lado los registros no documentados asignados a $P$. flaviventris y $P$. citreola en un único set de datos, y por el otro se hizo un set de datos con los 5 registros documentados de $P$. flaviventris en época no-reproductiva.

En resumen, luego del proceso de reagrupamiento y validación de datos, se obtuvieron 834 localidades con registros para todas las especies, con los que se elaboraron 10 sets de datos: dos de $P$. sclateri (época reproductiva y no-reproductiva), dos para $P$. acutipennis (época reproductiva y no-reproductiva), dos de $P$. dinelliana (época reproductiva y no-reproductiva), dos de $P$. flaviventris (época reproductiva y no-reproductiva), uno de $P$. citreola (solo época reproductiva) y uno para $P$. flaviventris/citreola (solo época no-reproductiva).

\section{Modelos de Nicho ECológico (MNE) y de Distribución Potencial (MDP)}

Se modeló la distribución estacional de las especies de Pseudocolopteryx en base a los 10 sets de datos de presencia utilizando MaxEnt 3.3.3k, configurado con 500 iteraciones, 0.00001 umbral de convergencia, 10.000 max. puntos de fondo, y las 5 clases de función automática (Phillips et al. 2006). El programa retuvo aleatoriamente el $25 \%$ de las localidades de presencia para poner a prueba el rendimiento del modelo. Para cada categoría estacional primero se corrió un modelo en MaxEnt usando 19 variables bioclimáticas de un conjunto de capas climáticas sudamericanas de WorlClim (www.worldclim.org) a una resolución de 2.5 arc-min.

Se evaluó la capacidad predictiva de estas 19 variables usando el test jackknife de importancia de variables (con datos de entrenamiento y de prueba). Este test permite 
identificar cuáles variables contribuyen en mayor grado de manera individual, al comparar la ganancia de cada variable de manera independiente contra la ganancia obtenida por la variable si es corrida con todas las demás variables juntas (Phillips et. al., 2006). Se eliminaron las variables que mostraron valores de ganancia bajos (cercanos a 0 ) o negativos para los datos de entrenamiento (ver Tabla 1). Los valores bajos de ganancia indican que las variables no tienen información útil por sí solas para estimar la distribución, mientras que las ganancias negativas indican que las variables hacen que el modelo sea menos transferible a otras áreas o condiciones (Phillips et al. 2006). Habiendo removido estas variables, se corrió un modelo final para cada categoría estacional y cada especie usando solo las variables informativas.

Tabla 1. Variables bioclimáticas de WorldClim utilizadas (X) para correr los MNE finales de Pseudocolopteryx spp

\begin{tabular}{|c|c|c|c|c|c|c|c|c|c|c|}
\hline \multirow[b]{2}{*}{$\begin{array}{c}\text { Variable } \\
\text { bioclimática }\end{array}$} & \multicolumn{2}{|c|}{ P. sclateri } & \multicolumn{2}{|c|}{ P. acutipennis } & \multicolumn{2}{|c|}{ P. dinelliana } & \multicolumn{2}{|c|}{ P. flaviventris } & \multirow{2}{*}{$\begin{array}{c}\text { P. citreola } \\
\text { cría }\end{array}$} & \multirow{2}{*}{$\begin{array}{c}\text { P. flaviventris/citreola } \\
\text { no-cría }\end{array}$} \\
\hline & cría & $\begin{array}{l}\text { no- } \\
\text { cría }\end{array}$ & cría & $\begin{array}{l}\text { no- } \\
\text { cría }\end{array}$ & cría & $\begin{array}{l}\text { no- } \\
\text { cría }\end{array}$ & cría & $\begin{array}{l}\text { no- } \\
\text { cría }\end{array}$ & & \\
\hline bio_1 & $x$ & $\mathrm{x}$ & $x$ & & $x$ & $\mathrm{x}$ & $x$ & & $x$ & $x$ \\
\hline bio_2 & & & $\mathrm{x}$ & & $\mathrm{x}$ & $x$ & & $\mathrm{x}$ & $x$ & \\
\hline bio_3 & $x$ & $x$ & $x$ & & $x$ & $x$ & $x$ & $\mathrm{x}$ & $x$ & $x$ \\
\hline bio_4 & $x$ & $x$ & $x$ & $x$ & $x$ & $x$ & $x$ & $x$ & $\mathrm{x}$ & $x$ \\
\hline bio_5 & $x$ & & & & & $x$ & $x$ & & $x$ & \\
\hline bio_6 & $\mathrm{x}$ & $\mathrm{x}$ & $x$ & $x$ & $\mathrm{x}$ & $x$ & $x$ & & $x$ & $x$ \\
\hline bio_7 & $\mathrm{x}$ & $x$ & $x$ & $\mathrm{x}$ & $\mathrm{x}$ & $x$ & $x$ & & $x$ & $x$ \\
\hline bio_8 & & & $\mathrm{x}$ & $\mathrm{x}$ & & $\mathrm{x}$ & $\mathrm{x}$ & & $x$ & \\
\hline bio_9 & $\mathrm{x}$ & $x$ & $x$ & $x$ & $x$ & $x$ & $\mathrm{x}$ & & $x$ & $x$ \\
\hline bio_10 & & & $x$ & & & $x$ & $x$ & & $\mathrm{x}$ & $x$ \\
\hline bio_11 & $\mathrm{x}$ & $x$ & $x$ & $x$ & $x$ & $x$ & $x$ & $x$ & $x$ & $x$ \\
\hline bio_12 & $\mathrm{x}$ & $\mathrm{x}$ & $\mathrm{x}$ & $x$ & $\mathrm{x}$ & $x$ & $x$ & & $x$ & $x$ \\
\hline bio_13 & $\mathrm{x}$ & $\mathrm{x}$ & $\mathrm{x}$ & $\mathrm{x}$ & $\mathrm{x}$ & $\mathrm{x}$ & $\mathrm{x}$ & & $x$ & $\mathrm{x}$ \\
\hline bio_14 & $x$ & $x$ & & $x$ & $x$ & & $x$ & $x$ & $x$ & $x$ \\
\hline bio_15 & $x$ & $x$ & & $x$ & & & $x$ & $x$ & & $x$ \\
\hline bio_16 & $x$ & $x$ & $x$ & $x$ & $x$ & $x$ & $x$ & & $x$ & $x$ \\
\hline bio_17 & $x$ & $x$ & & $x$ & $x$ & & $x$ & $x$ & $x$ & $x$ \\
\hline bio_18 & $x$ & $x$ & $x$ & $x$ & $x$ & $x$ & $x$ & $x$ & $x$ & $x$ \\
\hline bio_19 & $x$ & $x$ & $x$ & $x$ & $x$ & $x$ & $x$ & $x$ & & $x$ \\
\hline
\end{tabular}

Se evaluó el desempeño del modelo final usando el área bajo la curva (AUC; Fielding \& Bell 1997). Mientras que un AUC = 1 indica que el modelo discrimina con precisión entre áreas con presencia y sin ella, un $A U C=0.5$ indica que el modelo predice tanto como un modelo aleatorio y un AUC $<0$ indica que la capacidad predictiva del modelo es peor que aleatoria (Elith et al. 2006). Los valores de AUC fueron interpretados usando la clasificación de Pearce y Ferrier (2000): excelente $A U C>0.90$; razonable $0.70<A U C<0.90$; y pobre $0.50<A U C<0.70$. Se utilizó la salida logística, que representa la idoneidad de hábitat potencial en una escala de 0 a 
1 , donde los valores más altos representan condiciones más favorables para la presencia de la especie (Phillips et al. 2006). Para determinar el límite o "cutoff" entre valores de hábitat idóneos y no idóneos, se usó el umbral "Equal training sensitivity and specificity" (ETSS) que iguala la sensibilidad y especificidad. En este caso la sensibilidad es la proporción de las presencias correctamente predichas entre todas las presencias, y la especificidad es la proporción de ausencias correctamente predichas entre todas las ausencias (Liu et al. 2013). Para la representación gráfica de los MDP en los mapas finales, se dividieron los valores de idoneidad de hábitat en cuatro clases discretas de intervalos iguales, restando el valor más bajo (indicado por el umbral ETSS) al valor más alto de la predicción establecido por el modelo, y dividiendo el resultado por 4 . Se compararon los MDP finales de cada especie con las distribuciones conocidas según BirdLife (2014) y con las localidades utilizadas para los análisis.

\section{GRADO DE SUPERPOSICIÓN EN EL ESPACIO DE NICHO BIOCLIMÁTICO}

En un primer paso, se midió la similitud de nicho entre las predicciones de idoneidad de hábitat sólo en la época reproductiva entre todos los pares de las cinco especies de Pseudocolopteryx calculando el índice D de Schoener y Gorman (1968) y siguiendo la metodología propuesta por Warren et al. (2008). El índice D de Schoener cuantifica la similitud de nicho a partir de las distribuciones de probabilidad definidas sobre el espacio geográfico, donde $\mathrm{P} x, i(\mathrm{o} P y, i)$ es la probabilidad asignada por el MNE para la especie X (o Y) a la celda $i$.

$$
D(P x, P y)=1-\frac{1}{2} \sum_{i}|P x, i-P y, i|
$$

Los valores de similitud $\mathrm{D}$ varían entre 0 (los modelos no tienen solapamiento) y 1 (los modelos muestran solapamiento total de nicho). Este índice fue calculado para todos los pares de las cinco especies de Doraditos.

Luego se llevó a cabo una prueba de identidad de nicho (niche identity test) entre todos los pares de especies, en la cual se pone a prueba si los valores de idoneidad de hábitat generados por los MNE para las distribuciones en época reproductiva de dos especies muestran diferencias ecológicas significativas (Warren et al. 2008). Para eso, se agrupan los datos de ocurrencia de dos especies y se crean dos nuevos conjuntos de datos pseudoreplicados del mismo tamaño que los originales particionando aleatoriamente los datos originales. Luego se corre un MNE para cada nuevo conjunto de datos y se calcula un valor de similitud D' esperado. Este proceso se repite 100 veces para generar una distribución nula de valores de similitud $D^{\prime}$ esperados. Finalmente los valores de similitud D observados para cada 
par de especies (calculados en el primer paso) fueron comparados con la distribución nula de valores $D^{\prime}$ esperados, a través de una prueba a una cola con un alfa de 0,05 . Si el valor D observado cae fuera del $95 \%$ de la distribución nula de valores de $D^{\prime}$, entonces se infiere que los MNE de las dos especies no son equivalentes.

Por último, se realizó una prueba de similitud ambiental (background similarity test) donde se pone a prueba si las similitudes o diferencias del nicho bioclimático observado entre especies pueden ser explicadas por similitudes o diferencias regionales en los hábitats disponibles para cada especie, o si por el contrario esas diferencias observadas representan verdaderas diferencias en las preferencias de hábitat de las especies. Para eso se evalúa si el MNE de una especie es capaz de predecir la ocurrencia de otra especie mejor que lo esperado por el azar (Warren et al 2008, 2010). A diferencia de la prueba de identidad de nicho, esta prueba compara el valor de superposición de nicho $D$ observado entre las especie $A$ y $B$ versus el valor de superposición $D^{\prime}$ que se obtuvo de la comparación de los MNE de la especie A versus un MNE generado a partir de las variables bioclimáticas tomadas de puntos aleatorios dentro del rango de distribución de la especie B (background ambiental). Este análisis se repite 100 veces en ambas direcciones (de la especie $A$ a la especie $B, y$ viceversa) para construir una distribución nula de los valores de $\mathrm{D}^{\prime}$ esperados. Los rangos de distribución de cada especie se definieron a partir de las mismas localidades que fueron utilizadas para desarrollar los MNE en la época reproductiva, pero sin tener en cuenta aquellas que quedaron fuera de los límites de idoneidad impuestos por el umbral en los MNE. Se construyó un buffer de $45 \mathrm{~km}$ de radio alrededor de cada localidad y luego se definieron los polígonos convexos uniendo los bordes de los buffers para generar una capa vectorial (modificado de Warren et al. 2010) (Fig. 1). 


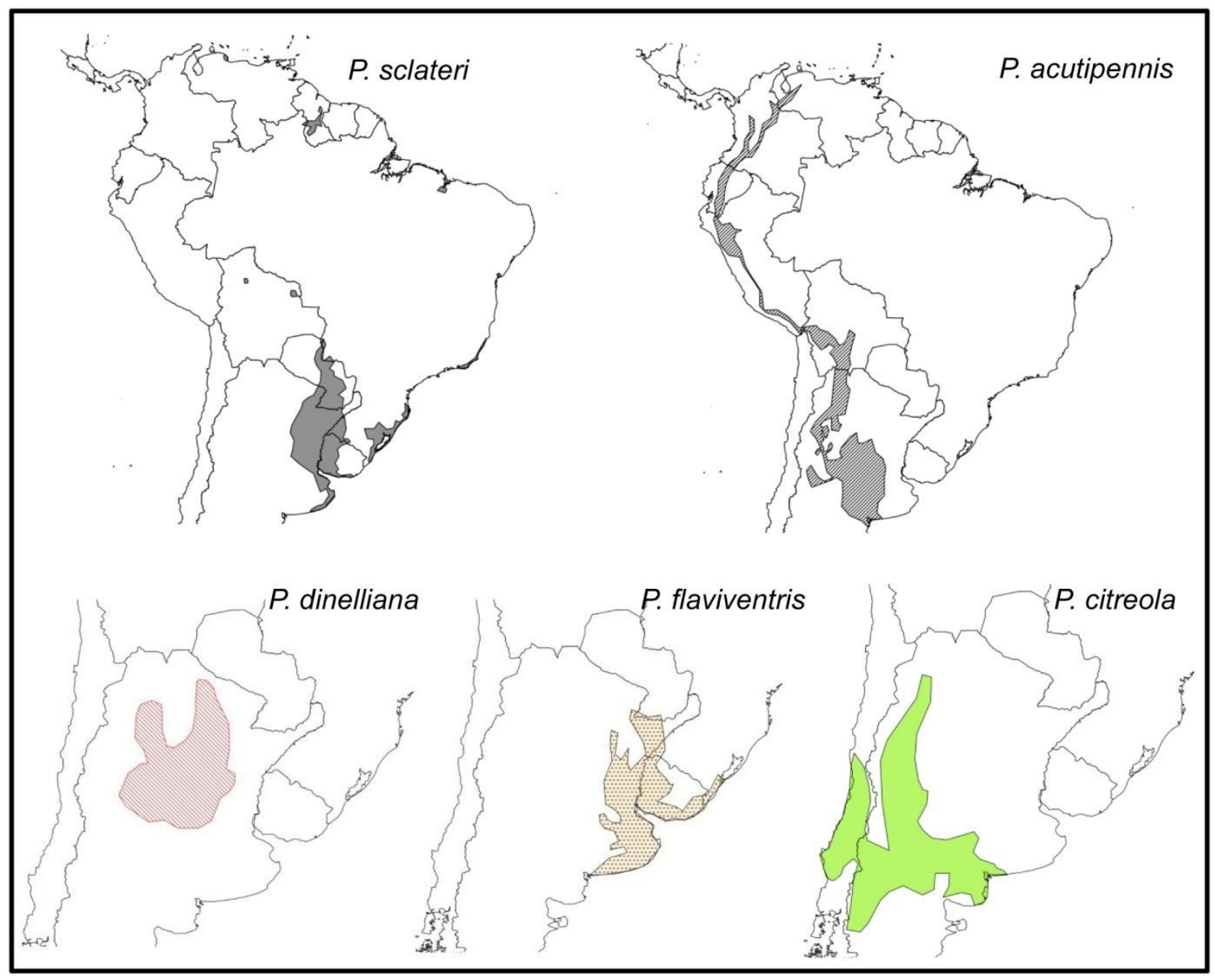

FIG 1. Rangos de distribución en época reproductiva de cada especie de Pseudocolopteryx utilizados para generar los backgrounds ambientales para las pruebas de similitud ambiental, y para calcular la superposición geográfica.

La hipótesis nula en la prueba de similitud ambiental es que el grado de superposición de nicho entre especies es explicada por diferencias o similitudes en el hábitat disponible. Aplicando una prueba a dos colas con un alfa de 0,05, la hipótesis nula es rechazada cuando la similitud D observada entre especies cae por fuera del 95\% del límite de confianza. En el caso de que el valor D observado caiga dentro del 95\% del límite de confianza, se apoya la hipótesis nula. Si la prueba es significativa en una dirección pero no en otra (i.e. es significativa sólo para la especie A contra el background de la especie B, pero no para la especie B contra el background de la Especie A), se adoptó una interpretación conservadora y este resultado fue considerado como apoyo a la hipótesis nula. Los tres análisis se desarrollaron con el programa ENMtools versión 1.4.4 (Warren et al. 2010). 


\section{GRADO DE SUPERPOSICIÓN EN EL ESPACIO GEOGRÁFICO}

Se calculó el grado de superposición en la distribución geográfica entre todos los pares de especies de doraditos. Para eso se tomaron los mismos polígonos vectoriales utilizados como backgrounds en las pruebas de similitud ambiental de cada especie, y se midió la superficie intersectada entre ellos. El grado de superposición geográfica (GSG) entre dos especies se calculó de dos maneras recíprocas: como la relación entre el área de superposición y el área de la más pequeña de las dos distribuciones (GSGp), y como la relación entre el área de superposición y el área de la más extensa de las dos distribuciones (GSGe). Un valor de GSGp o GSGe igual a 0 indica que las distribuciones no se solapan, mientras que un valor GSGp o GSGe cercano a 1 significa un alto grado de solapamiento geográfico. Un GSGp igual a 1 significa que una de las especies está incluida por completo dentro de la distribución de la otra, mientras que por supuesto, no es posible un GSGe igual a 1 (tomado y modificado de Barraclough \& Vogler 2000).

$$
\begin{aligned}
& \text { GSGp }=\frac{\text { área de superposición }}{\text { área de la especie con menor rango de distribución }} \\
& G S G e=\frac{\text { área de superposición }}{\text { área de la especie con mayor rango de distribución }}
\end{aligned}
$$

\section{DISTANCIA GENÉTICA Y SUPERPOSICIÓN EN EL ESPACIO GEOGRÁFICO Y DE NICHO}

Se integró la información de solapamiento geográfico y de nicho con información filogenética para evaluar de qué manera operaron estos dos procesos en la especiación de Pseudocolopteryx. Bajo un escenario de especiación alopátrica, se espera que la superposición en la distribución aumente en tanto aumenta la distancia genética. Lo opuesto se espera en la especiación simpátrica (Fig. 2). La distancia genética puede ser estimada como una variable cuantitativa (distancia genética interespecífica) o como una variable nominal (nivel o posición del nodo) la cual puede estar asociada a una medida temporal (Berlocher \& Feder 2002). La tendencia de las especies a conservar aspectos de su nicho fundamental en el tiempo se llama conservadurismo de nicho (Wiens \& Graham 2005). Si la superposición en el espacio de nicho aumenta en tanto disminuye la distancia genética (o el nivel del nodo), se interpreta que el conservadurismo de nicho es la regla. Por lo contrario, si la superposición de nicho aumenta en tanto aumenta la distancia genética, el conservadurismo de nicho no sería un factor importante en la evolución del grupo (Warren et al. 2008). 
Alopatría

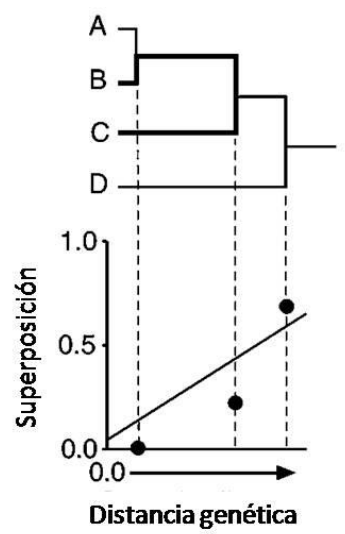

Simpatría

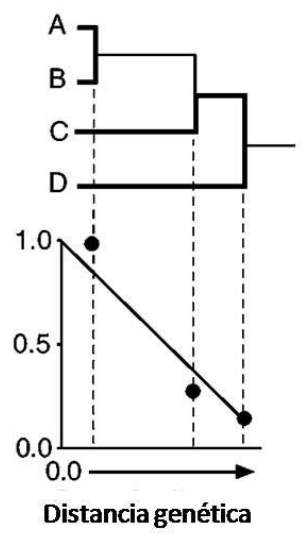

Figura 2. En la especiación alopátrica, las distribuciones de las especies hermanas comienzan en alopatría, y el cambio de distribución post-especiacional da como resultado un aumento de la simpatría en el tiempo. En la especiación simpátrica, las distribuciones de especies hermanas empiezan en simpatría total, y el cambio de distribución post-especiacional da lugar a unadisminución de la simpatría en el tiempo. Tomado de Berlocher y Feder (2002).

Primero se analizó el grado de superposición geográfica (GSGp) entre pares de especies en relación con la divergencia genética (Berlocher \& Feder2002).Este análisis se repitió utilizando grado de superposición de nicho (D). Para ambos casos, se calculó la divergencia genética media no-corregida ( $p$-distance) de todos los pares de especies mediante el programa MEGA7 versión 7.0.14 (Kumar et al. 2017) utilizando los datos de ADN mitocondrial obtenidos según lo explicado en el Capítulo 1.

También se implementó una metodología que toma en cuenta las distribuciones ancestrales. Estimar las distribuciones ancestrales mediante la unión de las distribuciones actuales ha sido criticado por ser una reconstrucción poco realista y limitada (Chesser \& Zink 1994), por eso utilizamos el cálculo de promedios anidados en las superposiciones geográficas entre especies (Fitzpatrick \& Turelli 2006). Esta metodología provee para cada nodo de la filogenia una estima de la superposición geográfica ancestral teniendo en cuenta la posición relativa de tal nodo. El cálculo del promedio anidado de cada nodo se puede expresar de forma compacta como sigue. Supongamos que el nodo i separa clados C1 y C2, cuantificamos la superposición media (ö) en el nodo $i$ por:

$$
\ddot{\mathrm{o}}_{\mathrm{i}}=\sum_{j \in C 1} \sum_{\mathrm{k} \in \mathrm{C} 2}\left(\frac{1}{2}\right)^{\mathrm{n}_{\mathrm{j}}-1} \mathrm{o}_{\mathrm{jk}}
$$

donde la suma doble es sobre todas las especies en los dos clados, $\mathrm{o}_{\mathrm{jk}}$ denota la superposición entre las especies $j$ y $k, y n_{j k}$ es el número de nodos que separan las dos especies en el árbol. 
Estos valores de superposición anidados se calcularon en base a la filogenia construida en el Capítulo 1.

Para este análisis se utilizó el grado de superposición geográfica que denominamos GSGp (ver apartado "Grado de superposición en el espacio geográfico").

Además, se hizo un análisis similar donde se calculó, del mismo modo que con las distribuciones geográficas (GSGp), el promedio anidado de la superposición de nicho (D de Schoener). Éste, al igual que la distribución en el espacio geográfico, pretende ser una estima del nicho ecológico en cada nodo de la filogenia (Warren et al. 2008).

\section{Resultados}

\section{MODELOS DE NICHO ECOLÓGICO Y DE DISTRIBUCIÓN POTENCIAL}

Todos los modelos de distribución potencial fueron capaces de discriminar las áreas de presencia y ausencia (Figs. 2 a 6) tanto para los datos de entrenamiento como para los de prueba con un buen rendimiento (Tabla 2).

Tabla 2. Valores de desempeño y de umbrales para cada modelo de distribución potencial basado en nicho. AUCe: área bajo la curva para datos de entrenamiento, AUCp: área bajo la curva de prueba, ETSS: umbral "equal training sensitivity and specifity". R: época reproductiva, NR: época no reproductiva.

\begin{tabular}{|c|c|c|c|c|c|c|c|c|c|c|}
\hline & \multicolumn{2}{|c|}{ P. sclateri } & \multicolumn{2}{|c|}{ P. acutipennis } & \multicolumn{2}{|c|}{ P. dinelliana } & \multicolumn{2}{|c|}{ P. flaviventris } & \multirow{2}{*}{$\begin{array}{c}\text { P. citreola } \\
\mathrm{R}\end{array}$} & \multirow{2}{*}{$\begin{array}{c}\text { P. flaviventris / } \\
\text { P. citreola } \\
\text { NR }\end{array}$} \\
\hline & $\mathrm{R}$ & NR & $\mathrm{R}$ & NR & $\mathrm{R}$ & NR & $\mathrm{R}$ & NR & & \\
\hline AUCe & 0.979 & 0.945 & 0.963 & 0.91 & 0.987 & 0.988 & 0.989 & 0.98 & 0.981 & 0.975 \\
\hline$A \cup C p$ & 0.97 & 0.901 & 0.928 & 0.858 & 0.988 & 0.955 & 0.983 & 0.882 & 0.983 & 0.964 \\
\hline ETSS & 0.204 & 0.15 & 0.225 & 0.314 & 0.286 & 0.342 & 0.141 & 0.482 & 0.132 & 0.139 \\
\hline
\end{tabular}

Pseudocolopteryx sclateri. Para la época reproductiva, el MDP muestra que las áreas de mayor idoneidad están restringidas a las cuencas de los ríos Paraná y Uruguay (especialmente en la región mesopotámica de Argentina), con áreas de baja probabilidad de ocurrencia dispersas sobre la costa atlántica de Brasil y Guyana (Fig. 2A). Fuera de la época reproductiva, el modelo es muy similar aunque muestra una distribución potencial más amplia, en la que las áreas de mayor idoneidad se extienden sobre la cuenca del río Paraguay en la región chaqueña, con zonas de baja idoneidad en las pampas. Además sobre la costa atlántica de Brasil aparecen zonas de alta idoneidad de hábitat (Fig. 2B). Fuera de la Mesopotamia argentina y costa brasilera la especie cuenta con registros dispersos, tanto para verano como para el invierno, en el norte de Bolivia, norte y centro de Brasil, Guyana, Venezuela y la isla de Trinidad. Así como los datos de ocurrencia, los MDP muestran una distribución estacional en la que no se detecta ningún patrón migratorio claro (Fig. 2A-B). 


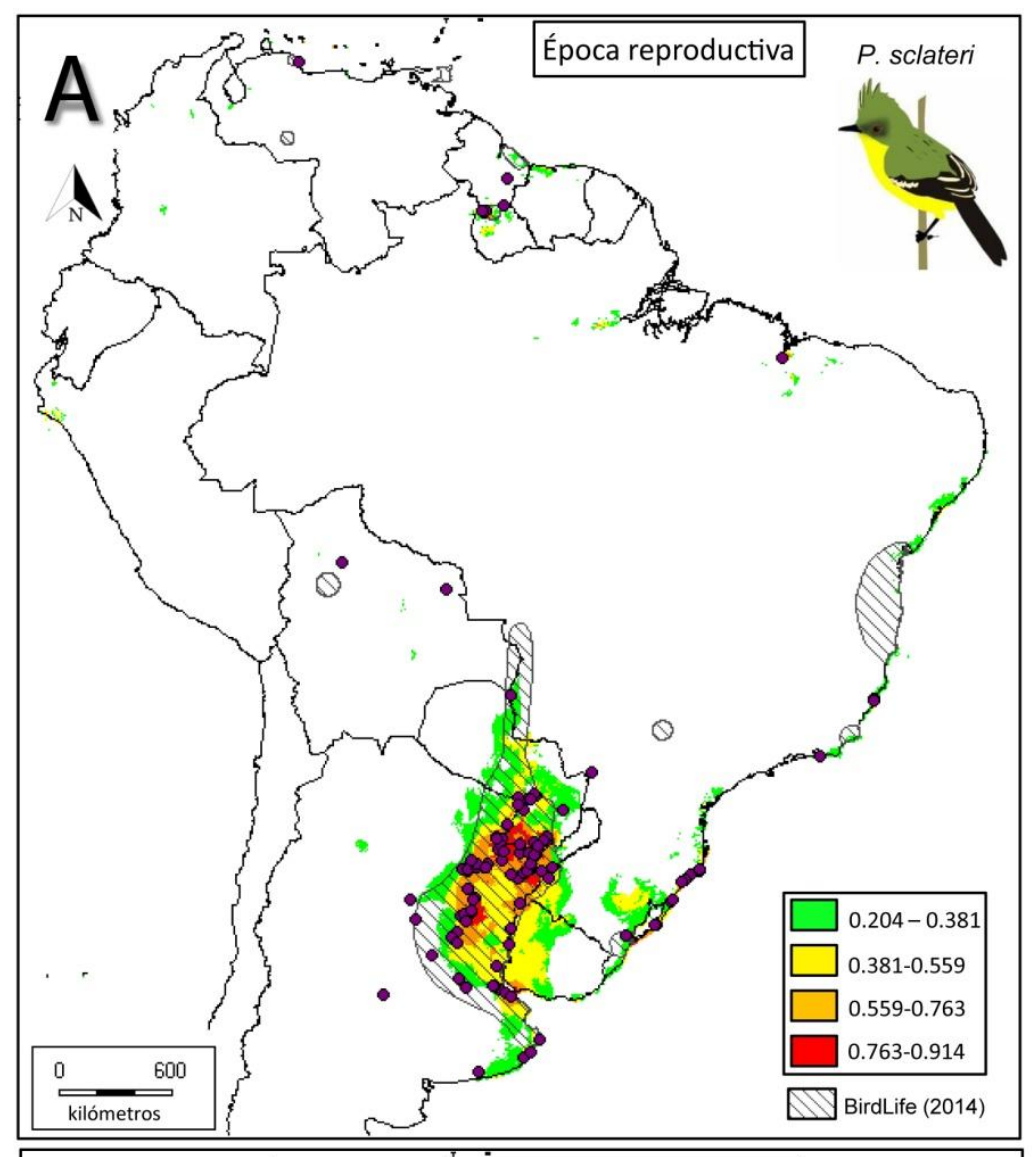

FIGURA 2. Localidades de presencia y distribución potencial estacional de Pseudocolopteryx sclateri. Distribución geográfica de acuerdo a BirdLife 2014 (líneas oblicuas). En el recuadro se muestran los valores de idoneidad de hábitat: el valor menor corresponde al umbral de corte (ETSS) entre áreas idóneas y no idóneas. Los colores mas cálidos indican áreas con mejores condiciones predichas.

A) Época reproductiva. Localidades de presencia usadas para construir el modelo: círculos morados ( $\mathrm{N}=108$ ).

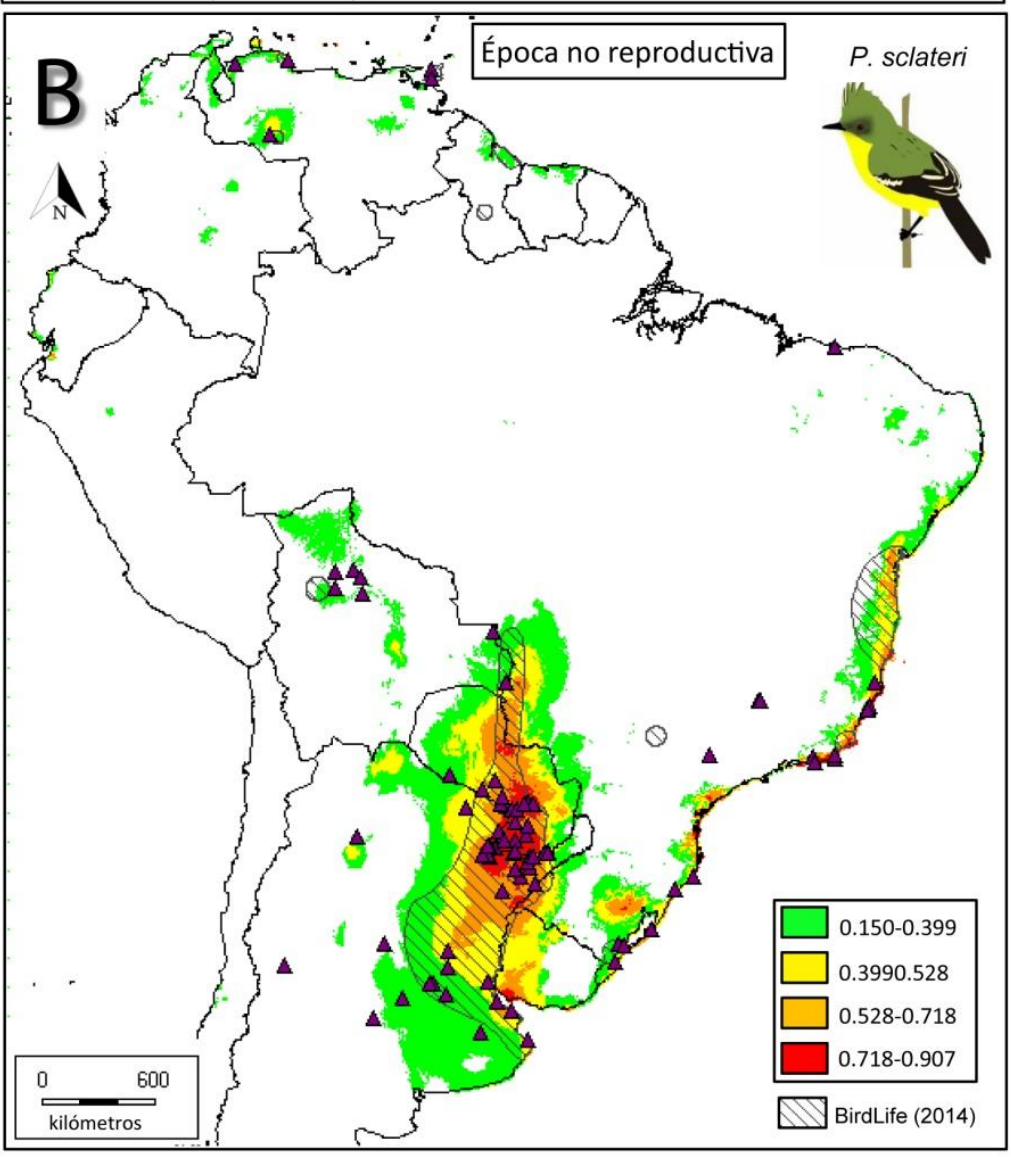

B) Época no-reproductiva. Localidades de presencia usadas para construir el modelo: triángulos morados $(\mathrm{N}=85)$. 
Pseudocolopteryx acutipennis. Para la temporada reproductiva (Fig. 3A), el MDP final indica como idóneas las zonas andinas desde Venezuela hasta el centro de Argentina, más las Serranías Centrales y región Pampeana de Argentina. Gran parte de esta distribución potencial está en relativa buena coincidencia con lo indicado en la bibliografía (BirdLife 2014). El modelo muestra a toda la región pampeana de Argentina como un área idónea para $P$. acutipennis, con los mayores valores de idoneidad en el extremo oeste de esta región, los cuales descienden hacia la costa atlántica. Esto coincide con la distribución de los registros de ocurrencia: la mayoría de ellos se agrupa sobre el oeste, mientras que existe un solo registro en el este pampeano (partido de Lobería, Buenos Aires). Zonas de baja y muy baja probabilidad de presencia aparecen indicadas en la costa marítima sur de Brasil, las cuales se corresponden con tres registros de ocurrencia (Pontal do Paraná, Tramandaí y Mostardas; Bornschein et al. 2017). El MDP de época reproductiva fue incapaz de predecir tres localidades con registros en la Chiquitanía boliviana y el Chaco paraguayo. Sin embargo estos registros se ubican en zonas que el modelo predice como idóneo para la época no reproductiva (ver más adelante).

En el caso de la época no reproductiva (Fig. 3B), el MDP predijo áreas idóneas para $P$. acutipennis en la zona andina desde Venezuela hasta el sur de Perú, y en las zonas bajas desde el centro de Perú hacia el sureste en Bolivia, Paraguay y oeste de Brasil. Las áreas de más alta probabilidad de presencia se ubican en la región biogeográfica del Pantanal paraguayo y brasilero, y la Chiquitanía boliviana. Esta última región coincide con la distribución invernal conocida (BirdLife 2014), mientras que la zona del Pantanal y el Chaco paraguayo aparecen como zonas de invernada antes desconocidas. El modelo predijo tres amplias áreas de baja a muy baja idoneidad en el centro y sureste de Brasil.

Tanto las localidades como los MDP muestran un patrón en el que las poblaciones más australes migran en la época no reproductiva hacia el norte, mientras que las poblaciones del Perú hacia el norte parecen ser residentes anuales. 


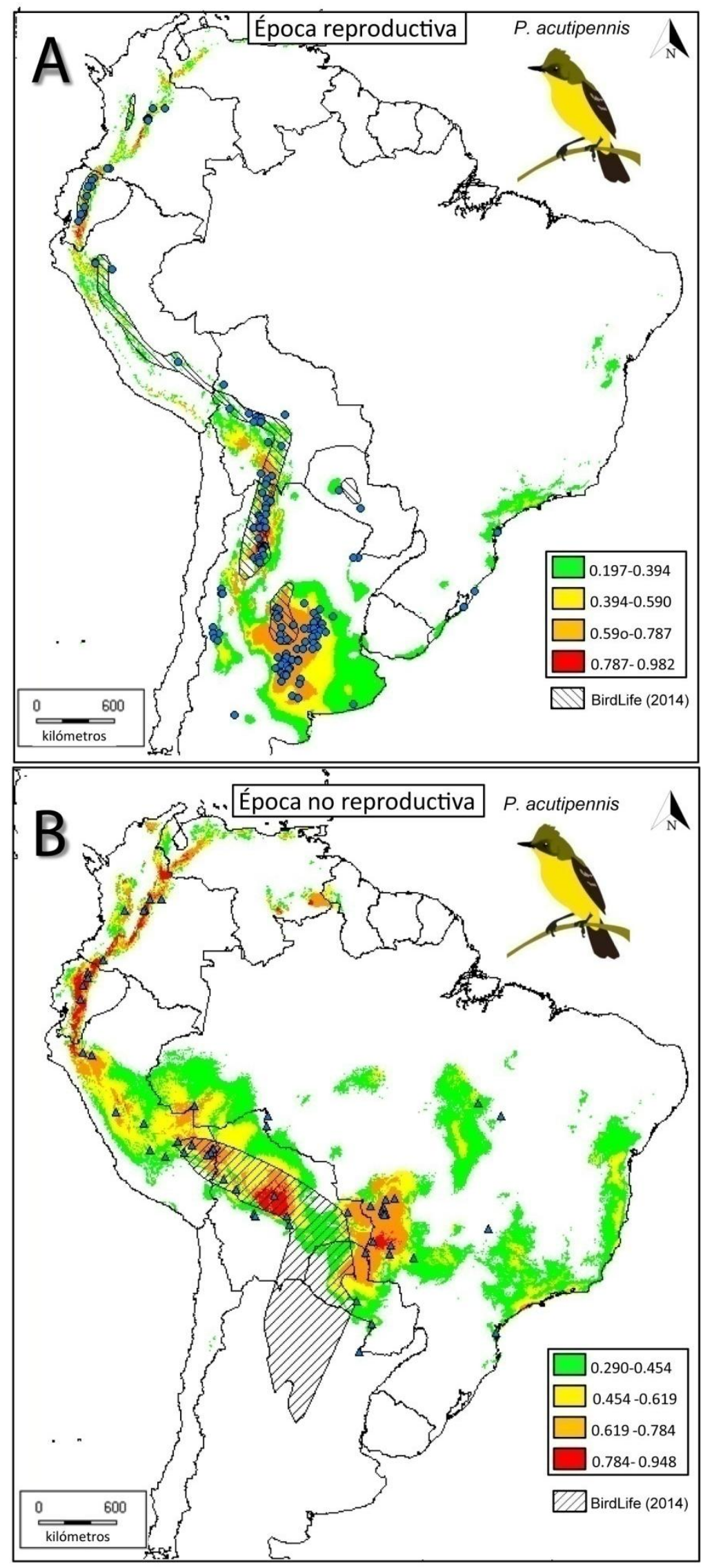

FIgURA 3. Localidades de presencia y distribución potencial estacional de Pseudocolopteryx acutipennis. Distribución geográfica de acuerdo a BirdLife 2014 (líneas oblicuas). En el recuadro se muestran los valores de idoneidad de hábitat: el valor menor corresponde al umbral de corte (ETSS) entre áreas idóneas y no idóneas. Los colores mas cálidos indican áreas con mejores condiciones predichas.

A) Época reproductiva. Localidades de presencia usadas para construir el modelo: círculos azules ( $\mathrm{N}=140$ ).

B) Época no-reproductiva. Localidades de presencia usadas para construir el modelo: triángulos azules ( $\mathrm{N}=59)$. 
Pseudocolopteryx dinelliana. Tanto los análisis de datos de ocurrencia como los MDP muestran una distribución con marcada estacionalidad para la especie (Fig. 4). El modelo estival indica que el área de cría se restringe a la porción más austral de la región Chaqueña y parte del Espinal en Argentina (Fig. 4A), mientras que fuera de la época reproductiva las zonas de más alta idoneidad de hábitat están indicadas en el norte del Chaco de Bolivia, Paraguay y Argentina (Fig. 4B). El modelo se ajustó con contundencia a los datos de ocurrencia, esto es: no mostró importantes sobre- o sub- predicciones (aún cuando el umbral elegido lo permite). Esto puede ser interpretado como un reflejo de la fuerte preferencia (o especialización) de hábitat que $P$. dinelliana muestra en la región Chaqueña. Los datos de presencia y los MDP muestran un área de distribución escasamente más extendida que lo reportado por BirdLife (2014) para ambas estaciones. 

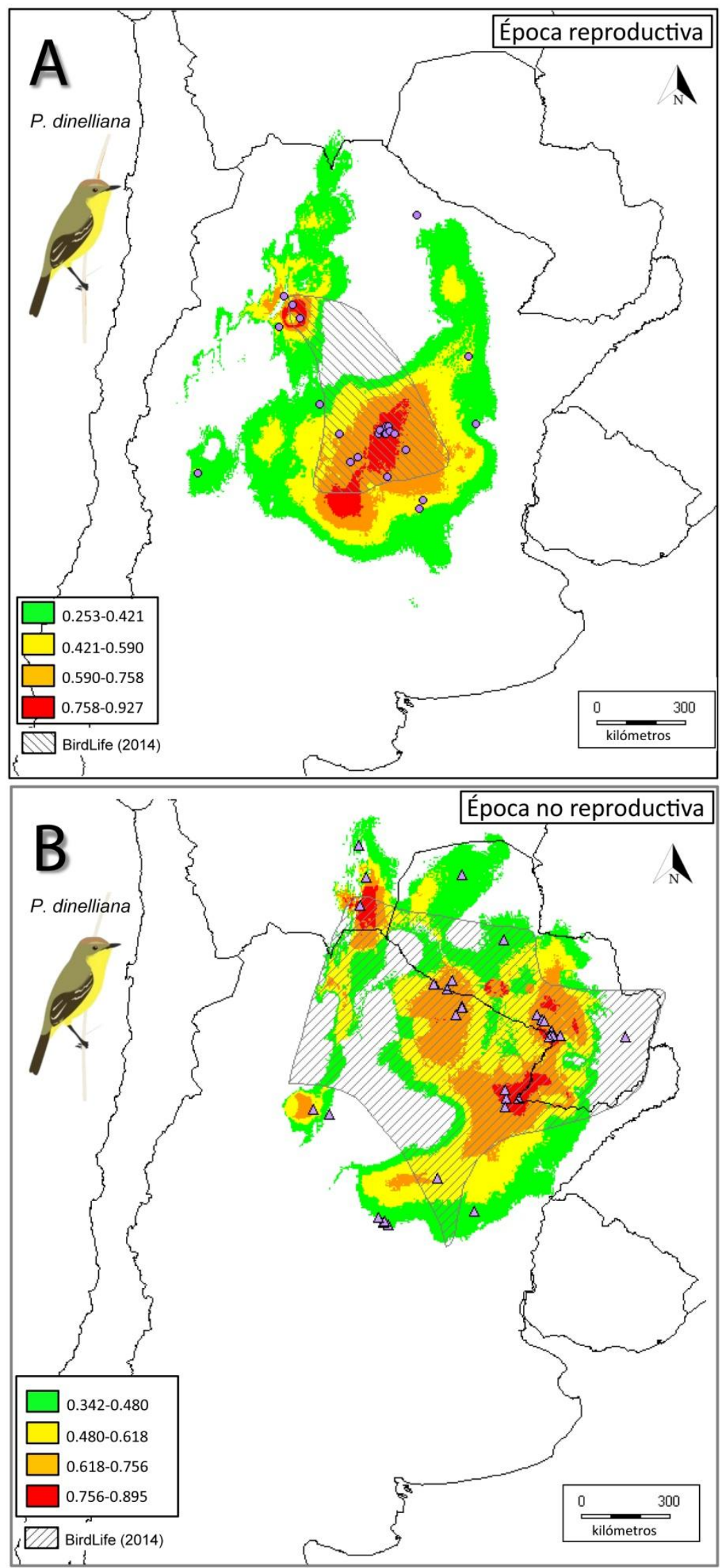

FIGURA 4. Localidades de presencia y distribución potencial estacional de Pseudocolopteryx dinelliana. Distribución geográfica de acuerdo a BirdLife 2014 (líneas oblicuas). En el recuadro se muestran los valores de idoneidad de hábitat: el valor menor corresponde al umbral de corte (ETSS) entre áreas idóneas y no idóneas. Los colores mas cálidos indican áreas con mejores condiciones predichas.

A) Época reproductiva. Localidades de presencia usadas para construir el modelo: círculos violetas $(\mathrm{N}=27)$.

B) Época no-reproductiva. Localidades de presencia usadas para construir el modelo: triángulos violetas ( $\mathrm{N}=33$ ). 
Pseudocolopteryx citreola. Los datos de ocurrencia y especialmente el MDP muestran que durante la época reproductiva la especie se distribuye en las provincias de Río Negro, Neuquén, Mendoza, La Rioja, San Juan y sur de Buenos Aires (Fig. 5A). Al oeste de los Andes, la especie se encuentra principalmente en el centro de Chile. Existen cuatro registros (todos de noviembre) ubicados en el centro-este de Argentina (sureste de Córdoba, y centro y norte de Santa Fe y Entre Ríos) más uno en el norte de Salta que no responden a este patrón y que parecieran ser individuos que se han retrasado en su migración (ver Discusión). Dos grandes áreas de baja idoneidad en Uruguay y en la estepa patagónica parecen ser sobre estimaciones del modelo.

Pseudocolopteryx flaviventris. Los registros de ocurrencia para la época reproductiva muestran que la especie se distribuye sobre las cuencas de los ríos Paraná y Uruguay desde Formosa y Corrientes hasta la costa atlántica de Buenos Aires, Uruguay y sur de Brasil. El MDP restringe las zonas de mayor idoneidad de hábitat en la región de la Pampa Húmeda y la Savana Uruguaya. En este caso el modelo muestra una distribución mucho más restringida y, al igual que en $P$. citreola, un mayor especificidad biogeográfica respecto a lo reportado en la literatura (Fig. 5B). 


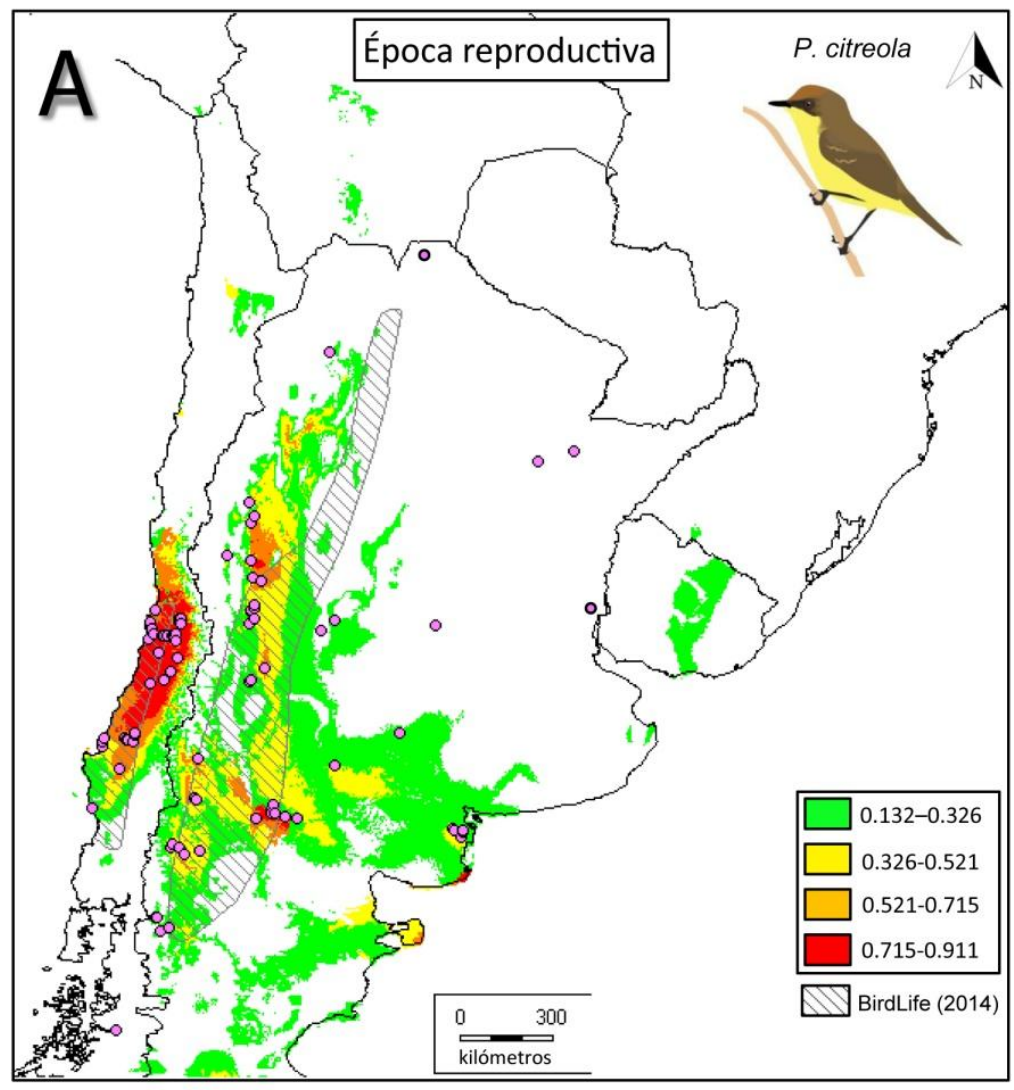

FIGURA 5. Localidades de presencia y distribución potencial en época reproductiva de Pseudocolopteryx citreola y $P$. flaviventris. Distribución geográfica estival de acuerdo a BirdLife 2014 (líneas oblicuas). En el recuadro se muestran los valores de idoneidad de hábitat: el valor menor corresponde al umbral de corte (ETSS) entre áreas idóneas y no idóneas. Los colores mas cálidos indican áreas con mejores condiciones predichas.

A) P. citreola. Localidades de presencia usadas para construir el modelo: círculos magenta ( $\mathrm{N}=82$ ).

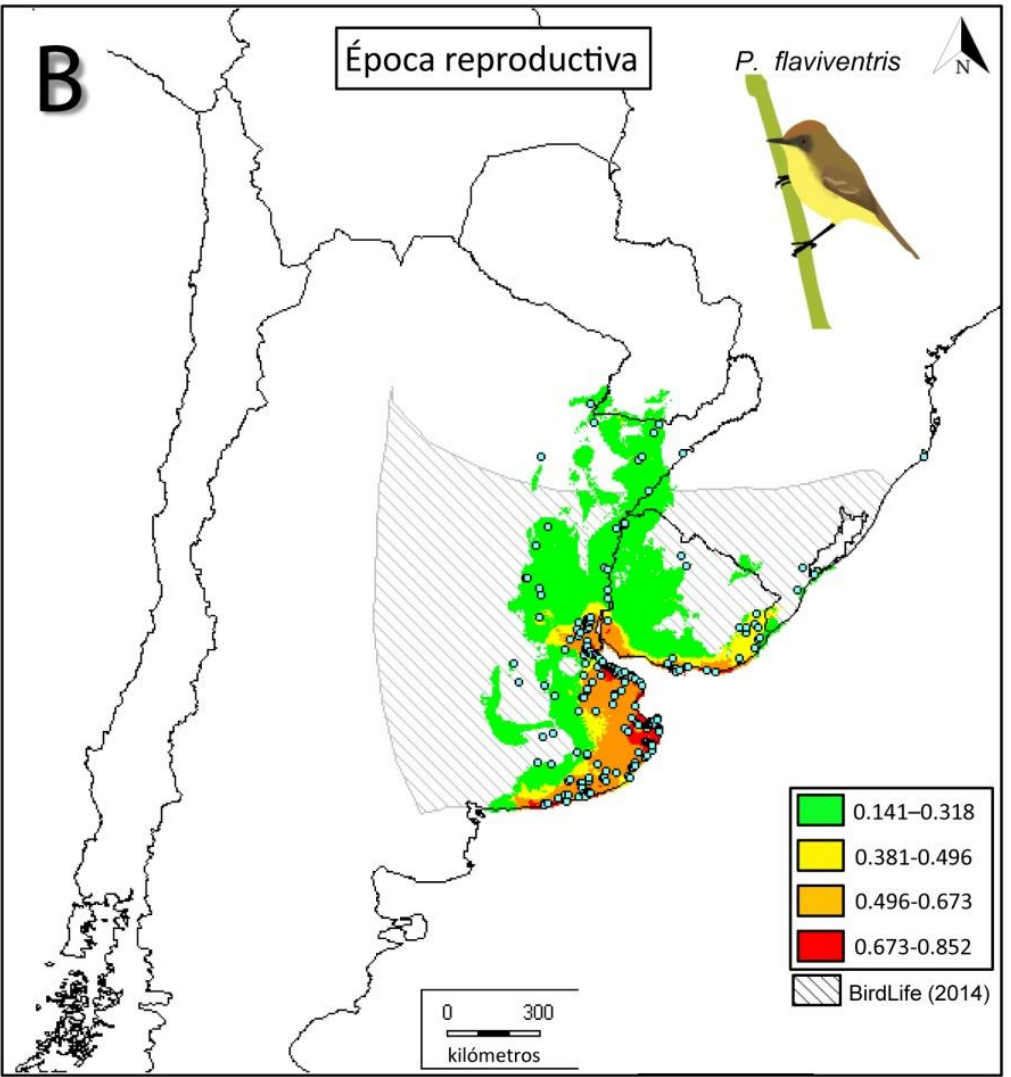

B) P. flaviventris. Localidades de presencia usadas para construir el modelo: círculos celestes ( $\mathrm{N}=199)$. 
Pseudocolopteryx citreola y P. flaviventris en época no reproductiva. Dada la dificultad para validar los datos de ocurrencia de ambas especies fuera de la época reproductiva (i.e. hay solo cinco datos certeros de $P$. flaviventris y sólo uno de $P$. citreola en la época invernal; ver Materiales y Métodos) la interpretación de los datos de ocurrencia y de los MDP son más complejas. Los pocos datos invernales validados de $P$. flaviventris se ubican en su mayoría (4 de 5) sobre la costa atlántica de Uruguay y sur de Brasil, y aunque existe un registro aislado en Formosa, el modelo muestra zonas de alta idoneidad en los márgenes del Río de la Plata y la costa atlántica de Uruguay y sur de Brasil (Fig. 6B). Por otro lado, el modelo en el que se agrupan datos invernales de $P$. citreola/flaviventris (i.e. registros de los que no se puede asegurar si pertenecen a $P$. citreola o $P$. flaviventris), muestra zonas de más alta idoneidad semejantes a las de $P$. flaviventris validadas en invierno (costa de Buenos Aires, Uruguay y sur de Brasil), a la que se suma una nueva zona en el Chaco Húmedo de Argentina y Paraguay (Fig. $6 A)$. 


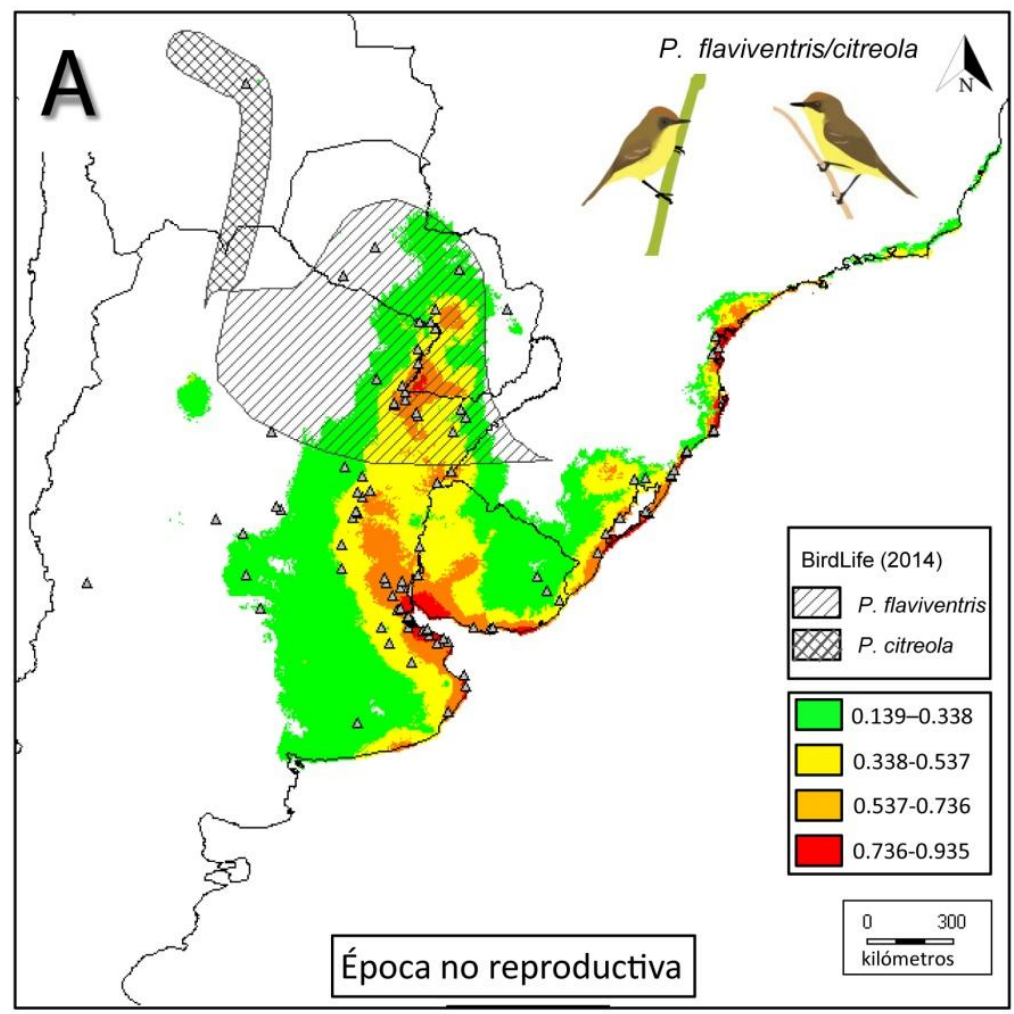

FigURA 6. Localidades de presencia y distribución potencial en época noreproductiva de Pseudocolopteryx flaviventris y $P$. citreola. En el recuadro se muestran los valores de idoneidad de hábitat: el valor menor corresponde al umbral de corte (ETSS) entre áreas idóneas y no idóneas. Los colores mas cálidos indican áreas con mejores condiciones predichas.

A) P. flaviventris/citreola. Localidades de presencia usadas para construir el modelo: triángulos grises $(\mathrm{N}=$ 96).Distribución geográfica invernal de acuerdo a BirdLife 2014 (líneas oblicuas: $P$. flaviventris; líneas cruzadas: $P$. citreola).

B) P. flaviventris. Localidades de presencia confirmada usadas para construir el modelo: triángulos celestes $(\mathrm{N}=5)$.

Localidad con presencia confirmada de P. citreola: triángulo rojo. (no usada para construir el modelo) 


\section{SUPERPOSICIÓN EN EL ESPACIO DE NICHO BIOCLIMÁTICO Y EN EL ESPACIO GEOGRÁFICO}

Ninguno de los pares de especies presentan MNE de época reproductiva equivalentes, ya que en todas las parejas se rechaza la hipótesis de equivalencia de nicho (Tabla 3). Además las especies muestran diferentes grados de superposición en el espacio de nicho bioclimático y en el espacio geográfico (Tabla 3, Figura 7). El par $P$. sclateri-P. flaviventris ( $D=0,441, G S G p=0,652$, $\mathrm{GSGe}=0,399)$ y el par $P$. acutipennis- $P$. dinelliana $(\mathrm{D}=0,531, \mathrm{GSGp}=0,466, \mathrm{GSGe}=0,225)$ tienen los mayores grados de solapamiento de nicho y el mayor grado de solapamiento en el espacio geográfico. En el otro extremo están los pares $P$. sclateri-P. citreola ( $D=0,092, \mathrm{GSG}$ y GSGe=0) у $P$. flaviventris- $P$. citreola $(D=0,08, G S G p=0,007, G S G e=0,008)$ que muestran los valores de Dy GSG más bajos, indicando que el solapamiento en el nicho bioclimático y en el espacio geográfico entre estas especie es muy escaso.

Las pruebas de similitud ambiental mostraron que en 6 de los 10 pares de especies comparados se rechaza la hipótesis nula de que el grado de superposición de nicho observado es explicado por diferencias o similitudes en el hábitat disponible (Figura 7, Tabla 3). En los restantes 4 pares de especies el grado de superposición de nicho es explicado por las diferencias y similitudes en el hábitat disponible. En ninguno de estos 4 casos los resultados fueron recíprocos entre los pares de especies. Esto es: la hipótesis de similitud ambiental fue rechazada cuando se comparó el background ambiental de la especie $\mathrm{X}$ sobre los datos de ocurrencia de la especie $Y$, pero fue aceptada cuando el background de la especie $Y$ se comparó contra los datos de ocurrencia de X (o viceversa). En el caso del par $P$. sclateri- $P$. acutipennis no se rechazó la hipótesis de similitud ambiental cuando se comparó el background de $P$. acutipennis sobre los datos de ocurrencia de $P$. sclateri. Para $P$. sclateri $-P$. dinelliana no se rechazó la similitud ambiental cuando la comparación fue del background de $P$. sclateri sobre datos de ocurrencia de $P$. dinelliana. Al comparar el background de $P$. citreola contra los datos de ocurrencia de $P$. acutipennis no se rechazó la hipótesis de similitud ambiental, y lo mismo ocurrió al comparar el background de $P$. dinelliana contra los datos de ocurrencia de $P$. flaviventris. 

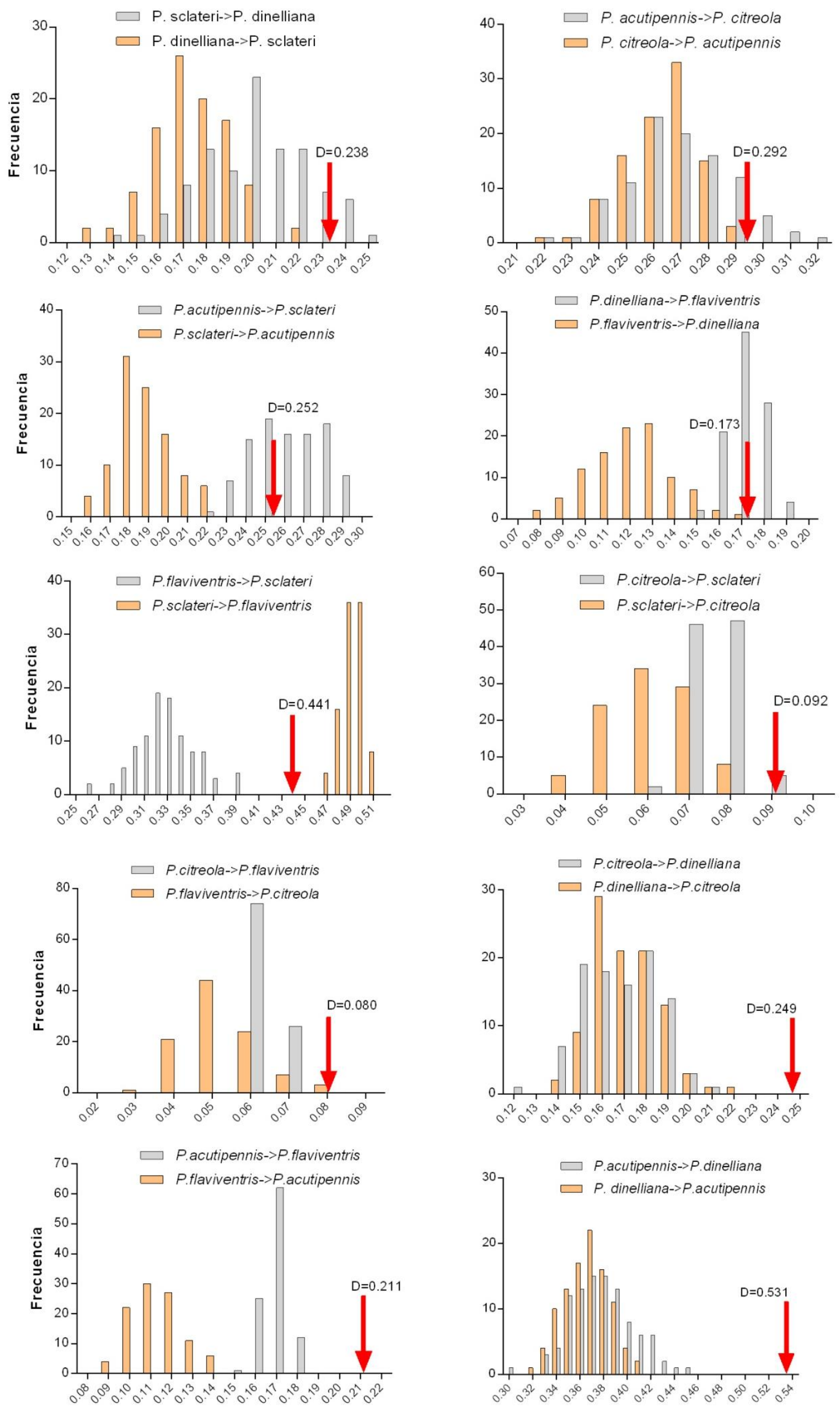

índice $D$ de Schoener

Índice D de Schoener

FIGURA 7. Histogramas mostrando los resultados de las pruebas de similitud ambiental entre pares de especies de Pseudocolopteryx spp. Las flechas rojas indican dónde cae el valor D observado, comparado con la distribución nula de los valores $D^{\prime}$ esperados. 
TABLA 3. Resultados de las pruebas de identidad de nicho, similitud ambiental y superposición geográfica para todos los pares de especies de Pseudocolopteryx. Para cada par de especies se resalta en negrita la que tiene el área de distribución mayor. Se resaltan en negrita los $p>0,05$.

\begin{tabular}{|c|c|c|c|c|c|c|c|}
\hline \multirow{2}{*}{ Especie X } & \multirow{2}{*}{ Especie Y } & \multirow{2}{*}{$\begin{array}{c}\text { Superposición } \\
\text { geográfica } \\
\text { (GSGp) }\end{array}$} & \multirow{2}{*}{$\begin{array}{c}\text { Superposición } \\
\text { geográfica } \\
\text { (GSGe) }\end{array}$} & \multirow{2}{*}{$\begin{array}{c}\text { Superposición } \\
\text { de nicho (D) }\end{array}$} & \multirow{2}{*}{$\begin{array}{l}\text { Identidad } \\
\text { de nicho }\end{array}$} & \multicolumn{2}{|c|}{ Similitud ambiental } \\
\hline & & & & & & $X->Y$ & $Y->X$ \\
\hline P. sclateri & P. acutipennis & 0,015 & 0,011 & 0,252 & $p<0,01$ & $p<0,01$ & $p=0,20$ \\
\hline P. sclateri & P. dinelliana & 0,107 & 0,075 & 0,238 & $p<0,01$ & $p=0,06$ & $p<0,01$ \\
\hline P. sclateri & P. flaviventris & 0,652 & 0,399 & 0,441 & $p<0,01$ & $p<0,01$ & $p<0,01$ \\
\hline P. sclateri & P. citreola & 0 & 0 & 0,092 & $p<0,01$ & $p<0,01$ & $p<0,01$ \\
\hline P. acutipennis & P. dinelliana & 0,466 & 0,225 & 0,531 & $p<0,01$ & $p<0,01$ & $p<0,01$ \\
\hline P. acutipennis & P. flaviventris & 0,056 & 0,024 & 0,211 & $p<0,01$ & $p<0,01$ & $p<0,01$ \\
\hline P. acutipennis & P. citreola & 0,215 & 0,167 & 0,292 & $p<0,01$ & $p=0,03$ & $p=0,20$ \\
\hline P. dinelliana & P. flaviventris & 0,033 & 0,029 & 0,173 & $p<0,01$ & $p=0,77$ & $p=0,01$ \\
\hline P. dinelliana & P. citreola & 0,022 & 0,013 & 0,249 & $p<0,01$ & $p<0,01$ & $p<0,01$ \\
\hline P. flaviventris & P. citreola & 0,007 & 0,004 & 0,080 & $p<0,01$ & $p=0,01$ & $p<0,01$ \\
\hline
\end{tabular}

\section{DISTANCIA GENÉTICA Y SUPERPOSICIÓN EN EL ESPACIO GEOGRÁFICO Y DE NICHO}

En términos generales, $P$. sclateri muestra los más altos valores de divergencia genética respecto a todas las demás especies, siendo la mayor diferencia entre éste y $P$. dinelliana. EI menor valor de divergencia se observa entre $P$. citreola y $P$. flaviventris (Tabla 4).

Tabla 4. Estimaciones de la divergencia genética (distancia genética p no corregida \%) a partir de de secuencias de ADN mitocondrial (COI y ND2) entre especies de Pseudocolopteryx.

\begin{tabular}{lcccccc}
\hline \hline & & & & & Divergencia genética \\
& P. sclateri & P. acutipennis & P. dinelliana & P. citreola & P. flaviventris & \begin{tabular}{c} 
intraespecífica \\
\hline P. sclateri
\end{tabular} \\
\hline P. acutipennis & 6 & & & & 0.173 \\
P. dinelliana & 6.595 & 0 & & & 0.058 \\
P. citreola & 6.911 & 4.732 & 0 & & 0.254 \\
P. flaviventris & 6.782 & 4.553 & 3.222 & 0 & 0.050 \\
\hline
\end{tabular}

Al comparar la divergencia genética con la superposición de nicho (Fig. 8A) y con la superposición geográfica (Fig. 8B) entre pares de especies, se observa un patrón general de correlación positiva entre la divergencia genética y el grado superposición geográfica y de nicho. Los pares $P$. flaviventris $-P$. sclateri y $P$. acutipennis $-P$. dinelliana muestran los más altos valores de divergencia genética y de superposición tanto de nicho como en el espacio geográfico. En el otro extremo, el patrón se repite con el par P. citreola - P. flaviventris mostrando los valores más bajos para las tres variables. El par $P$. citreola $-P$. sclateri muestra altos valores de divergencia genética, pero bajos valores de superposición de nicho y de espacio geográfico. Al comparar las medias anidadas de superposición geográfica y de nicho versus la divergencia medida como posición relativa del nodo (Fig. 9), se ve una tendencia en la 
que el grado de superposición aumenta en tanto aumenta la divergencia. Este patrón se corresponde con las predicciones para en un escenario de especiación alopátrica.

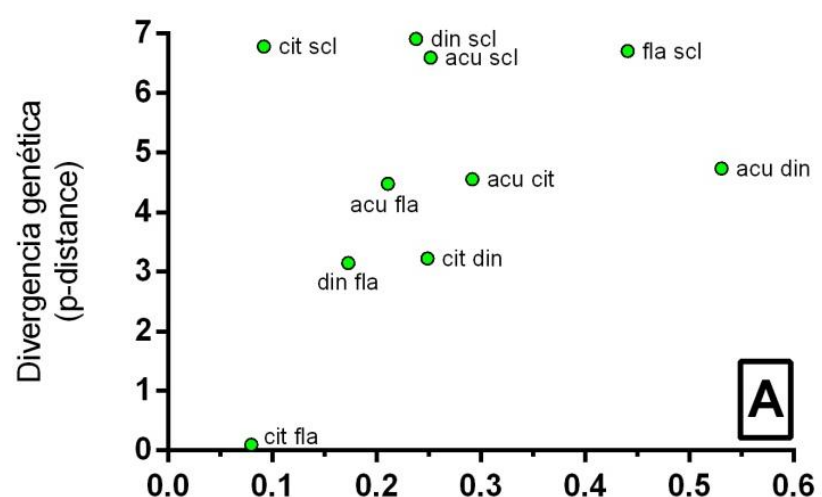

Superposición de nicho (índice D)

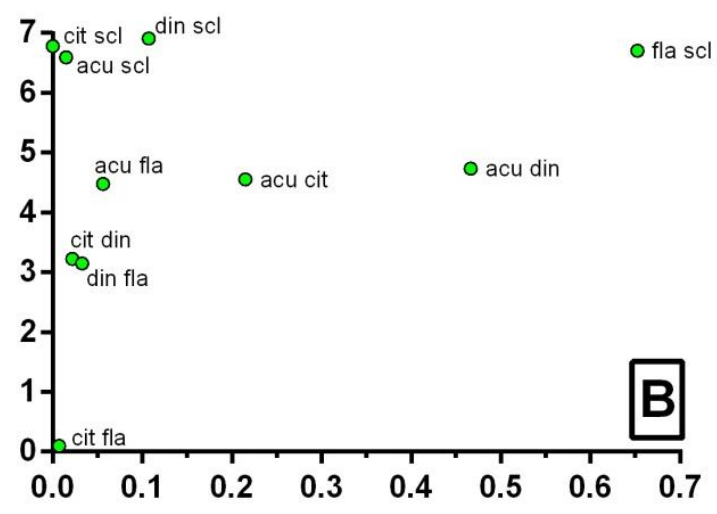

Superposición geográfica (GSGp)

FigURA 8. Comparaciones pareadas entre todas las especies de Pseudocolopteryx mostrando la distancia genética versus superposición en el espacio de nicho bioclimático (A) y en el espacio geográfico (B). Las especies están identificadas con las siguientes abreviaturas: $\mathbf{s c l}=P$. sclateri, $\mathbf{a c u}=P$. acutipennis, $\operatorname{din}=P$. dinelliana, fla $=P$. flaviventris, cit $=P$. citreola 


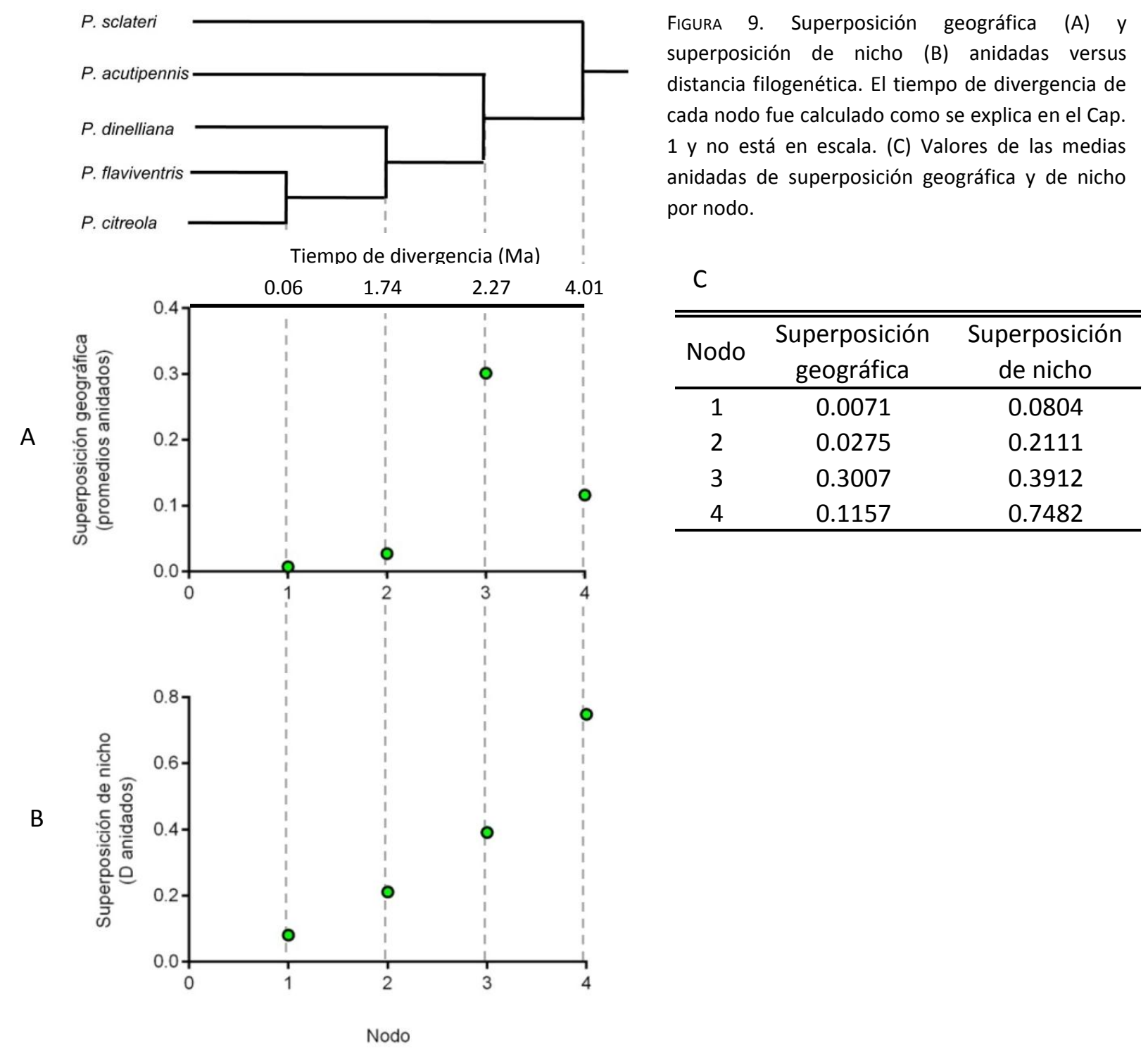




\section{Discusión}

Los resultados aquí presentados exponen nuevos esquemas en la geonemia y en los movimientos estacionales de Pseudocolopteryx, en donde cuatro especies exhiben distribuciones en época reproductiva diferentes a las de la época no reproductiva, mientras que solo una (P. sclateri) muestra un patrón distribucional y temporal más complejo. Nuestros datos demuestran que ninguna de las especies tiene nichos ecológicos equivalentes entre sí, y que para algunas de las comparaciones pareadas entre especies no hermanas, las diferencias entre nichos se explican mejor por diferencias regionales en los hábitats disponibles para cada especie que por verdaderas diferencias en las preferencias de hábitat. Además se observa una correlación positiva en las comparaciones pareadas de Pseudocolopteryx entre la divergencia genética interespecífica y el grado de superposición geográfica y de nicho. Al ponderar las comparaciones en cada nodo del árbol filogenético se pudo analizar la ascendencia compartida, demostrando una tendencia a la especiación alopátrica y divergencia de nicho en la evolución de los doraditos.

\section{DISTRIBUCIÓN Y MIGRACIÓN}

Pseudocolopteryx sclateri. A diferencia de las demás especies, P. sclateri no muestra un patrón migratorio claro. La especie es registrada en todos los meses del año, tanto en su porción más austral (Bolivia, Paraguay y Argentina) como en la costa este de Brasil y extremo norte de Sudamérica (Venezuela, Trinidad y las Guyanas) (ver Fig. 2).

A pesar de que $P$. sclateri es registrada durante todo el año a lo largo de toda su geonemia, la especie no muestra una presencia constante en una misma localidad a lo largo de los años. Los registros (con evidencias de cría) en Venezuela y Trinidad corresponden a cortos períodos de 2 o 3 años alternados con muchos años de ausencias (Hilty 2002, ffrench 2012). En el este de Formosa (Reserva El Bagual; $26^{\circ} 11^{\prime} \mathrm{S}, 58^{\circ} 56^{\prime} \mathrm{O}$ ) fue un residente común que nidificó regularmente entre los años 2012 y 2014, sin embargo luego de ese período no se volvió a observar a $P$. sclateri en el lugar (Di Giacomo in litt.). Además existen algunos datos concretos de nidificación durante los meses que fueron categorizados como de época no reproductiva (sobre la costa sur de Brasil [Díaz 2014], en Trinidad [Belcher \& Smooker 1937, D. Smith y M. Kenefick in litt.] y en Venezuela [Hilty 2002]). Los datos de cría distribuidos a lo largo de distintos momentos del año y su presencia de forma impredecible en localidades bien muestreadas sugieren que $P$. sclateri es una especie nómade, que podría criar cuando y donde ciertas condiciones estén dadas haciendo que su geonemia sea muy dinámica. Dado que es la especie más palustre de todos los doraditos, generalmente asociada a ambientes inundados 
para criar, es plausible que los regímenes variables de precipitaciones y de condiciones de cada ambiente palustre impongan limitaciones a la repetibilidad interanual de condiciones de cría en un mismo sitio. Incluso $P$. sclateri podría nidificar más de una vez en un mismo año pero en diferentes localidades, fenómeno denominado "reproducción itinerante" (itinerant breeding; Jaeger et al. 1986, Bucher 1982, Hamilton 1998). Nuestros resultados aportan nuevas hipótesis en los patrones migratorios y de distribución de P. sclateri (en este caso, nomadismo y reproducción itinerante) que pueden ponerse a prueba en futuros estudios.

Pseudocolopteryx acutipennis. Al analizar los datos de ocurrencia y los MDP en época reproductiva y no reproductiva en conjunto, se observa que las poblaciones del sur y del norte de $P$. acutipennis tienen comportamientos migratorios diferentes (ver Fig. 3 ). Las poblaciones andinas desde el sur de Perú hacia el norte (aproximadamente desde los $14^{\circ} \mathrm{S}$ ) no realizarían movimientos estacionales, coincidiendo con lo indicado para Colombia y Ecuador, donde es un escaso y local residente durante todo el año (Ridgely \& Greenfield 2001, Henry 2012). Por otro lado, las poblaciones que en época reproductiva ocurren en las zonas más australes, desde los andes peruanos, bolivianos y argentinos hasta las Serranías Centrales y en el oeste de la región Pampeana de Argentina, migran en época post reproductiva, mostrando áreas de invernada en las tierras bajas del sureste peruano, el Pantanal paraguayo y brasilero, la Chiquitanía boliviana, y el Chaco húmedo de Paraguay y Argentina, con algunos individuos llegando a la costa sudeste de Brasil. Las poblaciones del Perú y Bolivia parecen realizar migraciones eminentemente altitudinales, descendiendo durante el invierno hasta las tierras bajas del noreste, mientras que las de Argentina harían migraciones latitudinales, con algún componente altitudinal descendiendo en invierno. El área de invernada aquí propuesta es notoriamente diferente a la de BirdLife (2014), que la ubica básicamente sobre la región chaqueña de Argentina. Otro aporte importante de nuestros resultados es la extensión de la distribución en el oeste de la región pampeana en época reproductiva.

Pseudocolopteryx dinelliana. Los resultados muestran claramente que $P$. dinelliana tiene una distribución fundamentalmente chaqueña, con registros en el norte del Espinal y noroeste de las Pampas (ver Fig. 4). La especie realiza una migración post reproductiva hacia la porción más norteña del Chaco, aunque al menos algunos individuos permanecen en la zona de la laguna de Marchiquita (Córdoba) y en los bajos submeridionales del norte de Santa Fe. El área de cría podría ser algo más extensa que lo predicho por el modelo, ya que se conocen nidos en el noreste de Córdoba (Molli 1985, Narosky \& Salvador 1998) y en Tucumán (Dinelli 1933), se presume que también nidifica en Salta y Santiago del Estero (Narosky \& Salvador 1998) y en la 
Reserva Natural Formosa se observaron adultos desplegando y juveniles en enero (Areta et al. in prep), lo cual refuerza esta idea.

Pseudocolopteryx flaviventris y P. citreola. Nuestros resultados muestran que $P$. flaviventris se establece en primavera y verano en la Mesopotamia argentina, y principalmente en la Pampa Húmeda del este de Buenos Aires, y que al menos las poblaciones más australes migran al norte y noreste en invierno, llegando hasta el sureste de Brasil. Esta propuesta se refuerza con los escasos datos de estacionalidad de la bibliografía: en el sur de su distribución Cardoni et al. (2016) muestra que la especie solo está presente allí en época reproductiva, mientras que Repenning y Fontana (2009) muestra el patrón complementario en Río Grande do Sul, Brasil, en donde se lo registra desde Marzo hasta Septiembre. En cuanto a los limites en su distribución reproductiva, es interesante remarcar que los datos concretos de nidificación mas norteños son de Villa Paranacito, en el sur de la provincia de Entre Ríos (Narosky \& Salvador 1998) y de Colastiné Sur, en Santa Fe (Leiva et al. 2004). Parece probable que la distribución efectiva en época reproductiva esté restringida solo a las áreas de más alta idoneidad indicados en los MDP (Fig. 5B), lo que confirmaría una distribución de cría restringida y limitada a la región pampeana.

Pseudocolopteryx citreola ocurre durante la época reproductiva en la ecoregión del Matorral Chileno y en Argentina principalmente sobre las cuencas de los ríos DesaguaderoAtuel, Colorado, Limay y Negro en la ecoregión del Monte (ver Fig. 5A). Esta distribución es claramente más extensa y muestra una especificidad biogeográfica mas marcada que lo hasta ahora conocido (BirdLife 2014). En cuanto a su migración invernal, se han propuesto dos hipótesis principales: que migran hacia el norte bordeando los Andes llegando hasta Bolivia (Reed 1877, Ábalos \& Areta 2009), o que las poblaciones de Chile cruzan los Andes y junto con las poblaciones del oeste de Argentina migran hacia el noreste hasta las Pampas (Fjdelsa \& Krabbe 1990). La evidencia disponible todavía es insuficiente para solucionar de manera definitiva estas hipótesis, sin embargo se pueden ensayar algunas inferencias válidas.

No todos los individuos de las especies migrantes realizan los movimientos migratorios todos los años, ni todos los individuos se mueven en absoluta sincronía. Por eso es esperable que algunos individuos sean registrados en sus sitios de cría, o en sus rutas de paso, durante la época no reproductiva, haciendo que los MDP de invierno sobreestimen la idoneidad de esas áreas. Si tomamos en cuenta esto, y solo analizamos las localidades más norteñas de los registros de $P$. flaviventris/citreola (ver Fig. $6 \mathrm{~A}$ ), se pueden identificar dos grandes áreas de distribución: una en el noreste de Argentina y Paraguay, y otra en la costa sureste de Brasil. Esta última zona es la misma que cuenta con registros validados sólo de $P$. flaviventris, pero no 
de $P$. citreola (ver Fig. 6B). Así, se puede afirmar que el sur de Brasil es un área de invernada para $P$. flaviventris pero no para $P$. citreola.

El otro gran área de invernada indicada por el MDP de invierno (noreste de Argentina y Paraguay) cuenta con un registro validado para P. flaviventris en el este de Formosa (F. Gorleri in litt.) y un individuo observado y escuchado de $P$. citreola en Bolivia, cerca del límite con Paraguay (Vidoz \& Roesler in litt.)(ver Fig. 6B). Esto hace probable que el Chaco boliviano y paraguayo, y el Chaco Húmedo de Argentina sean áreas de invernada de ambas especies. Los registros de $P$. citreola en el sureste de Córdoba, norte de Santa Fe, este de Entre Ríos y norte de Salta durante la temporada reproductiva, podrían pertenecer a individuos retrasados o que no han completa su migración hacia la zona de cría, indicando que esas localidades son parte de la ruta migratoria de la especie.

\section{ECOLOGÍA, BIOGEOGRAFÍA Y ESPECIACIÓN}

Debido a cambios post especiacionales en las distribuciones y en los nichos de las especies, las distribuciones y nichos actuales pueden no ser un buen reflejo de los patrones de especiación ocurridos lejos en el tiempo (Losos \& Glor 2003, Graham et al. 2004). Nuestros análisis abordan el problema por un lado utilizando comparaciones pareadas de divergencia genética versus superposición de distribución y nicho entre especies (Berlocher \& Feder 2002), y por otro lado calculando distribuciones hipotéticas y nichos ancestrales mediante un método que pondera las comparaciones en cada nodo del árbol filogenético, para tener en cuenta la ascendencia compartida en el grupo (Fitzpatrick \& Turelli 2006, Warren et al. 2008).

Utilizando estos dos enfoques, nuestros resultados apoyan un modelo general de especiación alopátrica de Pseudocolopteryx donde el conservadurismo de nicho no se comprueba, sino que la divergencia de nicho parece ser la regla en el grupo. Esta evidencia sugiere que las especies más cercanamente emparentadas no son propensas a compartir los mismos nichos ecológicos, y es poco probable que muestren una tendencia a ocurrir simpátricamente. Sin embargo, este patrón general para el género Pseudocolopteryx tiene sus excepciones cuando las comparaciones pareadas se dan entre especies más alejadas.

Pseudocolopteryx sclateri y $P$. acutipennis presentan los tiempos de divergencia y son filogenéticamente basales las demás especies de doraditos. Es por eso que el grado de solapamiento geográfico y las diferencias y similitudes observadas en su espacio ambiental respecto a los demás doraditos podrían verse muy afectados por cambios post especiacionales en su nicho ecológico y distribución (Losos \& Glor 2003, Graham et al. 2004). De hecho, ambas tienen distribuciones muy extendidas y dispersas, no parecen estar asociadas a alguna región biogeográfica y mostraron una relación muy variable entre superposición geográfica y de nicho 
respecto a las demás especies. En los extremos de estas relaciones se observan el alto grado de superposición geográfica y de nicho entre $P$. sclateri y $P$. flaviventris, y su contraparte opuesta en el par $P$. sclateri - P. citreola, quienes no tienen superposición geográfica y la superposición de nicho es muy baja (ver Fig. 8). Con los demás pares de especies que involucran a $P$. sclateri y $P$. acutipennis, se dan situaciones intermedias en la relación superposición geográfica/superposición de nicho.

El efecto de cambios distribucionales post especiacionales podría ser particularmente marcado en $P$. acutipennis ya que es posible que el reporte relativamente reciente de las poblaciones pampeanas (Navas 2002, Roesler 2009) y la expansión de su área geográfica con los nuevos registros aquí presentados, se deban a un real proceso de expansión. El avance de la frontera agrícola parece facilitar la expansión de esta especie que nidifica en las "malezas" que quedan entre los lotes de cultivos en la zona pampeana (Roesler 2009, obs. pers.). Por otro lado, parece posible que $P$. sclateri sea un nómade capaz de moverse regularmente entre ambientes palustres, haciendo que su geonemia sea muy dinámica en tiempo y espacio (ver "Distribución y migración" más arriba). Esta dinámica distribucional podría responder a adaptaciones post especiacionales que operaron en dos escalas. Por un lado, P. sclateri está netamente asociado a humedales cálidos, lo cual explicaría la alopatría total y el bajo solapamiento de nicho con $P$. citreola. Y por otro lado, $P$. sclateri podría responder a adaptaciones a una escala de micro hábitat, las cuales permitirían el alto grado de simpatría con $P$. flaviventris junto a un bajo grado de sintopía.

Por otro lado, $P$. dinelliana, $P$. citreola y $P$. flaviventris pertenecen al clado terminal (ver Capítulo 1) y han sufrido procesos de especiación más recientes. Esto permite encontrar patrones de especiación y biogeográficos que no han sido tan obscurecidos por eventos post especiacionales. Al combinar información ambiental con las distribuciones geográficas actuales de las especies, Graham et al. (2004) plantean cinco escenarios generales (ver Fig. 10). Los casos A-C sugieren una selección divergente mediada ecológicamente asociada con especiación que ocurre en simpatría (caso A), parapatria (caso B) o alopatría (caso C). Cuando no hay divergencia en los parámetros ambientales, se propone una especiación en ausencia de divergencia ecológica (plausible para los casos D y E). 


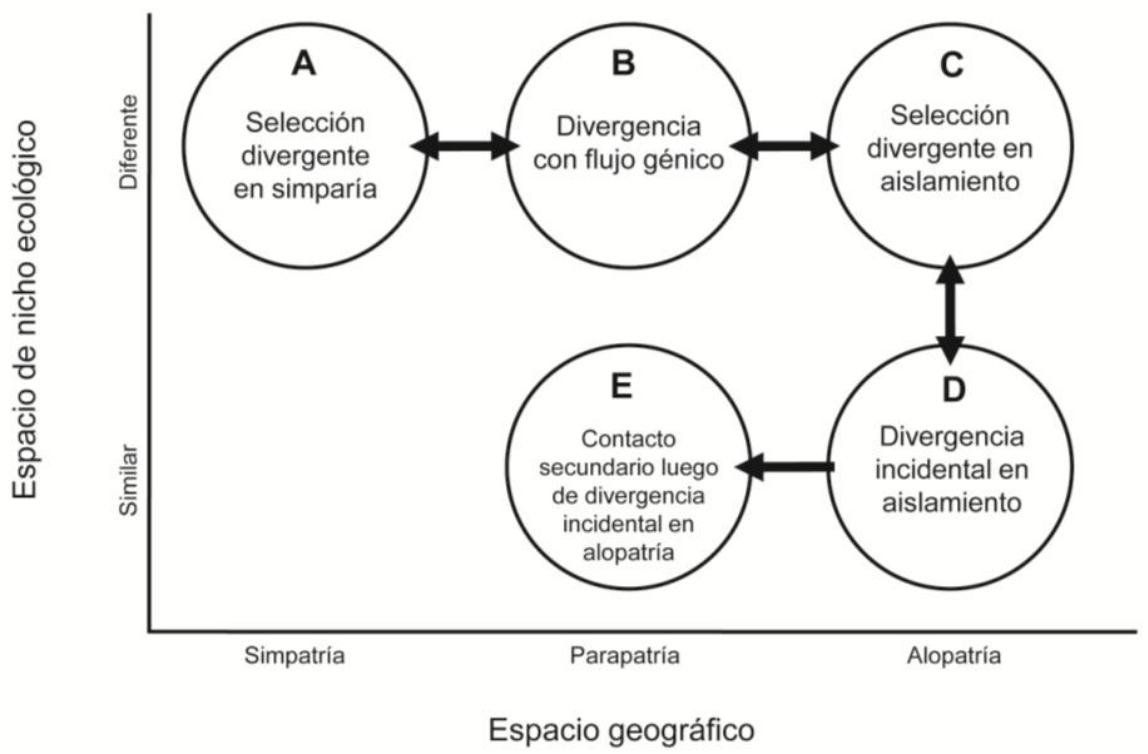

Figura 10. Mecanismos de especiación predichos para linajes hermanos por Graham et al. (2004) a partir de información combinada de distribución en el espacio geográfico y ambiental.

Los tres pares de especies del clado terminal muestran bajos grados de solapamiento en el espacio geográfico y de nicho, lo que significa altos grados de alopatría y de diferencia de nicho (Tabla 3, Fig. 11). Considerando los escenarios planteados por Graham et al. (2004), éste sería un caso de selección divergente en aislamiento geográfico (escenario C), lo que implica que las presiones mediadas por el hábitat habrían tenido un papel importante en los procesos de especiación de $P$. dinelliana, $P$. citreola y $P$. flaviventris. Esto resulta especialmente cierto para $P$. citreola y $P$. flaviventris que, a pesar de haber especiado muy recientemente (ca. 60000 años, ver Capítulo 1), mostraron por lejos los valores más bajos de solapamiento geográfico y de nicho.

Respecto al espacio geográfico actual, las tres especies muestran distribuciones de cría esencialmente alopátricas entre sí, con pequeñas áreas de simpatría en los bordes de sus distribuciones (Fig. 11). De hecho existen muy pocas localidades efectivamente compartidas entre $P$. dinelliana y $P$. citreola (e.g. Humedal del Carau, límite entre San Juan y Mendoza) y entre $P$. dinelliana y $P$. flaviventris (e.g. Bajos Submeridionales, norte de Santa $\mathrm{Fe}$, donde posiblemente $P$. flaviventris no reproduce). Para el caso de $P$. citreola y $P$. flaviventris no se conocen zonas efectivas de contacto, y las localidades conocidas más cercanas en época reproductiva están separadas por aproximadamente $200 \mathrm{~km}$ (Hilario Ascasubi para P. citreola y Claromecó para P. flaviventris en el sur de Buenos Aires). Las distribuciones de estas tres especies se ven restringidas a zonas biogeográficas específicas. Así, podemos definir una especie del Chaco ( $P$. dinelliana), una del Monte de Argentina y del Matorral de Chile con ingresiones menores en otros biomas ( $P$. citreola) y una de la Pampa Húmeda ( $P$. flaviventris). 


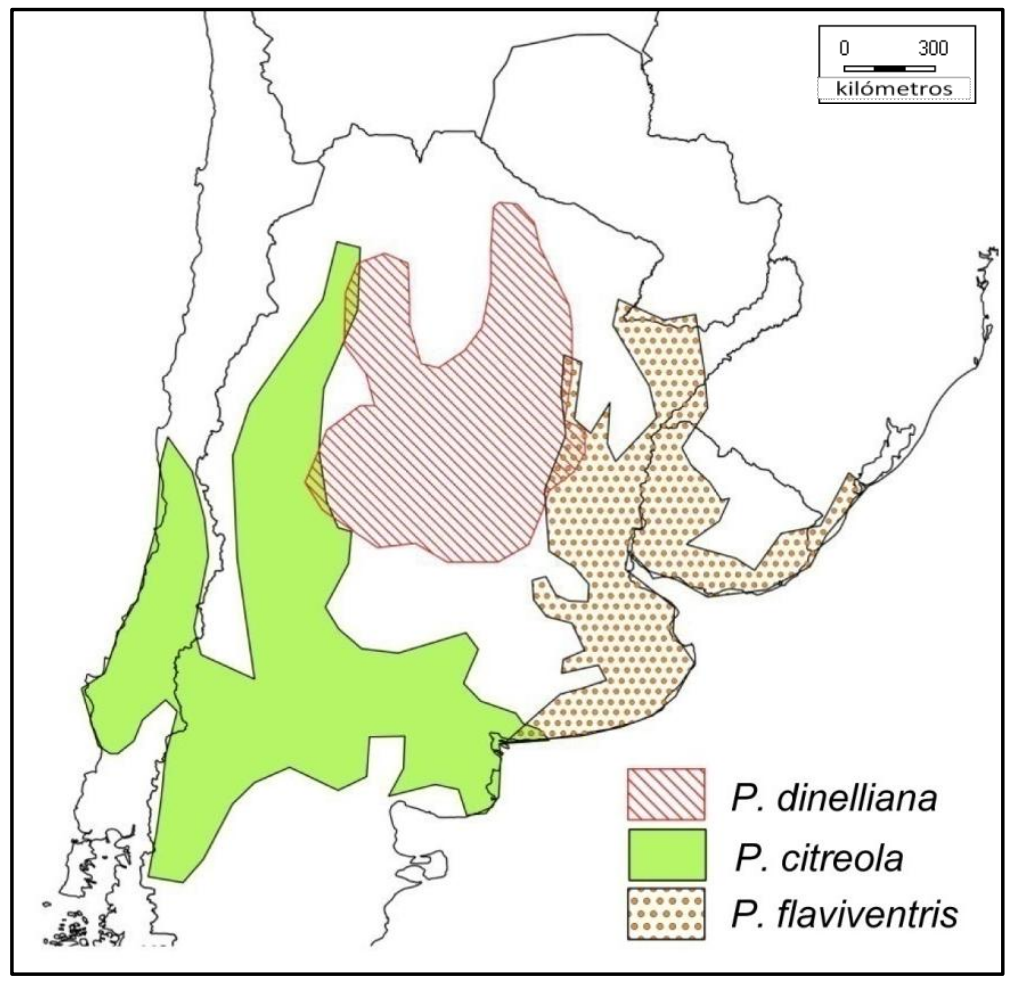

Figura 11. Distribuciones en época reproductiva de $P$. dinelliana, $P$. citreola y $P$. flaviventris construidas a partir de los datos de ocurrencia (ver apartado "Grado de superposición en el espacio de nicho bioclimático" en Materiales y Métodos).

\section{ESPECIACIÓN CRÍPTICA Y ANCESTRALIDAD}

Desde un enfoque puramente cladista, las especies de un grupo monofilético están contenidas en un clado que comparte un ancestro común hipotético (Hennig 1966). Sin embargo, la perspectiva Hennigiana ha sido criticada por su visión poco realista y sesgada de las complejidades en las transformaciones evolutivas de los organismos, y especialmente por negar la existencia real de los ancestros (Mayr 1974, Cavalier-Smith 2009). El evento de divergencia entre $P$. citreola y $P$. flaviventris ocurrió hace apenas unos 60000 años (Capítulo 1) lo que permite plantear la posibilidad de que tanto la especie ancestral como la descendiente existan en la actualidad. En otras palabras, es posible que una de las dos especies sea el ancestro de la otra. Los datos de distribución y migración son consistentes con dos escenarios de especiación que indican que $P$. citreola es el ancestro de $P$. flaviventris y no al revés:

Especiación peripátrica. La especiación peripátrica es un tipo de especiación alopátrica, donde una pequeña parte de la población se aísla geográficamente de la población mayor y comienza un proceso de divergencia que culmina en la imposibilidad de flujo génico (Mayr 1982, Coyne \& Orr 2004). Algunos estudios en aves usando ADN mitocondrial demostraron que pequeñas poblaciones aisladas están débilmente diferenciadas de su población ancestral (Bates 2002), lo que podría sugerir etapas tempranas de divergencia peripátrica (Seddon \& Tobias 2007). 
Pseudocolopteryx citreola tiene una distribución de cría mucho más amplia que la de $P$. flaviventris, lo que sugiere que es más antigua. Particularmente si se tiene en cuenta que la distribución de cría real de $P$. flaviventris no se extendería hacia el norte más allá de Entre Ríos. En este escenario de especiación peripátrica una pequeña población periférica de $P$. citreola habría quedado aislada geográficamente de la población principal, divergiendo subsecuentemente y dando origen a $P$. flaviventris.

Especiación por "dosificación de migrantes" (migration dosing speciation). Bildstein (2004) demostró que algunos individuos de rapaces migrantes se asientan en zonas que anteriormente habían sido solo parte de su ruta migratoria, y comienzan a criar en aislamiento de su población parental. Estas poblaciones extralimitales pueden eventualmente especiarse mediante un proceso al que llamaron "dosificación de migrantes" (migration dosing). Bajo esta misma idea, Winkler et al. (2017) sugieren que las recientes poblaciones reproductivas de Hirundo rustica de Argentina estarían en un temprano proceso de especiación por dosificación de migrantes. Esta perspectiva puede adoptarse para analizar la especiación de los doraditos crípticos. Pseudocolopteryx citreola cría fundamentalmente en el Matorral chileno y el Monte de Argentina e invernaría mayormente en el Chaco boliviano y paraguayo, y el Chaco Húmedo de Argentina. Durante su paso migratorio algunos individuos de $P$. citreola (¿posiblemente los del sureste de su distribución?) atraviesan zonas de cría de $P$. flaviventris, aunque el fenómeno contrario no ocurre. De hecho existen al menos dos registros concretos de individuos de $P$. citreola en migración en zonas en las que $P$. flaviventris nidifica en el sureste de la provincia de Entre Ríos (López-Lanús et al. 2010, I. Roesler com. pers., Narosky \& Salvador 1998, obs. pers). En este escenario de dosificación de migrantes, algunos individuos de $P$. citreola habrían alterado su patrón migratorio comenzando a criar en la Pampa Húmeda, dando comienzo así al proceso de aislamiento reproductivo y especiación que derivó en $P$. flaviventris. 


\section{Discusión general}

A lo largo de este estudio se discutieron diferentes aspectos de la evolución y biogeografía en Pseudocolopteryx que resultaron de interés y que sirven como base de futuros estudios.

En este trabajo se discutió que en la evolución del plumaje, el pasaje del dicromatismo sexual al monocromatismo se dio por la adquisición de caracteres femeninos por parte de los machos. Este fenómeno es interesante, no solo porque parece ser contrario a la regla general en aves en donde el pasaje de dicromatismo a monomorfismo se suele dar por hembras adquiriendo el fenotipo masculino (ver revisión de Badyaev \& Hill 2003), sino porque además esta pérdida de dicromatismo fue acompañado por una complejización del canto. El caso más llamativo es el de $P$. dinelliana en donde machos y hembras son extremadamente parecidos y solo en el pico se evidencia notoriamente el dicromatismo ancestral. En esta especie el canto es realmente complejo y elaborado, con frases extensas en donde la extrema repetición de notas iniciales intercaladas con notas intermedias es una constante. Esta complejidad está dada no solo por la repetición sino también por la alta variabilidad que presenta cada evento de canto. El canto de $P$. dinelliana es probablemente uno de las mas (sino el mas) complejo y elaborado entre los tiránidos (obs pers.). Como contraparte $P$. sclateri, la especie con el dicromatismo más marcado tiene un canto muy sencillo en donde los tres tipos de notas casi no presenta variaciones. Esta relación negativa entre el grado de dicromatismo y la elaboración del canto en la evolución de Pseudocolopteryx puede ser el producto de un cambio de las presiones selectivas que operaron sobre el canto de $P$. dinelliana en detrimento de otros caracteres dimórficos (Badyaev et al 2002).

La existencia de especies crípticas también resultó un tema relevante en la evolución de los Doraditos. El fenotipo de plumaje prácticamente indistinguible entre $P$. citreola y $P$. flaviventris fue producto de la ancestralidad común, y no por convergencia ni retención de plesiomorfías previas, en donde en un muy corto tiempo de divergencia las voces divergieron mucho mientras que el plumaje se mantuvo en un estasis prácticamente total. Dada esta bajísima divergencia genética y de plumaje y el carácter innato de las vocalizaciones en los tiránidos, futuros estudios genómicos que busquen los genes responsables de las vocalizaciones, podrían explicar las bases genéticas de la evolución vocal en estas dos especies. Recientes estudios en los que se exploran las bases genéticas de las diferencias de plumaje han dado buenos resultados (Brelsford et al. 2017), y por lo tanto parece promisorio aplicar estas mismas técnicas en la los caracteres vocales de $P$. citreola y $P$. flaviventris. 
En este trabajo se aborda por primera vez el estudio de los despliegues visuales de un grupo de tiránidos bajo el paradigma de la modularidad. El carácter modular del comportamiento y el acople de los componentes acústicos y visuales de los módulos permitió analizar la relación entre movimiento y sonidos de manera comparada, y funcionó como una herramienta útil para analizar las homologías entre módulos. Por ejemplo, permitió entender el reemplazo de sonidos vocales por sonidos putativamente mecánicos (y viceversa), en donde los chasquidos del pico de $P$. sclateri fueron reemplazados por sonidos vocales en las demás especies, y las notas finales siringeales fueron reemplazadas por sonidos producidos por los aleteos en $P$. acutipennis. El descubrimiento de que los despliegues visuales de Pseudocolopteryx poseen las características de modularidad organizacional y variacional (Scholes 2006, 2008a, 2008b) podría ser un primer paso para abordar estudios más profundos acerca de la evolución del comportamiento, no solo dentro este género sino aplicando los conceptos de modulariad en estudios comparados con otros tiránidos. Por ejemplo es posible que los módulos de mayor jerarquía encontrados en Pseudocolopteryx (Presentación, Remate y Despliegue aéreo de dos perchas) tengan su correlato en Knipolegus y Lessonia (ver Areta \& Miller 2014). De manera complementaria, la aplicación del paradigma de la modularidad en los despliegues de estos tiránidos podría arrojar nuevos datos que permitan reelaborar los análisis en Pseudocolopteryx.

Los análisis biogeográficos permitieron plantear nuevas propuestas sobre las distribuciones y patrones migratorios de los Doraditos. Estas propuestas son un primer paso para elucidar las rutas migratorias y áreas de invernada de algunas especies de Doraditos que todavía siguen sin esclarecerse con precisión. El caso de $P$. citreola y $P$. flaviventris es el más complejo y a la vez el más promisorio: el hecho de su cripsis de plumaje, de que probablemente usen rutas migratorias "solapadas" y de la baja divergencia genética hace necesario echar mano de manera integrada a herramientas genéticas y de modelos de distribución más potentes para poder comprender por dónde y hacia dónde migran estas dos especies.

Desde el punto de vista histórico, el análisis de datos geográficos y ecológicos junto con los análisis filogenéticos, mostraron que la especiación alopátrica fue la regla en la evolución de Pseudocolopteryx. Las distribuciones y nichos ecológicos actuales de las especies basales ( $P$. sclateri y $P$. acutipennis) se vieron modificados fuertemente por cambios post especiacionales, mientras que $P$. dinelliana, $P$. citreola y $P$. flaviventris sufrieron procesos de especiación más recientes donde se pudo encontrar que las presiones mediadas por el hábitat habrían tenido un papel importante. Las propuestas en los procesos de especiación entre $P$. citreola y P. flaviventris (Especiación peripátrica y Especiación por "dosificación de migrantes") 
podrían ser puestos a prueba (o nuevas hipótesis podrían ser planteadas) estudiando la genética poblacional de estas dos especies. Por ejemplo, el efecto fundador o una expansión geográfica podrían haber afectado el posible patrón espacial de la diversidad genética en estas dos especies (Maldonado-Cohelo 2012). 


\section{Bibliografía}

Ábalos R \& Areta Jl. 2009. Historia natural y vocalizaciones del Doradito Limón (Pseudocolopteryx cf. citreola) en Argentina. Ornitología Neotropical 20: 215-230

Accordi IA \& Hartz SM. 2006. Distribuição espacial e sazonal da avifauna em uma área úmida costeira do sul do Brasil. Revista Brasileira de Ornitologia, 14(2), 117-135.

Anderson RP, Gómez-Laverde M \& Peterson AT. 2002. Geographical distributions of spiny pocket mice in South America: insights from predictive models. Global Ecology and Biogeography, 11(2), 131-141.

Areta JI \& Miller EH. 2014. Display flight and mechanical sounds of the Andean negrito (Lessonia oreas), with comments on the basic structure of flight displays in Fluvicoline flycatchers. Ornitol. Neotrop, 25, 95-105.

Armenta JK, Dunn PO \& Whittingham LA. 2008. Quantifying avian sexual dichromatism: a comparison of methods. Journal of Experimental Biology, 211(15): 2423-2430.

Azpiroz AB. 2001. Aves del Uruguay. Lista e introducción a su biología y conservación. Montevideo: Aves Uruguay, 104.

Badyaev, A. V., Hill, G. E., \& Weckworth, B. V. 2002. Species divergence in sexually selected traits: increase in song elaboration is related to decrease in plumage ornamentation in finches. Evolution, 56(2), 412-419.

Badyaev AV \& Hill GE. 2003. Avian sexual dichromatism in relation to phylogeny and ecology. Annual Review of Ecology, Evolution, and Systematics 3: 27-4

Bard, J. B., \& Rhee, S. Y. (2004). Ontologies in biology: design, applications and future challenges. Nature Reviews Genetics, 5(3), 213-222.

Barraclough TG, Vogler AP \& Harvey PH. 1998. Revealing the factors that promote speciation. Philosophical Transactions of the Royal Society B: Biological Sciences, 353(1366), 241-249.

Barraclough TG \& Vogler AP. 2000. Detecting the geographical pattern of speciation from species-level phylogenies. The American Naturalist, 155: 419-434

Bates, J. M. (2002). The genetic effects of forest fragmentation on five species of Amazonian birds. Journal of Avian Biology, 33(3), 276-294.

Belcher, C., \& Smooker, G. D. (1937). XXV.-Birds of the Colony of Trinidad and Tobago. Part VI. Ibis, 79(3), 504-550.

Belton W. 1994. Aves do Rio Grande do Sul, distribução e biologia. Editora Unisinos, São Leopoldo, Brasil. 
Bergeron ZT \& Fuller RC. 2018. Using Human Vision to Detect Variation in Avian Coloration: How Bad Is It?. The American Naturalist, 191(2)

Berglund A, Bisazza A \& Pilastro A. 1996. Armaments and ornaments: an evolutionary explanation of traits of dual utility. Biological Journal of the Linnean Society, 58(4): 385-399.

Berlocher, S. H., and J. L. Feder. 2002. Sympatric speciation in phytophagous insects: moving beyond controversy? Annu. Rev. Entomol. 47:773-815.

Bickford, D., Lohman, D. J., Sodhi, N. S., Ng, P. K., Meier, R., Winker, K., ... \& Das, I. (2007). Cryptic species as a window on diversity and conservation. Trends in ecology \& evolution, 22(3), 148155.

Bildstein, K. L. (2004). Raptor migration in the Neotropics: patterns, processes, and consequences. Ornitologia Neotropical, 15, 83-99.

BirdLife International (2014) Bird Species Distribution Maps of the World

Birdsley JS. 2002. Phylogeny of the tyrant flycatchers (Tyrannidae) based on morphology and behavior. Auk 119:715-734

Borgia G \& Coleman SW. 2000. Co-option of male courtship signals from aggressive display in bowerbirds. Proceedings of the Royal Society B 267: 1735-1740

Bornschein MR, Reinert BL, Machado-de-Souza T, Golec C, Whitney BM \& Favretto MA. 2017. Abundance, occurrence, and seasonality of the Subtropical Doradito (Pseudocolopteryx acutipennis) on the coast of Brazil. The Wilson Journal of Ornithology 129: 199-206

Bostwick KS. 2004. Subtropical Doradito Pseudocolopteryx acutipennis. Pp. 289 in Handbook of the birds of the world. Volume 9. Cotingas to pipits and wagtails (J. del Hoyo, A. Elliott, and D. A. Christie, Editors). Lynx Edicions, Barcelona.

Bostwick K \& Prum RO. 2003. High-speed video analysis of wingsnapping in two manakin clades (Pipridae: Aves). Journal of Experimental Biology 206: 3693-3706

Bostwick K \& Zyskowski K. 2001. Mechanical sounds and sexual dimorphism in the Crested Doradito. Condor 103: 961-865

Bradbury JW \& Vehrencamp SL. 2011. Principles of animal communication. Second edition. Sinauer Associates, Massachusetts

Brelsford A, Toews DPL \& Irwin D. 2017. Admixture mapping in a hybrid zone reveals loci associated with avian feather coloration. Proceedings of the Royal Society. B 284: 20171106.

Broennimann O, Fitzpatrick MC, Pearman PB, Petitpierre B, Pellissier L, Yoccoz NG, Thuiller W, Fortin MJ, Randin C, Zimmermann NE, Graham CH \& Guisan A. 2012. Measuring ecological niche overlap from occurrence and spatial environmental data. Global Ecology and Biogeography 21(4), 481-497. 
Bucher EH. 1982. Colonial breeding of the Eared Dove (Zenaida auriculata) in northeastern Brazil. Biotropica, 255-261.

Candolin U. 2003. The use of multiple cues in mate choice. Biological Reviews 78: 575-595.

Canevari M, Carrizo GR, \& Canevari P. 1991. Nueva guía de las aves argentinas. Fundación Acindar.

Capllonch PD, Ortiz D \& Soria K. 2009. Migrations of Tyrannidae species of Argentina: part 2. Acta Zoológica Lilloana 53:77-97.

Cardoni DA, Pretelli MG, Isacch JP, Madrid E, Baladrón AV \& Chiaradia NM. 2016. Parental care and external sexual characters in the Warbling Doradito (Pseudocolopteryx flaviventris). Journal of Ornithology 158(1), 159-167.

Cavalier-Smith T. 2009. Deep phylogeny, ancestral groups and the four ages of life. Philosophical Transactions of the Royal Society of London B: Biological Sciences, 365(1537), 111-132.

Chesser RT. 1997. Patterns of seasonal and geographical distribution of austral migrant flycatchers (Tyrannidae) in Bolivia. Ornithological Monographs 48:171-204.

Chesser RT \& Zink RM. 1994. Modes of speciation in birds: a test of Lynch's method. Evolution 48(2), 490-497.

Claessens O \& Comité d'Homologation de Guyane. 2015. Cotinga 37: 66-78

Clark CJ, Elias DO \& Prum RO. 2011. Aeroelastic flutter produces hummingbird feather songs. Science 333:1430-1433

Clark, C. J., Feo, T. J., \& Van Dongen, W. F. (2013). Sounds and courtship displays of the Peruvian sheartail, Chilean woodstar, oasis hummingbird, and a hybrid male Peruvian sheartail $\times$ Chilean woodstar. The Condor 115(3): 558-575

Coconier EG. 2007. Las aves silvestres de Acambuco, provincia de Salta, Argentina. Relevamientos de una AICA prioritaria de la Selva Pedemontana. Temas de Naturaleza y Conservación, 6, 1-127.

Contino FN. (1982). Aves del noroeste argentino. Universidad Nacional de Salta

Cooper BG \& Goller F. 2004. Multimodal signals: enhancement and constraint of song motor patterns by visual display. Science 303(5657), 544-546.

Coyne, J. A., \& Orr, H. A. (2004). Speciation. Sinauer Associates, Inc. Sunderland, MA.

Dalziell AH, Peters RA, Cockburn A, Dorland AD, Maisey AC \& Magrath RD. 2013. Dance choreography is coordinated with song repertoire in a complex avian display. Current Biology 23: 1132-1135. de La Peña (1987) Nidos y huevos de aves Argentinas. Edición del autor, Santa Fe de Vasconcelos MF, Lopes LE, Hoffmann D, Silveira LF, \& Schunck F. 2008. Noteworthy records of birds from the Pantanal, Chiquitano dry forest and Cerrado of south-western Brazil. Bulletin of the British Ornithologists' Club, 128(1), 57-67. 
Dias MF. 2014. [WA1634995, Pseudocolopteryx sclateri (Oustalet, 1892)]. Wiki Aves - A Enciclopédia das Aves do Brasil. Disponível em: <http://www.wikiaves.com/1634995> Acesso em: 28 Set 2017.

Di Giacomo, A. G. (1992). Descripción de los nidos de Knipolegus cyanirostris y Pseudocolopteryx sclateri. El Hornero, 13(03), 244-245.

Di Giacomo AG. 2005. Aves de la Reserva El Bagual. Pp. 201-465 en Di Giacomo \& Krapovickas (eds.). Historia natural y paisaje de la Reserva El Bagual, Provincia de Formosa, Argentina. Inventario de la fauna de vertebrados y flora vascular de un área protegida del Chaco húmedo. Temas de Naturaleza y Conservación № 4, Aves Argentinas/AOP, Buenos Aires.

Dinelli, L. M. (1933). El tiránido Pseudocolopteryx dinellianus y su nido. El Hornero, 5(02), 221-222.

Drummond, A. J., et al. (2012). "Bayesian phylogenetics with BEAUti and the BEAST 1.7." Molecular Biology and Evolution 29 (8): 1969-1973.

Eble GJ. 2005. Morphological modularity and macroevolution: conceptual and empirical aspects. In: Callebaut W, Rasskin-Gutman D, eds. Modularity: understanding the development and evolution of natural complex systems. Cambridge, MA: MIT Press, 221-238.

Elith J, Graham CH, Anderson RP, Dudík M, Ferrier S, Guisan A, Hijmans RJ, Huettmann F, Leathwick JR, Lehmann A, Li, J, Lohmann LG, Loiselle BA, Manion G, Moritz C, Nakamura M, Nakazawa Y, Mc. Overton J, Peterson AT, Phillips ST, Richardson K, Scachetti-Pereira R, Schapire RE, Soberón J, Williams S, Wisz MS, Zimmermann NE \& Araujo M. 2006. Novel methods improve prediction of species' distributions from occurrence data. Ecography, 129-151.

ffrench R (2012). A guide to the birds of Trinidad and Tobago. Comstock Publishing Associates

Fielding, A. H., \& Bell, J. F. (1997). A review of methods for the assessment of prediction errors in conservation presence/absence models. Environmental Conservation, 24, 38-49

Fitzpatrick JW. 2004. Tyrannidae. Pp. 170-462 en del Hoyo J, Elliot A \& Chrisite D (eds.). Handbook of the Birds of the World. Volume 9: Cotingas to pipits and wagtails. Lynx edicions, Barcelona.

Fitzpatrick, B. M., \& Turelli, M. (2006). The geography of mammalian speciation: mixed signals from phylogenies and range maps. Evolution, 60(3), 601-615.

Fjeldså J \& Krabbe N. 1990. Birds of the high Andes. Zoological Museum, Univ. of Copenhagen and Apolo Books, Svendborg, Denmark.

Fourcade, Y., Engler, J. O., Rödder, D., \& Secondi, J. (2014). Mapping species distributions with MAXENT using a geographically biased sample of presence data: a performance assessment of methods for correcting sampling bias. PloS one, 9(5), e97122.

Godown ME \& Peterson AT. 2000. Preliminary distributional analysis of US endangered bird species. Biodiversity \& Conservation, 9(9), 1313-1322. 
Gómez, C., Tenorio, E. A., Montoya, P., \& Cadena, C. D. (2016). Niche-tracking migrants and nicheswitching residents: evolution of climatic niches in New World warblers (Parulidae). Proceeding of the Royal Society B 283: 20152458

Graham, C. H., Ron, S. R., Santos, J. C., Schneider, C. J., \& Moritz, C. (2004). Integrating phylogenetics and environmental niche models to explore speciation mechanisms in dendrobatid frogs. Evolution, 58(8), 1781-1793.

Griggio M, Zanollo V \& Hoi H. 2010. Female ornamentation, parental quality, and competitive ability in the rock sparrow. Journal of Ethology 28: 455-462.

Guilherma E. 2012. Birds of the Brazilian state of Acre: diversity, zoogeography, and conservation. Revista Brasileira de Ornitologia 20: 393-442.

Guyra Paraguay. 2004. Lista comentada de las aves del Paraguay. Asunción: Guyra Paraguay.

Hamilton III WJ. 1998. Tricolored Blackbird itinerant breeding in California. Condor 100: 218-226.

Hartert \& Venturi (1909) Notes sur les oiseaux de la République Argentine. Novitates Zoologicae 16:159-267

Hayes, F. E. (1995). Status, distribution and biogeography of the birds of Paraguay. Monographs in Field Ornithology No. 1. American Birding Association

Hayes F, Scharf PA \& Ridgely RS. 1994. Austral birds migrants in Paraguay. Condor 96: 83-97

Hebets EA \& Papaj DR. 2005. Complex signal function: developing a framework of testable hypotheses. Behavioral Ecology and Sociobiology 57: 197-214.

Hellmayr CE. 1927. Catalogue of birds of the Americas, part 5. Field Mus. Nat. Hist. Publ., Zoological series 13 , Chicago

Hennig W. 1966. Phylogenetic Systematics. Chicago University Press, Illinois.

Henry PY. 2012. Distributional and altitudinal range extensions for birds from Ecuador. Boletín de la Sociedad Antioqueña de Ornitología 20: 89-106

Herzog, S. K., Terril, R. S., Jahn, A. E., Remsen, J. V., Maillard, O. Z., García-Solís, V. H., ... \& Vidoz, J. Q. (2016). Birds of Bolivia. Field Guide. Asociación Armonía: Santa Cruz de la Sierra.

Hilty S. 1999. Three bird species new to Venezuela and notes on the behaviour and distribution of other poorly known species. Bulletin of the British Ornithological Club, 119, 220-235.

Hilty, SL . 2003. Birds of Venezuela. Princeton University Press, Princeton, NJ.

Holland AH \& Sclater PL. 1897. Field-Notes on the Birds of the Estancia Sta. Elena, Argentine Republic.-Part IV. Ibis, 39(2), 166-169.

Hosner PA \& Moyle RG. 2012. A molecular phylogeny of Black-tyrants (Tyrannidae: Knipolegus) reveals strong geographic patterns and homoplasy in plumaje and display behavior. Auk 129: 156-167

Housse RE .1947. Las aves de Chile en su clasifiación moderna. Su vida y costumbres. Ediciones Universidad de Chile. Santiago, Chile. 
Hudson, W. H. (1920). Birds of La Plata (Vol. 1). JM Dent \& Sons Limited.

Huelsenbeck, J. P., Ronquist, F., 2001, MRBAYES: Bayesian inference of phylogeny, Bioinformatics, 17: 754-755.

Jaeger MM, Bruggers RL, Johns BE \& Erickson WA. 1986. Evidence of itinerant breeding of the Red-billed Quelea Quelea quelea in the Ethiopian Rift Valley. Ibis, 128(4), 469-482.

Johnson AW. 1967. The birds of Chile and adjacent regions of Argentina, Bolivia and Perú. Volume 2. Platt establecimientos gráficos, Buenos Aires, Argentina.

Johnson, N. K., \& Cicero, C. (2002). The role of ecologic diversification in sibling speciation of Empidonax flycatchers (Tyrannidae): multigene evidence from mtDNA. Molecular Ecology, 11(10), 2065-2081.

Johnstone RA. 1996. Multiple displays in animal communication: backup signals' and multiple messages'. Philosophical Transactions of the Royal Society of London B: Biological Sciences 351: 329-338.

Kimball RT, Braun EL, Ligon JD, Lucchini V \& Randi E. 2001. A molecular phylogeny of the peacockpheasants (Galliformes: Polyplectron spp.) indicates loss and reduction of ornamental traits and display behaviours. Biological Journal of the Linnean Society 73: 187-198

Kroodsma, D. E. (1984). Songs of the Alder Flycatcher (Empidonax alnorum) and Willow Flycatcher (Empidonax traillii) are innate. The Auk, 13-24.

Kroodsma, D. E., \& Konishi, M. (1991). A suboscine bird (eastern phoebe, Sayornis phoebe) develops normal song without auditory feedback. Animal Behaviour, 42(3), 477-487.

Kumar S, Stecher G \& Tamura K. 2017. MEGA7: Molecular Evolutionary Genetics Analysis version 7.0 for bigger datasets. Molecular Biology and Evolution: msw054

Lanyon WE. 1988. A phylogeny of the 32 genera in the Elaenia assemblage of tyrant flycatchers. American Museum Novitates 2914: 1-57

Leiva, L. A., \& Bierig, P. L. (2014). Doradito Limón Pseudocolopteryx citreola (Aves-Tyrannidae) en la provincia de Santa Fe, Argentina. Natura Neotropicalis, 45: 87.

Leiva LA, Verón SM \& Acosta MD. 2004. Nidos de Aves pertenecientes a la colección del Museo Provincial de Ciencias Naturales "Florentino Ameghino", Santa Fe-Argentina. Serie Catálogos 18: $1-68$

Lillo, M. (1905). Fauna tucumana: aves, catálogo sistemático. Revista de Letras y Ciencias Sociales.

Liu, C., White, M., \& Newell, G. (2013). Selecting thresholds for the prediction of species occurrence with presence-only data. Journal of Biogeography, 40(4), 778-789

Lloyd-Jones, DJ \& Briskie JV. 2016. Mutual wattle ornaments in the South Island Saddleback (Philesturnus carunculatus) function as armaments. Ethology, 122(1): 61-71. 
López Lanús, B. (1997). Inventario de las aves del Parque Nacional "Río Pilcomayo", Formosa, Argentina. LOLA Monografía, 4.

López-Lanús B, Unterkofler LD, Ornstein U, Güller R, Lejarraga R, Cabre CD, Scoffield RM \& Kopuchian C. 2010. La presencia de Pseudocolopteryx citreola en el este de Argentina y comparación de su voz con la de otros doraditos. Boletín Chileno de Ornitología, 16(1), 51-58.

Losos JB \& Glor RE. 2003. Phylogenetic comparative methods and the geography of speciation. Trends in Ecology \& Evolution, 18(5), 220-227.

Maddison WP \& Maddison DR. 2009. Mesquite: a modular system for evolutionary analysis. 3.0. Available at http://mesquiteproject.wikispaces.com/installa

Maldonado-Coelho, M. (2012). Climatic oscillations shape the phylogeographical structure of Atlantic Forest fire-eye antbirds (Aves: Thamnophilidae). Biological Journal of the Linnean Society, 105(4), 900-924.

Mayr E. 1974. Cladistic analysis or cladistic classification?. Journal of Zoological Systematics and Evolutionary Research, 12(1), 94-128.

Mayr E. 1982. Processes of speciation in animals. Progress in clinical and biological research, 96, 1.

Mazar Barnett J \& Pearman M. 2001. Lista comentada de las aves argentinas. Lynx Edicions, Barcelona Molli, AF 1985. Nido de Doradito Tucumano. Nuestras Aves 8: 12

Morrone JJ, Roig-Juñent S \& Crisci JV. 1994. Cladistic biogeography of terrestrial subantarctic beetles (Insecta: Coleoptera) from South America. National Geographic Research and Exploration 10(1): 104-115.

Mota-Vargas C \& Rojas-Soto OR. 2012. The importance of defining the geographic distribution of species for conservation: The case of the Bearded Wood-Partridge. Journal for Nature Conservation, 20(1), 10-17.

Narosky T \& Di Giácomo AG. 1993. Las aves de la provincia de Buenos Aires: distribución y status. Asociación Ornitológica del Plata, Vazquez Mazzini Editores y LOLA, Buenos Aires.

Narosky T \& Salvador S. 1998. Nidificación de las aves argentinas. Tyrannidae. Asociación Ornitológica del Plata, Buenos Aires.

Narosky T \& Yzurieta D. 1987. Guía para la identificación de las aves de Argentina y Uruguay. Asociación Ornitológica del Plata, Vazquez Mazzini Editores, Buenos Aires.

Navas JR. 2002. La distribución geográfica de Pseudocolopteryx acutipennis (Tyrannidae) en la Argentina. Hornero 17:45-48

Nores M \& Yzurieta D. 1980. Aves de ambientes acuáticos de Córdoba y centro de Argentina. Secretaría de Estado de Agricultura y Ganadería, Dirección de Caza, Pesca y Actividades Acuáticas, Academia Nacional de Ciencias de Córdoba.

Olrog, C. C. (1979). Nueva lista de la avifauna argentina. Ministerio de cultura y educación. 
Omland KE. 1997. Examining two standard assumptions of ancestral reconstructions: repeated loss of dichromatism in dabbling ducks (Anatini). Evolution, 51(5), 1636-1646.

Omland, K. E., \& Lanyon, S. M. (2000). Reconstructing plumage evolution in orioles (Icterus): repeated convergence and reversal in patterns. Evolution, 54(6), 2119-2133.

Ortiz D, Aráoz R \& Capllonch P. 2006. Registros novedosos de doraditos (Pseudocolopteryx) en la provincia de Tucumán. Nuestras Aves, 52, 24-25.

Ota N, Gahr M, \& Soma M. 2015. Tap dancing birds: the multimodal mutual courtship display of males and females in a socially monogamous songbird. Scientific reports 5: 16614

Pagano LG, Jordan EA, Areta JI, Jensen RF \& Roesler I (2013). Aves de la Reserva Natural Punta Lara en Roesler \& Agostini (eds.) Los Vertebrados de la Reserva Natural Punta Lara. Aves Argentinas/AOP, Ciudad Autónoma de Buenos Aires

Pagel, M. (1999). The maximum likelihood approach to reconstructing ancestral character states of discrete characters on phylogenies. Systematic biology, 48(3), 612-622.

Parker T. 1982. Observations of some unusual rainforest and marsh birds in southeastern Perú. Willson Bulletin 94: 477-493

Parker TA \& Willis EO. 1997. Notes on three tiny grassland flycatchers, with comments on the disappearance of South Americas fire-diversified savannas. Ornithological Monographs 48:549555

Partan SR \& Marler P. 2005. Issues in the classification of multimodal communication signals. The American Naturalist 166: 231-245.

Paynter, R. A., \& Traylor, M. A. (1991). Ornithological gazetteer of Brazil. Bird Department, Museum of Comparative Zoology, Harvard University.

Paynter, R. A. (1992). Ornithological gazetteer of Bolivia. Obtainable from Bird Department, Museum of Comparative Zoology, Harvard University.

Paynter, R. A. (1995). Ornithological gazetteer of Argentina. Obtainable from Bird Department, Museum of Comparative Zoology, Harvard University.

Pearce, J., \& Ferrier, S. (2000). Evaluating the predictive performance of habitat models developed using logistic regression. Ecological modelling, 133(3), 225-245.

Peterson AT. 2001. Predicting species geographic distributions based on ecological niche modeling. Condor 103: 599-605

Peterson, A. T., Soberón, J., \& Sánchez-Cordero, V. (1999). Conservatism of ecological niches in evolutionary time. Science, 285(5431), 1265-1267.

Pfenninger M \& Schwenk K. 2007. Cryptic animal species are homogeneously distributed among taxa and biogeographical regions. BMC evolutionary biology 7(1): 121. 
Phillips, S. J., Anderson, R. P., \&Schapire, R. E. (2006). Maximum entropy modeling of species geographic distributions. Ecological Modelling, 190, 231-259

Posada, D., 2008, jModelTest: Phylogenetic Model Averaging, Molecular Biology and Evolution, 25: 1253-1256.

Posada, D., Buckley, T. R., 2004, Model selection and model averaging in phylogenetics: advantages of Akaike information criterion and Bayesian approaches over likelihood ratio tests, Systematic Biology, 53: 793-808

Price T \& Birch GL. 1996. Repeated evolution of sexual color dimorphism in passerine birds. The Auk, $842-848$.

Price T. 2008. Speciation in birds. Roberts and Company. Colorado

Prum, R. O. (1990). Phylogenetic analysis of the evolution of display behavior in the Neotropical manakins (Aves: Pipridae). Ethology, 84(3), 202-231.

Rambaut A, Suchard MA, Xie D \& Drummond AJ. 2014. Tracer v1.6, disponible de http://beast.bio.ed.ac.uk/Tracer

Reed C. 1877. Apuntes de la zoolojía de la hacienda de los Cauquenes, provincia de Colchagua. Anales de la Universidad de Chile 49:535-569

Repenning M \& Fontana CS. 2009. Estatus de ocurrencia del Doradito Común (Pseudocolopteryx flaviventris) en Rio Grande do Sul, Brasil. Ornitología Neotropical 20: 131-135

Rheindt, F. E., Norman, J. A., \& Christidis, L. (2008). DNA evidence shows vocalizations to be a better indicator of taxonomic limits than plumage patterns in Zimmerius tyrant-flycatchers. Molecular Phylogenetics and Evolution, 48(1), 150-156.

Rheindt, F. E., Christidis, L., \& Norman, J. A. (2009). Genetic introgression, incomplete lineage sorting and faulty taxonomy create multiple cases of polyphyly in a montane clade of tyrant-flycatchers (Elaenia, Tyrannidae). Zoologica scripta, 38(2), 143-153.

Rheindt, F. E., Fujita, M. K., Wilton, P. R., \& Edwards, S. V. (2013). Introgression and phenotypic assimilation in Zimmerius flycatchers (Tyrannidae): population genetic and phylogenetic inferences from genome-wide SNPs. Systematic Biology, 63(2), 134-152.

Ridgely RS \& Tudor G. 1989. The birds of South America. Volume 2. Univ. of Texas Press. Austin, Texas.

Ridgely, R. S., \& Greenfield, P. J. (2001). The birds of Ecuador (Vol. 1). Status, distribution and taxonomy. Cornell University Press, Ithaca.

Roesler I. 2009. El Doradito Oliváceo (Pseudocolopteryx acutipennis) en las pampas Argentinas: nuevos registros y comentarios sobre su historia natural. Cotinga 31: 1-4

Ronquist, F., Teslenko, M. Van de Mark, P., Ayres, D.L., Darling, A., Honhna, S., Larget, B., Liu, L., Suchard, M.A. , Huelsenbeck, J.P., 2012, MrBayes 3.2: Efficient Bayesian phylogenetic inference and model choice across a large model space, Systematic Biology, 61: 539-542 
Schlosser G \& Wagner GP. 2004. Modularity in development and evolution. Chicago, IL: University of Chicago Press.

Schoener TW \& Gorman GC. 1968. Some niche differences in three Lesser Antillean lizards of the genus Anolis. Ecology, 49(5), 819-830.

Scholes E. (2006). Courtship ethology of Carola's Parotia (Parotia carolae). The Auk, 123(4), 967-990.

Scholes, E. (2008a). Courtship ethology of Wahnes' parotia Parotia wahnesi (Aves: Paradisaeidae). Journal of Ethology, 26(1), 79-91.

Scholes, E. (2008b). Evolution of the courtship phenotype in the bird of paradise genus Parotia (Aves: Paradisaeidae): homology, phylogeny, and modularity. Biological journal of the Linnean Society, 94(3), 491-504.

Schulenberg TS, Stotz DF, Lane DF, O’Neill JP \& Parker TA. 2007. Birds of Peru. Princeton University Press, Princeton, New Jersey.

Searcy, W. A., \& Nowicki, S. (2005). The evolution of animal communication: reliability and deception in signaling systems. Princeton University Press.

Seddon, N., \& Tobias, J. A. (2007). Song divergence at the edge of Amazonia: an empirical test of the peripatric speciation model. Biological Journal of the Linnean Society, 90(1), 173-188.

Short LL. 1975. A zoographical analysis of the South American Chaco avifauna. Bulletin of the American Museum of Natural History 154: 163-352

Shultz, A. J., \& Burns, K. J. (2017). The role of sexual and natural selection in shaping patterns of sexual dichromatism in the largest family of songbirds (Aves: Thraupidae). Evolution, 71(4), 10611074.

Smith, W. J. (1971). Behavior of Muscisaxicola and related genera. Bull. Mus. Comp. Zool, 141, 233-268.

Smith P, lesterhuis AJ \& Clay RP. 2014. Status and distribution of the doraditos (Tyrannidae: Pseudocolopteryx) in Paraguay, including a new country record. Revista Brasileira de Ornitologia 22:180-188.

Soberón J, Osorio-Olvera L \& Peterson T. 2017. Diferencias conceptuales entre modelación de nichos y modelación de áreas de distribución. Revista Mexicana de Biodiversidad, 88(2), 437-441.

Stamatakis, A. (2006). "RAxML-VI-HPC: maximum likelihood-based phylogenetic analyses with thousands of taxa and mixed models." Bioinformatics 22(21): 2688-2690

Straneck RJ. 1993. Aportes para la unificación de Serpophaga subcristata y Serpophaga munda, y la revalidación de Serpophaga griseiceps (Aves: Tyrannidae). Revista del Museo Argentino de Ciencias Naturales "Bernardino Rivadavia". Zoología, 16: 51-63.

Straneck RJ. 2007. Una nueva especie de Serpophaga (Aves: Tyrannidae). FAVE Sección Ciencias Veterinarias, 6(1/2): 31-42. 
Straneck R \& Carrizo. 1983. El despliegue de proclamación territorial de Knipolegus aterrimus Kaup e Hymenops p. perspicillata (Gmelin). Com. Mus. Arg. Cs. Nat. 1: 50-60.

Stephens, L., \& Traylor, M. A. (1983). Ornithological gazetteer of Peru. Bird Dept., Museum of Comparative Zoology, Harvard University.

Tello JG, Moyle RG, Marchese DJ \& Cracraft J. 2009. Phylogeny and phyllogenetic classification of the tyrant flycatchers, cotingas, manakins, and their allies (Aves: Tyrannidae). Cladistics 25: 1-31

Tinbergen, N. (1963). On aims and methods of ethology. Ethology, 20(4), 410-433.

Tobias JA, Gamarra-Toledo V, García-Olaechea D, Pulgarin PC \& Seddon N. 2011. Year-round resource defence and the evolution of male and female song in suboscine birds: Social armaments are mutual ornaments. Journal of evolutionary biology, 24(10): 2118-2138.

Vuilleumier F. 1971. Generic relationships and speciation patterns in Ochthoeca, Myiotheretes, Xolmis, Neoxolmis, Agriornis, and Muscisaxicola. Bulletin of the Museum of Comparative Zoology 141, $181-232$

Wagner GP, Altenberg L. 1996. Perspective: complex adaptations and the evolution of evolvability. Evolution 50: 967- 976.

Warren, D. L., Glor, R. E., \& Turelli, M. (2008). Environmental niche equivalency versus conservatism: quantitative approaches to niche evolution. Evolution, 62(11), 2868-2883.

Warren, D. L., Glor, R. E., \& Turelli, M. (2010). ENMTools: a toolbox for comparative studies of environmental niche models. Ecography, 33(3), 607-611.

Weir, J.T., Schluter, D.S., 2008, Calibrating the avian molecular clock, Molecular Ecology, 17: 23212328.

Weir, J.T., Bermingham, E., Schluter, D., 2009, The Great American Biotic Interchange in birds, Proceedings of the National Academy of Sciences, 106: 21737-21742

Wenzel JW. 1992. Behavioral homology and phylogeny. Annual Review Ecology Systematics 23: 361381

West-Eberhard MJ. 2003. Developmental plasticity and evolution. New York, NY: Oxford University Press.

Wetmore A. 1926. Observations on the birds of Argentina, Paraguay, Uruguay and Chile. Bulletin of the United State of Natural Museum 133: 1-448

Whittaker A. 2004. Noteworthy ornithological records from Rondonia, Brazil, including a first country record, comments on austral migration, life history, taxonomy and distribution, with relevant data from neighbouring states, and a first record for Bolivia. Bulletin of the British Ornithologists' Club 124:239-271.

Wiens JJ. 2001. Widespread loss of sexually selected traits: how the peacock lost its spots. Trends in Ecology \& Evolution, 16(9), 517-523. 
Wiens JJ \& Graham CH. 2005. Niche conservatism: integrating evolution, ecology, and conservation biology. Annu. Rev. Ecol. Evol. Syst., 36, 519-539.

WIKIAVES. 2008. WikiAves: a enciclopédia das aves do Brasil. www.wikiaves.com.br

Winkler DW, Gandoy FA, Areta JI, Iliff MJ, Rakhimberdiev E, Kardynal KJ \& Hobson KA. 2017. LongDistance Range Expansion and Rapid Adjustment of Migration in a Newly Established Population of Barn Swallows Breeding in Argentina. Current Biology, 27(7), 1080-1084.

Zimmer JK. 1940. Studies on Peruvian birds. No. 35. Notes on the genera Phylloscartes, Euscarthmus, Tachuris, Spizitornis, Yanacea, Uromyias, Stigmatura, Serpophaga, and Mecocerculus. American Museum Novitates 1095: 1-19.

Zimmer KJ, Whittaker A \& Oren DC. 2001. A cryptic new species of flycatcher (Tyrannidae: Suiriri) from the Cerrado region of central South America. The Auk, 118(1), 56-78. 